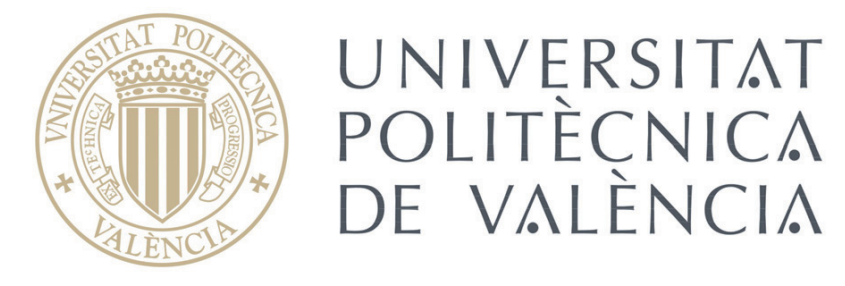

Departamento de Comunicaciones

Técnicas Secuenciales y Paralelas para la Resolución de Problemas Computacionales en Electromagnetismo

TESIS DOCTORAL
Autor:
Dña. Ana Vidal Pantaleoni
Directores:
Dr. Antonio Manuel Vidal Maciá
Dr. Miguel Ferrando Bataller

Valencia, junio de 2013 

A mi familia 



\section{Agradecimientos}

En primer lugar tengo que nombrar a mis padres, Manuel y Gemma. Gracias a ellos, por sus esfuerzos y por su ejemplo. Me gustaría que mi padre pudiera haber estado aquí conmigo mucho más tiempo para compartir con él este momento.

Muchas gracias a todas las personas que me han dado fuerza y me han animado en esta dura carrera de fondo que ha supuesto la presentación de mi tesis doctoral. De entre ellos destaco a mis directores de tesis, Miguel y Antonio. Antonio, muchas gracias por tu paciencia y tus ánimos. Miguel, gracias por estar ahí cuando lo he necesitado.

Gracias Vicente por estar conmigo y apoyarme y gracias también a mis tres soles, que me iluminan cada momento: Vicente, Carlos y Gemma. Gracias por el tiempo que me habéis dado.

Ana Vidal Pantaleoni Valencia, junio de 2013 



\section{Resumen}

La mejora en términos de eficiencia en problemas de análisis de dispositivos pasivos de microondas y la dispersión de objetos es un tema de creciente interés. Pese a que el avance de la tecnología de computadores permite la ejecución de programas muy complejos, la eficiencia computacional sigue siendo importante debido a la tendencia de aumentar la frecuencia de trabajo en los citados problemas electromagnéticos. En esta tesis se recogen una serie de herramientas para la mejora de la eficiencia de técnicas de análisis electromagnético en espacio abierto y cerrado mediante una recopilación de artículos indexados en prensa científica, que se presentan de forma razonada. En primer lugar se aplica la transformada Wavelet en al análisis de dispersores cilíndricos mediante la técnica de la Ecuación Integral. Posteriormente se introducen distintas técnicas de discretización, así como rutinas de solución de problemas de autovalores y autovectores adaptadas a la estructura matricial y al procesado en paralelo en el entorno del análisis de dispositivos cerrados. En concreto, dichas técnicas se han aplicado al método denominado Boundary Integral Resonant Mode Expansion (BI-RME) en el dominio bidimensional. Este método realiza una expansión modal de una guía de ondas arbitraria en función de los modos correspondientes a una guía canónica de referencia. Finalmente se han introducido mejoras en la técnica BI-RME aplicada en entornos tridimensionales para el análisis de cavidades con geometría arbitraria. El objetivo en todos los casos consiste en obtener una mejora del tiempo de cálculo y en la memoria requerida, sin perder precisión en gran medida. Todo este trabajo se ha integrado en un software comercial existente, que se emplea actualmente en el diseño y la caracterización de dispositivos pasivos de microondas utilizados en aplicaciones espaciales. 



\section{Resum}

La millora en l'eficiència en l'anàlisi de dispositius passius de microones i la dispersió d'objectes és un tema de creixent interès. Malgrat que l'avanç de la tecnologia de computadors permet l'execució de programes molt complexos, l'eficiència computacional segueix sent important a causa de la tendència d'augmentar la freqüència de treball del problemes electromagnètics. En aquesta tesi s'arrepleguen una sèrie d'eines per a la millora de l'eficiència de tècniques d'anàlisi electromagnètica en espai obert $i$ tancat mitjançant una recopilació d'articles indexats en premsa científica, que es presenten de forma raonada. En primer lloc s'aplica la transformada Wavelet en l'anàlisi de dispersors cilíndrics mitjançant la tècnica de l'Equació Integral. Posteriorment s'introdueixen diferents tècniques corresponents a la segmentació, rutines de solució de problemes d'autovalors i autovectors adaptades a l'estructura matricial, i al processament en paral-lel a l'entorn de l'anàlisi de dispositius tancats. En concret s'han aplicat al mètode Boundary Integral Resonant Mode Expansion (BI-RME) en el domini bidimensional. Aquest mètode realitza una expansió modal d'una guia d'ones arbitrària en funció de la expansió modal corresponent a una guia canònica de referència. Finalment s'han introduït millores en la tècnica BI-RME aplicada en entorns tridimensionals per a l'anàlisi de cavitats de geometria arbitrària. L'objectiu en tots els casos consisteix a obtenir una millora del temps de càlcul i memòria requerida sobre la tècnica original, sense perdre precisió en gran mesura. Tot aquest treball s'ha integrat en un software comercial existent, que s'està emprant actualment en el disseny i caracterització de dispositius pasius de microones per aplicacions espacials. 



\section{Abstract}

Efficiency improvement in the the electromagnetic (EM) analysis of passive microwaves devices and scatterers is a subject of increasing interest. Even with the recent advancements in computing power, which allows the execution of very complex programs, optimization of the computational efficiency keeps on being important because of the tendency to increase the radio frequency in different EM applications. This thesis collects a series of tools for the improvement of the efficiency for the EM analysis in open and closed environments by means of a compilation of papers published in scientific press, that are presented in a reasoned manner. In first place, it applies the Wavelet transform to the analysis of cylindrical scatterers by means of the Integral Equation technique. Later, different techniques concerning discretization, specifically designed solutions of eigenvalues and eigenvectors problems adapted to the matrix structure and parallel processing are introduced in the analysis of closed space devices. In particular, we have applied them to the two-dimensional Boundary Integral Resonant Mode Expansion (BI-RME) technique. This method provides the modal expansion of a waveguide with arbitrary contour in terms of the corresponding modal expansion of a canonical reference waveguide. Finally some improvements in the BI-RME technique applied in the three-dimensional space for the analysis of cavities of arbitrary geometry are described. In all cases, the aim consists in obtaining an improvement of the computing time and memory required over the original technique with very low precision loss. All this work has been integrated in an existent commercial software, that is being employed at present in the design and characterization of passive microwave devices for space applications. 



\section{Índice}

I Contexto 1

1. Introducción 3

1.1. Estado del arte y motivación . . . . . . . . . . . . . 3

1.2. Objetivos de la investigación . . . . . . . . . 7

1.3. Entorno de trabajo y proyectos de investigación relacionados . . . . . . . . . . . . . . . 8

1.4. Definición del problema . . . . . . . . . . . . 9 9

1.4.1. Dispersión 2D en entornos abiertos . . . . . . 10

1.4.2. Métodos modales en entornos cerrados bidimensionales: BI-RME 2D . . . . . . . . . . . 13

1.4.3. Métodos modales en entornos cerrados 3D: BIRME 3D . . . . . . . . . . . . 16

1.5. Herramientas empleadas . . . . . . . . . . . . . . 17

1.5.1. Métodos de discretización . . . . . . . . . . . . 17

1.5.2. Problemas algebraicos que aparecen en Electromagnetismo . . . . . . . . . . . . . . . . . 18

1.5.3. La transformada Wavelet . . . . . . . . . . . 20

1.5.4. Técnicas de procesado en paralelo . . . . . . . 23

1.6. Organización de la memoria . . . . . . . . . . . . . 26

Bibliografía . . . . . . . . . . . . . . . . . . 27 
II Recopilación de artículos 33

2. Wavelet Spectral Scattering 37

2.1. Introduction . . . . . . . . . . . . . . . . 38

2.2. Theory . . . . . . . . . . . . . . . . 40

2.2.1. Basics of the Spectral MoM Technique . . . . . . . 41

2.2.2. MoM Implementation using the Wavelet Transform 43

2.2.3. Wavelet and Wavelet-like Bases Description . . . 45

2.2.4. Efficient System Basis Transformation . . . . . . . 48

2.2.5. Computational Cost Evaluation . . . . . . . . . 49

2.3. Results and Discussion . . . . . . . . . . . . . . . 50

2.4. Conclusions . . . . . . . . . . . . . 57

Bibliography . . . . . . . . . . . . . . . 58

3. Wavelet Analysis of Radomes 63

3.1. Introduction . . . . . . . . . . . . . . . . 64

3.2. Theory . . . . . . . . . . . . . 66

3.2.1. Equivalent surface formulation . . . . . . . . . 67

3.2.2. Wavelet Transform . . . . . . . . . . . . 71

3.3. Validation Results . . . . . . . . . . . . . . . . . . . 74

3.3.1. Circular radome and circular reflector . . . . . . 75

3.3.2. Circular sandwich radome mounted on a telecommunications tower with square basis . . . . . . . 81

3.3.3. Half-circular dielectric shell with metallic back plate 84

3.3.4. Ogive radome with parabolic reflector . . . . . . 85

3.4. Conclusions . . . . . . . . . . . . . . . 87

Bibliography . . . . . . . . . . . . . . . . . . 90

4. Nyström BI-RME 95

4.1. Introduction . . . . . . . . . . . . . . . 96

4.2. Nyström Formulation . . . . . . . . . . . . . . . 98

4.2.1. TM Modes . . . . . . . . . . . . . . . . . . . . . 99

4.2.2. TE Modes . . . . . . . . . . . . . . . . . . 102

4.2.3. Coupling Coefficients . . . . . . . . . . . . 106

4.3. Validation Results . . . . . . . . . . . . . . . . . 108

4.3.1. Cross-Shaped Iris . . . . . . . . . . . . . . . 109

4.3.2. Ridged Circular Iris . . . . . . . . . . . . . . 110 
4.3.3. Inductively Coupled Rectangular Waveguide Filter with Rounded Corners . . . . . . . . . . . . . . 111

4.3.4. Circular Waveguide Dual-Mode Filter with Elliptical Irises and Tuning Elements . . . . . . . 112

4.4. Conclusions . . . . . . . . . . . . . . . . . . . 115

4.5. Acknowledgements . . . . . . . . . . . . . . . . 116

Bibliography . . . . . . . . . . . . . . . 121

5. Efficient mode computation 125

5.1. Introduction . . . . . . . . . . . . . 126

5.2. Theory . . . . . . . . . . . . . . . . 127

5.2.1. The Electromagnetic Problem . . . . . . . . . . . 128

5.2.2. Eigenvalue Equation Solution . . . . . . . . . . . 133

5.3. Validation Results . . . . . . . . . . . . . . . . . . 140

5.4. Conclusions . . . . . . . . . . . . . . 145

Bibliography . . . . . . . . . . . . . . . . . 147

6. Parallel BI-RME 151

6.1. Introduction . . . . . . . . . . . . . . . 152

6.2. BI-RME Theory . . . . . . . . . . . . . . . . . . 153

6.3. Sequential Generalized Solution . . . . . . . . . . . 154

6.4. Parallel Generalized Solution . . . . . . . . . . . . 158

6.4.1. Selection of subintervals . . . . . . . . . . . . 159

6.4.2. Implementation Details . . . . . . . . . . . . . 160

6.5. Numerical Results and Discussion . . . . . . . . . . 161

6.6. Conclusions . . . . . . . . . . . . . . . 164

Bibliography . . . . . . . . . . . . . . 167

7. Robust Parallel BI-RME 169

7.1. Introduction and examples . . . . . . . . . . . . . 170

7.2. Problem Description . . . . . . . . . . . . . . . 171

7.2.1. The electromagnetic problem . . . . . . . . . . . 171

7.2.2. The sequential algorithm . . . . . . . . . . . 171

7.3. Parallel implementations . . . . . . . . . . . . . . . . 175

7.3.1. Algorithmic approach . . . . . . . . . . . . 175

7.3.2. Implementation details . . . . . . . . . . . 176

7.4. Experimental results . . . . . . . . . . . . . 177

7.4.1. Description of the test environment . . . . . . . 177 
7.4.2. Experimental results . . . . . . . . . . . . 178

7.4.3. Analysis of the experimental results . . . . . . 178

7.5. Conclusions . . . . . . . . . . . . . . . 182

Bibliography . . . . . . . . . . . . . . . . 183

III Discusión general y conclusiones 185

8. BI-RME 3D 187

8.1. Base teórica de BI-RME 3D . . . . . . . . . . . . . . 187

8.2. Desarrollo de una nueva técnica numérica . . . . . . . . . 191

8.3. Dispositivos analizados . . . . . . . . . . . . . . 195

Bibliografía . . . . . . . . . . . . . . . . . . . 199

9. Discusión general de resultados 201

9.1. Resumen de las mejoras . . . . . . . . . . . . . . . . 201

9.2. Integración de las mejoras en software . . . . . . . . . 204

10. Conclusiones y líneas futuras 207

10.1. Conclusiones de los resultados obtenidos . . . . . . . 207

10.2. Trabajo futuro . . . . . . . . . . . . . . . 209

10.3. Aportaciones adicionales de la tesis . . . . . . . . . . . 210

10.4. Contribuciones en otros ámbitos . . . . . . . . . . . 213 


\section{Parte I}

\section{Contexto}





\section{Capítulo 1}

\section{Introducción}

En este capítulo se expone en primer lugar el estado del arte en el tema de la mejora de eficiencia computacional para los problemas de electromagnetismo planteados en esta tesis, que se presentarán en forma de artículos indexados en prensa científica. Posteriormente se exponen los objetivos que se pretenden alcanzar con el trabajo desarrollado. En este punto se describe el entorno de trabajo en el que se ha desarrollado el proyecto incluyendo los grupos de investigación con los que se ha colaborado y los proyectos de investigación en los que se ha participado. A continuación se presentan los problemas analizados y las herramientas empleadas para su solución.

\subsection{Estado del arte y motivación}

El análisis eficiente de dispositivos pasivos de microondas y la dispersión de objetos en entornos de propagación abiertos son problemas de interés creciente en los últimos tiempos, debido a la tendencia de aumentar la frecuencia de trabajo y el ancho de banda en los sistemas de comunicaciones actuales. Dicho análisis se ha resuelto en el pasado con distintos métodos, de los menos precisos y clásicos a los más modernos y costosos computacionalmente. Pese a que el avance de la tecnología de computadores hoy en día permite la ejecución de programas muy complejos, la eficiencia computacional sigue siendo importante en el desarrollo de metodología de análisis electromagnético, especialmen- 
te en el caso de algunos problemas concretos tales como el análisis de dispositivos en guía de onda en entornos de propagación cerrados, y el comportamiento de elementos dieléctricos y metálicos o estructuras radiantes en entornos abiertos.

La solución a problemas electromagnéticos basada en la Ecuación Integral se ha empleado de forma clásica para la resolución, por ejemplo, de elementos dispersores en [26]. También se aplicó en el análisis de circuitos multicapa encapsulados [13] y en el cálculo modal eficiente de guías de onda con geometrías arbitrarias descritas en el método Boundary Element Resonant Mode Expansion (BI-RME) en [9]. Todos estos métodos basados en la Ecuación Integral se suelen resolver mediante la aplicación del extendido Método de los Momentos (MoM) descrito en [17]. El análisis eficiente de la dispersión de objetos bidimensionales dieléctricos y/o magnéticos con posibles pérdidas también se ha realizado tradicionalmente mediante la utilización de técnicas de la Ecuación Integral (IE). Si los cuerpos dispersores no son homogéneos, resulta conveniente formular el problema en términos de una ecuación integral de volumen, siendo el objeto reemplazado por corrientes volumétricas equivalentes de polarización [27]. Por el contrario, si se trata de estudiar cuerpos totalmente homogéneos u homogéneos a trozos, resulta más eficiente plantear el problema de ecuación integral mediante la aplicación del principio de equivalencia superficial [25]. De esta forma, las incógnitas del problema se reducen a densidades superficiales de corriente eléctrica y magnética distribuidas sobre el contorno de separación de medios.

Otro problema considerado es el análisis de radomos. Estas estructuras son protecciones de antena necesarias en muchas aplicaciones de telecomunicación, sobre todo en aeronaves y estaciones terrestres de comunicación vía satélite. Los radomos pueden realizarse con materiales dieléctricos con pérdidas y en menor medida usando materiales con permeabilidades magnéticas variadas, incluyendo antenas reflectoras realizadas en metal y con alimentación directiva. Estos problemas son complejos de analizar debido a su gran tamaño en número de incógnitas y a las geometrías complejas que se deben caracterizar. Debido a ello, este es un tema de gran interés que está recibiendo una atención considerable de la comunidad científica [39, 32].

De forma tradicional, los radomos se han analizado utilizando métodos de alta frecuencia, tales como la Propagación por Rayos [14], o 
el método Geometrical Theory of Diffraction [12]. De forma alternativa, se desarrollaron técnicas rigurosas para la solución de problemas bidimensionales incluyendo superficies reflectoras, radomos con geometrías canónicas y fuentes complejas $[8,33,37,23,24]$. La solución de dispersión de estructuras bidimensionales encuentra también aplicaciones útiles en el campo del diseño de filtros inductivos guiados, utilizados de forma extensiva en aplicaciones de telefonía móvil y de comunicaciones por satélite. También aparecen sistemas cilíndricos o bidimensionales en el caso de las antenas reflectoras radomizadas empleadas en aeronaves, tal y como se describe en [22]. Este tipo de aplicaciones justifican la búsqueda de técnicas numéricas eficientes para el estudio de problemas de dispersión bidimensionales.

Recientemente se ha empezado a analizar radomos tridimensionales sin superficies reflectoras basados en formulaciones en volumen y superficie [20,39], donde la técnica empleada ha sido Adaptive Integral Method [39], y el Multilevel Fast Multipole Algorithm [19, 20]. Estos radomos tridimensionales normalmente se usan para estaciones terrestres fijas, que presentan geometría esférica. De cualquier modo, los sistemas navales y aéreos [22], así como las torres de difusión, suelen presentar geometrías arbitrarias que requieren nuevas formulaciones. En estos escenarios reales se emplean materiales multicapa y superficies y reflectores metálicos con fuentes radiantes directivas.

Otra opción consiste en emplear el Principio de la Equivalencia para formular la Ecuación Integral para el análisis de problemas bidimensionales con geometrías arbitrarias. Usando esta teoría, una integral de contorno caracteriza completamente el problema. Esta fue la aproximación seguida en [4] para radomos pequeños, que con una formulación más general se presentó en [29]. Otra opción de formulación del problema es la basada en Poggio Miller Chang Harrington Wu Tsai (PMCHWT) [18]. Incluso en el caso de formulaciones en contorno, si el radomo es suficientemente grande habrá un problema matricial de gran tamaño, y por lo tanto será interesante pensar en técnicas que sirvan para disminuir el tiempo de cálculo y la necesidad de espacio en memoria y disco.

Pese a que las técnicas basadas en la Ecuación Integral son métodos eficientes de partida porque discretizan el contorno de los objetos, existen situaciones en las que el coste de cálculo y el tamaño del problema es excesivamente grande. Esto ocurre en primer lugar cuando dicho 
método se aplica a objetos dispersores grandes en términos eléctricos o se requiere una alta precisión. En este caso el número de incógnitas necesario se puede llegar a incrementar notablemente. Por ejemplo, éste es el caso cuando se emplea una variante simple del Método de los Momentos como Point-Matching para resolver objetos grandes, problemas compuestos por una gran cantidad de dispersores, o geometrías muy complejas que exigen un alto nivel de detalle como las estructuras fractales. En estas situaciones, el coste computacional, particularmente a la hora de resolver y almacenar grandes sistemas de ecuaciones lineales, comienza a ser muy importante.

En este contexto se podría analizar la ventaja producida por la transformada Wavelet (ver [30]), teniendo en cuenta además que la formulación de superficie descrita anteriormente produce sistemas de ecuaciones con estructura en banda de forma natural. Esta estructura matricial particular está especialmente indicada para la transformada Wavelet. La idea de usar la transformada Wavelet para reducir el coste computacional en problemas electromagnéticos se aplicó inicialmente al análisis de circuitos microtira por parte de [36] y [28], y para el cálculo eficiente de los modos de una guía en [35]. Recientemente, se ha extendido la aplicación de la transformada Wavelet al análisis eficiente de problemas de dispersión electromagnética bidimensionales (ver $[31,34,5,6,21,11,7,15]$ y [16]). En las referencias [6, 11, 5, 7] se propone una nueva técnica para la incorporación de bases Wavelet en ecuaciones integrales, que estaban principalmente basadas en la compresión de la matriz de impedancias usando funciones bases adaptadas de forma iterativa al problema. La introducción de distintas funciones base Wavelet en la solución de IEs se produjo en [21], en esta referencia se demostró que las bases de soporte finito semi-ortogonales mejoraban los resultados proporcionados por las bases completamente ortogonales. Por otra parte, [15] y [16] estudiaron las funciones base más adecuadas para problemas de dispersión y concluyeron que en estos problemas, la ortogonalidad de las funciones base es la característica más importante que se debía cumplir.

A pesar del desarrollo en la mejora computacional empleando funciones Wavelet comentada anteriormente, todavía queda un amplio abanico de posibilidades basadas en la transformada Wavelet aplicadas a los problemas que se han seleccionado para su estudio. En concreto las bases wavelet-like en el marco de los problemas de dispersión bidi- 
mensionales no han sido suficientemente comparadas con otras bases clásicas tales como las Daubechies. Por lo tanto, y teniendo en cuenta la investigación que se está desarrollando en el área, parece apropiado realizar un estudio completo para integrar las nuevas técnicas con los algoritmos de análisis electromagnético.

Por último, una vez optimizados los algoritmos y pese a las ventajas de mejora en tiempos de cálculo comprobadas, se observan problemas en los que las funciones Wavelet no producen una mejora sustancial en tiempo de cálculo. Sin embargo la solución de estos problemas se puede optimizar aprovechando la estructura matricial que presentan los sistemas discretos obtenidos y aprovechando también técnicas de procesado en paralelo. Estas técnicas de paralelismo permiten resolver problemas grandes en tamaño que ni siquiera podrían abarcarse con una técnica secuencial en un procesador convencional. Por lo tanto parece claro que si se pretende la solución a problemas electromagnéticos grandes en términos eléctricos se debe recurrir al uso de técnicas de procesado en paralelo. Estas técnicas se han aplicado en el ámbito electromagnético con anterioridad (ver [38]), aunque su implementación depende en gran medida del problema que se quiera resolver. En esta tesis se han aplicado técnicas de procesado en paralelo al problema BI-RME y se ha requerido un diseño cuidadoso de software con el objetivo de obtener las mejores prestaciones del procesado en paralelo.

\subsection{Objetivos de la investigación}

Los objetivos a desarrollar en la presente tesis están orientados de forma general a la mejora en la eficiencia computacional de los diversos métodos que se emplean en la resolución de problemas electromagnéticos en entornos abiertos y cerrados. Se analizarán técnicas de mejora de eficiencia aplicadas a la dispersión producida por obstáculos bidimensionales en espacios abiertos. Además, se estudiarán las posibilidades de mejora de eficiencia computacional en la caracterización de dispositivos pasivos de microondas con geometrías complejas.

Los objetivos concretos a desarrollar en la presente tesis serán pues:

1. El empleo de nuevas técnicas de discretización para la mejora en coste computacional de distintos métodos electromagnéticos, que se usan para caracterizar guías de onda, y están basados en la 
Ecuación Integral. Los métodos que originalmente se formularon mediante el Método de los Momentos (version Galerkin), se van a implementar empleando el método de discretización espacial llamado método de Nyström.

2. Desarrollo de algoritmos basados en la Transformada Discreta Wavelet para la mejora en tiempo de cálculo de los problemas matriciales que se obtienen en la solución de problemas electromagnéticos empleando la Ecuación Integral. El estudio se centrará en la reducción de tiempo de resolución gracias a la utilización de distintos tipos de transformada Wavelet.

3. Evaluación de distintos métodos para la aceleración de problemas matriciales de autovalores y autovectores grandes y estructurados, que se obtienen en la caracterización de dispositivos guiados de microondas, basados en la aplicación de técnicas iterativas tales como la técnica de Lanczos y la obtención eficiente de autovectores.

4. Desarrollo de técnicas numéricas eficientes y adaptadas a la estructura matricial de cada problema (solución a sistemas de ecuaciones lineales o problemas de autovalores) para la mejora de los algoritmos numéricos que implementan las técnicas clásicas de resolución de problemas electromagnéticos.

5. Implementación de métodos de programación en paralelo para las rutinas numéricas basadas en la Ecuación Integral en grupos de procesadores. Esta tarea se puede realizar una vez se hayan identificado las etapas que requieren mayor capacidad de cálculo en la solución de los problemas electromagnéticos.

\subsection{Entorno de trabajo y proyectos de investi- gación relacionados}

En esta tesis se ha colaborado con distintos grupos de investigación de la Universitat Politècnica de València, así como de la Universidad Politécnica de Cartagena. Dicha colaboración ha dado lugar a distintas publicaciones en prensa científica que constituyen los capítulos de la 
Parte II. Así, se ha colaborado de forma continuada y activa con miembros del grupo de investigación de la autora: Grupo de Aplicaciones de Microondas del Instituto de Telecomunicaciones y Aplicaciones Multimedia (iTEAM) así como con miembros del Grupo Interdisciplinar de Computación y Comunicaciones (INCO2) del Departamento de Sistemas Informáticos y Computación, ambos de la Universitat Politècnica de València. Además se ha trabajado de forma conjunta con otras Universidades: investigadores del Departamento de Tecnologías de la Información y las Comunicaciones de la Universidad Politécnica de Cartagena y finalmente con miembros del Departamento de Física Aplicada y Electromagnetismo (ICMUV) de la Universidad de Valencia.

El trabajo desarrollado en los artículos se enmarca en distintos proyectos de investigación de financiación pública. Así, el estudio de estructuras radiantes y radomos se realizó en colaboración con la Universidad Politécnica de Cartagena en el marco de los proyectos del Ministerio de Educación y Ciencia con referencia TEC2004/04313-C02-01 y TEC2004/04313-C02-02. El trabajo realizado sobre un nuevo algoritmo Lanczos para el problema BI-RME en colaboración con el INCO2 se realizó bajo el proyecto del Ministerio de Educación y Ciencia con referencia TEC2004/04313-C02-01 y la financiación del fondo FEDER de la Comisión Europea TIC2003-08238-C02-02. Además se ha producido una estrecha colaboración a lo largo de los años entre el INCO2 y el GAM en forma de proyectos interdisciplinares propios de la Universitat Politècnica de València y los proyectos de la Generalitat de València PROMETEO 2009/013 y PROMETEO 2011/061. Como consecuencia de esta colaboración se han realizado varios de los trabajos presentados en esta tesis y en el futuro se van a desarrollar más avances en la mejora de la eficiencia de los algoritmos electromagnéticos.

\subsection{Definición del problema}

El punto de partida en el desarrollo de esta tesis es la existencia previa de distintos métodos para la caracterización electromagnética en escenarios de propagación en espacios abiertos y cerrados. Estos métodos que vamos a tomar como punto de partida están basados en la Ecuación Integral que se obtiene de aplicar las ecuaciones de Maxwell en estos dominios. En el caso de los problemas formulados en entornos 
cerrados la solución que se recoge como punto de partida es la formulación modal llamada Boundary Integral - Resonant Mode Expansion Method (BI-RME).

Estos métodos están probados en la prensa científica y producen resultados altamente satisfactorios, sin embargo en algunos casos su coste en tiempo de cálculo se hace muy elevado. Por lo tanto, en esta tesis se plantean técnicas de distinto tipo pero orientadas todas ellas a mejorar el rendimiento de los algoritmos, y a bajar el coste computacional de las soluciones ofrecidas sin tener una pérdida importante de precisión. El trabajo a realizar consiste en llevar a cabo las líneas de investigación propuestas como objetivos, para seleccionar en cada caso la técnica individual o la combinación de técnicas que resultan más apropiadas para cada uno de los problemas bajo estudio. Así pues, se han seleccionado los problemas electromagnéticos descritos a continuación.

\subsubsection{Dispersión 2D en entornos abiertos}

El primer problema que se presenta para su análisis y optimización es el producido en la dispersión de ondas electromagnéticas en estructuras invariantes en una de las dimensiones espaciales (eje $z$ ) y realizadas en material conductor perfecto.

La dispersión en este tipo de estructuras metálicas bidimensionales o cilíndricas de contorno arbitrario puede ser tratada con diferentes técnicas de análisis. En primer lugar se ha tenido en cuenta la solución del problema mediante una técnica espectral que caracteriza de forma completa la respuesta de una estructura cilíndrica arbitraria cuando una onda transversal magnética (TM) polarizada según el eje $z$ incide sobre ella $\left(T M^{z}\right)$. Primero se realiza una descomposición modal del campo eléctrico incidente y dispersado mediante modos cilíndricos.

$$
\begin{gathered}
\mathbf{E}^{i}(\boldsymbol{\rho})=\sum_{p=-N_{i}}^{N_{i}} i_{p} J_{p}(k|\boldsymbol{\rho}|) e^{j p \phi} \mathbf{z} \\
\mathbf{E}^{S}(\boldsymbol{\rho})=\sum_{q=-N_{d}}^{N_{d}} c_{q} H_{q}^{(2)}(k|\boldsymbol{\rho}|) e^{j q \phi} \mathbf{z}
\end{gathered}
$$

donde $(\rho, \phi, z)$ son las coordenadas cilíndricas de un punto de observación $\rho, k$ es el número de onda en espacio libre, $J_{p}$ y $H_{q}^{(2)}$ son, respec- 
tivamente, la función de Bessel de orden $p$ y la función de Hankel de segunda clase de orden $q, i_{p}$ y $c_{q}$ son los coeficientes espectrales para el campo incidente y dispersado. Finalmente, $N_{i}$ y $N_{d}$ son el número de modos necesarios para reconstruir de forma precisa el campo incidente y dispersado respectivamente.

Posteriormente se hace uso de la Ecuación Integral de Campo Eléctrico (EFIE). Se debe calcular $J_{z_{p}}$, que es la corriente inducida en el cilindro de contorno arbitrario debida al modo espectral $p$. Para ello, se formula la EFIE (ver [17]):

$$
\left.E_{z_{p}}^{i}(\boldsymbol{\rho})\right|_{C}=\frac{k \eta}{4} \int_{C} J_{z_{p}}\left(\boldsymbol{\rho}\left(l^{\prime}\right)\right) H_{0}^{(2)}\left(k\left|\boldsymbol{\rho}-\boldsymbol{\rho}\left(l^{\prime}\right)\right|\right) d l^{\prime}
$$

donde $E_{z_{p}}^{i}$ es la componente longitudinal del modo incidente $p$-ésimo, $C$ es el contorno de la sección transversal del cuerpo dispersor parametrizado con la variable $l^{\prime}$, y el vector $\rho\left(l^{\prime}\right)$ apunta a cada punto del contorno. Para resolver la EFIE se discretiza en el dominio espacial mediante el método de los momentos versión Point-Matching, obteniendo el siguiente sistema algebraico:

$$
\begin{gathered}
V_{m p}=\sum_{n=1}^{N} Z_{m n} \cdot I_{n p} m=1, \ldots, N \\
Z_{m n}=\frac{k \eta}{4} \int_{\Delta C_{n}} H_{0}^{(2)}\left(k\left|\boldsymbol{\rho}_{m}-\boldsymbol{\rho}\left(l^{\prime}\right)\right|\right) d l^{\prime} \\
V_{m p}=E_{z_{p}}^{i}\left(\boldsymbol{\rho}_{m}\right)=J_{p}\left(k\left|\boldsymbol{\rho}_{m}\right|\right) e^{j p \phi_{m}}
\end{gathered}
$$

donde $\Delta C_{n}$ es el intervalo $n$-ésimo en el que se subdivide el contorno $C$ y $\boldsymbol{\rho}_{m}(m \in[1, \ldots, N])$ son los puntos centrales de dichos subintervalos (ver [17]). El operador integral discretizado en este caso implica a la función de Hankel, que presenta carácter oscilatorio en el dominio estudiado. Finalmente se obtiene la incógnita planteada mediante la solución de un sistema lineal de ecuaciones, que se puede extender a cualquiera de los posibles modos incidentes $\left(p \in\left[-N_{i}, \ldots, N_{i}\right]\right)$ mediante la expresión:

$$
\mathbf{Z}_{N \times N} \cdot \mathbf{I}_{N \times\left(2 N_{i}+1\right)}=\mathbf{V}_{N \times\left(2 N_{i}+1\right)} .
$$


Una vez se obtiene la matriz I, se puede calcular fácilmente la matriz generalizada de dispersión gracias a la matriz de transformación de Bessel.

El segundo problema de dispersión 2D en entornos abiertos planteado es diferente en cuanto resuelve el campo dispersado por objetos cilíndricos anidados de contornos arbitrarios realizados con materiales homogéneos metálicos, dieléctricos o magnéticos con pérdidas incluyendo fuentes puntuales de radiación en la región más interna, que producen excitación transversal magnética $\left(T M^{z}\right)$ o eléctrica $\left(T E^{z}\right)$. El tipo de estructuras que se quieren simular mediante este planteamiento son antenas cilíndricas radomizadas con la opción de la inclusión de superficies reflectoras, que se encuentran con frecuencia en ámbitos militares o de radiodifusión.

En este caso la formulación electromagnética hace uso del principio de equivalencia en superficie, trabajando con densidades superficiales de corriente eléctricas $\mathbf{J}(\boldsymbol{\rho})$ y magnética $\mathbf{M}(\boldsymbol{\rho})$ en las superficies. Estas corrientes dan lugar a las siguientes expresiones de campo eléctrico y magnético dispersado en cada una de las regiones $i$

$$
\begin{gathered}
\mathbf{E}_{i}^{s}(\boldsymbol{\rho})=-j \omega \mathbf{A}_{i}(\boldsymbol{\rho})-\nabla V_{i}(\boldsymbol{\rho})-\frac{1}{\epsilon_{i}} \nabla \times \mathbf{F}_{i}(\boldsymbol{\rho}) \\
\mathbf{H}_{i}^{s}(\boldsymbol{\rho})=-j \omega \mathbf{F}_{i}(\boldsymbol{\rho})-\nabla U_{i}(\boldsymbol{\rho})+\frac{1}{\mu_{i}} \nabla \times \mathbf{A}_{i}(\boldsymbol{\rho})
\end{gathered}
$$

donde se ha empleado la representación de potencial mixto para los campos. Cuando se trata un problema bidimensional, la función de Green del kernel es la siguiente:

$$
G_{i}\left(\boldsymbol{\rho}, \boldsymbol{\rho}^{\prime}\right)=\frac{1}{4 j} H_{0}^{(2)}\left(k_{i}\left|\boldsymbol{\rho}-\boldsymbol{\rho}^{\prime}\right|\right)
$$

donde $H_{q}^{(2)}$ es la función de Hankel de segunda clase de orden cero.

En lugar de plantear la ecuación integral de campo eléctrico, se hace uso de la formulación PMCHWT, que presenta ventajas de estabilidad con respecto a la solución EFIE. Se discretiza el problema mediante el método MoM versión Galerkin y se llega finalmente a un sistema lineal de ecuaciones con estructura de banda. Tiene la diferencia con respecto al caso anterior en que se plantean dos tipos de corrientes: magnéticas 
y eléctricas y que I tiene estructura de vector en lugar de matriz:

$$
\begin{gathered}
\mathbf{Z} \cdot \mathbf{I}=\mathbf{V} \\
\mathbf{Z}=\left[\begin{array}{ccccc}
\mathbf{Z}^{11} & \mathbf{Z}^{12} & 0 & \cdots & 0 \\
\mathbf{Z}^{21} & \mathbf{Z}^{22} & \ddots & \ddots & \vdots \\
0 & \ddots & \ddots & \ddots & 0 \\
\vdots & \ddots & \ddots & \mathbf{Z}^{(N-1)(N-1)} & \mathbf{Z}^{(N-1) N} \\
0 & \cdots & 0 & \mathbf{Z}^{N(N-1)} & \mathbf{Z}^{N N}
\end{array}\right] \\
\mathbf{I}=\left[\begin{array}{c}
\mathbf{I}_{J M}^{1} \\
\mathbf{I}_{J M}^{2} \\
\vdots \\
\vdots \\
\mathbf{I}_{J M}^{N}
\end{array}\right], \mathbf{I}_{J M}^{i}=\left[\begin{array}{c}
\mathbf{J}_{i} \\
\mathbf{M}_{i}
\end{array}\right], \mathbf{V}=\left[\begin{array}{c}
\mathbf{V}_{E H}^{2} \\
\vdots \\
\vdots \\
\mathbf{V}_{E H}^{N}
\end{array}\right], \mathbf{V}_{E H}^{i}=\left[\begin{array}{c}
\mathbf{E}_{i} \\
\mathbf{H}_{i}
\end{array}\right] .
\end{gathered}
$$

Cuando en la capa más interna se encuentra un conductor perfecto, la matriz de impedancias relacionada se debe formular de forma simplificada, al no existir en ese caso corrientes magnéticas en la superficie.

\subsubsection{Métodos modales en entornos cerrados bidimen- sionales: BI-RME 2D}

El otro problema que aparece en cuatro de los artículos presentados a continuación resuelve la caracterización modal de una guía de ondas metálica de contorno arbitrario mediante el método BI-RME. En este escenario se parte de una guía de ondas canónica rectangular que rodea al contorno arbitrario y se resuelve el problema discretizando únicamente en el dominio espacial las perturbaciones que se realizan sobre el contorno rectangular. En este método se hace uso de una expansión modal tomando como bases los modos de la guía rectangular y una ecuación integral en contorno.

En primer lugar se analizan los modos TM de la guía perturbada. La componente longitudinal del campo eléctrico en un punto de observación $\mathbf{r}$ dentro de la guía arbitraria de contorno $S$ se puede representar 
como (ver [9]):

$$
\begin{array}{r}
E_{z}(\mathbf{r})=-j \eta k^{\prime} \int_{\sigma} g\left(\mathbf{r}, \mathbf{s}^{\prime}\right) J_{z}\left(l^{\prime}\right) d l^{\prime} \\
-j \eta k^{\prime 3} \sum_{m=1}^{M^{\prime}} \frac{\psi_{m}^{T M \square}(\mathbf{r})}{h_{m}^{\prime 2}\left(h_{m}^{\prime 2}-k^{\prime 2}\right)} \int_{\sigma} \psi_{m}^{T M \square}\left(\mathbf{s}^{\prime}\right) J_{z}\left(l^{\prime}\right) d l^{\prime}
\end{array}
$$

donde $g\left(\mathbf{r}, \mathbf{s}^{\prime}\right)$ es la función escalar bidimensional de Green de convergencia rápida y $J_{z}\left(l^{\prime}\right)$ es la componente longitudinal de la densidad de corriente superficial $\mathbf{J}_{\sigma}$. Además, $h_{m}^{\prime}$ y $\psi_{m}^{T M \square}$ son, respectivamente, el número de onda de corte y el potencial escalar normalizado del $m$-ésimo modo TM de la guía rectangular canónica.

Tras imponer las condiciones de contorno $\left(E_{z}=0\right.$ en el contorno) y discretizar espacialmente la ecuación integral, ésta da lugar a un problema generalizado de autovalores y autovectores. Sin embargo la discretización puede realizarse mediante el clásico MoM versión Galerkin, o bien se puede emplear el método de Nyström, que simplifica el desarrollo teórico y el tiempo de cálculo y que se ha implementado en esta tesis para su comparación con la discretización Galerkin. En cualquier caso, el problema algebraico final para la solución de los modos TM es el siguiente:

$$
\left\{\left[\begin{array}{ll}
\mathbf{U} & \mathbf{O}_{\mathbf{t}} \\
\mathbf{O} & \mathbf{O}^{\prime}
\end{array}\right]-k^{\prime 2}\left[\begin{array}{ll}
\mathbf{D}^{\prime} & \mathbf{R}_{\mathbf{t}}^{\prime} \\
\mathbf{R}^{\prime} & \mathbf{L}^{\prime}
\end{array}\right]\right\}\left[\begin{array}{l}
\mathbf{a}^{\prime} \\
\mathbf{b}^{\prime}
\end{array}\right]=0
$$

donde $\mathbf{U}$ es la matriz unidad de dimensión $M^{\prime} \times M^{\prime}, \mathbf{O}$ es la matriz nula de dimensión $N \times M^{\prime}$ y $\mathbf{O}^{\prime}$ es la matriz nula de dimensión $N \times$ $N$. El resto de matrices presentan diferentes expresiones en función del método de discretización empleado. Las incógnitas de este problema se corresponden con los autovectores y los autovalores generalizados del par de matrices:

$$
\left(\left[\begin{array}{ll}
\mathbf{U} & \mathbf{O}_{\mathbf{t}} \\
\mathbf{O} & \mathbf{O}^{\prime}
\end{array}\right],\left[\begin{array}{ll}
\mathbf{D}^{\prime} & \mathbf{R}_{\mathbf{t}}^{\prime} \\
\mathbf{R}^{\prime} & \mathbf{L}^{\prime}
\end{array}\right]\right)
$$

La columna de autovectores representa en $\mathbf{a}^{\prime}$ los coeficientes modales y en $\mathbf{b}^{\prime}$ la información de discretización de la corriente longitudinal $J_{z}$. Los autovalores $k^{\prime}$ son los números de onda de corte de los modos TM de la guía perturbada. 
En segundo lugar se analizan los modos TE de la guía perturbada. En este caso, la componente transversal del campo eléctrico observada en un punto $\mathbf{r}$ de la guía tiene la expresión:

$$
\begin{array}{r}
\mathbf{E}_{t}(\mathbf{r})=j \frac{\eta}{k} \int_{\sigma} \nabla \frac{\partial g\left(\mathbf{r}, \mathbf{s}^{\prime}\right)}{\partial l^{\prime}} J_{t}\left(l^{\prime}\right) d l^{\prime} \\
-j \eta k \int_{\sigma} \overline{\mathbf{G}}_{s t}\left(\mathbf{r}, \mathbf{s}^{\prime}\right) \cdot \widehat{\mathbf{t}}\left(l^{\prime}\right) J_{t}\left(l^{\prime}\right) d l^{\prime} \\
-j \eta k^{3} \sum_{m=1}^{M} \frac{\mathbf{e}_{m}^{T E^{\square}}(\mathbf{r})}{h_{m}^{2}\left(h_{m}^{2}-k^{2}\right)} \int_{\sigma} \mathbf{e}_{m}^{T E^{\square}}\left(\mathbf{s}^{\prime}\right) \cdot \widehat{\mathbf{t}}\left(l^{\prime}\right) J_{t}\left(l^{\prime}\right) d l^{\prime}
\end{array}
$$

donde $\overline{\mathbf{G}}_{s t}\left(\mathbf{r}, \mathbf{s}^{\prime}\right)$ es la función diádica solenoidal de Green y $J_{t}\left(l^{\prime}\right)$ es la componente transversal de la densidad de corriente superficial $\mathbf{J}_{\sigma}$. Además, $h_{m}$ y $\mathbf{e}_{m}^{T E^{\square}}$ son, respectivamente, el número de onda de corte y el campo eléctrico normalizado del $m$-ésimo modo TE de la guía rectangular canónica.

De nuevo, tras aplicar la condición de contorno al campo eléctrico tangencial al contorno $\left(\mathbf{E}_{t} \cdot \widehat{\mathbf{t}}=0\right)$ y discretizar la ecuación integral, se obtiene otro problema generalizado de autovalores y autovectores para los modos TE de la guía:

$$
\left\{\left[\begin{array}{cc}
\mathbf{U} & \mathbf{O}_{\mathbf{t}} \\
\mathbf{O} & \mathbf{C}
\end{array}\right]-k^{2}\left[\begin{array}{cc}
\mathbf{D} & \mathbf{R}_{\mathbf{t}} \\
\mathbf{R} & \mathbf{L}
\end{array}\right]\right\}\left[\begin{array}{l}
\mathbf{a} \\
\mathbf{b}
\end{array}\right]=0
$$

donde $\mathbf{U}$ es la matriz unidad de dimensión $M \times M$ y $\mathbf{O}$ es la matriz nula de dimensión $N \times M$. El resto de matrices presentan diferentes expresiones en función del método de discretización empleado. Las incógnitas de esta problema de nuevo se corresponden con los autovectores y los autovalores generalizados del par de matrices:

$$
\left(\left[\begin{array}{cc}
\mathbf{U} & \mathbf{O}_{\mathbf{t}} \\
\mathbf{O} & \mathbf{C}
\end{array}\right],\left[\begin{array}{cc}
\mathbf{D} & \mathbf{R}_{\mathbf{t}} \\
\mathbf{R} & \mathbf{L}
\end{array}\right]\right)
$$

La columna de autovectores representa en a los coeficientes modales y en b la información de discretización de la corriente longitudinal $J_{t}$. Los autovalores $k$ son los números de onda de corte de los modos TE de la guía perturbada.

En cualquier caso, el problema BI-RME 2D da lugar a problemas de autovalores y autovectores de tamaño muy grande, sobre todo cuando 
se pretende calcular frecuencias de corte de modos de orden muy elevado para aplicaciones de gran precisión. En ese caso, las matrices involucradas son muy grandes y presentan una estructura dispersa, que se puede explotar mediante algoritmos especialmente diseñados. En este caso y empleando algoritmos de Lanczos se obtienen ganancias de tiempo de cálculo muy elevadas. En un segundo paso se procede a la paralelización de estos algoritmos especiales obteniendo ganancias aún mayores de tiempo de cálculo.

\subsubsection{Métodos modales en entornos cerrados 3D: BI-RME 3D}

El siguiente problema electromagnético que se presenta para su optimización en términos numéricos consiste en la solución modal de una cavidad tridimensional planteando una expansión modal en función de los modos de una cavidad canónica y discretizando la perturbación sobre esta guía haciendo uso de una IE. Es un problema semejante al presentado anteriormente pero extendido a tres dimensiones, aumentando sobre todo la complejidad de la discretización espacial, que hace uso del método MoM versión Galerkin, en este caso con funciones base definidas en superficie. Las funciones base que se emplean de partida en este método son las funciones Rao-Wilton-Glisson (RWG) también conocidas como rooftop (ver [25]).

En este problema se presentan las mismas dificultades de tiempo de cálculo que en el problema anterior, pero acentuadas aún más debido al aumento de una dimensión espacial. En este problema se pueden aplicar varias de la técnicas presentadas en la tesis, incluyendo el tratamiento de la estructura del problema matricial y las técnicas de procesado paralelo. En este caso dichas técnicas aportan ventajas aún más elevadas debido al mayor tamaño del problema que se obtiene en el caso del análisis en cavidades tridimensionales y al mallado en superficie. Este trabajo es reciente y se han presentado dos comunicaciones en congresos internacionales, por lo que que no se indexan en la Parte II del documento de la tesis. No obstante, se presentan la base teórica y sus resultados en el Capítulo 8. El trabajo realizado consiste en la obtención de un resultado numérico estable empleando funciones RWG de partida gracias a una técnica numérica que incluye el uso de la Descomposición en Valores Singulares (SVD). Gracias a esta descomposi- 
ción se obtienen matrices de proyección a funciones base solenoidales $\mathrm{y}$ no solenoidales que permiten resolver el problema.

\subsection{Herramientas empleadas}

En este capítulo se realiza un repaso de las herramientas que se han utilizado en los distintos artículos que se presentan en esta tesis. En primer lugar se presentan técnicas de discretización y los problemas algebraicos que se van a tratar en esta tesis y que aparecen en la solución de problemas electromagnéticos. Posteriormente se presenta la transformada Wavelet, con aplicación en la mejora de la eficiencia de técnicas de cálculo numérico. Finalmente se introducen las técnicas de procesado en paralelo, que explotan la existencia de máquinas con múltiples procesadores.

\subsubsection{Métodos de discretización}

En esta tesis se han empleado distintos métodos de discretización para la resolución de las ecuaciones integrales que aparecen en los problemas de electromagnetismo planteados anteriormente.

\section{Método de los Momentos}

De forma clásica el método de los momentos ha sido el más empleado en la solución de este tipo de problemas. Dicha solución normalmente discretiza en el espacio la incógnita (suele ser la corriente eléctrica o magnética) mediante un número entero de funciones de dominio acotado y continuo (ver [25] y [17]). Estas funciones se denominan funciones base y se completan con un conjunto de funciones de test que discretizan el espacio del operador y pueden ser bien iguales a las funciones base (método Galerkin) o bien funciones Delta de Dirac (método PointMatching). Tanto en un caso como en otro, la solución final se logra mediante la proyección del espacio del operador (integral) al espacio de la incógnita, dando lugar a un número de integrales de carácter simple o doble. Estas integrales se tratan con métodos numéricos cuando la parte analítica ya se ha resuelto. Sin embargo, se debe prestar una atención principal a los elementos que contienen singularidades en el problema. Esto ocurre un número de veces que incluye como mínimo 
los casos en que la función de test involucrada en la integral comparte dominio espacial con la función base correspondiente (elementos de la diagonal de las matrices que representan al operador).

\section{Método de Nyström}

Una alternativa al Método de los Momentos que rara vez se emplea en electromagnetismo es la discretización mediante el método de Nyström. En esta alternativa, el operador integral se sustituye directamente por un sumatorio ponderado de la función particularizada en una serie de puntos de evaluación. Es una técnica muy simple y semejante a la integración numérica, en la que de nuevo se debe prestar especial atención a las singularidades presentes en la diagonal de la matriz que caracteriza al operador. Este método se ha aplicado al problema BIRME por primera vez en esta tesis, requiriendo un desarrollo matemático acorde a la nueva formulación y a las integrales hiper-singulares que han aparecido. Mediante este nuevo desarrollo se han obtenido resultados altamente satisfactorios con una formulación muy simplificada y unos tiempos de cálculo reducidos en un $30 \%$.

\subsubsection{Problemas algebraicos que aparecen en Electromag- netismo}

En los problemas electromagnéticos estudiados aparecen principalmente dos tipos de problemas algebraicos: los sistemas lineales de ecuaciones y los problemas generalizados de autovalores y autovectores.

\section{Sistemas de ecuaciones lineales}

El primer problema algebraico a resolver es la solución a un sistema de ecuaciones lineales del tipo:

$$
\mathbf{Z} \cdot \mathbf{I}=\mathbf{V}
$$

donde $\mathbf{Z}_{N \times N}$ se denomina matriz de impedancias y suele ser una matriz simétrica, de carácter real o complejo que representa el operador integral del problema electromagnético. El vector $\mathbf{I}_{N \times 1}$ es el vector de incógnitas, normalmente la corriente eléctrica discretizada en el espacio y $\mathbf{V}_{N \times 1}$ es el vector excitación (tensión). En algunos casos, tales como 
la dispersión en entornos abiertos bidimensional mediante técnicas espectrales, el problema algebraico se resuelve mediante un conjunto de sistemas lineales que comparten la matriz de impedancia y se puede expresar mediante la misma ecuación, donde ahora $\mathbf{I}_{N \times N_{s}}$ y $\mathbf{V}_{N \times N_{s}}$ son matrices rectangulares y $N_{s}$ es el número de modos espectrales empleado en la expansión.

La matriz de impedancias $\mathbf{Z}$ de los problemas electromagnéticos estudiados recoge singularidades en los elementos de la diagonal, ya que dichos elementos evalúan la interacción de una función base con una función de test que comparte soporte espacial. Por ello serán los elementos que presenten un mayor valor absoluto en la matriz.

Este tipo de sistemas de ecuaciones lineales se resuelven mediante métodos enmarcados en la descomposición Lower Triangular matrix Upper Triangular matrix (LU). Esta sería la técnica adecuada para matrices llenas y sin ningún tipo de estructura capaz de ser explotada y tienen un orden de complejidad de $O\left(N^{3}\right)$.

En nuestro escenario, bien porque el problema conduce a matrices estructuradas, bien porque se han modificado mediante la transformada Wavelet o bien por ambos motivos, es posible que la matriz de impedancias sea una matriz dispersa y/o estructurada. En tal caso se emplearán técnicas de algebra especiales para matrices dispersas, donde la complejidad depende del número de entradas no nulas de la matriz. Estos métodos para matrices dispersas y simétricas se suelen basar en métodos iterativos tales como el Método de Gradiente Conjugado.

\section{Problemas generalizados y estándar de autovalores y autovectores}

Otro de los problemas algebraicos que aparecen en los problemas electromagnéticos previamente mencionados es el cálculo de autovalores y autovectores generalizado de un sistema como el siguiente:

$$
\mathbf{A} \mathbf{x}=\lambda \mathbf{B} \mathbf{x}
$$

donde A y $\mathbf{B}$ son matrices cuadradas simétricas y reales y se desean obtener sus autovalores y sus correspondientes autovectores incógnita $\mathrm{x}$. Este problema con matrices llenas para obtener un número significativo de autovalores se trataría mediante la rutina estándar correspondiente de LAPACK [1] (por ejemplo DSYGV), calculando en el proceso 
la descomposición de Cholesky de la matriz $\mathbf{B}$, puesto que en la mayoría de los casos esta matriz es definida positiva. Sin embargo, y dadas las características de las matrices, se obtienen resultados mucho mejores mediante rutinas optimizadas.

El problema electromagnético BI-RME que conduce a estos problemas tiene dos tipos de incógnita (coeficientes de la expansión modal y corriente discretizada) agrupados en el vector $\mathrm{x}$ que dan lugar a una estructura por subbloques de las matrices A y B. Por lo tanto, es esta tesis se diseñan estrategias de resolución basadas en el método de Arnoldi-Lanczos que sacan provecho de esta estructura matricial y obtienen grupos de autovalores-autovectores en grupos reducidos.

\subsubsection{La transformada Wavelet}

La transformada Wavelet es una herramienta matemática que ha supuesto una auténtica revolución en campos de procesado de señal e imagen, ya que ofrece un marco muy flexible de análisis espaciofrecuencia. La principal ventaja que aporta la transformada Wavelet es que trabaja en un esquema de multirresolución y puede adaptarse muy bien a las características locales de la señal a representar, que se considerará de dominio finito. Este hecho destaca frente a la limitaciones tradicionales de otros escenarios de representación tales como la transformada de Fourier [10].

Las bases Wavelets serán versiones trasladadas y expandidas de la función Wavelet madre $\psi(x)$ que se completarán con una función de escalado $\varphi(x)$.

$$
\psi_{k}^{j}(x)=2^{-j / 2} \psi\left(2^{-j} x-k+1\right)
$$

donde $j$ es un número entero positivo que representa un nivel de escala y $k$ representa el índice de traslación. La siguiente expresión se debe cumplir para la normalización de la función de escalado.

$$
\int_{-\infty}^{\infty} \varphi(x) d x=1
$$

La transformada Wavelet establece un marco muy flexible a la hora de escoger las funciones involucradas (función Wavelet $\psi(x)$ y su correspondiente función de escalado $\varphi(x)$ ). Normalmente las funciones 
Wavelet y de escalado se escogen con dominio finito y se deben cumplir los siguientes requisitos

$$
\begin{gathered}
\psi(x)=\sqrt{2} \sum_{k=0}^{L-1} g_{k+1} \varphi(2 x-k) \\
\varphi(x)=\sqrt{2} \sum_{k=0}^{L-1} h_{k+1} \varphi(2 x-k) \\
g_{k}=(-1)^{k-1} h_{L-k+1}
\end{gathered}
$$

donde $L$ es la longitud de los filtros Finite Impulse Response (FIR) asociados, cuyos coeficientes son $h_{k}$ para el filtro paso bajo y $g_{k}$ para el filtro paso alto, siendo $k$ el índice paramétrico correspondiente. Los filtros Wavelet sirven para la implementación de la transformada rápida Wavelet en cascada.

La transformada Wavelet se puede aplicar a los problemas basados en el método de los momentos siguiendo dos estrategias. En la primera de ellas se consideran funciones base de dominio continuo Wavelet para implementar las funciones base y de test del Método de los Momentos. En una segunda aproximación, se discretiza la ecuación integral mediante la técnica MoM con unas funciones base y de test estándar, dando lugar a un problema matricial. Cuando el problema algebraico está formulado de forma matricial, entonces se realiza un cambio de bases a las nuevas bases Wavelet en este caso de dominio discreto. Ésta es la aproximación al problema que se ha seguido en esta tesis.

La transformación de la matriz que contiene al operador a las nuevas bases Wavelet discretas se puede conseguir mediante distintas técnicas. La primera de ellas y la más simple consiste en multiplicar por matrices de cambio de base. Esta opción se descarta porque la multiplicación de matrices es una operación costosa en tiempo de cálculo. Otra opción consiste en emplear la transformada rápida Wavelet por filas y por columnas. La transformada rápida Wavelet requiere los filtros Wavelet $h_{k}$ y $g_{k}$ y módulos diezmadores por 2. En la implementación estándar de la transformada Wavelet se aplica de forma recursiva el filtrado-diezmado a la salida de la etapa anterior paso-bajo. Existen otras versiones de la transformada Wavelet que desarrollan todas las ramas (paso alto y paso bajo) de la señal para escoger finalmente aquellas 
que mejor representan a la señal. Este tipo de transformada se conoce como Wavelet Packets.

Una de las propiedades más importantes de la función Wavelet escogida consiste en el número de momentos nulos que presenta. Se dice que una familia Wavelet presenta $M$ momentos nulos si las siguientes expresiones correspondientes a la función Wavelet $\psi$ y su filtro paso alto asociado $g_{k}$ se cumplen

$$
\begin{gathered}
\int \psi(x) x^{m} d x=0, \quad m=0, \ldots, M-1 \\
\sum_{k=0}^{L-1} g_{k} k^{m}=0, \quad m=0, \ldots, M-1
\end{gathered}
$$

Este esquema de desarrollo ofrece múltiples grados de libertad, ya que la función Wavelet original puede presentar diferentes características. Podrán ser de soporte finito o infinito. Las funciones podrán presentar simetría o no en su diseño, podrán ofrecer diferentes propiedades de ortogonalidad, número de momentos nulos, localización en frecuencia y regularidad.

Algunas propiedades de las anteriores son incompatibles entre sí, por lo que la búsqueda de la familia de funciones Wavelet consistirá en buscar las características más adecuadas para cada aplicación.

Finalmente, existen otros escenarios de transformación de la señal que se inspiran en la transformada Wavelet, pero que parten de un escenario diferente de representación (ver [3]). Estas son las llamadas bases Wavelet-like, que comparten muchas de las propiedades de la bases Wavelet estándar pero no son versiones trasladadas y expandidas de una función original. En contraposición se obtienen de un número de procesos de ortogonalización Gram-Schmidt sobre un polinomio original definido en la malla de discretización. La transformada Wavelet-like se puede implementar de forma rápida y se ha comprobado que en los problemas electromagnéticos planteados proporciona mejores resultados que las familias clásicas de funciones Wavelet tales como las familias de bases Daubechies o Coiflets. 


\subsubsection{Técnicas de procesado en paralelo}

En la actualidad los problemas de modelado electromagnético de estructuras complejas cada vez requieren de un mayor esfuerzo de cálculo numérico mediante computador. Cuando los problemas requieren cálculo matricial de dimensiones elevadas, la solución al problema cada vez se hace más costosa en tiempo y manejo de memoria, incluso llegando a ser intratable en un ordenador convencional funcionando en modo secuencial. El uso de varios procesadores de forma optimizada para resolver el problema es muchas veces una buena solución. Además se pueden emplear supercomputadores profesionales o bien agrupaciones o clusters de ordenadores convencionales, como solución más económica y fácilmente alcanzable (ver [2]).

Sin embargo el uso del paralelismo necesita un adecuado diseño de los algoritmos para adaptarlos al cálculo en paralelo. Además requiere la elección de distintas opciones de paralelismo tales como el uso de memoria distribuida o compartida. En este trabajo se han estudiado distintas opciones de paralelismo adaptadas a la solución de un problema de autovalores, mediante el estudio de varios parámetros asociados a la evaluación de procesado en paralelo tales como el speed-up o escalabilidad.

\section{Parámetros de evaluación del procesado en paralelo}

El primer parámetro que se ha empleado en la evaluación del procesado en paralelo ha sido el tiempo de ejecución $t(n, p)$ de los algoritmos, donde $n$ representa el tamaño del problema y $p$ el número de procesadores. Hay que tener en cuenta que la ganancia en tiempo se hará mayor con el número de procesadores empleados en la operación. Normalmente el proceso secuencial se conseguirá en un tiempo $t(n)$ menor que el proceso paralelo empleando un procesador ya que en este caso al tiempo de procesado secuencial hay que añadir la preparación de los algoritmos al paralelismo posterior.

El speedup o ganancia de velocidad mide la relación entre el tiempo secuencial y el tiempo requerido por el algoritmo paralelizado con $\mathrm{p}$ procesadores. La expresión del speedup $S(n, p)$ es la siguiente:

$$
S(n, p)=\frac{t(n)}{t(n, p)}
$$


donde $p$ es el número de procesadores y $n$ es la dimensión del problema. En el mejor de los casos $S(n, p)$ será igual a $p$, correspondiendo al caso en que la paralelización se realiza de forma perfecta.

La eficiencia $E(n, p)$ mide el grado de utilización del sistema multiprocesador formado por $p$ procesadores. Se puede evaluar como:

$$
E(n, p)=\frac{S(n, p)}{p}=\frac{t(n)}{p \cdot t(n, p)}
$$

y tendrá un valor comprendido entre 0 y 1 . Cuanto más cerca estemos del valor unidad, mejor eficiencia se habrá conseguido del procesamiento en paralelo.

En un problema que se ha programado de forma paralelizada, interesa que las prestaciones del sistema se mantengan a medida que el problema crezca en dimensión (cuando aumente $n$ ). Por lo tanto aparece un nuevo concepto llamado escalabilidad. Se dice que un algoritmo presenta una buena escalabilidad cuando al aumentar el tamaño del sistema $(p)$ se siguen manteniendo las prestaciones sin que el tamaño del problema tenga que crecer en exceso. La escalabilidad se puede medir con distintos parámetros, pero en esta tesis se ha utilizado el speedup escalado con respecto al coste del problema por su facilidad de obtención cuando las medidas experimentales de tiempos están disponibles. El speedup escalado respecto al coste del problema $S_{c}(n, p)$ se define como el speedup obtenido cuando el tamaño del problema $W$ crece en igual medida que el número de procesadores $p$, es decir ambos crecen linealmente con respecto a un valor inicial mediante un factor $k$.

$$
\begin{aligned}
S_{c}\left(n_{k}, p_{k}\right) & =\frac{t\left(n_{k}\right)}{t\left(n_{k}, p_{k}\right)} \\
p_{k} & =k p_{0} \\
n_{k} & =W^{-1}\left(k \cdot W\left(n_{0}\right)\right)
\end{aligned}
$$

donde $n_{0}$ y $p_{0}$ son los valores iniciales del tamaño del problema y de procesadores y $W(n)$ es el coste computacional del problema. En el caso por ejemplo de una multiplicación de dos matrices $W(n)=O\left(n^{3}\right)$. En teoría el speedup presenta un valor óptimo igual a $p_{k}$, por lo que en la representación del speedup escalado respecto al coste del problema frente al número de procesadores la curva óptima obtenida será la recta unidad. 


\section{Entorno de memoria distribuida MPI}

Existen diversos modelos de programación en máquinas paralelas. El basado en el paso de mensajes se caracteriza por su simplicidad y su facilidad para la adaptación a distintos tipos de hardware, ya que puede utilizarse tanto en supercomputadores como en clusters de estaciones de trabajo. El Message Passing Interface (MPI) fue el resultado de la estandarización de distintas primitivas de paso de mensajes por parte de un gran número de personas e instituciones. Recoge las ventajas y aciertos de las implementaciones previas de paso de mensajes, aportando mayor portabilidad y rendimiento. El estándar MPI define una librería que se puede utilizar para realizar programas portables de paso de mensajes en Fortran, $\mathrm{C}$ o C++. Recoge más de 120 funciones, aunque en la práctica para la mayoría de los programas sólo son necesarias unas cuantas de ellas.

En este tipo de filosofía, la memoria es local a cada procesador y lo que se arbitra es la comunicación entre los procesadores. Existen operaciones básicas de recepción y emisión, que pueden ser síncronas o asíncronas y bloqueantes o no bloqueantes. También existen operaciones de comunicación colectiva tales como sincronizaciones, difusiones o reducciones.

\section{Entorno de memoria compartida OpenMP}

La idea del paralelismo en memoria compartida es una estrategia completamente opuesta al de memoria distribuida que se acaba de describir. En esta filosofía es importante definir el concepto de hilo o thread de ejecución, que consiste en un flujo o secuencia independiente de instrucciones de un programa que puede ser programado por parte del sistema operativo. Desde el punto de vista del programador, los threads son procesos ligeros que se pueden ejecutar de forma independiente y planificada por parte de un programa principal. La ejecución simultánea de varios threads da lugar a un escenario de programación multithread (ver [2]).

El entorno de programación OpenMP es una Application Program Interface (API) que puede ser utilizada para diseñar programas paralelos multithread en memoria compartida. Esta API se compone de directivas de compilación, rutinas de librería y variables de entorno. OpenMP presenta una solución estandarizada y portable para programación en C, 
$\mathrm{C}++$ y Fortran, que puede ser extendida a múltiples plataformas. También es sencilla de usar porque permite construir programas paralelos a partir de un conjunto reducido de directivas (3 o 4). OpenMP proporciona la posibilidad de aproximación incremental al desarrollo de los programas frente a MPI que presenta una aproximación de todo o nada. Además permite el paralelismo de grano fino y grano grueso de forma simultánea.

\section{Entorno de memoria mixta}

También se pueden implementar entornos de programación que introducen paralelismo en varios niveles con distintos tipos de memoria. Así se puede pensar en una estrategia MPI+OpenMP en la que en un primer nivel se creen $p$ procesos MPI en $p$ procesadores de memoria distribuida. Estos procesos pueden a su vez ser fragmentados en $p^{\prime}$ threads OpenMP de memoria compartida. Esto supondría trabajar en un entorno de memoria mixta empleando $p^{*} p^{\prime}$ procesadores.

En esta tesis se han comprobado distintos tipos de procesado en paralelo, incluyendo entornos de memoria distribuida MPI, de memoria compartida OpenMP y mixtos y se han evaluado varios parámetros de paralelismo para obtener la mejor eficiencia y capacidad de escalado en problemas BI-RME bidimensionales.

\subsection{Organización de la memoria}

Esta memoria de tesis está organizada en base a varios artículos indexados y consta de tres partes:

La Parte I contiene la presente introducción con el Estado del Arte y los objetivos de la tesis. Posteriormente se describe el entorno de trabajo multidisciplinar y los trabajos de investigación en los que se ha desarrollado la tesis. Después se formulan los problemas abordados en la tesis y las herramientas empleadas para su solución.

La Parte II de la tesis contiene la relación de artículos en prensa científica indexados con una lista inicial que encuadra cada artículo en los objetivos correspondientes de la tesis y añade el factor de impacto de la revista en el JCR. Otras aportaciones de la tesis en forma de comunicaciones a congresos se añaden en el capítulo final de conclusiones. 
La Parte III de la tesis contiene un trabajo adicional contemplado en la tesis ya publicado en actas de congresos y en fase de preparación para prensa científica y por lo tanto no se podía incluir en la Parte II. Además se añade un capítulo de discusión general de resultados que resume las aportaciones de la tesis y describe su integración en software desarrollado en colaboración con empresas relacionadas en el sector. Finalmente se incluye un capítulo que contiene las conclusiones obtenidas del trabajo desarrollado, las aportaciones adicionales además de los artículos en prensa indexados y también otras aportaciones de la autora no relacionadas con el tema de la tesis.

\section{Bibliografía}

[1] http://www.netlib.org/lapack.

[2] F. Almeida, D. Giménez, José M. Mantas y A. M. Vidal. Introducción a la Programación Paralela. Ediciones Paraninfo, Madrid, 2008.

[3] B. Alpert, G. Beylkin, R. Coifman y V. Rokhlin. Wavelet-like bases for the fast solution of second-kind integral equations. SIAM J. Sci. Comp., 44(1):159-184, Enero 1993.

[4] E. Arvas y S. Ponnapalli. Scattering cross section of a small radome of arbitrary shape. IEEE Transactions on Antennas and Propagation, 37(5):655-658, Mayo 1989.

[5] Z. Baharav y Y. Leviatan. Impedance matrix compression using adaptively constructed basis functions. IEEE Transactions on Antennas and Propagation, 44(9):1231-1238, Septiembre 1996.

[6] Z. Baharav y Y. Leviatan. Impedance matrix compression with the use of wavelet expansions. Microwave and Optical Tecnology Letters, 12(5):268-272, Agosto 1996.

[7] Z. Baharav y Y. Leviatan. Impedance matrix compression (IMC) using iteratively selected wavelet basis. IEEE Transactions on Antennas and Propagation, 46(2):226-233, Febrero 1998.

[8] J-H. Chang y K-K. Chan. Analysis of a two-dimensional radome of arbitrarily curved surface. IEEE Transactions on Antennas and Propagation, 38(10):1565-1568, Octubre 1990. 
[9] G. Conciauro, M. Bressan y C. Zuffada. Waveguide modes via an integral equation leading to a linear matrix eigenvalue problem. IEEE Transactions on Microwave Theory and Techniques, 32(11):14951504, Noviembre 1984.

[10] I. Daubechies. Ten Lectures on Wavelets. SIAM, Pennsylvania, 1992.

[11] H. Deng y H. Ling. Fast solution of electromagnetic integral equations using adaptive wavelet packet transform. IEEE Transactions on Antennas and Propagation, 47(4):674-682, Abril 1999.

[12] D.-W. Duan, Y. Rahmat-Samii y J. P. Mahon. Scattering from a circular disk: a comparative study of PTD and GTD techniques. Proceedings of the IEEE, 79(10):1472-1480, Octubre 1991.

[13] G. V. Eleftheriades, J. R. Mosig y M. Guglielmi. A fast integral equation technique for shielded planar circuits defined on nonuniform meshes. IEEE Transactions on Microwave Theory and Techniques, 44(12):2293-2296, Diciembre 1996.

[14] X. J. Gao y L. B. Felsen. Complex ray analysis of beam transmission through two-dimensional radomes. IEEE Transactions on Antennas and Propagation, 33(9):963-975, Septiembre 1985.

[15] W. Golik. Sparsity and conditioning of impedance matrices obtained with semi-orthogonal and bi-orthogonal wavelet bases. IEEE Transactions on Antennas and Propagation, 48(4):473-481, Abril 2000.

[16] N. Guan, K. Yashiro y S. Ohkawa. On a choice of wavelet bases in the wavelet transform approach. IEEE Transactions on Antennas and Propagation, 48(8):1186-1191, Agosto 2000.

[17] R. F. Harrington. Field Computation by Moment Methods. The Mac Millan Company, New York, 1968.

[18] A. A. Kishk y Lotfollah Shafai. Different formulations for numerical solution of single or multibodies of revolution with mixed boundary conditions. IEEE Transactions on Antennas and Propagation, 34(5):666-673, Mayo 1986. 
[19] J.-Y. Li y L.-W. Li. Characterizing scattering by 3-D arbitrarily shaped homogeneous dielectric objects using fast multipole method. IEEE Antennas and Wireless Propagation Letters, 3:1-4, 2004.

[20] C-C. Lu. A fast algorithm based on volume integral equation for analysis of arbitrarily shaped dielectric radomes. IEEE Transactions on Antennas and Propagation, 51(3):606-612, Marzo 2003.

[21] R. D. Nevels, J. C. Goswami y H. Tehrani. Semi-orthogonal versus orthogonal wavelet basis sets for solving integral equations. IEEE Transactions on Antennas and Propagation, 45(9):1332-1339, Septiembre 1997.

[22] Alexander I. Nosich. The method of analytical regularization in wave- scattering and eigenvalue problems: Foundations and review of solutions. IEEE Antennas and Propagation Magazine, 41(3):982-986, Junio 1999.

[23] T. Oguzer. Analysis of circular reflector antenna covered by concentric dielectric radome. IEEE Transactions on Antennas and Propagation, 49(3):458-463, Marzo 2001.

[24] T. Oguzer, A. Nosich y A. Altintas. Analysis of an arbritrary conic section profile cylindrical reflector antenna, H-polarization case. IEEE Transactions on Antennas and Propagation, 52(11):3156-3162, Noviembre 2004.

[25] A. F. Peterson, S. L. Ray y R. Mittra. Computational Methods for Electromagnetics. IEEE Press, New York, 1998.

[26] A. J. Poggio y E. K. Miller. Computer techniques for electromagnetics, chapter Integral equation solutions of three-dimensional scattering problems. Oxford, Pergamon, 1973.

[27] J. H. Richmond. Scattering by a dielectric cylinder of arbitrary cross section shape. IEEE Trans. Antennas Propagation, 13:334-341, Mayo 1965.

[28] K. Sabetfakhri y L. P. B. Katehi. Analysis of integrated millimeterwave and submillimeter-wave waveguides using orthonormal wavelet expansions. IEEE Transactions on Microwave Theory and Techniques, 42(12):2412-2422, Diciembre 1994. 
[29] A. Sadigh y E. Arvas. Deformation of the horizontal radiation pattern of TV transmitting antennas due to thin dielectric radome. IEEE Transactions on Antennas and Propagation, 40(8):942-949, Agosto 1992.

[30] T. K. Sarkar, M. Salazar-Palma y M. C. Wicks. Wavelet Applications in Engineering Electromagnetics. Artech House, Norwood MA, 2002.

[31] B. Z. Steinberg y Y. Leviatan. Periodic wavelet expansions for analysis of scattering from metallic cylinders. Microwave and Optical Technology Letters, 7(6):266-268, Abril 1994.

[32] O. I. Sukharevsky, S. V. Kukobko y A. Z. Sazonov. Volume integral equation analysis of a two-dimensional radome with a sharp nose. IEEE Transactions on Antennas and Propagation, 53(4):1500-1506, Abril 2005.

[33] A. Y. Svezhentsev, A. I. Nosich y T. Oguzer. Simulation of reflector antenna covered by a circular radome. En ICAP'95 Ninth International Conference on Antennas and Propagation, páginas 532-535, Abril 1995.

[34] R. L. Wagner y W. C. Chew. A study of wavelets for the solution of electromagnetic integral equations. IEEE Trans. Antennas Propagation, 43(8):802-810, Agosto 1995.

[35] R. L. Wagner, G. P. Otto y W. C. Chew. Fast waveguide mode computation using wavelet-like basis functions. IEEE Microwave and Guided Wave Letters, 3(7):208-210, Julio 1993.

[36] G. Wang y G. Pan. Full-wave analysis of microstrip floating line structures by wavelet expansion method. IEEE Transactions on Microwave Theory and Techniques, 43(1):131-142, Enero 1995.

[37] V. Yurchenko, A. Altintas y A. Nosich. Numerical optimization of a cylindrical reflector-in-radome antenna system. IEEE Transactions on Antennas and Propagation, 47(4):668-673, Abril 1999.

[38] Y. Zhang y T. K. Sarkar. Parallel Solution of Integral Equation-based EM problems in the frequency doamin. John Wiley \& Sons, Hoboken, New Jersey, 2009. 
[39] W-J. Zhao, L-W. Li y Y-B Gan. Efficient analysis of antenna radiation in the presence of airborne dielectric radomes of arbitrary shape. IEEE Transactions on Antennas and Propagation, 53(1):442449, Enero 2005. 



\section{Parte II}

\section{Recopilación de artículos}





\section{Lista de artículos}

- Efficient and accurate spectral analysis of large scattering problems using wavelet and wavelet-like bases (RADIO SCIENCE, 2004, ISSN: 0048-6604, Factor de impacto de la revista en Journal Citation Reports, JCR 2004: 1.007, doi: 10.1029/2003RS002991). Esta contribución está relacionada con los objetivos 1 y 2 de la tesis, ya que se emplea una técnica de discretización basada en la técnica MoM para la solución de un problema electromagnético en espacio abierto y se aplican técnicas eficientes empleando la transformada Wavelet en los problemas de sistemas de ecuaciones.

- Wavelet-like efficient analysis of two-dimensional arbitrarily shaped radomes using a surface formulation (RADIO SCIENCE, 2007, ISSN: 0048-6604, Factor de impacto de la revista en JCR 2007: 0.972, doi: 10.1029/2006RS003522). En este caso, el trabajo desarrolla los objetivos 1, 2 y 4 de la tesis. Se emplea discretización basada en la técnica MoM, se aplican técnicas eficientes empleando la transformada Wavelet y se aprovecha la especial estructura matricial para un problema de solución de sistemas de ecuaciones que aparece en un problema electromagnético en el espacio abierto.

- CAD of complex passive devices composed of arbitrarily shaped waveguides using Nyström and BI-RME methods (IEEE Transactions on Microwave Theory and Techniques, 2005, ISSN: 0018-9480, doi: 10.1109/TMTT.2005.848795, Factor de impacto de la revista en JCR 2005: 2.275). Aquí, la contribución desarrolla los objetivos 1 y 4 de la tesis. Se utiliza una técnica de discretización basada en el método de Nyström y se aprovecha la especial estructura matricial para resolver un problema de autovalores y autovectores 
que aparece al resolver los campos modales de una guía cerrada perturbada en su contorno.

- Efficient and accurate waveguide mode computation using BIRME and Lanczos methods (International Journal for Numerical Methods in Engineering, 2006, ISSN: 1097-02071.007, Factor de impacto de la revista en JCR 2006: 1.497, doi: 10.1002/nme.1520). En este caso, el trabajo desarrolla los objetivos 1, 3 y 4 de la tesis. Se emplea discretización basada en la técnica MoM y se aprovecha la especial estructura matricial para un problema de solución de autovalores y autovectores, que se mejora a su vez con técnicas iterativas, tales como la técnica de Lanczos.

- Parallel computation of arbitrarily shaped waveguide modes using BI-RME and Lanczos methods (Communications in Numerical Methods in Engineering, 2006, Online ISSN: 2040-7947, Factor de impacto de la revista en JCR 2006: 0.518, doi: 10.1002/cnm.901). Aquí, la contribución desarrolla en parte los objetivos 1,3, 4 y 5. Se emplea una técnica de discretización MoM y se aprovecha la estructura matricial para resolver un problema de autovalores y autovectores, se emplea la técnica de Lanczos y se resuelve el problema de forma paralelizada.

- Robust parallel implementation of a Lanczos-based algorithm for an structured electromagnetic eigenvalue problem (Scalable Computing: Practice and Experience, 2007, ISSN 1895-1767, esta revista no está listada en JCR). Finalmente, este trabajo desarrolla en parte los objetivos 1, 3, 4 y 5. Se emplea una técnica de discretización MoM y se aprovecha la estructura matricial para un problema de solución de autovalores y autovectores, se emplea la técnica de Lanczos y se resuelve el problema de forma paralelizada. 
2

\title{
Efficient and Accurate Spectral Analysis of Large Scattering Problems using Wavelet and Wavelet-like Bases
}

\section{Authors}

A. Vidal, A. Belenguer, H. Esteban, V. E. Boria, C. Bachiller and M. Taroncher.

\begin{abstract}
This paper presents a novel technique for the very efficient and accurate 2-D spectral analysis of large cylindrical scatterers with arbitrary geometries using the wavelet and wavelet-like transform. When such complex problems are solved through an integral equation (IE) technique combined with the method of moments (MoM), a linear equation system with a huge number of unknowns needs to be solved for each incident field. In this work, wavelet bases are successfully proved to expand the integral operator in a very sparse matrix form, thus providing large savings on computational costs and memory storage re-
\end{abstract}


quirements. Furthermore, the use of the spectral formulation allows to characterize the scattering behavior of an object for any possible incidence, thus drastically reducing the number of linear equation systems to be solved. Comparative benchmarks between the new wavelet technique and the original approach for solving the scattering of circular cylinders and strips are presented for different orthogonal families: locally supported Daubechies bases, orthogonal quasi-symmetric Coiflets bases and wavelet-like bases. Then, the efficient wavelet technique is applied to the accurate characterization of more complex geometries, such as large square cylinders.

\subsection{Introduction}

IEs have been traditionally employed for the accurate solution of a wide variety of electromagnetic problems, such as the analysis of scatterers solved in [23], the analysis and design of boxed multilayered circuits described by [12], and the efficient modal computation of arbitrarily shaped waveguides shown in the work of [8]. These integral equation problems are usually solved following the well-known MoM described by [18]. When such approach is applied to either electrically large structures, highly accurate applications, or objects with many small geometry details, matrix problems with a very large number of unknowns arise.

To avoid the aforementioned drawback related to the IE-MoM approach, and take profit of the accuracy and efficiency advantages of such technique, the use of the wavelet transform has been recently proposed (see [26]). It was initially applied to microstrip circuits by [32] and [24], to the efficient waveguide mode computation by [31], and to the analysis of double-slot apertures in planar conducting screens by [27]. In the recent years, the application of the wavelet transform to the efficient analysis of 2-D electromagnetic scattering problems has become rather popular, as can be seen in [28, 30, 2, 3, 20, 11, 4, 15] and [16]. For instance, [28] proposed a periodic wavelet expansion to overcome the classical problem of expanding a given function of finite support. An extensive comparison of wavelets with other fast algorithms for solving the cited 2-D problem can be found in the work of [30], where it is concluded that the use of wavelets in small problems is not very 
advantageous. [3, 11, 2, 4] proposed novel approaches for the incorporation of wavelet expansions into integral equations, which are mainly based on the impedance matrix compression using either adaptively constructed, or iteratively selected, wavelet basis functions. These wavelet transforms are computationally very expensive and they have not been selected for further study in this paper. Different wavelet bases for solving IEs were first studied in [20], where semi-orthogonal compact support bases outperformed infinite support orthogonal ones. On the other hand, [15] and [16] studied the most suitable wavelet bases for scattering problems, and they conclude that, in such case, the orthogonality of wavelets is a crucial issue to be fulfilled. Another research direction is to use smooth local cosine bases instead of wavelet bases. This is proposed in [29] and applied to scattering analysis in [21]. However, if no a priori information about the scatterer is known, many processing parameters should be adjusted in search for the best matrix compression and that increases consequently the computing cost.

It is also convenient to remark that most of the works on scattering problems cited in the previous paragraph have been mainly focused on small 2-D scatterers, whose cylindrical conducting contours have been coarsely segmented. Such approach leads to small matrix problems, where the advantages of the wavelet approach are clearly lessened. Furthermore, the MoM solution followed in such references has been always formulated in the spatial domain, thus leading to incidence dependent solutions, which are not very suitable for the later consideration of multiple scattering problems. In those methods, the solution of the scattering problem for different incidences involves the solution of a linear equation system for each incident field. In this paper, a formulation that computes the solution of the scattered field for any incidence solving only a limited set of linear equation systems is followed (see [13]).

Despite of all the previously commented efforts, much research on the wavelet transform, and its practical application to the accurate solution of electromagnetic scattering problems, is still needed. Specially, wavelet-like bases have not been sufficiently studied in the frame of 2-D scattering problems compared to other popular wavelet bases such as Daubechies. Therefore, taking into account the present state-of-the-art reached in this research area, it seems appropriate to face the combination of wavelet and wavelet-like bases and the new spectral domain 
technique for the efficient and accurate solution of large MoM matrix problems with oscillatory kernels. If the application of wavelet theory in this new scenario gave good enough results, a further step for the very efficient and accurate solution of large scattering problems by personal computers without special memory arrangements would be given. The improvement of the efficiency related to the use of the wavelet transform for solving large 2-D scatterers would encourage its use in more complex 3-D scattering scenarios.

This paper is organized as follows. First, the 2-D electromagnetic scattering problem under consideration is formulated and solved in the spectral domain. Next, the wavelet transform is successfully introduced for the compression of the corresponding impedance matrix. After testing several wavelet and wavelet-like families, the best ones have been selected to perform a comparative study included in this work. Such study has been realized through simple 2-D large scattering problems, such as circular and square cylinders, as well as strips. Very accurate numerical results for the scattering behavior of such objects are presented, and the efficiency gain provided by the use of wavelets is discussed. Finally, the main conclusions derived from the detailed study performed in this paper are briefly outlined.

\subsection{Theory}

The electromagnetic problem to be solved is to fully characterize the scattering response of perfectly electric conducting cylinders (invariant in $z$ axis) with arbitrary cross section when any transverse magnetic (TM) wave polarized along z-axis $\left(\mathrm{TM}^{z}\right)$ excites it in open space.

In this section, we first present the basics of the spectral and MoM techniques which will be used to solve our problem. Next, we briefly describe how the wavelet transform can be used to improve the efficiency of such technique. Then, the wavelet and wavelet-like bases employed in this study, as well as their practical implementation, are introduced. Finally, the procedure for evaluating the efficiency improvement related to the use of the wavelet transform is described. 


\subsubsection{Basics of the Spectral MoM Technique}

To solve the scattering problem, the following modal decomposition of incident $\mathbf{E}^{i}$ and scattered electric fields $\mathbf{E}^{s}$ using cylindric modes, described in [13], is applied:

$$
\begin{gathered}
\mathbf{E}^{i}(\boldsymbol{\rho})=\sum_{p=-N_{i}}^{N_{i}} i_{p} J_{p}(k|\boldsymbol{\rho}|) e^{j p \phi} \mathbf{z} \\
\mathbf{E}^{s}(\boldsymbol{\rho})=\sum_{q=-N_{d}}^{N_{d}} c_{q} H_{q}^{(2)}(k|\boldsymbol{\rho}|) e^{j q \phi} \mathbf{z}
\end{gathered}
$$

where $(\rho, \phi, z)$ are the coordinates of an observation point $\rho$ in the selected cylindrical system, $k$ is the free-space wavenumber, $J_{p}$ and $H_{q}^{(2)}$ are, respectively, the $p$-th order Bessel function and the $q$-th order Hankel function of the second kind, and $i_{p}$ and $c_{q}$ are the corresponding incident and scattered spectral coefficients. With regard to the number of modal coefficients, $N_{i}$ and $N_{d}$, required to reconstruct accurately the incident and scattered fields, they can be determined following the practical criteria proposed by $[13,14]$.

The main aim of the spectral technique is to fully characterize the scattering behaviour of any electrical conducting object by means of a generalized scattering matrix, $\mathbf{D}$, which will provide the scattered field by the object under any arbitrary incidence as follows

$$
c_{q}=\sum_{p=-N_{i}}^{N_{i}} d_{q p} i_{p}, q=-N_{d}, \ldots, N_{d}
$$

The generalized scattering matrix elements $\left(d_{q p}\right)$ can be analytically known for some canonical geometries (i.e. a circular cylinder), as can be seen in [5]. However, for arbitrary geometry objects, a numerical strategy based on MoM will be followed. Next, we offer a brief description of such strategy in order to better understand the new contents of this paper. More technical details can be found in the work of $[13,14]$.

The unknown longitudinal current induced on the arbitrary scatterer conducting surface due to the $p$-th incident mode $J_{z_{p}}$ must be first computed. To do so, the following electric field integral equation (EFIE) 
outlined by [18] is first established:

$$
\left.E_{z_{p}}^{i}(\boldsymbol{\rho})\right|_{C}=\frac{k \eta}{4} \int_{C} J_{z_{p}}\left(\boldsymbol{\rho}\left(l^{\prime}\right)\right) H_{0}^{(2)}\left(k\left|\boldsymbol{\rho}-\boldsymbol{\rho}\left(l^{\prime}\right)\right|\right) d l^{\prime}
$$

where $E_{z_{p}}^{i}$ is the longitudinal component of the $p$-th incident field mode, $C$ is the contour of the scatterer cross section defined by the $l^{\prime}$ parameter, and $\rho\left(l^{\prime}\right)$ is a vector pointing to such contour. In order to solve this EFIE, a classical MoM technique in the point-matching variant described by [18] and [22] has been used, thus obtaining the following algebraic linear equation system:

$$
\begin{gathered}
V_{m p}=\sum_{n=1}^{N} Z_{m n} \cdot I_{n p} m=1, \ldots, N \\
Z_{m n}=\frac{k \eta}{4} \int_{\Delta C_{n}} H_{0}^{(2)}\left(k\left|\boldsymbol{\rho}_{m}-\boldsymbol{\rho}\left(l^{\prime}\right)\right|\right) d l^{\prime} \\
V_{m p}=E_{z_{p}}^{i}\left(\boldsymbol{\rho}_{m}\right)=J_{p}\left(k\left|\boldsymbol{\rho}_{m}\right|\right) e^{j p \phi_{m}}
\end{gathered}
$$

where $\Delta C_{n}$ is the $n$-th interval in which the whole contour $C$ of the scatterer has been segmented. To implement the MoM technique, pulse basis functions centered at $\rho_{n}(n \in[1, \ldots, N])$ points have been used, and $\boldsymbol{\rho}_{m}(m \in[1, \ldots, N])$ indicates the center of each segment where the Dirac Delta functions are placed. It must be noticed that the diagonal elements of the $\mathbf{Z}$ matrix ( $Z_{m m}$ terms) do involve a singular integral, but approximated expressions for such diagonal elements, as well as for the non-singular elements $\left(Z_{m n}\right.$ with $\left.m \neq n\right)$, can be found in the work of [18].

If the previous MoM approach is repeated for all possible incident spectral modes $\left(p \in\left[-N_{i}, \ldots, N_{i}\right]\right)$, a global matrix system is finally obtained

$$
\begin{gathered}
\mathbf{Z} \cdot \mathbf{I}=\mathbf{V} \\
{\left[Z_{m n}\right]_{N \times N} \cdot\left[I_{n p}\right]_{N \times\left(2 N_{i}+1\right)}=\left[V_{m p}\right]_{N \times\left(2 N_{i}+1\right)}}
\end{gathered}
$$

In conventional 2-D scattering problems, the solution of one of such linear equation systems is needed for each possible incident field, and therefore the computation cost grows with the number of incident fields to be considered. In our approach, equation (2.8) represents a set of 
$2 N_{i}+1$ linear equation systems, which do share the same impedance matrix $\mathbf{Z}$ and fully characterize any possible TM incident field. Consequently, it should be pointed out that the new spectral formulation drastically decreases the computation time compared to the classical formulation. Anyway, the effort related to the solution of (2.8) clearly dominates the global computational effort. Once matrix $\mathbf{I}$ is calculated, the generalized scattering matrix can be easily found as follows

$$
\mathbf{D}=\mathbf{S} \cdot \mathbf{I}
$$

where $\mathbf{S}$ is a transformation matrix based on the Bessel addition theorem (see $[18,17])$.

In order to evaluate the accuracy of this method, the square boundary condition error $\Delta E_{b c}(\%)$ defined by [4] has been employed. Such error takes into account the degree of accomplishment of the boundary condition along $N_{0}$ points of the scatterer contour in the following way

$$
\Delta E_{b c}=100 \cdot \sum_{N_{0}} \frac{\left|E_{z}^{i}+E_{z}^{s}\right|^{2}}{\left(\sum_{N_{0}}\left|E_{z}^{i}\right|\right)^{2}} \quad(\%)
$$

where $E_{z}^{s}$ is the scattered field by the object under an arbitrary incident wave defined by $E_{z}^{i}$. For all the examples considered in this paper, a very low threshold value $(0,05 \%)$ has been chosen for $\Delta E_{b c}$, which guarantees a high degree of accuracy for most real applications. The choice of such threshold value directly affects the number of discrete points $N$ related to the MoM implementation. Therefore, following this error criterium, a linear equation system with a large number of unknowns will have to be solved. Such large linear systems will also appear when solving the scattering behaviour of either electrically large objects or scatterers with very small geometric details. In the next paragraphs we propose the use of the wavelet transform to alleviate the CPU cost related to the solution of the aforementioned large linear systems.

\subsubsection{MoM Implementation using the Wavelet Transform}

The solution of the linear equation systems in (2.8) can be solved by two main techniques. The first one is a direct solver, based on Gaussian elimination or LU decomposition, that achieves a solution in $O\left(N^{3}\right)$ 
operations. The second approach is to use a recursive method, in which each iteration involves matrix-vector products taking $O\left(N^{2}\right)$ operations. That solution is usually avoided because the total number of iterations for solving a matrix equation depends on the matrix condition number. Consequently, iterative techniques are not extensively employed in the case of large dense matrices, unless some suitable preconditioning schemes are found, as described by [19]. Furthermore, both techniques do require high computational efforts and management of large memory blocks. Therefore, the discrete wavelet transform can improve the overall computation cost and memory requirements by turning the impedance matrix $\mathbf{Z}$ into a sparse one. The challenge when applying this technique comes from the fact that wavelet transform for integral operators compression is well suited for large smooth real systems of equations, as can be seen in the work of [1] and [6]. However, oscillatory kernels, like the Hankel function that appears in our problem, have not been so well characterized through wavelet bases up to now.

Then, the main goal of this work is to reduce the computation cost and the memory requirements in the solution of the matrix equation (2.8) using the wavelet transform, whereas high accuracy is kept. For that purpose, several wavelet families have been considered, and three bases have been finally selected for a deeper analysis: the well known compactly supported orthonormal Daubechies bases described by [9], Coiflet quasi-symmetric orthonormal bases described by [10] and [26] and the wavelet-like scheme shown by $[1,7]$. To the authors knowledge, the wavelet-like scheme has been only proposed in the work of [31] for solving waveguide mode computation problems. Consequently, the use of wavelet-like bases in the frame of scattering problems with oscillatory kernels is firstly considered in this paper .

In all the selected wavelet bases, the transformed integral operator presents a diagonal banded form usually known as finger structure. After applying a threshold, the operator is converted into a very sparse matrix. Then, very efficient special-purpose recursive techniques for sparse matrices can be applied, whose computational burden is in the order of the non-zero matrix entries. Nevertheless, the wavelet approach involves a matrix transformation, whose cost should be included within the global computation budget. So, the benchmark proposed in this work is to reduce the total number of operations including forward and inverse wavelet transform for a certain large number of 
unknowns when compared to the direct approach.

The conversion of the discrete integral operator into the new wavelet bases is equivalent to carry out a similarity transformation defined by a real and unitary matrix $\mathbf{W}$, whose rows contain the new orthogonal wavelet or wavelet-like bases as described by [27]. The original problem is now represented in the wavelet domain as follows

$$
\mathbf{Z} \mathbf{I}=\mathbf{V} \Rightarrow\left(\mathbf{W Z W}^{T}\right) \cdot(\mathbf{W I})=\mathbf{W} \mathbf{V} \Rightarrow \mathbf{Z}_{t} \mathbf{I}_{t}=\mathbf{V}_{t}
$$

where $\mathbf{W}$ is the transformation matrix, superscript $T$ stands for the transpose of a matrix, and $\mathbf{Z}_{t}, \mathbf{I}_{t}$ and $\mathbf{V}_{t}$ are, respectively, $\mathbf{Z}, \mathbf{I}$ and $\mathbf{V}$ expressed in the new bases. This transformation method is called tensorproduct or standard form wavelet transform. Due to the wavelet bases properties, $\mathbf{Z}_{t}$ presents many elements that are close to zero. However, they should be zero to become a sparse matrix. So, the application of a threshold is necessary, which is a key step related to the desired accuracy and efficiency gain. The threshold value $\tau$ is given in percentage units, and it is normalized to the maximum absolute value of the matrix entry. In our study, we have implemented the threshold operation through a simple comparison of the absolute value of the complex elements, and sparsity is defined as the percentage of matrix zero entries after thresholding.

\subsubsection{Wavelet and Wavelet-like Bases Description}

Functions $\psi$ and $\varphi$ are, respectively, the wavelet function and its corresponding scaling function described by [10]. They are defined in the frame of the wavelet theory and can be constructed with finite spatial support under the following conditions

$$
\begin{gathered}
\psi(x)=\sqrt{2} \sum_{k=0}^{L-1} g_{k+1} \varphi(2 x-k) \\
\varphi(x)=\sqrt{2} \sum_{k=0}^{L-1} h_{k+1} \varphi(2 x-k) \\
\int_{-\infty}^{\infty} \varphi(x) d x=1
\end{gathered}
$$


where $L$ is the length of the wavelet filters whose coefficients are $h_{k}$ and $g_{k}$, and $k$ is the corresponding spatial index. In this study, only orthonormal bases with corresponding $h_{k}$ and $g_{k}$ with the same finite support are studied. The scaling function must also satisfy (2.15) for normalization purposes. The wavelet filters are related by the following relationship that turns them into a set of quadrature mirror filters, being $h_{k}$ a low pass filter and $g_{k}$ its corresponding high pass filter

$$
g_{k}=(-1)^{k-1} h_{L-k+1}
$$

The wavelet family presents $M$ vanishing moments if the following expressions related to the wavelet function $\psi$ and its corresponding high pass filter $g_{k}$ apply

$$
\begin{gathered}
\int \psi(x) x^{m} d x=0, \quad m=0, \ldots, M-1 \\
\sum_{k=0}^{L-1} g_{k} k^{m}=0, \quad m=0, \ldots, M-1
\end{gathered}
$$

Then, the translated and dilated wavelet functions form the following set of bases

$$
\psi_{k}^{j}(x)=2^{-j / 2} \psi\left(2^{-j} x-k+1\right)
$$

where $j$ is a positive integer representing a certain scale level. Starting from a decomposition level $j$, the corresponding dilated $j$-th scaling function, the dilated $j$-th wavelet function and the rest of dilated and translated wavelet functions at finer levels also form a set of orthogonal bases, which are used in their discrete version to form the rows of matrix $\mathbf{W}$.

The wavelet family may be designed with several degrees of freedom to get different properties, such as finite spatial support, symmetry, orthogonality, a certain number of vanishing moments, frequency localization and a level of regularity. However, not all these features may be simultaneously achieved as shown by [10]. In this paper, the most important properties for our problem have been identified as orthogonality, compact spatial support and high number of vanishing moments. First, orthogonality is important to preserve the matrix conditioning properties as explained by [15] and [16]. If orthogonality is given, 
only slight variations in the operator condition number would arise due to the non linear threshold operation. Secondly, the compact support is interesting to improve the transformation efficiency, since the computational cost is proportional to the spatial support. Finally, a high number of vanishing moments is important to increase the compression property of the wavelet transform. However, local support and number of vanishing moments are in inverse dependence. For that reason, the best compression ratio in this study is provided by the wavelet-like scheme, because such bases give the highest moment order with the lowest local support.

The well-known Daubechies orthonormal family of compactly supported bases presented by [10] is selected in first place, since these bases provide excellent moment order and some degree of regularity. For that reason, they characterize very accurately rapidly varying functions under some constrains, which is the case for the characterization of smooth and oscillatory integral operators (see [10] and [6]). However, their main drawback is that they present very poor symmetry properties. Another orthogonal family considered in this study is the one called Coiflets, which is also described by [10]. Such wavelet bases are quasi-symmetric at the cost of larger spatial support, and they have been considered in order to test the symmetry effects in our study. For the sake of comparison, Daubechies quadrature filters present $M$ vanishing moments with filter length $L$ equal to $2 M$, and Coiflets quadrature filters provide $M$ vanishing moments with filter length $L$ equal to $3 M$.

Both wavelet families provide overlapping base support at the same resolution level. As a result, some bases spill out of the interval $[1, N]$ on which the contour is originally defined. Therefore, the spatial support of some bases has to be extended with its $N$-periodic version, which can affect the sparsity of the transformed matrix. Another constraint is given by the number of unknowns in the problem, which should be a power of two in order to be able to use the hierarchical fast transform.

Another interesting approach considered in this study is the waveletlike transform, which was originally introduced by [1]. This technique does not lie in the wavelet transform scheme, but it shares some of its properties. The wavelet-like bases are orthonormal, they present local support and all of them have at least $M$ vanishing moments except for $M$ bases. In this case, the dimension of the transformation matrix $N$ should be equal to $M \cdot 2^{n}$ for some integer $n$, and no periodic extension 
is needed thanks to the bases construction procedure.

\subsubsection{Efficient System Basis Transformation}

The transformation of the dense matrix into the discrete wavelet domain is a critical step in this method. If equation (2.12) is directly applied using matrix-matrix products, no gain is achieved, since the transformation process itself involves $O\left(N^{3}\right)$ operations. Obviously, this computation cost is comparable to the order of the original direct solver, and some efficient transformation method should be implemented in order to improve the overall efficiency. Fortunately, the wavelet transform can be accomplished by a different method, which needs less computation cost. Using this new fast wavelet transform, the system transformation can be done in $O\left(N^{2}\right)$ operations (see [30]), which is low compared to the original $O\left(N^{3}\right)$ operations.

Such fast wavelet transform does only apply to wavelet families with finite quadrature filters, which is the case of Daubechies and Coiflets. In these cases, the fast wavelet transform is accomplished by filtering and decimating (see [25] for details). At the coarsest level, the vectors of $N$ elements are filtered by $h_{k}$ and $g_{k}$ employing $2 L N$ multiplications for each vector, where $L$ is the filter length. At each iteration, the number of required operations is divided by two with regard to the previous stage, due to the data decimation. Therefore, the number of multiplications per each vector transformation is

$$
2 L\left(N+\frac{N}{2}+\frac{N}{4}+\cdots+1\right)=2 L(2 N-1)
$$

where $\mathrm{N}$ rows and $\mathrm{N}$ columns must be processed. Consequently, the overall number of multiplications is given by $4 L N(2 N-1)$, and the 2-D transform is made in $O\left(N^{2}\right)$ operations.

Alternatively, the wavelet-like implementation is performed following the tensor product approach described by (2.12), since matrix $\mathbf{W}$ used for the wavelet-like transform is sparse (see [1] and [7]), and matrixmatrix products may be carried out with $M N^{2}\left(1+\log _{2} \frac{N}{M}\right)$ multiplications. The 2-D transform is achieved in $2 M N^{2}\left(1+\log _{2} \frac{N}{M}\right)$ multiplications, and the whole process also presents a computation cost of order $O\left(N^{2}\right)$ operations, as in the previous case, but with a higher constant factor. 
For both transformation methods, the number of vanishing moments is a key parameter. It is clear that an increment of the vanishing moment order would characterize the matrix with greater accuracy and higher matrix sparsity, but, at the same time, it would also increase the number of operations in both implementations. Therefore, a trade-off between filter length and efficiency must be assumed in order to find the optimum wavelet or wavelet-like order.

To conclude, it must be noticed that the cost of the system bases transformation just described will domain in the whole process when $N$ increases (see [16]), since the computational burden of the sparse iterative solver can be reduced to a function of the number of non-zero elements, which is low due to the wavelet transform and threshold application.

\subsubsection{Computational Cost Evaluation}

In our efficiency study, a comparison between the original method and the new wavelet approach has been carried out. The procedure that has been measured in the original problem includes the computation of I, sized $N \times\left(2 N_{i}+1\right)$, in the matrix equation (2.8) using a direct solver based on Gaussian elimination for the number of unknowns $N$ given by the desired accuracy and the scatterer size. In the case of the wavelet approach, the procedures that have been taken into account in the computation budget are the wavelet transform of matrix $\mathbf{Z}$ in both dimensions, the wavelet transform of matrix $\mathbf{V}$ in one dimension, the solution of the system in (2.12) using a sparse solver and the wavelet inverse transform of $\mathbf{I}_{t}$ to enter the original algorithm chain at the same step. It must be noticed that the number of unknowns grows in the case of the wavelet approach, since $N$ must be a power of two equal or greater than the previous original bound. This fact has been used to enhance the accuracy degraded by the threshold operation. Obviously, this effect has been taken into account in the computational budget just described, which has been measured using the standard command provided by the commercial software Matlab $^{\circledR}$.

The construction of matrix $\mathbf{Z}$ has not been taken into account for comparison, because it is a common factor in all procedures. Besides, it has been proved that it does not affect the results even in the case when $\mathrm{N}$ is increased to a power of two. 


\subsection{Results and Discussion}

The different scattering geometries considered in this work are circular and square cylinders, as well as strips. In such problems, the square boundary condition error $\Delta E_{b c}$ has been always kept below $0,05 \%$ as explained in section 2.2.1. The choice of such error condition has required to use at least 72 points per contour wavelength in the case of the circular cylinder, and 100 points per wavelength in the case of the strip and the square cylinder. The previous figure is needed in order to meet the desired error in the original problem. However, when the wavelet transform is applied, the number of points grows to a power of two as explained before, and the threshold value $(\tau)$ is chosen equal to $0,1 \%$, since it has been proved that such combined values also keep the error $\Delta E_{b c}$ under the targeted limit.

Two kinds of comparative studies among the selected wavelet families have been performed. Since the wavelet transform is the dominant factor in the efficiency budget, a first approach consists on constructing the wavelet bases with approximately the same spatial support, i.e. the same number of non-zero entries in the $\mathbf{W}$ matrix. To accomplish such condition, the Daubechies bases with filter length $L$ equal to $6(M=3)$, the orthogonal Coiflets with filter length equal to $6(M=2)$, and wavelet-like bases with $M$ equal to 4 are selected. These particular values of filter lengths and consequent moment orders are chosen because they offer the best results for the original problem segmentation. A second kind of comparative study is performed among wavelets with the same number of vanishing moments, which has allowed to identify the wavelet family with a lower transformation cost.

The first example considered is the circular cylinder. The structure of the transformed impedance matrix $\mathbf{Z}_{t}$ for a circumference equal to $6,3 \lambda$ and $N$ equal to 512 , using wavelet-like and wavelet transform, are shown in Fig. 2.1. As it can be observed, the expected finger structure of wavelet transformed integral operators has been obtained in both cases.

For the circular cylinder case, the results for the first kind of comparative study mentioned above can be seen in Fig. 2.2, 2.3 and 2.4 for different circumference contours (from $3,14 \lambda$ to $28,27 \lambda$ ). As seen in Fig. 2.2, the error $\Delta E_{b c}$ is mostly kept below the upper limit as required, even though there are some particular cases in which Coiflets and Daubechies do not satisfy such requirement. The error oscillatory na- 


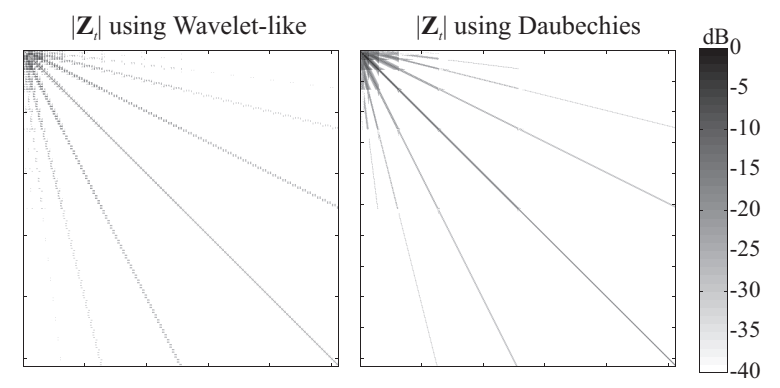

Figure 2.1: Circular cylinder: normalized absolute value of $\mathbf{Z}_{t}$ for a cylinder of circumference equal to $6,3 \lambda(N=512)$ after applying 4 th order wavelet-like bases and 6-length Daubechies bases with threshold $\tau$ equal to $1 \%$.

ture observed in Fig. 2.2 and the rest of figures is produced because the number of unknowns grows proportionally to the scatterer size, but in the wavelet case it is increased to the next power of two. As mentioned previously, extra segmentation compensates for the threshold error. However, when the original matrix size reaches up to a power of two, the error gets higher consequently because in that case the number of unknowns is the same for the original and the transformed problem. In Fig. 2.2, it can be also noticed that the wavelet-like scheme always provide the lower error values, which can be attributed to its higher number of vanishing moments. Consequently, the sparsity is clearly higher (around $99 \%$ ) in the case of the 4 -th order wavelet-like bases (see Fig. 2.3).

In the previous study, the number of millions of floating point operations (Mflops) gets rather lower than the original problem for all cases, as it is graphically shown in Fig. 2.4, where it can be observed a quadratic behavior with $N$ in comparison with the cubic dependance of the original problem. That is due to the fact that the sparsity gets very high for the three wavelet families, and the sparse solver achieves the solution with very low cost. As it can be seen in Fig. 2.4, the efficiency improvement increases as the scatterer becomes larger. Although all the wavelet families get the main objective of this study, wavelet-like bases characterize more accurately the impedance matrix because they present a higher number of vanishing moments ( $M$ equal to 4 ) for the same 


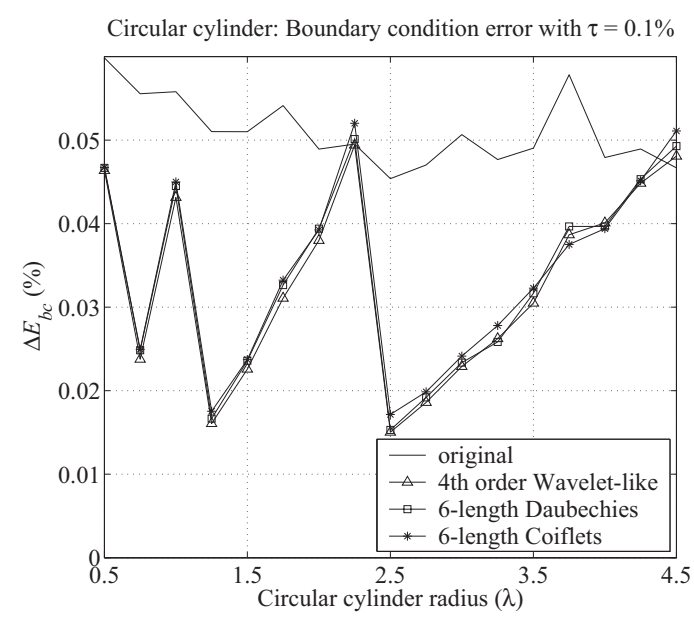

Figure 2.2: Circular cylinder: Square boundary condition error for different bases with approximately the same spatial support using a threshold equal to $0.1 \%$.

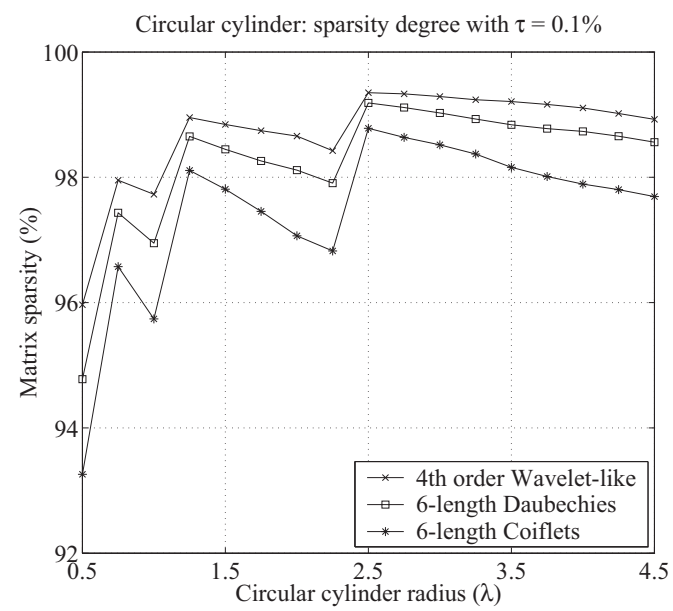

Figure 2.3: Circular cylinder: sparsity degree for different bases with approximately the same spatial support using a threshold equal to $0.1 \%$. 


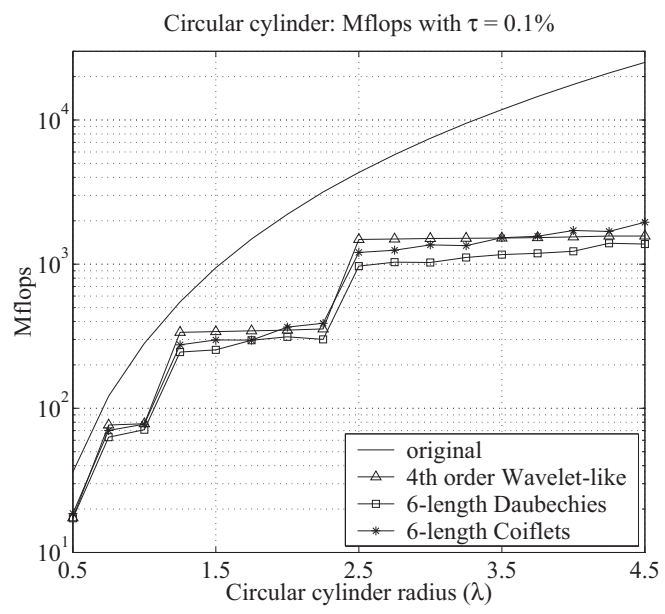

Figure 2.4: Circular cylinder: number of floating point operations for different bases with approximately the same spatial support using a threshold equal to $0.1 \%$.

spatial support (see Fig. 2.2 and 2.3). This is also confirmed by the sustained form of the Mflops curve in Fig. 2.4 for such wavelet-like bases in the interval of radius between $2,5 \lambda$ and $4,5 \lambda$. Such behavior means that the dominating operation is the wavelet-like transform, and the sparse solver hardly contributes to the number of operations in the waveletlike case. However, the drawback of wavelet-like bases comes from the fact that its transform is performed in a different way, which usually demands a slight larger number of operations than the Daubechies and Coiflets transforms, as explained before in Section 2.2.4.

For the case of the circular cylinder, we have also performed the second kind of comparative study described before, which essentially consists on using the same amount of vanishing moments $(M=4)$ for the three families. In this study, similar errors and sparsity values have been obtained for all wavelet bases, and for that reason, no graphic results for such parameters are presented. However, a better efficiency should be obtained for the wavelet-like case, which is not fully confirmed by the results shown in Fig. 2.5. This can be attributed again to the higher cost related to the different transformation procedure imple- 


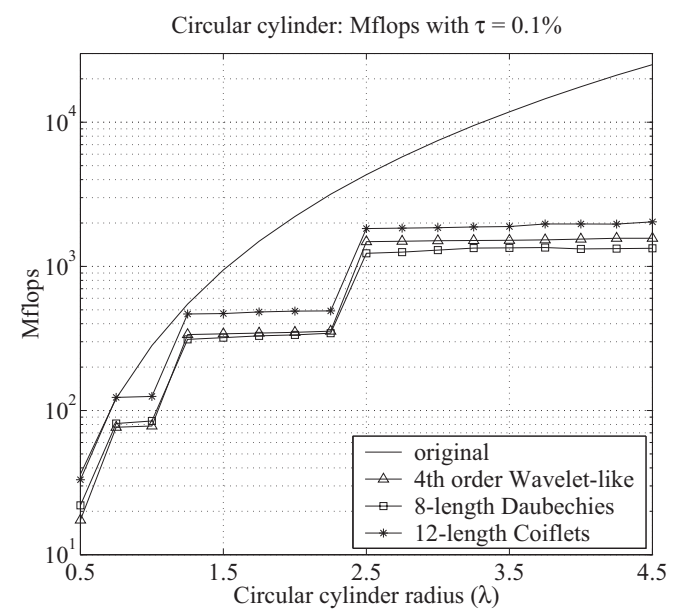

Figure 2.5: Circular cylinder: number of floating point operations for different bases with the same number of vanishing moments using a threshold equal to $0.1 \%$.

mented with the wavelet-like bases.

From the previous analysis, it can be concluded that both Daubechies and wavelet-like bases are good candidates to be used with the MoM spectral approach for solving large scattering problems, both from the accuracy and efficiency point of view. Another feature that can be extracted from this work is that the quasi-symmetry property introduced by the Coiflets family scarcely improves the results provided by Daubechies bases.

In order to confirm the accuracy provided by the wavelet approach, the induced current on a circular scatterer of circumference $6,3 \lambda$ under a plane wave incidence with $\phi=\pi / 4$ has been computed. Fig. 2.6 successfully compares the results obtained using the wavelet-like bases with those provided by the original MoM spectral approach. The small spikes in the current distribution come from the threshold application. That feature is common to all the studies that apply wavelet transform and thesholding to similar problems (see [28, 3, 20, 11, 15]). However, errors in current distribution do not affect very severely either the accomplishment of the boundary conditions or the far field radar cross 


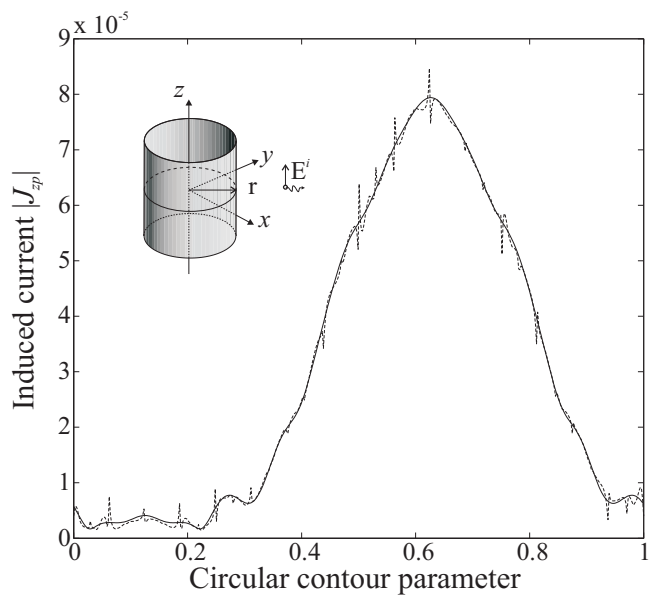

Figure 2.6: Comparison of the induced current $J_{z_{p}}$ when a plane wave with $\phi=\pi / 4$ excites a circular cylinder of circumference equal to $6,3 \lambda$ for the original method (solid line, $N=450$ ) and for the 4 th order wavelet-like accelerated procedure (dotted line, $N=512$ ). The contour parameter origin is located at $(\phi=0)$.

section.

A comparative study using bases with similar spatial support has been performed for a strip with different lengths (from $\lambda$ to $20 \lambda$ ). From Fig. 2.7 and Fig. 2.8, the same conclusions for the error and efficiency improvement reached in the previous geometry can also be derived for the strip scatterer.

Finally, the square scatterer shown in Fig. 2.9 has been accurately and efficiently solved with the wavelet-like proposed family. The error values and the sparsity degree reached for several contour lengths are collected in Table 2.1. Such results are in good agreement with the previous comments made for the circular and the strip cases. Additionally, the comparison of the current induced in a square cylinder of perimeter $2 \lambda$ by an incident plane wave with $\phi=\pi / 4$, obtained by the original method and the wavelet-like accelerated method, is shown in Fig. 2.9. These results allow to conclude that the wavelet technique proposed in this paper can be successfully applied to a wide range of geometries, 


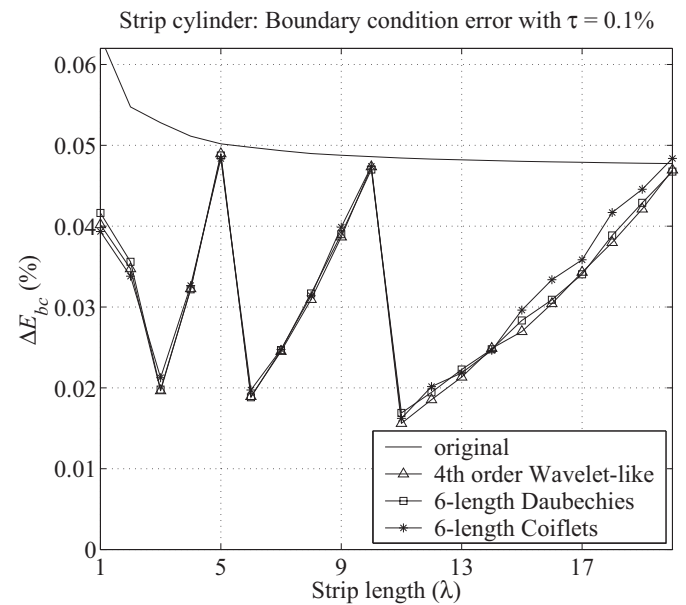

Figure 2.7: Strip: Square boundary condition error for different bases with approximately the same spatial support using a threshold equal to $0.1 \%$.

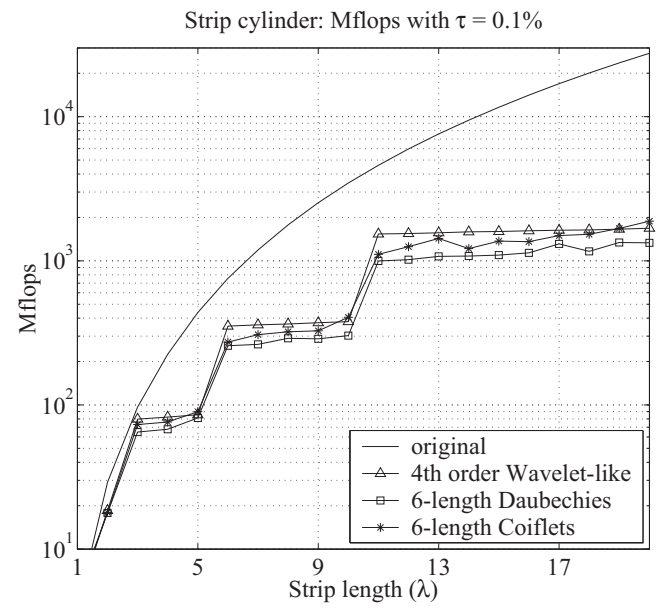

Figure 2.8: Strip: number of floating point operations for different bases with approximately the same spatial support using a threshold equal to $0.1 \%$. 


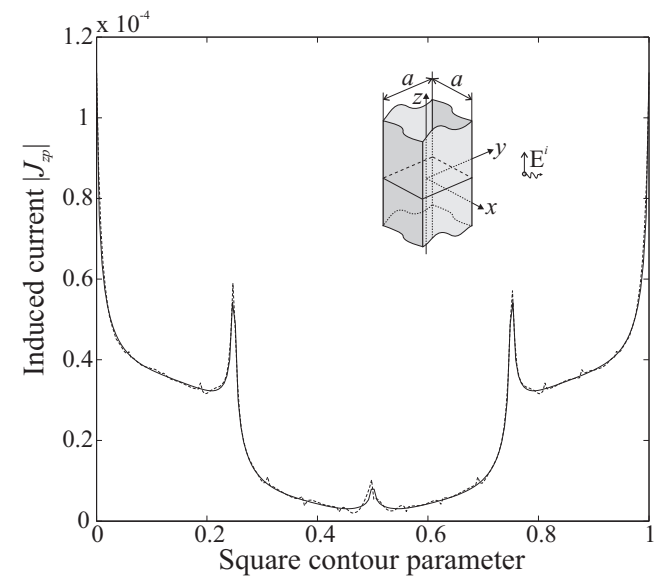

Figure 2.9: Comparison of the induced current $J_{z_{p}}$ when a plane wave with $\phi=\pi / 4$ excites a squared cylinder of perimeter equal to $2 \lambda$ for the original method (solid line, $N=200$ ) and for the 4 th order wavelet-like accelerated procedure (dotted line, $N=256$ ). The contour parameter origin is located at $(x=-a / 2, y=-a / 2)$.

without significative alteration of its performance.

\subsection{Conclusions}

This paper presents the application of recently proposed wavelet and wavelet-like bases to the spectral MoM characterization of large scattering problems with high accuracy. In such problems, the size of the involved matrices is usually very large. This drawback is alleviated by changing the traditional spatial MoM bases into a new set of wavelet or wavelet-like functions. Furthermore, the use of a spectral formulation allows to characterize the scattering problems under any possible incidence by solving a reduced number of linear equation systems. In order to select the most suitable wavelet bases for such scattering problems, a careful trade-off in search of the optimum parameters like moment order and threshold choice has been investigated. The spectral scattering characterization of several geometries, such as circular and square cylinders as well as strips, has been solved using three different 
Table 2.1: Square scatterer: $\Delta E_{b c}$ and sparsity degree using 4 th order wavelet-like bases and $\tau=0,1 \%$ for different scatterer contour lengths (4a) shown in Fig. 2.9.

\begin{tabular}{lccc}
\hline & Original & \multicolumn{2}{c}{$\begin{array}{c}\text { 4th order } \\
\text { wavelet-like }\end{array}$} \\
\hline Contour & $\begin{array}{c}\Delta E_{b c} \\
\text { length }\end{array}$ & $\begin{array}{c}\Delta E_{b c} \\
(\%)\end{array}$ & $\begin{array}{c}\text { Sparsity } \\
(\%)\end{array}$ \\
\hline $1 \lambda$ & 0.0386 & 0.0231 & 93.8599 \\
$2 \lambda$ & 0.0298 & 0.0186 & 96.7194 \\
$4 \lambda$ & 0.0254 & 0.0162 & 98.2239 \\
$8 \lambda$ & 0.0245 & 0.0160 & 99.0074 \\
$12 \lambda$ & 0.0241 & 0.0094 & 99.5254 \\
$16 \lambda$ & 0.0239 & 0.0154 & 99.4230 \\
$20 \lambda$ & 0.0232 & 0.0234 & 99.2635 \\
\hline
\end{tabular}

wavelet and wavelet-like families. Computational gain has been obtained for all the selected wavelets with no accuracy loss. However, the best compression ratio has been provided by the wavelet-like and the Daubechies bases. From these successful results, we conclude that wavelet bases combined with the spectral MoM approach offer a simple and extremely efficient method for the accurate solution of large electromagnetic scattering problems. Their main advantages are important savings in computation time and memory storage. However, ever greater gains could be achieved if the wavelet transform, which now dominates the computational effort, could be improved in terms of efficiency.

\section{Bibliography}

[1] B. Alpert, G. Beylkin, R. Coifman, and V. Rokhlin. Wavelet-like bases for the fast solution of second-kind integral equations. SIAM J. Sci. Comp., 44(1):159-184, January 1993.

[2] Z. Baharav and Y. Leviatan. Impedance matrix compression using adaptively constructed basis functions. IEEE Transactions on An- 
tennas and Propagation, 44(9):1231-1238, September 1996.

[3] Z. Baharav and Y. Leviatan. Impedance matrix compression with the use of wavelet expansions. Microwave and Optical Tecnology Letters, 12(5):268-272, August 1996.

[4] Z. Baharav and Y. Leviatan. Impedance matrix compression (IMC) using iteratively selected wavelet basis. IEEE Transactions on Antennas and Propagation, 46(2):226-233, February 1998.

[5] C. A. Balanis. Advanced Engineering Electromagnetics. John Wiley \& Sons, Toronto, 1989.

[6] G. Beylkin, R. Coifman, and V. Rohklin. Fast wavelet transforms and numerical algorithms. Communications on Pure and Applied Mathematics, 44:141-183, 1991.

[7] C. K. Chui, editor. Wavelets: A Tutorial in Theory and Applications, pages 181-816. Academic Press Inc., 1991.

[8] G. Conciauro, M. Bressan, and C. Zuffada. Waveguide modes via an integral equation leading to a linear matrix eigenvalue problem. IEEE Transactions on Microwave Theory and Techniques, 32(11):14951504, November 1984.

[9] I. Daubechies. Orthonormal bases of compactly supported wavelets. Communications Pure Applied Mathematics, 41, 1988.

[10] I. Daubechies. Ten Lectures on Wavelets. SIAM, Pennsylvania, 1992.

[11] H. Deng and H. Ling. Fast solution of electromagnetic integral equations using adaptive wavelet packet transform. IEEE Transactions on Antennas and Propagation, 47(4):674-682, 1999.

[12] G. V. Eleftheriades, J. R. Mosig, and M. Guglielmi. A fast integral equation technique for shielded planar circuits defined on nonuniform meshes. IEEE Transactions on Microwave Theory and Techniques, 44(12):2293-2296, December 1996.

[13] H. Esteban, V.E. Boria, M. Baquero, and M. Ferrando. Generalised iterative method for solving $2 \mathrm{~d}$ multiscattering problems using spectral techniques. IEE Proceedings on Microwave, Antennas and Propagation, 144(2):73-80, April 1997. 
[14] H. Esteban, S. Cogollos, V. E. Boria, A. San Blas, and M. Ferrando. A new hybrid Mode-Matching numerical method for the analysis of arbitrarily shaped inductive obstacles and discontinuities in rectangular waveguides. IEEE Trans. Microwave Theory Techniques, 50(4):1219-1224, April 2002.

[15] W. Golik. Sparsity and conditioning of impedance matrices obtained with semi-orthogonal and bi-orthogonal wavelet bases. IEEE Transactions on Antennas and Propagation, 48(4):473-481, April 2000.

[16] N. Guan, K. Yashiro, and S. Ohkawa. On a choice of wavelet bases in the wavelet transform approach. IEEE Transactions on Antennas and Propagation, 48(8):1186-1191, August 2000.

[17] R.F. Harrington. Time-Harmonic Electromagnetic Fields. McGrawHill Book Company, New York, 1961.

[18] R.F. Harrington. Field Computation by Moment Methods. The Mac Millan Company, New York, 1968.

[19] A. Heldring, J. M. Rius, and L. Ligthart. New block ILU preconditioner scheme for numerical analysis of very large electromagnetic problems. IEEE Transactions on Magnetics, 38(2):337-340, March 2002.

[20] R. D. Nevels, J. C. Goswami, and H. Tehrani. Semi-orthogonal versus orthogonal wavelet basis sets for solving integral equations. IEEE Transactions on Antennas and Propagation, 45(9):13321339, 1997.

[21] G. W. Pan, Y. V. Tretiakov, and B. Gilbert. Smooth local cosine based galerkin method for scattering problems. IEEE Transactions on Antennas and Propagation, 51(6):1177-1184, 2003.

[22] A. F. Peterson, S. L. Ray, and R. Mittra. Computational Methods for Electromagnetics. IEEE Press, Piscataway, 1998.

[23] A. J. Poggio and E. K. Miller. Computer techniques for electromagnetics, chapter Integral equation solutions of three-dimensional scattering problems. Oxford, Pergamon, 1973. 
[24] K. Sabetfakhri and L. P. B. Katehi. Analysis of integrated millimeter-wave and submillimeter-wave waveguides using orthonormal wavelet expansions. IEEE Transactions on Microwave Theory and Techniques, 42(12):2412-2422, December 1994.

[25] T. K. Sarkar and K. Kim. Solution of large dense complex matrix equations utilizing wavelet-like transforms. IEEE Transactions on Antennas and Propagation, 47(10):1628-1632, October 1999.

[26] T. K. Sarkar, M. Salazar-Palma, and M. C. Wicks. Wavelet Applications in Engineering Electromagnetics. Artech House, Norwood MA, 2002.

[27] B. Z. Steinberg and Y. Leviatan. On the use of wavelet expansions in the method of moments. IEEE Trans. Antennas Propagation, 41(5):610-619, May 1993.

[28] B. Z. Steinberg and Y. Leviatan. Periodic wavelet expansions for analysis of scattering from metallic cylinders. Microwave and Optical Technology Letters, 7(6):266-268, April 1994.

[29] W. Sweldens. Wavelets: What next? Proceedings of the IEEE, 84(4):680-685, 1996.

[30] R. L. Wagner and W. C. Chew. A study of wavelets for the solution of electromagnetic integral equations. IEEE Trans. Antennas Propagation, 43(8):802-810, August 1995.

[31] R. L. Wagner, G. P. Otto, and W. C. Chew. Fast waveguide mode computation using wavelet-like basis functions. IEEE Microwave and Guided Wave Letters, 3(7):208-210, July 1993.

[32] G. Wang and G. Pan. Full-wave analysis of microstrip floating line structures by wavelet expansion method. IEEE Transactions on Microwave Theory and Techniques, 43(1):131-142, January 1995. 



\title{
Wavelet-like Efficient Analysis of Two-Dimensional Arbitrarily Shaped Radomes Using a Surface Formulation
}

\section{Authors}

F.D. Quesada-Pereira, A. Vidal, V.E. Boria, A. Alvarez-Melcón and B. Gimeno.

\begin{abstract}
Radomes are usually made of lossy dielectric materials, and their accurate analysis is often cumbersome because of their typical large electrical size and geometrical complexity. In real reflector antenna structures, there are always complex interactions between the radome, the reflector surfaces and the directional feeds, which are typically neglected for the sake of simplicity. In this paper we will consider all such interactions in a very accurate way, thus requiring a high number of unknowns for the numerical solution of the problem. To overcome such
\end{abstract}


drawback, an integral equation formulation based on the Equivalence Principle in combination with the wavelet transform has been employed, obtaining finally a robust and accurate CAD tool for the rigorous analysis of arbitrarily shaped radomes containing continuous and discrete electromagnetic sources. It will be shown that the use of waveletlike bases substantially improves the numerical efficiency and memory requirements of the original integral equation method. For verification purposes, the results obtained with the new technique are successfully compared with examples taken from the literature. Complex antenna structures are then discussed in order to prove the usefulness of the new method.

\subsection{Introduction}

Radomes made of lossy dielectric layered materials, including antenna reflectors and feeding sources, are scattering problems whose accurate solution is typically difficult to compute, mainly due to their large size and complex geometries. For these reasons, it is a topic of growing interest which is presently receiving considerable attention by the electromagnetic community (see [35] and [29]).

Traditionally, radomes were first analyzed using high frequency methods, such as Ray Propagation in [9], or the Geometrical Theory of Diffraction in [8]. Alternatively, rigorous solutions for 2-D problems including canonical reflectors and radomes, combined with complex sources, were employed in [5, 30, 34, 19] and [21]. Although with reduced complexity, the scattering analysis of 2-D structures finds useful applications, for instance in the design of inductive or capacitive waveguide filters widely used in mobile and satellite systems. For these devices, the analysis can be carried out by solving a 2-D scattering problem. Also, cylindrical reflector antennas, which can be modelled as 2-D structures, are used in airborne navigation applications, as recognized in [18]. These applications show the interest of investigating efficient numerical techniques for the study of 2-D scattering problems.

Recently, solutions for 3-D radomes without reflectors based on volume and surface formulations have also appeared in [15] and [35], where the analysis has been performed through the Adaptive Integral Method (see [35]), and the Multilevel Fast Multipole Algorithm propo- 
sed in [14] and [15]). These 3-D radomes, typically used for fixed earth stations, usually present a spherical geometry. However, several cylindrical scenarios with arbitrary geometries appear in naval radar systems (see [18]), as well as in telecommunications towers with radiant elements. In these complex real situations, multilayered radome materials are used, and metallic surfaces and reflectors combined with directive complex sources are often found in practice.

In this paper, we propose to use the Equivalence Principle in order to formulate an integral equation problem for the analysis of 2-D cylindrical problems with arbitrary geometries. To set up the formulation we employ the Extinction Theorem to transform the classical volume formulation for dielectric obstacles into a more efficient surface approach. Proceeding in this way, the unknowns of the problem are the equivalent electric and magnetic surface currents defined only over the surfaces of the different homogeneous objects. Therefore, following this approach, a boundary integral equation fully characterizes the problem. That approach was already proposed in [2] for small radomes scattering problems, and a more complete formulation for considering thin dielectric radomes under $\mathbf{T E}^{z}$ polarization was presented in [24]. In this paper, a Poggio Miller Chang Harrington Wu Tsai (PMCHWT) field formulation of the type shown in [12] for large dielectric radomes under $\mathbf{T M}^{z}$ and $\mathbf{T E}^{z}$ polarization, including also metallic reflectors and complex sources, will be proposed. Furthermore, we have successfully combined such new formulation with the wavelet-like transform. If high accuracy is demanded, then the number of unknowns grows even in the case of surface formulations (see [22]). That is the case, for instance, if a simple point-matching Method of Moments (MoM) procedure is used to solve the problem involving electrically large radomes, and/or very complex geometries. Then, CPU cost becomes important, and the wavelet-like transform can be efficiently used to decrease the amount of required memory allocation and CPU computational time.

The use of wavelets to reduce the computational burden associated to MoM solutions is not new, and the idea has been used for instance in [33] to study the scattering from metallic objects. In that work periodic wavelet functions are used as basis functions in the MoM, and the backscattering of several metallic objects are successfully computed. Alternatively, in this paper we propose a surface formulation for the analysis of both metallic and dielectric objects, with subsequent ap- 
plication of the wavelet-like transform. Following this approach, the MoM formulation stays very simple (pulse-point matching), while obtaining big gain in computational cost through the use of the waveletlike transform.

It will also be shown in this paper that the use of the proposed surface formulation is very convenient for speed acceleration, since it leads to a matrix equation which naturally has a banded submatrix-type structure. This banded structure is very well suited for a subsequent introduction of the wavelet-like transform. An important contribution of this paper is that the wavelet-like transform is applied to each submatrix block, instead of using a global transformation scheme. It has been proved that a considerable gain in computational cost is obtained when the wavelet-like transform is applied following the new introduced subblock scheme. All these gains in CPU time and memory requirements are not possible if other volume based formulations (see [11, 15] and [29]) are employed. This is because a volume formulation produces full dense matrices, thus loosing some of the matrix sparsity introduced by the proposed surface formulation. Furthermore, the volume formulation presents problems associated to the sorting of the grid elements, which reduce the computation gain related to the application of the wavelet-like transform.

The structure of this paper is the following one. First, the surface formulation employed is briefly described. Then, the wavelet-like transformation is applied in order to obtain very sparse matrices. The theory is validated with general results obtained from the literature, such as canonical reflectors and radomes. Once the novel method is successfully verified, it has been applied to analyze complex shaped reflector-inradome structures and arrays-in-radome antennas. The results clearly show the validity and usefulness of the new strategy proposed in this paper for the efficient and accurate analysis of this kind of structures.

\subsection{Theory}

Let us consider a cylindrical radome problem like the one shown in Fig. 3.1, where the radome can be composed of a multilayered dielectric and/or magnetic media with losses. We will consider that the dielectric permittivity and the magnetic permeability are defined as $\varepsilon_{i}=\varepsilon_{0} \varepsilon_{r i}$ 


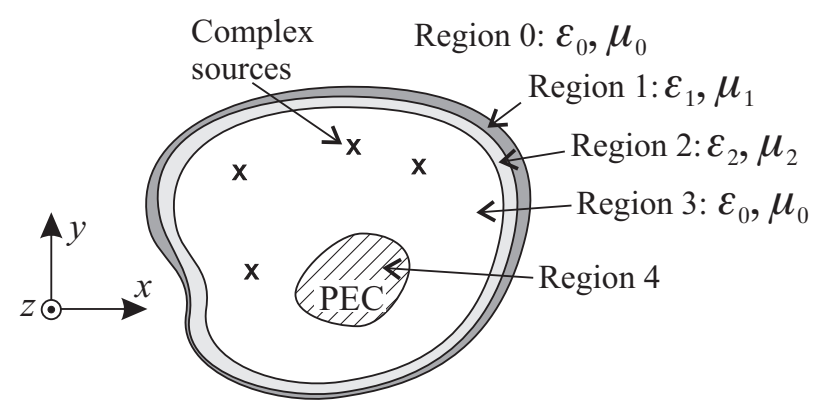

Figure 3.1: Scattering of lossy dielectric and magnetic multilayered radome with complex sources excitation including the presence of a metallic obstacle, under 2-D $\mathbf{T} \mathbf{M}^{z}$ or $\mathbf{T} \mathbf{E}^{z}$ excitation.

and $\mu_{i}=\mu_{0} \mu_{r i}$ respectively. We assume that a $\mathbf{T} \mathbf{M}^{z}$ or $\mathbf{T} \mathbf{E}^{z}$ polarization can be selected as the excitation for the $n$ complex sources situated in the innermost layer, where a Perfect Electric Conductor (PEC) may also be present for modelling typically a reflector placed inside the antenna structure.

First, we will set up the integral equations that arise for such problem following an equivalent surface formulation, and then the waveletlike transform will be introduced to increase the computational efficiency of the analysis technique.

\subsubsection{Equivalent surface formulation}

The scattering of homogeneous material bodies can be efficiently accomplished by using the Surface Equivalence Principle described in [4] and [6]. Following this technique, the scattered fields in each region of the problem are due to equivalent electric and magnetic surface current densities $\left(\vec{J}\left(\vec{\rho}^{\prime}\right), \vec{M}\left(\vec{\rho}^{\prime}\right)\right)$, and can be expressed as follows:

$$
\begin{aligned}
& \vec{E}_{i}^{s}(\vec{\rho})=-j \omega \vec{A}_{i}(\vec{\rho})-\nabla V_{i}(\vec{\rho})-\frac{1}{\epsilon_{i}} \nabla \times \vec{F}_{i}(\vec{\rho}) \\
& \vec{H}_{i}^{s}(\vec{\rho})=-j \omega \vec{F}_{i}(\vec{\rho})-\nabla U_{i}(\vec{\rho})+\frac{1}{\mu_{i}} \nabla \times \vec{A}_{i}(\vec{\rho})
\end{aligned}
$$

where the mixed potential representation for the fields has been used, and the index (i) stands for each region in the structure (see Fig. 3.1). For 
a two dimensional problem, the Green's functions used in the kernel of the integral equation takes the following form:

$$
G_{i}\left(\vec{\rho}, \vec{\rho}^{\prime}\right)=\frac{1}{4 j} H_{0}^{(2)}\left(k_{i}\left|\vec{\rho}-\vec{\rho}^{\prime}\right|\right)
$$

The application of the equivalence principle to a homogeneous body leads to four different integral equations, two involving the electric field (one for the interior problem and one for the exterior problem), and the other two involving the magnetic field. However, there are only two unknowns associated to the previous four integral equations, namely the equivalent electric and magnetic current densities defined on the surface of the body. Consequently, different combinations are possible for the formulation of the final scattering problem. If we choose the two equations involving only the electric field, then the E-field formulation is obtained. On the contrary, we may select the two equations involving the magnetic field, therefore leading to the $\mathrm{H}$-field formulation. It is known that the previous two formulations exhibit numerical difficulties at certain frequencies, corresponding to the natural resonances of the interior body (see [22]). To avoid this undesired numerical behavior, one has to combine the electric and magnetic field integral equations in a precise way. Three other different formulations are obtained in this manner, namely the combined or C-field, the so called PMCHWT formulation proposed in [23], and the Müller formulation (see [17]). The combined or C-field strategy formulates one equation for the exterior problem, by using a linear combination of the corresponding electric and magnetic field equations. In a similar way, the second equation is obtained by linear combination of the electric and magnetic field equations of the interior problem. On the other hand, the PMCHWT formulation is based on the direct imposition of the continuity of the tangential electric and magnetic field through the scatterer contour. Therefore, the first equation is obtained with the imposition of the continuity of the electric field, while the second equation is obtained through the imposition of the continuity of the magnetic field across the boundary. Finally, the Müller formulation is based on the PMCHWT formulation, with the introduction of a slight modification. In this case, the interior and exterior fields are scaled by the corresponding constitutive parameters, before imposing the field continuity. Either the PMCHWT or Müller formulations avoid the problem of the internal resonances, as 
recognized in [16]. In this work we have employed the PMCHWT alternative, which requires the imposition of the following two boundary conditions:

$$
\begin{aligned}
& \hat{n} \times{\overrightarrow{E_{i}}}^{s}=\hat{n} \times \vec{E}_{i+1}^{a} \\
& \hat{n} \times \vec{H}_{i}{ }^{s}=\hat{n} \times \vec{H}_{i+1}^{a}
\end{aligned}
$$

where superscript $(s)$ stands for scattered field, $(a)$ for the total field that may contain an excitation component, and $\hat{n}$ is the outgoing normal unitary vector to the surface at each point on the contour (see Appendix 3.4 for details).

The imposition of the appropriate boundary conditions leads to a system of coupled integral equations, which is solved by the well-known Method of Moments (MoM). The unknown equivalent electric and magnetic current densities have been expanded in terms of pulse basis functions, whereas delta functions have been employed for testing (PointMatching). The theory of the complex sources to include directionality in point sources has been used. This complex source model is a simple way to simulate the aperture width of a realistic horn feed, since an omnidirectional source in complex space is a beam source in real space (see [28]). In this case, the complex center of the point sources is defined as follows:

$$
\vec{\rho}_{s}=\overrightarrow{\rho_{0}}+j b(\cos \beta \hat{x}+\sin \beta \hat{y})
$$

where $\vec{\rho}_{0}$ is the actual point source center, $b$ determines the source directivity, and $\beta$ is the beam pointing direction measured from the $\hat{x}$ axis (see [20] and [28]). It is also known that the complex source beam is gaussian near its axis, as it happens for the main beams of most realistic antennas (see [28]). By properly adjusting both the directivity and the beam pointing direction, it is easy to model more realistic feeding structures for reflector antennas, such as horns or arrays.

The scattering of an object composed of $N$ nested homogenous layers is appropriately formulated on the outer contour of each layer. Once the standard Point-Matching method is applied to the numerical solution of the integral equation (see more details in [2]), a banded MoM matrix of the following form is obtained,

$$
\mathbf{Z} \cdot \mathbf{I}=\mathbf{V}
$$


where the known voltage vector $\mathbf{V}$ directly depends on the modal excitation in (3.4) and (3.5), and the current vector I represents the unknown expansion coefficients of the basis functions for the electric and magnetic current (see [22]). These previous vectors adopt the following general structure:

$$
\mathbf{I}=\left[\begin{array}{c}
\mathbf{I}_{J M}^{1} \\
\mathbf{I}_{J M}^{2} \\
\vdots \\
\vdots \\
\mathbf{I}_{J M}^{N}
\end{array}\right], \mathbf{V}=\left[\begin{array}{c}
\mathbf{V}_{E H}^{1} \\
\mathbf{V}_{E H}^{2} \\
\vdots \\
\vdots \\
\mathbf{V}_{E H}^{N}
\end{array}\right]
$$

Finally, the impedance matrix $\mathbf{Z}$ is the standard MoM matrix obtained from the overlapping integrals between the Green's functions (3.3) and the selected basis and test functions, as proposed in [22]. For the case of $N$-nested layers, treated with the surface integral equation, this impedance matrix can be further decomposed into the following subblock structure:

$$
\mathbf{Z}=\left[\begin{array}{ccccc}
\mathbf{Z}^{11} & \mathbf{Z}^{12} & 0 & \cdots & 0 \\
\mathbf{Z}^{21} & \mathbf{Z}^{22} & \ddots & \ddots & \vdots \\
0 & \ddots & \ddots & \ddots & 0 \\
\vdots & \ddots & \ddots & \mathbf{Z}^{(N-1)(N-1)} & \mathbf{Z}^{(N-1) N} \\
0 & \cdots & 0 & \mathbf{Z}^{N(N-1)} & \mathbf{Z}^{N N}
\end{array}\right]
$$

As it can be seen in (3.9), the sparsity of this matrix grows with the number of layers $(N)$. This fact, together with the wavelet-like transform proposed in this paper, reduces the computational time and also the memory requirements of the problem.

Each of the submatrices $\mathbf{Z}^{Q P}$ of the impedance matrix (3.9) can be further decomposed into four submatrices, each one representing the electric or magnetic fields imposed on the $Q$ layer contour, caused by the equivalent magnetic or electric current surface densities that flow on the contour $P$ :

$$
\mathbf{Z}^{Q P}=\left[\begin{array}{ll}
\mathbf{Z}_{E_{Q} J_{P}} & \mathbf{Z}_{E_{Q} M_{P}} \\
\mathbf{Z}_{H_{Q} J_{P}} & \mathbf{Z}_{H_{Q} M_{P}}
\end{array}\right]
$$

If the innermost layer $N$ is a PEC, the expression of the interaction matrices is slightly different due to the lack of magnetic current den- 
sity. In that case, the submatrix $Z^{N N}$ presents a single subblock structure, and the matrices involving the sub-indexes $N$ and $(N-1)$ contain only the corresponding 2 appropriate subblocks. Consequently, the sub-vector $\mathbf{I}_{J M}^{N}$ does only include the electric surface current, and $\mathbf{V}_{E H}^{N}$ considers the corresponding boundary conditions for the metallic surface. In the case of a closed metallic object a combined field approach is used. This is done by introducing in the integral equations a new parameter $\alpha$ suggested in [22] (see Appendix 3.4 for details). This parameter combines the EFIE and MFIE formulation for a conductor, thus avoiding again the internal resonance problem:

$$
\begin{gathered}
\mathbf{Z}^{N N}=\left[\alpha \mathbf{Z}_{E_{N} J_{N}}+(1-\alpha) \mathbf{Z}_{H_{N} J_{N}}\right] \\
\mathbf{Z}^{(N-1) N}=\left[\begin{array}{c}
\mathbf{Z}_{E_{N-1} J_{N}} \\
\mathbf{Z}_{H_{N-1} J_{N}}
\end{array}\right] \\
\mathbf{Z}^{N(N-1)}=\alpha\left[\begin{array}{ll}
\mathbf{Z}_{E_{N} J_{N-1}} & \mathbf{Z}_{E_{N} M_{N-1}}
\end{array}\right] \\
+(1-\alpha)\left[\begin{array}{ll}
\mathbf{Z}_{H_{N} J_{N-1}} & \mathbf{Z}_{H_{N} M_{N-1}}
\end{array}\right]
\end{gathered}
$$

In the above equations, $\alpha$ is selected between zero and one, depending on the weight given to each electric or magnetic type integral equation. For the problems investigated in this paper we have used a value of $\alpha=0,05$ in order to give some importance to the MFIE, thus avoiding resonance effects of the EFIE described in [7].

The proposed impedance matrix presents many submatrices that are systematically set to zero, since there are no interactions between noncontiguous layers, as it can be seen in (3.9).

\subsubsection{Wavelet Transform}

The next stage in the solution of the coupled integral equations system is the use of the wavelet transform. Wavelet bases may be applied in two different ways when solving integral equations through the MoM. The most rigorous approach consists on considering the wavelet family as base and test functions in the MoM implementation (see [27]), thus typically involving major computational efforts. An alternative strategy, which consists on applying a wavelet matrix transformation to the matrix arisen from the conventional application of the MoM, has 
been recently proposed in $[3,25]$ and [32]. In this paper, we have followed this second approach, which can improve the efficiency and the memory requirements when large matrices are involved in the numerical solution of the integral equation, as it typically happens when the objects are electrically large.

In [31] and [26], wavelet-like bases were proposed to reduce the CPU time and memory requirements related to the characterization of 2D large metallic objects. Due to such previous experiences, the study of the wavelet families has not been considered in this paper, and the waveletlike family described in the previous references has instead been directly applied to our problem. Here, a brief description of the waveletlike transform is given. The conversion of the discrete integral operator into the new wavelet-like bases is equivalent to carry out a similarity transformation. The similarity transformation matrix is defined by a real and unitary matrix, $\mathbf{T}$, whose rows contain the new wavelet-like bases as described in [1] and [31]. The wavelet-like transformation matrix $\mathbf{T}$ is built from the discretization grid $S=\left\{x_{1}, x_{2}, \ldots, x_{M_{s}}\right\} \subset \mathbb{R}$. Then, an orthonormal basis for the $M_{s}$-dimensional space of functions defined on $S$ is constructed following [1]. We assume that $M_{s}=2^{n} \cdot k$, where $n$ is an integer and $k$ is the wavelet-like order. The basis vectors present some fundamental properties: all but $k$ basis vectors have $k$ vanishing moments, they preserve the condition number of the full matrix and they present local support. Therefore, they provide a multiresolution representation, although they are not strictly dilations and translations of a mother function like a conventional wavelet scheme. Instead, the basis vectors are obtained by a number of Gram-Schmidt orthogonalizations starting from polynomials based on $S$ (see [1] for details). The transformation matrix $\mathbf{T}$ with its corresponding basis vectors are shown in Fig. 3.2 for an example of an equidistant grid $S$ with $M_{s}=64$ and $k=4$.

The application of the wavelet-like method can increase the sparsity of the original matrix $\mathbf{Z}$ (that contains $M^{2}$ elements including zero entries) shown in (3.9). So, an iterative sparse algorithm can be used to solve the new problem with complexity $O\left(M^{\prime}\right)$, where $M^{\prime}$ is the number of non-zero elements in the sparse impedance matrix that should be much lower than $M^{2}$. This strategy compares very favorably to the $O\left(M^{3}\right)$ operations that requires the direct solution of the original problem using a standard LU decomposition, or to the $O\left(M^{2}\right)$ operations 


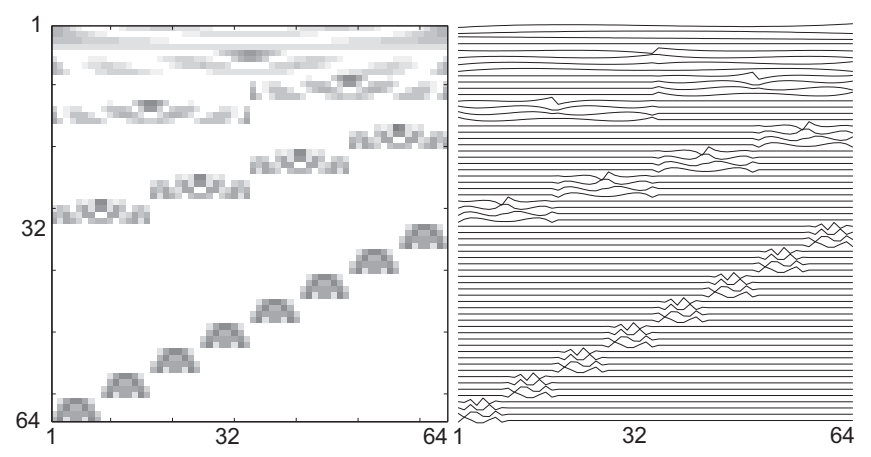

Figure 3.2: An example of a wavelet-like transformation matrix $\mathbf{T}$ with order $k=4$ and $M_{s}=64$ showing the basis vectors.

that needs an iterative solver that also depends on the condition number of the matrix.

The wavelet-like transform could directly be applied to the complete matrix at once. However, the numerical results obtained have revealed that much better results are obtained for a subblock wavelet transform. The idea of applying the wavelet transform, following a subblock scheme, to the impedance matrix resulting from the application of the surface formulation to radome problems is an important contribution of this work, not explored before to the authors' knowledge. As an example, the overall computational cost of the solution using wavelet-like approach applied in one block to the $\mathbf{Z}$ matrix takes 5 times more operations, leading to a much less sparse matrix ( $80 \%$ versus $95 \%$ ) than the subblock decomposition proposed in this paper. The selected problem to perform this comparative evaluation is the broadcast square tower with circular sandwiched radome described in Section 3.3.2. Nevertheless, sparsity gains due to this subblock scheme have been also observed for all the examples considered in this paper, which are more impressive when the number of layers grows. When applying the wavelet transform to each subblock, we must consider that all the submatrices are not square. This is due to the fact that each contour needs a different number of discretization segments, therefore requesting a different transformation matrix $\mathbf{T}_{P}$ for each layer $P$. The original problem 
is now represented, in the wavelet-like domain, as follows:

$$
\begin{gathered}
\tilde{\mathbf{Z}} \tilde{\mathbf{I}}=\tilde{\mathbf{V}} \\
\tilde{\mathbf{Z}}^{Q P}=\left[\begin{array}{cc}
\mathbf{T}_{Q} \mathbf{Z}_{E_{Q} J_{P}} \mathbf{T}_{P}^{t} & \mathbf{T}_{Q} \mathbf{Z}_{E_{Q} M_{P}} \mathbf{T}_{P}^{t} \\
\mathbf{T}_{Q} \mathbf{Z}_{H_{Q} J_{P}} \mathbf{T}_{P}^{t} & \mathbf{T}_{Q} \mathbf{Z}_{H_{Q} M_{P}} \mathbf{T}_{P}^{t}
\end{array}\right] \\
\tilde{\mathbf{I}}_{J M}^{P}=\left[\begin{array}{c}
\mathbf{T}_{P} \mathbf{J}_{P} \\
\mathbf{T}_{P} \mathbf{M}_{P}
\end{array}\right] \\
\tilde{\mathbf{V}}_{E H}^{Q}=\left[\begin{array}{c}
\mathbf{T}_{Q} \mathbf{E}_{Q} \\
\mathbf{T}_{Q} \mathbf{H}_{Q}
\end{array}\right]
\end{gathered}
$$

where superscript $(t)$ stands for the transpose of a matrix, and the tilde indicates that the matrices are expressed in the new wavelet-like bases. Due to the wavelet-like bases properties, $\tilde{\mathbf{Z}}$ presents many negligible elements that are set to zero through a hard threshold applied to each one of the submatrices of $\tilde{\mathbf{Z}}$. This last operation completes the subblock transformation scheme proposed in this paper.

However, the wavelet approach involves matrix and vector transformations, whose cost should be included within the global computational budget. The wavelet-like transform of a submatrix can be evaluated in $O\left(M_{s}^{2}\right)$ operations (see [31] and [26]), where $M_{s}$ is the number of unknowns for that submatrix. This operation should be carried out for the $(12 N-15)$ submatrices that compose the total matrix $\mathbf{Z}$ in the case of $N$-layers, including a final metallic object. For that reason, this extra computation cost has been considered in all the validation results.

The transformed impedance matrix presents a diagonal banded form usually known as finger structure, as it can be seen in Fig. 3.3 for the broadcast square tower with circular sandwiched radome described in Section 3.3.2.

\subsection{Validation Results}

In this section, several practical non-magnetic radome designs taken from the literature have been successfully considered. Some of them could be analyzed following the approximate technique for electrically thin radomes proposed in [24]. However, the more accurate formulation described in this paper has been employed in all the examples, since it 


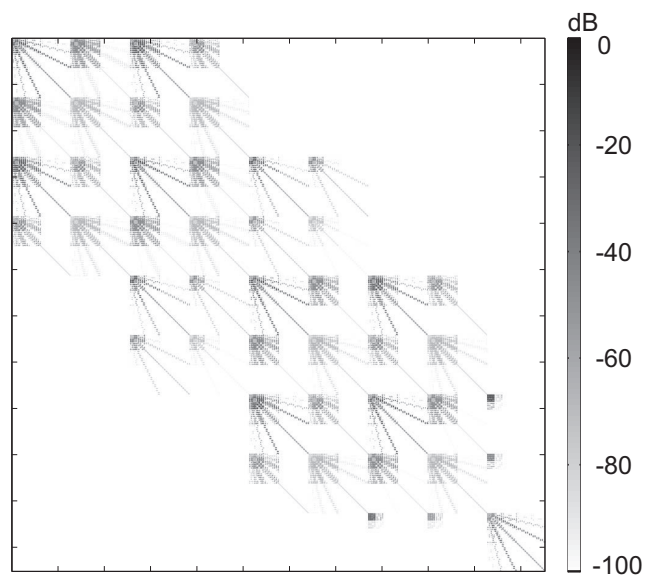

Figure 3.3: Matrix $\tilde{\mathbf{Z}}$ after thresholding for the sandwiched radome for the broadcasting tower taken from Section 3.3.2, with $\mathbf{T} \mathbf{E}^{z}$ incidence and threshold equal to $0,5 \%$.

can also be applied to thick radomes as well a considering the possible use of magnetic materials.

All the examples considered in this section contain elements with large physical dimensions. As a consequence, big computational savings can be obtained when using the proposed wavelet-like approach. A wavelet-like family of 8 vanishing moments has been considered for all the examples, and ten points per free space wavelength are used for discretization. The efficiency study compares the number of floating point operations (Mflops) required by each method including the wavelet-like transform, using a standard command provided by the commercial software Matlab ${ }^{\complement}$. The threshold value has been adapted to the geometry of each problem for the maximum computational gain, considering a certain low error that preserves the normalized field when compared with the conventional MoM solution.

\subsubsection{Circular radome and circular reflector}

The first example has been taken from [30]; the geometry is shown in Fig. 3.4. The data for this reflector are $\varepsilon_{r}=4, c=15,915 \lambda, a=9,995 \lambda$, 


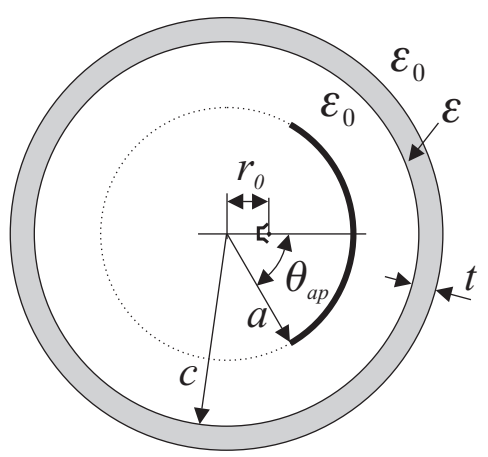

Figure 3.4: Circular dielectric 2-D radome $\left(\varepsilon=\varepsilon_{r} \varepsilon_{0}\right)$ with a complex source excitation, including a concentric circular metallic reflector.

$r_{0}=a / 2, b=0,796 \lambda, t=0,22 \lambda$ and $\theta_{a p}=30^{\circ}$. The size of this structure is considerably large, since the circular radome presents two contours of approximately $100 \lambda$ of perimeter.

The normalized electric fields obtained with the original and the wavelet-like implementation are both presented in Fig. 3.5 for $\mathbf{T M}^{z}$ polarization, where the radiation pattern of the antenna without radome is also shown for comparative purposes. The electric field also compares very well with the same example solved with a different method in [30]. Furthermore, the wavelet-like transform introduces strong savings in CPU cost, preserving at the same time the radiation pattern, where only small errors are observed for very low sidelobe levels. The sparsity achieved in this example reaches $83,4 \%$, and the computational cost is 3,7 times lower than the one required by the direct MoM method, for a relative mean square error of $0,04 \%$, and using a threshold level of $0,2 \%$. The error has been defined as the relative mean square difference between the original MoM field and the wavelet-like MoM one.

The normalized magnetic fields obtained with the original MoM method and the wavelet-like implementation are successfully compared in Fig. 3.6, in this case for $\mathbf{T E}^{z}$ polarization. The radiation pattern of the antenna without radome has been also shown for comparative purposes. The magnetic field provided by the wavelet-like implementation also compares very well in this case with the results given by the method proposed in [30]. In this second example, the wavelet-like 


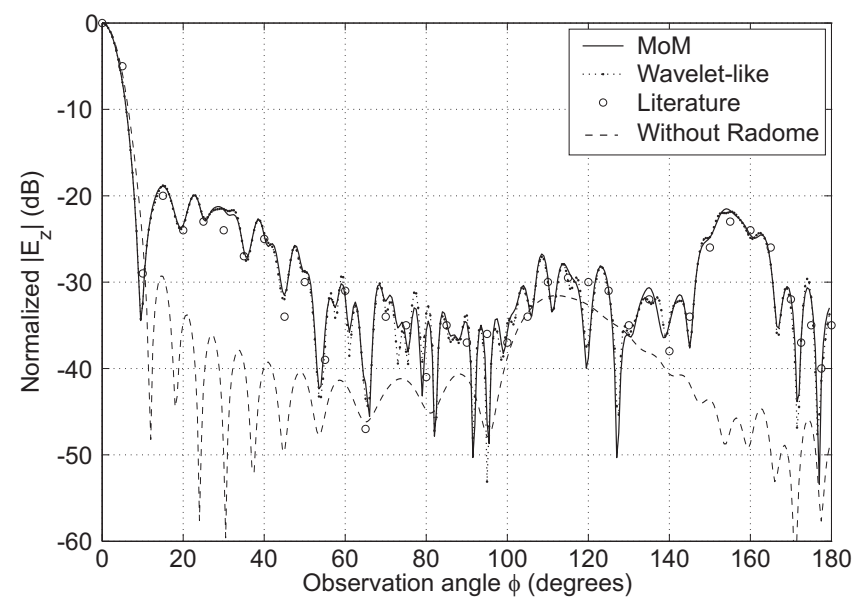

Figure 3.5: Normalized electric field under $\mathbf{T M}^{z}$ polarization, for the structure shown in Fig. 3.4 (In the legend, literature refers to data taken from [30]).

transform achieves $78 \%$ of matrix sparsity, and the computational cost is 3,3 times lower than the effort required by the direct MoM solution, for a relative mean square error of $0,02 \%$, and using a threshold level of $0,07 \%$.

The next example was originally reported in [34], with the geometry detailed in Fig. 3.7. The relevant dimensions in this case are: $L=4,271 \lambda$, $\varepsilon_{r}=2, c=5,984 \lambda, a=4,997 \lambda, r_{0}=0,56 a, b=0,414 \lambda, t=0,241 \lambda$ and $\theta_{a p}=30^{\circ}$. The normalized magnetic field obtained with the original and the wavelet-like implementation are both presented in Fig. 3.8 for $\mathbf{T E}^{z}$ polarization. The magnetic field again compares very well with the same example solved with a different method in [34]. In this case, the wavelet-like transform achieves $91 \%$ of matrix sparsity, and the computational cost is 7,3 times lower than the direct method, for a very low relative mean square error of $0,006 \%$, and using a threshold of $0,08 \%$. Again, this error has been defined by comparing the original MoM and the wavelet-like MoM.

In addition to the scattering behavior of the structure shown in Fig.3.7 at a given frequency, we have investigated the accuracy and numerical stability of the technique when the thickness of the radome increases. 


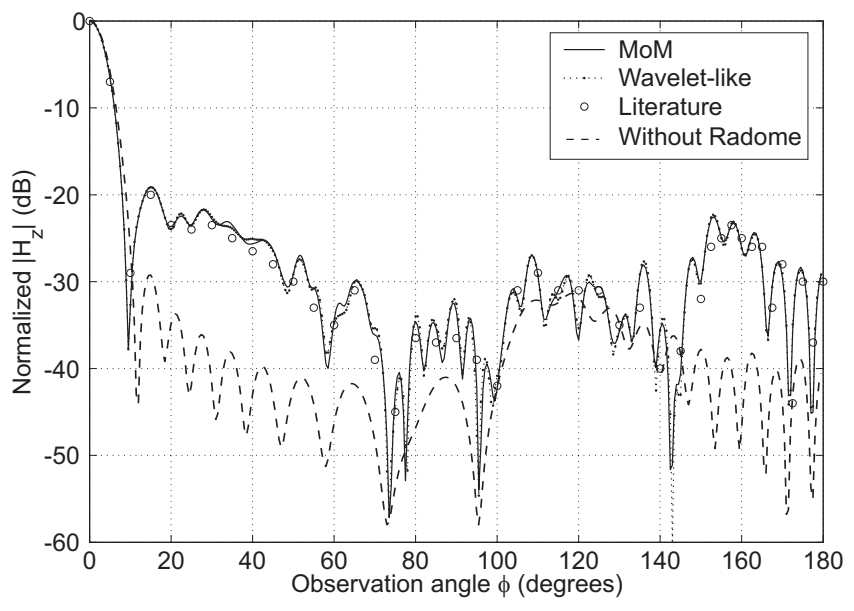

Figure 3.6: Normalized magnetic field under $\mathbf{T} \mathbf{E}^{z}$ polarization, for the structure shown in Fig. 3.4 (In the legend, literature refers to data taken from [30]).

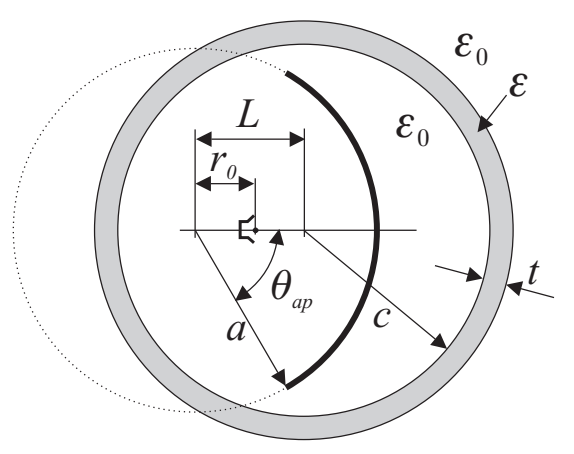

Figure 3.7: Circular dielectric 2-D radome $\left(\varepsilon=\varepsilon_{r} \varepsilon_{0}\right)$ with a complex source excitation, including a non-concentric circular metallic reflector. 


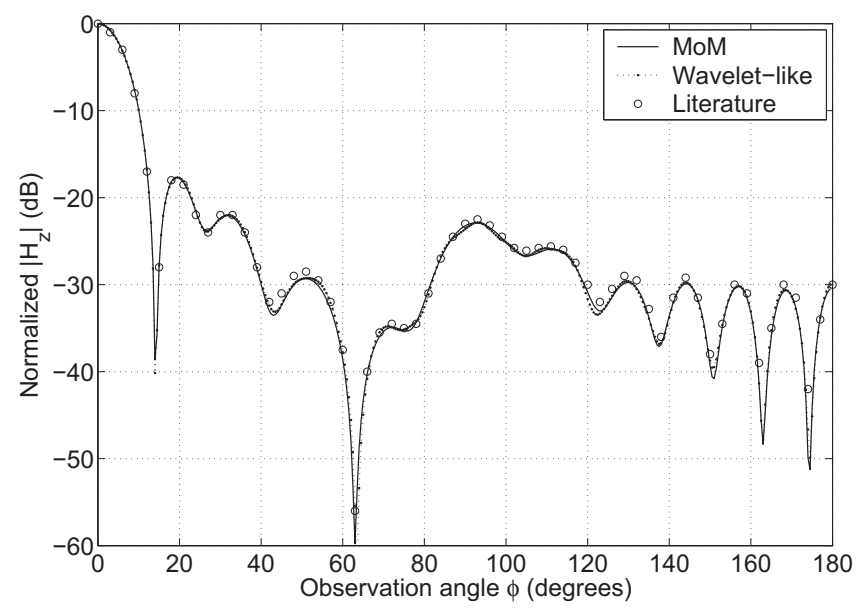

Figure 3.8: Normalized magnetic field under $\mathbf{T} \mathbf{E}^{z}$ polarization for the example shown in Fig. 3.7 (In the legend, literature refers to data taken from [34]).

Fig. 3.9 shows the normalized radiated power as a function of the radome thickness, while Fig. 3.10 shows the directivity. Results reported in [34] are shown for validation purposes. We can observe in the figure very good agreement with our technique, both for the radiated power and for the directivity, and in the whole range of dimensions considered.

The agreement obtained in the above example is very good since there are no natural resonances of the structure for the parameters studied. An interesting question that arises is how the developed IE surface technique behaves close to such resonances (see [10]). We have investigated this important issue for the example given in [10], comparing the technique developed in this paper with a volume surface integral equation and an FDTD technique presented in [10]. We have found that for a similar level of discretization, the surface integral equation leads to more accurate results than both the volume formulation and the FDTD technique. In particular we have checked that the surface formulation developed in this work is more accurate close to the natural resonances of the body. However, to maintain the same level of accuracy close to the resonance, we need around four times higher number of unknowns 


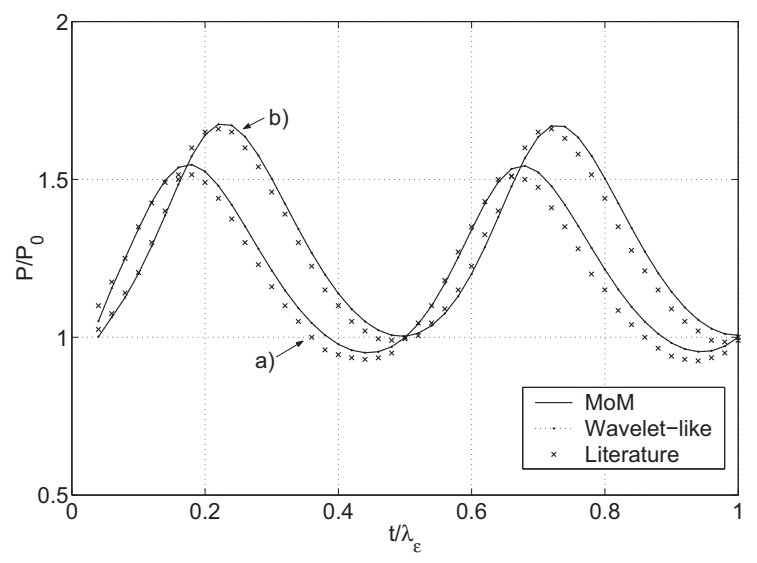

Figure 3.9: Normalized total radiation power as function of the radome thickness $t$ for the structure shown in Fig. 3.7. In a) $L=4,271 \lambda, c=$ $5,984 \lambda, r_{0}=0,56 a$, and in b), $L=4,330 \lambda, c=6,0 \lambda, r_{0}=0,533 a$. In both cases, the remaining dimensions are the same ones used to obtain Fig. 3.8 (literature refers to [34]).

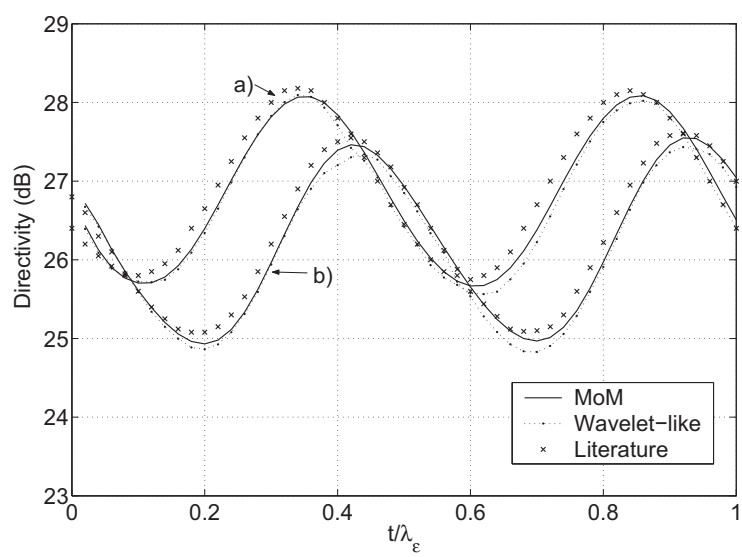

Figure 3.10: Directivity as function of the radome thickness $t$ for the example shown in Fig. 3.7. In a) $L=4,271 \lambda, c=5,984 \lambda, r_{0}=0,56 a$, and in b), $L=4,330 \lambda, c=6,0 \lambda, r_{0}=0,533 a$. In both cases, the remaining dimensions are the same ones used to obtain Fig. 3.8 (literature refers to [34]). 
than for a region far from the resonance. Increasing the number of basis functions, then, assures a good convergence of the method even close to the natural resonances of the structure. Alternatively, in order to solve this convergence problem, a regularization technique proposed in [18] can be employed to smooth the kernel of the integral equations close to singularities.

\subsubsection{Circular sandwich radome mounted on a telecom- munications tower with square basis}

The next example is taken from the cylindrical geometry typically employed in broadcasting towers considering hard weather conditions (see [24]). This example involves several elements, including a sandwiched circular radome, as shown in Fig. 3.11. In that case, the support of the tower is given by a fiberglass plastic reinforced radome that presents three layers. The core of low relative dielectric permittivity (foam) is made of a Rohacell ${ }^{\circledR}$ material, while the two side layers are made of thin fiberglass hard material, whose dielectric properties have been derived from the characteristics of a commercial fiber glass substrate, known as Pyrex ${ }^{\circledR}$. The complex sources present an equivalent directivity of $k_{0} b=2,6$, with $\mathbf{T E}^{z}$ polarization at a frequency of $800 \mathrm{MHz}$ (UHF band). The complex sources model accurately the directivity and the radiation performance of the real wire antennas mounted on a telecommunications tower.

In this analysis, we have first compared (see Fig. 3.12) the solution given by the conventional MoM with the wavelet-like results. The agreement between both data is very good, achieving a $95 \%$ of matrix sparsity, and a computational cost reduction factor of 6 , using a threshold of $0,5 \%$. The resulting error in the normalized magnetic field reconstruction has been in this case very low $(0,008 \%)$.

In order to assess the influence of the sandwiched radome in the radiation pattern of a realistic telecommunication tower, we have analyzed the same structure shown in Fig. 3.11 but with two different onelayer configurations. First, we have studied a radome composed only by the low permittivity foam material layer with its corresponding width $t_{2}$, whereas in the second case the layer is considered to be formed of a thin layer of fiberglass material of width $t_{1}$. In Fig. 3.13, we can see a considerable increase in the sidelobe levels of the antenna when 


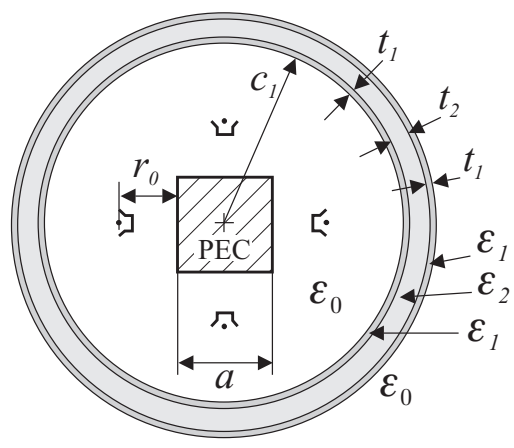

Figure 3.11: Circular dielectric 2-D radome with four complex source points and a square metallic base. The dimensions are: $t_{1}=1,8 \mathrm{~mm}$, $t_{2}=37,5 \mathrm{~mm}, c_{1}=0,82 \mathrm{~m}, a=0,41 \mathrm{~m}, r_{0}=93,7 \mathrm{~mm}, \varepsilon_{r_{1}}=4,7(1-$ $j 0,018)$ with $\varepsilon_{1}=\varepsilon_{r_{1}} \varepsilon_{0}, \varepsilon_{r_{2}}=1,07$ with $\varepsilon_{2}=\varepsilon_{r_{2}} \varepsilon_{0}$.

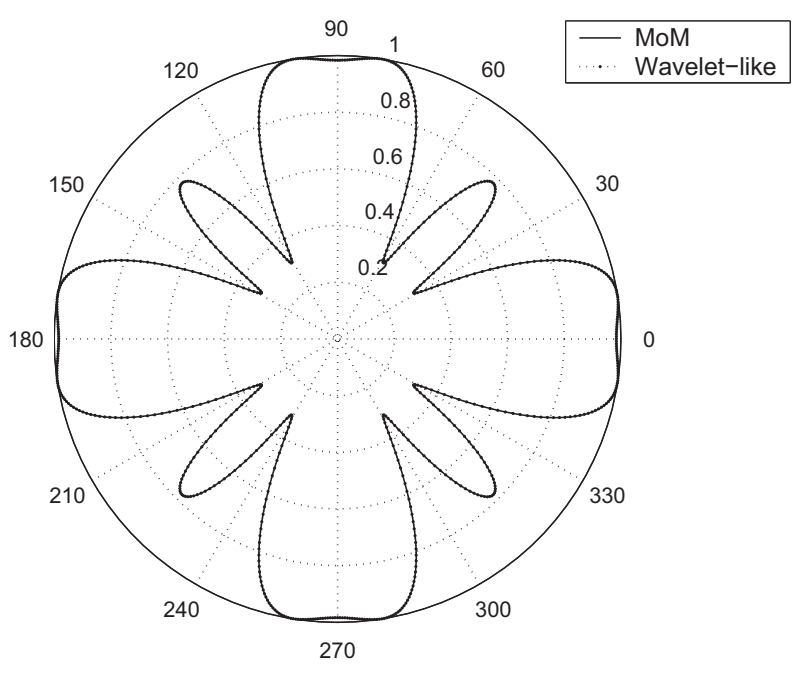

Figure 3.12: Normalized magnetic field produced by the structure shown in Fig. 3.11. The results for the sandwiched radome obtained with direct MoM are shown with solid line, and the ones obtained with the wavelet-like solution are represented by dotted symbols. 


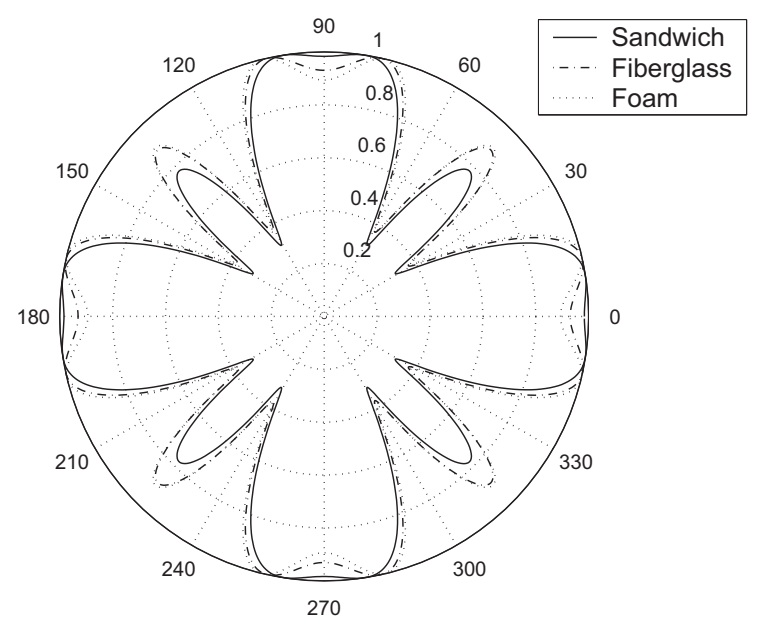

Figure 3.13: Normalized magnetic field produced by wavelet-like method for the original sandwiched radome (three layers) in solid line, and for two different simpler radomes. The dashed-dotted line shows the results obtained for a radome composed of only one layer of fiberglass material of width $t_{1}=1,8 \mathrm{~mm}$, while the dotted line shows the results when the single layer is made of foam with a width of $t_{2}=37,5 \mathrm{~mm}$.

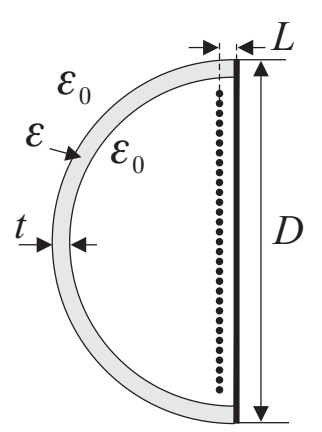

Figure 3.14: Dielectric half circular 2-D radome with a current array excitation and a back PEC finite plane. The dimensions are: $D=22 \lambda$, $t=0,2 \lambda, L=0,25 \lambda$ and $\varepsilon_{r}=4$ with $\varepsilon=\varepsilon_{r} \varepsilon_{0}$. 


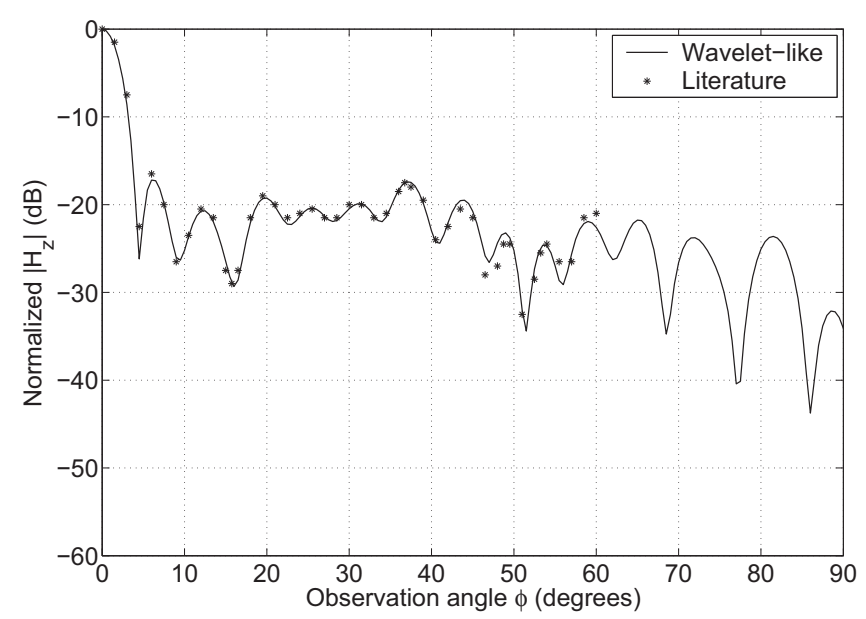

Figure 3.15: Normalized magnetic field obtained by the current array in the half-circular dielectric radome structure shown in Fig. 3.14 (literature refers to [29]).

the radome is modified. These results clearly show that a careful design of the radome considering the three layers of material is needed if low sidelobe levels are requested in a practical application.

\subsubsection{Half-circular dielectric shell with metallic back pla- te}

The following example considers a uniform phased array composed of 31 filaments, fed with cosine law amplitudes and with constant separation of $0,6 \lambda$ with $\mathbf{T E}^{z}$ polarization. The array is located inside a half dielectric circular shell with a finite metallic back plate, as shown in Fig. 3.14. A similar example was studied in [29] with the only difference that an infinite metallic back plate was used. The normalized electric field is shown in Fig. 3.15, where it is successfully compared with the analytical results given in [29]. The results compare very well for observation angles from $0^{\circ}$ to approximately $60^{\circ}$, where the effects of the finite back plate geometry begin to be important in a realistic scenario. In this case, the wavelet-like matrix sparsity is of $89 \%$, providing a reduction in computational cost of 6,8 using a threshold of $0,08 \%$. The 


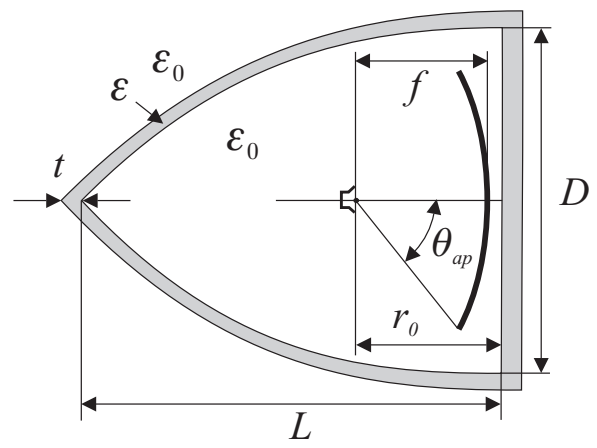

Figure 3.16: Dielectric 2-D radome with a complex source excitation and a parabolic metallic reflector. The dimensions are: $D=12 \lambda, L=14 \lambda$, $t=0,125 \lambda, f=4 \lambda, \theta_{a p}=45^{\circ}, r_{0}=5,875 \lambda, \varepsilon_{r}=2$ with $\varepsilon=\varepsilon_{r} \varepsilon_{0}$ and $k_{0} b=2,6$.

resulting error in the normalized electric field reconstruction has been of $0,03 \%$ when the wavelet-like technique is compared with the conventional MoM.

\subsubsection{Ogive radome with parabolic reflector}

An example considering a complex arbitrary radome surface is finally considered. A cylindrical parabolic reflector illuminated by a directive complex source with $\mathbf{T E}^{z}$ excitation is enclosed by an ogive-shaped radome. A similar problem has already been studied in [13]. The simulated structure has not been optimized, since the objective is to show that its analysis is possible using the proposed technique. In our case, the parametric curve for the ogive is taken from the superspheroidal profile $y^{2}=(D / 2 L)^{2}\left(L^{\nu}-x^{\nu}\right)^{2 / \nu}$, with $\nu=1,449$ (see [35]). The analysis has been performed including a parabolic reflector with the geometry shown in Fig. 3.16. The resulting normalized magnetic field is shown in Fig. 3.17. In this example, the number of unknowns is 4224 . The original sparsity before wavelet transformation is equal to $4,4 \%$, and the transformed matrix sparsity is equal to $94,5 \%$. The original computation cost is $195,5 \cdot 10^{9}$ floating point operations and the wavelet solution is achieved in $19,4 \cdot 10^{9}$ floating point operations, thus providing a reduction 


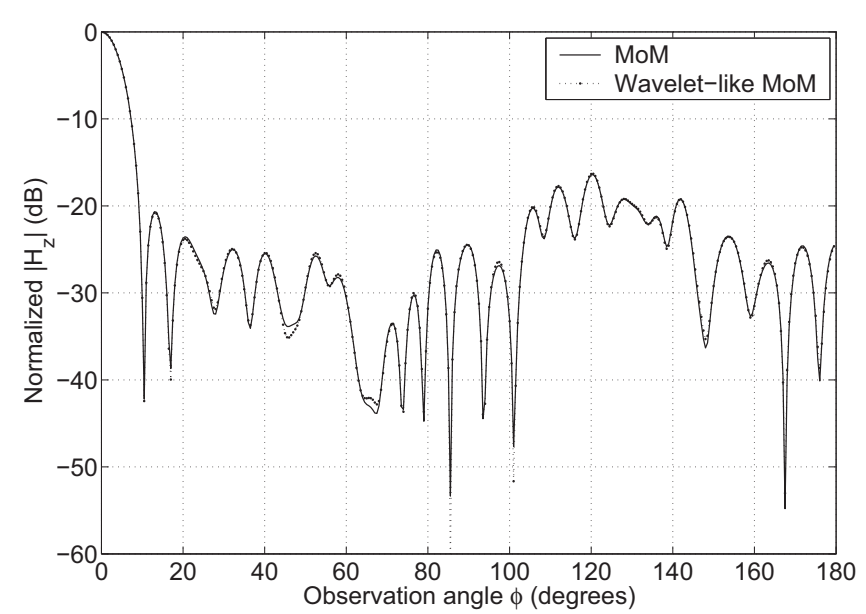

Figure 3.17: Normalized magnetic field obtained in the reflector-inradome structure shown in Fig. 3.16.

factor in computational cost of 10 , using a threshold of $0,07 \%$. The resulting error in the normalized magnetic field reconstruction has been of $0,01 \%$. This last result shows the versatility of the technique implemented, which leads to low error levels and large computational savings even for very complex antenna-radome structures. Then, some useful radome features may be easily obtained. In this example, the boresight error has been evaluated for gimbal angles up to 40 degrees, obtaining 0,3 degrees of maximum absolute error.

It is interesting to note the presence of a sharped nose in the considered ogive radome, which typically requires a finer meshing than the smoother boundaries in order to recover convergent results. This fact obviously involves additional CPU effort on the practical implementation of the proposed surface IE technique. In order to recover the convergent results shown in Fig. 3.17, the authors have observed that the number of unknowns in the sharp nose must be at least 2 times higher than those required by the smoother sections. 


\subsection{Conclusions}

This paper presents a surface formulation MoM solution for cylindrical complex radomes composed of multilayered lossy dielectric material with arbitrary shape, arbitrary reflector surfaces, and directive complex sources. It provides an accurate and efficient method to study any type of large radome structure, thanks to the use of the wavelet-like transform. The use of a surface formulation together with the application of the wavelet-like transform following a subblock scheme, converts the original problem into a highly sparse one exhibiting a strong banded structure. Results are given showing the accuracy and efficiency of the technique even for very complex radome-antenna structures. Therefore, this approach opens the possibility for the analysis of large and complex antenna-in-radome structures using a conventional computer.

\section{Appendix A: Details of the Integral Equation}

The continuity relations for the tangent components of the fields across an interface between two different homogenous media (see (3.4) and (3.5)) can be expanded in terms of their mixed-potentials expressions (see (3.1) and (3.2)), and the Green's functions of a homogenous medium with constitutive parameters $\left(\epsilon_{i}, \mu_{i}\right)$ (see (3.3)), yielding to a 
coupled system of integral equations, as follows:

$$
\begin{aligned}
& \hat{n} \times\left\{\vec{E}_{i}^{(e x c)}(\vec{\rho})-\frac{\omega \mu_{i}}{4} \int_{C} \vec{J}\left(\vec{\rho}^{\prime}\right) H_{0}^{(2)}\left(k_{i}\left|\vec{\rho}-\vec{\rho}^{\prime}\right|\right) d C^{\prime}\right. \\
& -\frac{1}{4 \omega \epsilon_{i}} \nabla \int_{C} \nabla^{\prime} \cdot \vec{J}\left(\vec{\rho}^{\prime}\right) H_{0}^{(2)}\left(k_{i}\left|\vec{\rho}-\vec{\rho}^{\prime}\right|\right) d C^{\prime} \\
& \left.-\frac{1}{4 j} \nabla \times \int_{C} \vec{M}\left(\vec{\rho}^{\prime}\right) H_{0}^{(2)}\left(k_{i}\left|\vec{\rho}-\vec{\rho}^{\prime}\right|\right) d C^{\prime}\right\}= \\
& \hat{n} \times\left\{\vec{E}_{i+1}^{(e x c)}(\vec{\rho})+\frac{\omega \mu_{i+1}}{4} \int_{C} \vec{J}\left(\vec{\rho}^{\prime}\right) H_{0}^{(2)}\left(k_{i+1}\left|\vec{\rho}-\vec{\rho}^{\prime}\right|\right) d C^{\prime}\right. \\
& +\frac{1}{4 \omega \epsilon_{i+1}} \nabla \int_{C} \nabla^{\prime} \cdot \vec{J}\left(\vec{\rho}^{\prime}\right) H_{0}^{(2)}\left(k_{i+1}\left|\vec{\rho}-\vec{\rho}^{\prime}\right|\right) d C^{\prime} \\
& \left.+\frac{1}{4 j} \nabla \times \int_{C} \vec{M}\left(\vec{\rho}^{\prime}\right) H_{0}^{(2)}\left(k_{i+1}\left|\vec{\rho}-\vec{\rho}^{\prime}\right|\right) d C^{\prime}\right\} \\
& \hat{n} \times\left\{\vec{H}_{i}^{(e x c)}(\vec{\rho})-\frac{\omega \epsilon_{i}}{4} \int_{C} \vec{M}\left(\vec{\rho}^{\prime}\right) H_{0}^{(2)}\left(k_{i}\left|\vec{\rho}-\vec{\rho}^{\prime}\right|\right) d C^{\prime}\right. \\
& -\frac{1}{4 \omega \mu_{i}} \nabla \int_{C} \nabla \nabla^{\prime} \cdot \vec{M}\left(\vec{\rho}^{\prime}\right) H_{0}^{(2)}\left(k_{i}\left|\vec{\rho}-\vec{\rho}^{\prime}\right|\right) d C^{\prime} \\
& \left.+\frac{1}{4 j} \nabla \times \int_{C} \vec{J}\left(\vec{\rho}^{\prime}\right) H_{0}^{(2)}\left(k_{i}\left|\vec{\rho}-\vec{\rho}^{\prime}\right|\right) d C^{\prime}\right\}= \\
& \hat{n} \times\left\{\vec{H}_{i+1}^{(e x c)}(\vec{\rho})+\frac{\omega \epsilon_{i+1}}{4} \int_{C} \vec{M}\left(\vec{\rho}^{\prime}\right) H_{0}^{(2)}\left(k_{i+1}\left|\vec{\rho}-\vec{\rho}^{\prime}\right|\right) d C^{\prime}\right. \\
& +\frac{1}{4 \omega \mu_{i+1}} \nabla \int_{C} \nabla^{\prime} \cdot \vec{M}\left(\vec{\rho}^{\prime}\right) H_{0}^{(2)}\left(k_{i+1}\left|\vec{\rho}-\vec{\rho}^{\prime}\right|\right) d C^{\prime} \\
& \left.-\frac{1}{4 j} \times \int_{C} \vec{J}\left(\vec{\rho}^{\prime}\right) H_{0}^{(2)}\left(k_{i+1}\left|\vec{\rho}-\vec{\rho}^{\prime}\right|\right) d C^{\prime}\right\} \\
& +3
\end{aligned}
$$

where $\vec{\rho}^{\prime}$ and $\vec{\rho}$ stand for the source and the observation points, whereas $\vec{J}\left(\vec{\rho}^{\prime}\right)$ and $\vec{M}\left(\vec{\rho}^{\prime}\right)$ are respectively the electric and magnetic equivalent surface current densities on a dielectric interface $C$ between media, 
with constitutive parameters $\left(\epsilon_{i}, \mu_{i}\right)$ and $\left(\epsilon_{i+1}, \mu_{i+1}\right)$. On the other hand, $\left(\vec{E}_{i}^{(e x c)}(\vec{\rho}), \vec{H}_{i}^{(e x c)}(\vec{\rho})\right)$ and $\left(\vec{E}_{i+1}^{(e x c)}(\vec{\rho}), \vec{H}_{i+1}^{(e x c)}(\vec{\rho})\right)$ are the excitation fields on each side of the dielectric interface delimited by contour $C$, and are produced by point complex sources and/or equivalent surface currents corresponding to other material interfaces.

On the other hand, the inner conducting reflectors are characterized by means of a Combined Field Integral Equation (CFIE) in order to avoid the internal resonance problem associated to either an Electric Field Integral Equation (EFIE) or a Magnetic Field Integral Equation (MFIE) (see [22]). The CFIE is a linear combination of an EFIE and an MFIE, where a parameter $\alpha$ is used to adjust the weight of each integral equation. Nevertheless, for the particular case of an open reflector, $\alpha$ is set to one, since an MFIE can not inherently be formulated for the electromagnetic analysis of closed conductors. The general expression for the CFIE used to analyze the inner reflector inside the radome is given below:

$$
\begin{aligned}
& \hat{n} \times\left\{\alpha \vec{E}_{i}^{(e x c)}(\vec{\rho})+(1-\alpha), \vec{H}_{i}^{(e x c)}(\vec{\rho})\right\}= \\
& \hat{n} \times\left\{\alpha \left[\frac{\omega \mu_{i}}{4} \int \vec{J}\left(\vec{\rho}^{\prime}\right) H_{0}^{(2)}\left(k_{i}\left|\vec{\rho}-\vec{\rho}^{\prime}\right|\right) d C^{\prime}\right.\right. \\
& \left.+\frac{1}{4 \omega \epsilon_{i}} \nabla \int \nabla^{\prime} \cdot \vec{J}\left(\vec{\rho}^{\prime}\right) H_{0}^{(2)}\left(k_{i}\left|\vec{\rho}-\vec{\rho}^{\prime}\right|\right) d C^{\prime}\right] \\
& \left.+(1-\alpha)\left[\vec{J}\left(\vec{\rho}^{\prime}\right) \times \hat{n}+\frac{1}{4 j} \nabla \times \int \vec{J}\left(\vec{\rho}^{\prime}\right) H_{0}^{(2)}\left(k_{i}\left|\vec{\rho}-\vec{\rho}^{\prime}\right|\right) d C^{\prime}\right]\right\}
\end{aligned}
$$

where $\vec{J}\left(\vec{\rho}^{\prime}\right)$ is the induced surface electric current density on the reflector contour $C$, placed inside an homogenous medium with constitutive parameters $\left(\epsilon_{i}, \mu_{i}\right)$. Moreover, $\left(\vec{E}_{i}^{(e x c)}(\vec{\rho}), \vec{H}_{i}^{(e x c)}(\vec{\rho})\right)$ are the electromagnetic fields imposed on the conducting body by complex sources and/or equivalent currents on an adjacent interface between media. This last step completes the integral equation formulation used for the analysis of the radome problems presented in the paper. 


\section{Acknowledgment}

This work has been supported by Ministerio de Educación y Ciencia, Spanish Government, under the Research Projects Ref. TEC2004/04313C02-01 and TEC2004/04313-C02-02.

\section{Bibliography}

[1] B. Alpert, G. Beylkin, R. Coifman, and V. Rokhlin. Wavelet-like bases for the fast solution of second-kind integral equations. SIAM J. Sci. Comp., 44(1):159-184, Enero 1993.

[2] E. Arvas and S. Ponnapalli. Scattering cross section of a small radome of arbitrary shape. IEEE Transactions on Antennas and Propagation, 37(5):655-658, Mayo 1989.

[3] Z. Baharav and Y. Leviatan. Impedance matrix compression (IMC) using iteratively selected wavelet basis. IEEE Transactions on Antennas and Propagation, 46(2):226-233, Febrero 1998.

[4] C. A. Balanis. Advanced Engineering Electromagnetics. John Wiley \& Sons, Toronto, 1989.

[5] J-H. Chang and K-K. Chan. Analysis of a two-dimensional radome of arbitrarily curved surface. IEEE Transactions on Antennas and Propagation, 38(10):1565-1568, Octubre 1990.

[6] Kun-Mu Chen. A mathematical formulation of the equivalence principle. IEEE Transactions on Microwave Theory and Techniques, 37(10), Octubre 1989.

[7] Clayton P. Davis and Karl F. Warnick. Error analysis of 2-d mom for mfie/efie/cfie based on the circular cylinder. IEEE Transactions on Antennas and Propagation, 53(1):321-331, Enero 2005.

[8] D.-W. Duan, Y. Rahmat-Samii, and J. P. Mahon. Scattering from a circular disk: a comparative study of PTD and GTD techniques. Proceedings of the IEEE, 79(10):1472-1480, Octubre 1991. 
[9] X. J. Gao and L. B. Felsen. Complex ray analysis of beam transmission through two-dimensional radomes. IEEE Transactions on Antennas and Propagation, 33(9):963-975, Septiembre 1985.

[10] G. L. Hower, R. G. Olsen, J. D. Earls, and J. B. Schneider. Inaccuracies in numerical calculation of scattering near natural frequencies of penetrable objects. IEEE Transactions on Antennas and Propagation, 41(7):982-986, Julio 1993.

[11] C.G. Hsu and H. A. Auda. Multiple dielectric posts in a rectangular waveguide. IEEE Transactions on Microwave Theory and Techniques, 34(8):883-891, Agosto 1986.

[12] A. A. Kishk and Lotfollah Shafai. Different formulations for numerical solution of single or multibodies of revolution with mixed boundary conditions. IEEE Transactions on Antennas and Propagation, 34(5):666-673, Mayo 1986.

[13] S. V. Kukobko, A. Z. Sazonov, and I. O. Sukharevsky. Electrodynamic calculation method for two-dimensional model of a doublereflector antenna system with a nose dielectric radome. Radio Phisics and Radio Astronomy, 10(2):157-165, Mayo 2005.

[14] J.-Y. Li and L.-W. Li. Characterizing scattering by 3-D arbitrarily shaped homogeneous dielectric objects using fast multipole method. IEEE Antennas and Wireless Propagation Letters, 3:1-4, 2004.

[15] C-C. Lu. A fast algorithm based on volume integral equation for analysis of arbitrarily shaped dielectric radomes. IEEE Transactions on Antennas and Propagation, 51(3):606-612, Marzo 2003.

[16] J.R. Mautz and R F Harrington. Electromagnetic scattering from a homogeneous body of revolution. A.E.U., 33:71-80, 1979.

[17] C. Müller. Foundations of the Mathematical Theory of Electromagnetic Waves. Springer-Verlag, Berlin, 1969.

[18] Alexander I. Nosich. The method of analytical regularization in wave- scattering and eigenvalue problems: Foundations and review of solutions. IEEE Antennas and Propagation Magazine, 41(3):982-986, Junio 1999. 
[19] T. Oguzer. Analysis of circular reflector antenna covered by concentric dielectric radome. IEEE Transactions on Antennas and Propagation, 49(3):458-463, Marzo 2001.

[20] T. Oguzer, A. Altintas, and A. Nosich. Accurate simulation of reflector antennas by the complex source-dual series approach. IEEE Transactions on Antennas and Propagation, 43(8):793-801, Agosto 1995.

[21] T. Oguzer, A. Nosich, and A. Altintas. Analysis of an arbritrary conic section profile cylindrical reflector antenna, H-polarization case. IEEE Transactions on Antennas and Propagation, 52(11):31563162, Noviembre 2004.

[22] A. F. Peterson, S. L. Ray, and R. Mittra. Computational Methods for Electromagnetics. IEEE Press, New York, 1998.

[23] A. J. Poggio and E. K. Miller. Integral Equation Solutions of Threedimensional Scattering Problems. Pergamon Press, Oxford, 1973.

[24] A. Sadigh and E. Arvas. Deformation of the horizontal radiation pattern of TV transmitting antennas due to thin dielectric radome. IEEE Transactions on Antennas and Propagation, 40(8):942-949, Agosto 1992.

[25] T. K. Sarkar and K. Kim. Solution of large dense complex matrix equations utilizing wavelet-like transforms. IEEE Transactions on Antennas and Propagation, 47(10):1628-1632, Octubre 1999.

[26] T. K. Sarkar, M. Salazar-Palma, and M. C. Wicks. Wavelet Applications in Engineering Electromagnetics. Artech House, Norwood MA, 2002.

[27] B. Z. Steinberg and Y. Leviatan. On the use of wavelet expansions in the method of moments. IEEE Trans. Antennas Propagation, 41(5):610-619, Mayo 1993.

[28] G. A. Suedan and E. V. Jull. Beam difreaction by planar and parabolic reflectors. IEEE Transactions on Antennas and Propagation, 39(4):521-527, Abril 1991. 
[29] O. I. Sukharevsky, S. V. Kukobko, and A. Z. Sazonov. Volume integral equation analysis of a two-dimensional radome with a sharp nose. IEEE Transactions on Antennas and Propagation, 53(4):15001506, Abril 2005.

[30] A. Y. Svezhentsev, A. I. Nosich, and T. Oguzer. Simulation of reflector antenna covered by a circular radome. In ICAP'95 Ninth International Conference on Antennas and Propagation, pages 532-535, Abril 1995.

[31] A. Vidal, A. Belenguer, H. Esteban, V. E. Boria, C. Bachiller, and $\mathrm{M}$. Taroncher. Efficient and accurate spectral analysis of large scattering problems using wavelet and wavelet-like bases. Radio Science, 39(5):5.1-5.17, Octubre 2004.

[32] R. L. Wagner and W. C. Chew. A study of wavelets for the solution of electromagnetic integral equations. IEEE Trans. Antennas Propagation, 43(8):802-810, Agosto 1995.

[33] Gaofeng Wang. A hybrid wavelet expansion and boundary element analysis of electromagnetic scattering from conducting objects. IEEE Trans. Antennas Propagation, 43(2):170-178, Febrero 1995.

[34] V. Yurchenko, A. Altintas, and A. Nosich. Numerical optimization of a cylindrical reflector-in-radome antenna system. IEEE Transactions on Antennas and Propagation, 47(4):668-673, Abril 1999.

[35] W-J. Zhao, L-W. Li, and Y-B Gan. Efficient analysis of antenna radiation in the presence of airborne dielectric radomes of arbitrary shape. IEEE Transactions on Antennas and Propagation, 53(1):442449, Enero 2005. 



\title{
4 \\ CAD Of Complex Passive Devices Composed of Arbitrarily Shaped Waveguides using Nyström and BI-RME Methods
}

\section{Authors}

Máriam Taroncher, Ana Vidal, Vicente E. Boria, Stephan Marini, Santiago Cogollos, Jordi Gil and Benito Gimeno.

\begin{abstract}
In this paper, a novel Computer-Aided Design (CAD) tool of complex passive microwave devices in waveguide technology is proposed. Such a tool is based on a very efficient Integral Equation (IE) analysis technique that provides a full-wave characterization of discontinuities between arbitrarily shaped waveguides defined by linear, circular and/or elliptical arcs. For solving the modal analysis of such arbitrary waveguides, a modified version of the well-known Boundary Integral Resonant Mode Expansion (BI-RME) method using the Nyström approach, instead of the traditional Galerkin version of the Method of
\end{abstract}


Moments (MoM), is proposed, thus providing significant savings on computational costs and implementation complexity. The novel theoretical aspects of this Nyström approach, as well as their impact on the original BI-RME formulation, are fully described. Comparative benchmarks between this new technique and the classical BI-RME formulation using Galerkin are successfully presented for the full-wave analysis of frequently used irises (i.e. rectangular cross-shaped and circular multi-ridged), and for the CAD of complex waveguide components (such as rectangular waveguide filters considering mechanization effects and dual-mode circular waveguide filters with elliptical irises).

\subsection{Introduction}

Arbitrarily shaped waveguides, whose cross-sections are defined by a combination of linear, circular and/or elliptical waveguides, are increasingly used in passive waveguide components (e.g. filters, diplexers and multiplexers, directional couplers, power dividers and combiners, orthomode transducers, polarizers, twisters and mode-launchers) [24]. Most available CAD tools used for such devices are based on numerical meshing techniques, i.e. the Finite-Element (FE) method [18], the Finite-Difference Time-Domain (FDTD) method [20] and the Transmission Line Matrix (TLM) method [14], which do have strong requirements on CPU time and memory storage. To alleviate these problems, several modal methods, such as those based on the Generalized Scattering, Admittance or Impedance Matrices (GSMs, GAMs and GIMs), have been successfully proposed [8].

The above mentioned modal methods do always require to know the complete modal chart (cutoff frequencies) of the involved arbitrarily shaped waveguides, as well as the coupling integrals between the modal vectors of such cascaded waveguides. Among the many different approaches proposed in the technical literature for the modal chart computation, the well-known BI-RME method has revealed to provide very accurate results in short computation times [7]. Recently, this method has been revisited in order to cope with arbitrary profiles defined by the combination of linear, circular and/or elliptical waveguides [6]. Another advantage of the BI-RME technique is that, without hardly additional CPU effort, the coupling coefficients between the arbitrarily- 
shaped waveguide and a standard rectangular contour enclosing the arbitrary profile can be computed (see [2] and [4]).

Both practical BI-RME implementations described in [7] and [6] are based on the Galerkin version of the MoM [13], where the basis and testing functions are chosen to be overlapping piece-wise parabolic splines. Such choice do obviously introduce additional complexities to the practical solution of the BI-RME integral equations: first, the contribution of each parabolic piece to several matrix entries must be carefully accounted for (see [7]), and secondly, the connection of different types of segments (linear, circular and elliptical ones) must be treated as described in [6]. Furthermore, following the Galerkin approach, the regular terms of the BI-RME matrix elements become single and double integrals that can be solved numerically via a Gauss quadrature rule (see [6]), which can require a large number of integrand evaluations for high-accuracy applications. An alternative way to solve the cited integral equations, thus avoiding the previous restrictions related to the Galerkin approach, is the so called Nyström method, described in [11]. This solution is much simpler than the Galerkin scheme since each matrix entry in the eigenvalue problem does only involve a function evaluation. However, the main disadvantage is that the Nyström method tends to increase the singularity problems that also arise with Galerkin.

The Nyström method is a simple and efficient point-based segmentation solution for solving IEs, where integrals are approximated by weighted sums of function evaluations:

$$
\int f(x) d s=\sum_{j=1}^{N} q_{j} f\left(x_{j}\right)
$$

When IEs involve singular kernels [11], it is necessary to adapt locally the quadrature weights $q_{j}$ to the singularity regions [10,17]. In this work, the new formulation leads to singular and hyper-singular operators (TE case of the BI-RME formulation), that are specifically treated. The authors have firstly proposed the application of the Nyström and BI-RME methods to the modal chart determination of arbitrarily shaped waveguides in [23, 22], where no theoretical details about the hyper-singularity treatment of the TE case are explicitly given.

This paper describes the fast and simple implementation of the Nyström-based BI-RME method for the accurate analysis of passive devices 


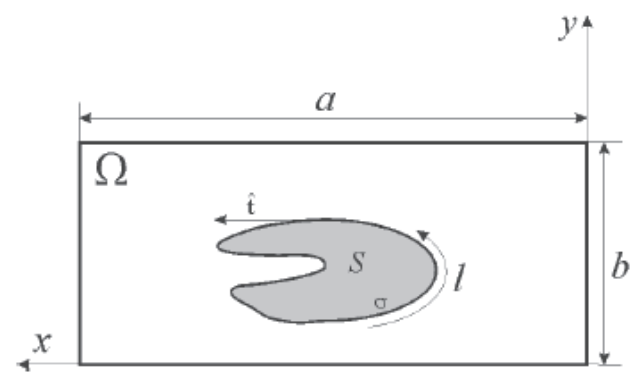

Figure 4.1: Arbitrarily shaped waveguide (with cross section $S$ ) to be analyzed by the combination of Nyström and BI-RME methods.

composed of waveguides with arbitrary contours (defined by linear, circular and/or elliptical arcs). The integration of such method within a CAD tool of complex passive devices, which is based on the characterization of waveguide discontinuities by means of an integral equation technique described in [12], is also discussed in this work. Making use of the novel Nyström approach proposed, the complete modal charts of a rectangular cross-shaped iris, and of a multi-ridged circular waveguide, have been successfully computed. The more efficient CAD tool developed has been used in the accurate design of an inductively coupled rectangular waveguide filter considering rounded corners, and a dualmode filter in circular waveguide with elliptical irises and triangular tuning elements. The gain in efficiency while preserving accuracy due to the Nyström approach has been successfully measured by comparing our results with those provided by the Galerkin solution.

\subsection{Nyström Formulation}

In this section, the formulation related to the combination of the Nyström and BI-RME methods is fully described. The arbitrarily shaped waveguide to be considered has a cross-section defined by a combination of linear, circular, and/or elliptical arcs (see $S$ in Fig. 4.1). The arbitrary contour $\sigma$ of such waveguide (defined by the tangent vector $\widehat{\mathbf{t}}$ and a suitable abscisa $l$ also shown in Fig. 4.1) must be completely enclosed within a standard rectangular waveguide of cross-section $\Omega$. 
To characterize the arbitrary waveguides under consideration, we will only present the novel theoretical aspects related to the application of the Nyström method. Special emphasis will be given to the suitable treatment of the singular integrals that appear in some BI-RME matrix elements.

\subsubsection{TM Modes}

The longitudinal component of the electric field at a generic observation point $\mathbf{r}$ inside $S$ (see Fig. 4.1) may be represented as follows (cf. (7) in [7])

$$
\begin{array}{r}
E_{z}(\mathbf{r})=-j \eta k^{\prime} \int_{\sigma} g\left(\mathbf{r}, \mathbf{s}^{\prime}\right) J_{z}\left(l^{\prime}\right) d l^{\prime} \\
-j \eta k^{\prime 3} \sum_{m=1}^{M^{\prime}} \frac{\psi_{m}^{T M \square}(\mathbf{r})}{h_{m}^{\prime 2}\left(h_{m}^{\prime 2}-k^{\prime 2}\right)} \int_{\sigma} \psi_{m}^{T M \square}\left(\mathbf{s}^{\prime}\right) J_{z}\left(l^{\prime}\right) d l^{\prime}
\end{array}
$$

where $g\left(\mathbf{r}, \mathbf{s}^{\prime}\right)$ is the rapidly convergent scalar two-dimensional Green's function and $J_{z}\left(l^{\prime}\right)$ is the longitudinal component of the current density $\mathbf{J}_{\sigma}$. Moreover, $h_{m}^{\prime}$ and $\psi_{m}^{T M \square}$ are, respectively, the cutoff wavenumber and normalized scalar potential of the $m$-th TM mode of the surrounding standard rectangular waveguide ( $\Omega$ in Fig. 4.1).

To compute the TM modes, first the boundary condition for the axial component of the electric field $\left(E_{z}=0\right)$ is imposed on $\sigma$. Then, the arbitrary contour $\sigma$ is segmented following the Nyström method, where the central point $\mathbf{s}_{j}$ and the length of a segment $\omega_{j}$ are only needed. With the Nyström approach, the integral is approximated at each point by a simple 1-point trapezoidal quadrature, being the quadrature weights equal to the length of the segments of the discretization $\omega_{j}$, as described in [1]. The scalar Green function $g\left(\mathbf{s}_{i}, \mathbf{s}_{j}\right)$ is singular when the discrete source $\left(\mathbf{s}_{j}\right)$ and observation points $\left(\mathbf{s}_{i}\right)$ coincide. In such a case, the contribution of the segment $\sigma_{i}$ that produces the singularity is isolated and 
treated separately. Then, the following system of equations is obtained

$$
\begin{gathered}
\sum_{\substack{j=1 \\
j \neq i}}^{N} \omega_{j} g\left(\mathbf{s}_{i}, \mathbf{s}_{j}\right) J_{z}\left(l_{j}\right)+\int_{\sigma_{i}} g\left(\mathbf{s}_{i}, \mathbf{s}^{\prime}\right) J_{z}\left(l^{\prime}\right) d l^{\prime} \\
+\sum_{m=1}^{M^{\prime}} \frac{\psi_{m}^{T M \square}\left(\mathbf{s}_{i}\right)}{h_{m}^{\prime 2}} a_{m}^{\prime}=0 \\
\left(1-\frac{k^{\prime 2}}{h_{m}^{\prime 2}}\right) \cdot a_{m}^{\prime}=k^{\prime 2} \sum_{j=1}^{N} \omega_{j} \frac{\psi_{m}^{T M \square}\left(\mathbf{s}_{j}\right)}{h_{m}^{\prime 2}} J_{z}\left(\mathbf{s}_{j}\right)
\end{gathered}
$$

where $N$ is the number of points used for the segmentation of the perturbed contour.

Equations (4.3)-(4.4) lead to an eigenvalue problem similar to the one obtained with the original Galerkin-based BI-RME formulation, which can be expressed in matrix form as

$$
\left\{\left[\begin{array}{ll}
\mathbf{U} & \mathbf{O}_{\mathbf{t}} \\
\mathbf{O} & \mathbf{O}^{\prime}
\end{array}\right]-k^{\prime 2}\left[\begin{array}{cc}
\mathbf{D}^{\prime} & \mathbf{R}_{\mathbf{t}}^{\prime} \\
\mathbf{R}^{\prime} & \mathbf{L}^{\prime}
\end{array}\right]\right\}\left[\begin{array}{l}
\mathbf{a}^{\prime} \\
\mathbf{b}^{\prime}
\end{array}\right]=0
$$

where $\mathbf{U}$ is the $M^{\prime} \times M^{\prime}$ unitary matrix, $\mathbf{O}$ is the $N \times M^{\prime}$ null matrix and $\mathbf{O}^{\prime}$ is the $N \times N$ null matrix. The detailed expressions for the other matrices are

$$
\begin{gathered}
\mathbf{D}^{\prime}=\operatorname{diag}\left(h_{1}^{\prime-2}, h_{2}^{\prime-2}, \ldots, h_{M}^{\prime-2}\right) \\
L_{i j}^{\prime}=g\left(\mathbf{s}_{i}, \mathbf{s}_{j}\right), i \neq j ; \quad L_{i i}^{\prime}=\frac{1}{\omega_{i}} \int_{\sigma_{i}} g\left(\mathbf{s}_{i}, \mathbf{s}^{\prime}\right) d l^{\prime} \\
R_{i m}^{\prime}=\frac{\psi_{m}^{T M \square}\left(\mathbf{s}_{i}\right)}{h_{m}^{\prime 2}} \\
i, j=1,2, \ldots, N \quad m=1,2, \ldots, M^{\prime}
\end{gathered}
$$

It must be noticed that the expressions for the elements of the $L^{\prime}$ and $R^{\prime}$ matrices are different to the equivalent ones deduced for the Galerkin approach (cf. (16b) and (16c) in [7]), and their new computation is much more efficient and simpler.

In the generalized eigenvalue problem defined by (4.5), $\mathbf{a}^{\prime}$ is a column vector including the modal coefficients $a_{m}^{\prime}$, whereas $\mathbf{b}^{\prime}$ contains 
the terms $b_{j}^{\prime}=\omega_{j} J_{z}\left(\mathbf{s}_{j}\right)$, where the quadrature weights have been included to preserve the symmetry of the involved matrices. The solution of the eigenvalue problem $\left(k^{\prime}\right)$ are the TM cutoff wavenumbers of the arbitrary waveguide.

As it happens with the Galerkin solution of the BI-RME method, the previous TM generalized eigenvalue problem can also be cast into the following standard form

$$
\left(\mathbf{D}^{\prime}-\mathbf{R}_{\mathbf{t}}^{\prime} \mathbf{L}^{\prime-1} \mathbf{R}^{\prime}\right) \mathbf{a}^{\prime}=k^{\prime-2} \mathbf{a}^{\prime}
$$

Finally, we must focus on the accurate computation of the diagonal elements $\left(L_{i i}^{\prime}\right)$ of the $\mathbf{L}^{\prime}$ matrix, which must cope with the singularity due to the evaluation of the scalar Green function with coincident observation and source points. In this case, a similar procedure to the one described in [6] for the Galerkin approach will be followed. First, the original scalar two-dimensional Green function can be split into a regular $\left(g_{r}\right)$ and a singular expression. Then, this singular expression is regularized following the technique explained in [25], giving as a final result a regular part of the singular expression $g_{r s}$ and a final singular term $g_{s}$ that can be analytically integrated. Consequently, the following expression for the diagonal elements of the $\mathbf{L}^{\prime}$ matrix is obtained in our case

$$
\begin{aligned}
L_{i i}^{\prime} & =\left[g_{r}\left(\mathbf{s}_{i}, \mathbf{s}_{i}\right)+g_{r s}\left(\mathbf{s}_{i}, \mathbf{s}_{i}\right)\right]+\frac{1}{\omega_{i}} \int_{\sigma_{i}} g_{s}\left(\mathbf{s}_{i}, \mathbf{s}^{\prime}\right) d l^{\prime} \\
& =L_{i i r}^{\prime}+L_{i i s}^{\prime}
\end{aligned}
$$

where the regular term $L_{i i r}^{\prime}$ can be directly computed, and the singular integral $L_{i i s}^{\prime}$ must be analytically solved. It should be noted that the integral solution depends on the geometry of the segment $\sigma_{i}$ (linear, circular or elliptical geometry), whose detailed expressions for each kind of arc is given below.

\section{Linear arcs}

$$
L_{i i s}^{\prime}=-\frac{1}{2 \pi}\left[\ln \left(\frac{\omega_{i}}{2}\right)-1\right]
$$




\section{Circular arcs}

$$
L_{i i s}^{\prime}=-\frac{1}{2 \pi}\left[\ln \left(\frac{\omega_{i}}{2}\right)-1\right]
$$

\section{Elliptical arcs}

$$
\begin{aligned}
L_{i i s}^{\prime}= & -\frac{1}{4 \pi} \ln \left(a^{2} \sin ^{2} \eta_{m i}+b^{2} \cos ^{2} \eta_{m i}\right) \\
& -\frac{\gamma}{4 \pi} \frac{\left|\Delta \eta_{i}\right| a}{\omega_{i}}\left[\ln \left(\frac{\left|\Delta \eta_{i}\right|}{2}\right)-1\right]
\end{aligned}
$$

where $\gamma=\sqrt{1-e^{2} \cos ^{2} \eta_{m i}}, \Delta \eta_{i}=\eta_{2 i}-\eta_{1 i}$ and $\eta_{m i}=0,5\left(\eta_{1 i}+\eta_{2 i}\right)$, being $\eta_{1 i}$ and $\eta_{2 i}$ the elliptical parametric initial and final angles for $\sigma_{i}$ as defined in [6].

If the arbitrary waveguide supports TEM modes, the Nyström approach just outlined can be also employed for solving such problem. Following the same procedure explained in [7], the TEM solution may be obtained from a linear system of equations that involves the $L^{\prime}$ matrix.

\subsubsection{TE Modes}

The transversal component of the electric field at a generic observation point $\mathbf{r}$ inside $S$ (see Fig. 4.1) may be represented as follows (c.f. (6) in [7])

$$
\begin{array}{r}
\mathbf{E}_{t}(\mathbf{r})=j \frac{\eta}{k} \int_{\sigma} \nabla \frac{\partial g\left(\mathbf{r}, \mathbf{s}^{\prime}\right)}{\partial l^{\prime}} J_{t}\left(l^{\prime}\right) d l^{\prime} \\
-j \eta k \int_{\sigma} \overline{\mathbf{G}}_{s t}\left(\mathbf{r}, \mathbf{s}^{\prime}\right) \cdot \widehat{\mathbf{t}}\left(l^{\prime}\right) J_{t}\left(l^{\prime}\right) d l^{\prime} \\
-j \eta k^{3} \sum_{m=1}^{M} \frac{\mathbf{e}_{m}^{T E^{\square}}(\mathbf{r})}{h_{m}^{2}\left(h_{m}^{2}-k^{2}\right)} \int_{\sigma} \mathbf{e}_{m}^{T E^{\square}}\left(\mathbf{s}^{\prime}\right) \cdot \widehat{\mathbf{t}}\left(l^{\prime}\right) J_{t}\left(l^{\prime}\right) d l^{\prime}
\end{array}
$$

where $\overline{\mathbf{G}}_{s t}\left(\mathbf{r}, \mathbf{s}^{\prime}\right)$ is the solenoidal dyadic Green function and $J_{t}\left(l^{\prime}\right)$ is the transversal component of the unknown current density $\mathbf{J}_{\sigma}$. On the other 
hand, $h_{m}$ and $\mathbf{e}_{m}^{T E^{\square}}$ are, respectively, the cutoff wavenumber and normalized transversal electric field of the $m$-th TE mode of the surrounding standard rectangular waveguide related to the BI-RME method.

To compute the TE modes, first the boundary condition to the tangential component of the electric field $\left(\mathbf{E}_{t} \cdot \widehat{\mathbf{t}}=0\right)$ is imposed on $\sigma$. It should be noticed that the evaluation of the first term of (4.14) requires the numerical computation of a double partial derivative of $g$ with respect to the observation and source contour parameters $l$ and $l^{\prime}$. The derivatives of the Green functions are usually avoided in the literature (see [17]) because they present stronger singularities than the original functions. However, the double derivative of the scalar Green function has been obtained and accelerated as shown in Appendix 4.5. Such double derivative presents a hypersingularity, that has been treated via the traditional method of adding and subtracting an asymptotic term $[11,10]$ :

$$
\int_{\sigma} \frac{\partial^{2} g\left(\mathbf{s}, \mathbf{s}^{\prime}\right)}{\partial l \partial l^{\prime}}\left[J_{t}\left(l^{\prime}\right)-J_{t}(l)\right] d l^{\prime}+J_{t}(l) \int_{\sigma} \frac{\partial^{2} g\left(\mathbf{s}, \mathbf{s}^{\prime}\right)}{\partial l \partial l^{\prime}} d l^{\prime}
$$

where it can be easily proved that the second term is equal to zero when the arbitrary geometry is composed of closed contours and / or arcs connected to the surrounding standard waveguide, which applies to the considered devices.

Once this treatment is employed in the application of the Nyström method, the following expressions are obtained

$$
\begin{array}{r}
\frac{1}{k^{2}} \sum_{\substack{j=1 \\
j \neq i}}^{N} \omega_{j} \frac{\partial^{2} g\left(\mathbf{s}_{i}, \mathbf{s}_{j}\right)}{\partial l \partial l^{\prime}}\left[J_{t}\left(\mathbf{s}_{j}\right)-J_{t}\left(\mathbf{s}_{i}\right)\right] \\
-\sum_{\substack{j=1 \\
j \neq i}}^{N} \omega_{j} \widehat{\mathbf{t}}\left(\mathbf{s}_{i}\right) \cdot \overline{\mathbf{G}}_{s t}\left(\mathbf{s}_{i}, \mathbf{s}_{j}\right) \cdot \widehat{\mathbf{t}}\left(\mathbf{s}_{j}\right) J_{t}\left(\mathbf{s}_{j}\right) \\
-\int_{\sigma_{i}} \widehat{\mathbf{t}}\left(\mathbf{s}_{i}\right) \cdot \overline{\mathbf{G}}_{s t}\left(\mathbf{s}_{i}, \mathbf{s}^{\prime}\right) \cdot \widehat{\mathbf{t}}\left(l^{\prime}\right) J_{t}\left(l^{\prime}\right) d l^{\prime} \\
\quad-\sum_{m=1}^{M} \frac{\mathbf{e}_{m}^{T E \square}\left(\mathbf{s}_{i}\right) \cdot \widehat{\mathbf{t}}\left(\mathbf{s}_{i}\right)}{h_{m}^{2}} a_{m}=0
\end{array}
$$




$$
\left(1-\frac{k^{2}}{h_{m}^{2}}\right) \cdot a_{m}=k^{2} \sum_{j=1}^{N} \omega_{j} \frac{\mathbf{e}_{m}^{T E \square}\left(\mathbf{s}_{j}\right) \cdot \widehat{\mathbf{t}}\left(\mathbf{s}_{j}\right)}{h_{m}^{2}} b_{j}
$$

that can be cast into matrix form as

$$
\left\{\left[\begin{array}{cc}
\mathbf{U} & \mathbf{O}_{\mathbf{t}} \\
\mathbf{O} & \mathbf{C}
\end{array}\right]-k^{2}\left[\begin{array}{cc}
\mathbf{D} & \mathbf{R}_{\mathbf{t}} \\
\mathbf{R} & \mathbf{L}
\end{array}\right]\right\}\left[\begin{array}{l}
\mathbf{a} \\
\mathbf{b}
\end{array}\right]=0
$$

where $\mathbf{U}$ is the $M \times M$ unitary matrix and $\mathbf{O}$ is the $N \times M$ null matrix. The expressions for the other matrices that compose the eigenvalue problem are

$$
\begin{gathered}
\mathbf{D}=\operatorname{diag}\left(h_{1}^{-2}, h_{2}^{-2}, \ldots, h_{M}^{-2}\right) \\
C_{i j}=\frac{\partial^{2} g\left(\mathbf{s}_{i}, \mathbf{s}_{j}\right)}{\partial l \partial l^{\prime}}, i \neq j ; \\
C_{i i}=-\frac{1}{\omega_{i}} \sum_{\substack{j=1 \\
j \neq i}}^{N} \omega_{j} \frac{\partial^{2} g\left(\mathbf{s}_{i}, \mathbf{s}_{j}\right)}{\partial l \partial l^{\prime}} \\
L_{i j}=\widehat{\mathbf{t}}\left(\mathbf{s}_{i}\right) \cdot \overline{\mathbf{G}}_{s t}\left(\mathbf{s}_{i}, \mathbf{s}_{j}\right) \cdot \widehat{\mathbf{t}}\left(\mathbf{s}_{j}\right), i \neq j ; \\
L_{i i}=\frac{1}{\omega_{i}} \int_{\sigma_{i}} \widehat{\mathbf{t}}\left(\mathbf{s}_{i}\right) \cdot \overline{\mathbf{G}}_{s t}\left(\mathbf{s}_{i}, \mathbf{s}^{\prime}\right) \cdot \widehat{\mathbf{t}}\left(l^{\prime}\right) d l^{\prime} \\
R_{i m}=\frac{\mathbf{e}_{m}^{T E \square}\left(\mathbf{s}_{i}\right) \cdot \widehat{\mathbf{t}}\left(\mathbf{s}_{i}\right)}{h_{m}^{2}} \\
i, j=1,2, \ldots, N \quad m=1,2, \ldots, M
\end{gathered}
$$

The solution of (4.18) provides as eigenvectors the modal coefficients $\left(a_{m}\right)$ and the amplitudes of the transversal current density in the discrete points of the contour modified by the quadrature weights (i.e. $\left.b_{j}=w_{j} J_{t}\left(\mathbf{s}_{j}\right)\right)$, and as eigenvalues the TE cutoff wavenumbers $(k)$ of the arbitrary waveguide.

When computing the $L_{i i}$ elements according to (4.21b), the singular contribution of the function $\overline{\mathbf{G}}_{s t}$ must be carefully considered. The dyadic Green function is composed of four components, $\bar{G}_{s t}^{x x}, \bar{G}_{s t}^{x y}, \bar{G}_{s t}^{y x}$ and $\bar{G}_{s t}^{y y}$. Two of them, $\bar{G}_{s t}^{x y}$ and $\bar{G}_{s t}^{y x}$, do no contribute with any singularity, 
whereas the singularities introduced by $\bar{G}_{s t}^{x x}$ and $\bar{G}_{s t}^{y y}$ are of the same kind as considered previously for the TM case. Therefore, the same technique proposed before for the rigorous treatment of the singularities can also be followed, but considering in this case the unitary tangent vector $\widehat{\mathbf{t}}$ present in (4.21b). In this case, the singular integrals $L_{i i s}$ are defined as

$$
\begin{aligned}
L_{i i s}^{x x} & =\frac{1}{\omega_{i}} \int_{\sigma_{i}} t_{x}\left(\mathbf{s}_{i}\right) \cdot \bar{G}_{s t}^{x x}\left(\mathbf{s}_{i}, \mathbf{s}^{\prime}\right) \cdot t_{x}\left(l^{\prime}\right) d l^{\prime} \\
L_{i i s}^{y y} & =\frac{1}{\omega_{i}} \int_{\sigma_{i}} t_{y}\left(\mathbf{s}_{i}\right) \cdot \bar{G}_{s t}^{y y}\left(\mathbf{s}_{i}, \mathbf{s}^{\prime}\right) \cdot t_{y}\left(l^{\prime}\right) d l^{\prime}
\end{aligned}
$$

whose analytical solution for each kind of arcs is just given below.

\section{Linear arcs}

$$
\begin{array}{r}
L_{i i s}^{x x}=\xi_{1} \cos ^{2} \theta ; \quad L_{i i s}^{y y}=\xi_{1} \sin ^{2} \theta \\
\xi_{1}=-\frac{1}{4 \pi} \ln \left(\frac{\omega_{i}}{2}\right)-1
\end{array}
$$

where $\theta$ is the angle between the linear arc and the $\hat{\mathbf{x}}$ axis.

\section{Circular arcs}

$$
\begin{array}{r}
L_{i i s}^{x x}= \pm \xi_{2} t_{x} \sin \varphi_{m} ; \quad L_{i i s}^{y y}= \pm\left(-\xi_{2}\right) t_{y} \cos \varphi_{m} \\
\xi_{2}=-\frac{1}{2 \pi \Delta \varphi_{i}}\left[\sin \left(\frac{\Delta \varphi_{i}}{2}\right) \ln \left|\frac{\Delta \varphi_{i}}{2}\right|-S i\left(\frac{\Delta \varphi_{i}}{2}\right)\right]
\end{array}
$$

where the selection of the \pm sign is related to the direction of the segment, clockwise $(+)$ or anticlockwise $(-)$. Moreover, $t_{x}$ and $t_{y}$ are respectively the $x$ and $y$ components of vector $\widehat{\mathbf{t}}\left(\mathbf{s}_{i}\right), \Delta \varphi_{i}=\varphi_{i 2}-\varphi_{i 1}$ and $\varphi_{m}=0,5\left(\varphi_{i 1}+\varphi_{i 2}\right)$, being $\varphi_{i 1}$ and $\varphi_{i 2}$ the parametric circular initial and final angles for $\sigma_{i}$ as defined in [6]. The definition of the function $S i$ can also be found in eq. (41) of [6]. 


\section{Elliptical arcs}

$$
\begin{array}{r}
L_{i i s}^{x x}= \pm \xi_{3} t_{x}\left[a \cos \alpha \sin \eta_{m}+b \sin \alpha \cos \eta_{m}\right] \\
L_{i i s}^{y y}= \pm \xi_{3} t_{y}\left[a \sin \alpha \sin \eta_{m}-b \cos \alpha \cos \eta_{m}\right] \\
\xi_{3}=-\frac{\left|\Delta \eta_{i}\right|}{2 \pi \Delta \eta_{i}}\left[\sin \left(\frac{\Delta \eta_{i}}{2}\right) \ln \left|\frac{\Delta \eta_{i}}{2}\right|-S i\left(\frac{\Delta \eta_{i}}{2}\right)\right]
\end{array}
$$

where the parameterization and notation previously described in Sections 4.2.1 and 4.2.2 has been used.

\subsubsection{Coupling Coefficients}

In order to use this Nyström-based BI-RME method within CAD tools of complex passive waveguide components, an efficient technique for computing the coupling coefficients between two cascaded arbitrarily shaped waveguides is required. To solve this problem, we choose the same standard rectangular contour for the application of the Nyström and BI-RME methods to both arbitrary waveguides. Once the cutoff frequencies are obtained, and after some post-processing explained next, the required coupling coefficients are easily computed by means of the following expression

$$
\left\langle\mathbf{e}_{i}^{\left(A W_{1}\right)}, \mathbf{e}_{j}^{\left(A W_{2}\right)}\right\rangle=\sum_{n=1}^{N_{(R W)}}\left\langle\mathbf{e}_{i}^{\left(A W_{1}\right)}, \mathbf{e}_{n}^{(R W)}\right\rangle\left\langle\mathbf{e}_{n}^{(R W)}, \mathbf{e}_{j}^{\left(A W_{2}\right)}\right\rangle
$$

where the $\left\langle\mathbf{e}_{i}^{\left(A W_{k}\right)}, \mathbf{e}_{n}^{(R W)}\right\rangle$ term represents the coupling integral between the $i$-th mode of the $k$-th arbitrary waveguide and the $n$-th mode of the common rectangular waveguide.

To derive the expressions for the required coupling coefficients between each arbitrary waveguide and the auxiliary rectangular contour, the fast method originally proposed in [2] will be adapted to our Nyströmbased formulation. Such a set of coupling integrals is defined as follows

$$
I_{p q}=\int_{S} \mathbf{e}_{p}^{\square} \cdot \mathbf{e}_{q}^{\diamond} d S
$$

where $\mathbf{e}_{p}^{\square}$ and $\mathbf{e}_{q}^{\diamond}$ are, respectively, the normalized electric modal vectors of the rectangular and arbitrarily shaped waveguides. 
Starting with the TM case, if the Nyström method is applied to the integral equation (4.2), the following expression is directly obtained for the potential scalar of such modes:

$$
\psi_{m}^{T M \diamond}(\mathbf{r})=k^{\prime} \sum_{i=1}^{N} g\left(\mathbf{r}, \mathbf{s}_{i}\right) b_{i}^{\prime}+k^{\prime} \sum_{m=1}^{M^{\prime}} \frac{\psi_{m}^{T M \square}(\mathbf{r})}{h_{m}^{\prime 2}} a_{m}^{\prime}
$$

This expression leads to normalized vector mode function for the TM modes if the modal expansion coefficients $a_{m}^{\prime}$ satisfy that $\mathbf{a}^{\prime T} \mathbf{a}^{\prime}=$ $k^{\prime 2}$ (see justification in Appendix 4.5).

Therefore, the normalized transversal electric field for the TM modes can be finally obtained as follows

$$
\begin{array}{r}
\mathbf{e}_{m}^{T M \diamond}(\mathbf{r})=\frac{-\nabla_{T} \psi_{m}^{T M \diamond}(\mathbf{r})}{k^{\prime}} \\
=-\sum_{i=1}^{N} \nabla_{T} g\left(\mathbf{r}, \mathbf{s}_{i}\right) b_{i}^{\prime}+\sum_{m=1}^{M^{\prime}} \frac{\mathbf{e}_{m}^{T M \square}(\mathbf{r})}{h_{m}^{\prime}} a_{m}^{\prime}
\end{array}
$$

where $\nabla_{T}$ is the two-dimensional nabla operator in the transversal coordinate system, and $\mathbf{e}_{m}^{T M \square}$ is the normalized modal vector of the auxiliary standard rectangular waveguide that must accomplish $\mathbf{e}_{m}^{T M \square}=$ $-\nabla_{T} \psi_{m}^{T M \square} / h_{m}^{\prime}$.

For the TE case, we must apply the Nyström method to the integral equation (4.14), thus obtaining the following expression for the tangent electric field

$$
\begin{array}{r}
\mathbf{e}_{m}^{T E \diamond}(\mathbf{r})=\frac{1}{k} \sum_{i=1}^{N} \nabla \frac{\partial g\left(\mathbf{r}, \mathbf{s}_{i}\right)}{\partial l} b_{i} \\
-k \sum_{i=1}^{N} \overline{\mathbf{G}}_{s t}\left(\mathbf{r}, \mathbf{s}_{i}\right) \cdot \widehat{\mathbf{t}}\left(\mathbf{s}_{i}\right) b_{i}-k \sum_{m=1}^{M} \frac{\mathbf{e}_{m}^{T E \square}(\mathbf{r})}{h_{m}^{2}} a_{m}
\end{array}
$$

which will be adequately normalized if the coefficients $a_{m}$ and $b_{i}$ satisfy the condition derived in Appendix 4.5.

Now, using the expressions (4.31) and (4.32) for the normalized TM and TE modal vectors, the required coupling integrals can be finally written as

$$
I_{p q}^{T M-T M}=h_{p}^{\prime} \sum_{j=1}^{N} R_{j p}^{\prime} b_{j}^{\prime q}+\frac{a_{p}^{\prime q}}{h_{p}^{\prime}}
$$




$$
\begin{gathered}
I_{p q}^{T E-T E}=k_{q}\left[\sum_{j=1}^{N} R_{j p} b_{j}^{q}+\frac{a_{p}^{q}}{h_{p}^{2}}\right] \\
I_{p q}^{T M-T E}=-\frac{1}{k_{q}} \sum_{j=1}^{N} R_{j p}^{\prime \prime} b_{j}^{q} \\
I_{p q}^{T E-T M}=0
\end{gathered}
$$

where the $R_{j p}^{\prime}$ and $R_{j p}$ terms are the entries of the $\mathbf{R}^{\prime}$ and $\mathbf{R}$ matrices just defined before, and the $a_{p}^{\prime}, b_{j}^{\prime}, a_{p}$ and $b_{j}$ coefficients are the solutions of the Nyström-based TM and TE eigenvalue problems. Therefore, only the new $R_{j p}^{\prime \prime}$ terms are easily evaluated as follows

$$
R_{j p}^{\prime \prime}=\mathbf{e}_{p}^{T M \square}\left(\mathbf{s}_{j}\right) \cdot \widehat{\mathbf{t}}\left(\mathbf{s}_{j}\right)
$$

\subsection{Validation Results}

In this section, we discuss the accuracy and efficiency of the Nyströmbased BI-RME approach through several application examples. First, we have computed the complete modal chart of two well-known irises, i.e. a crossed rectangular waveguide and a "triseptum" circular waveguide. Secondly, making use of the novel CAD tool, we have analyzed and designed two complex passive waveguide devices: an inductively coupled rectangular waveguide filter with rounded corners, and a dualmode filter in circular waveguide technology with elliptical irises and tuning elements. All these examples have been successfully validated through comparisons with numerical and experimental results, either available in the technical literature or provided by the authors.

In order to show the gain in efficiency of the new modal method proposed in this paper, CPU computation times for the considered examples are being compared with those obtained applying the traditional Galerkin-based BI-RME approach. All CPU costs offered in this section have been obtained with a Pentium IV platform at $2.4 \mathrm{GHz}$ with $1 \mathrm{~GB}$ RAM. 


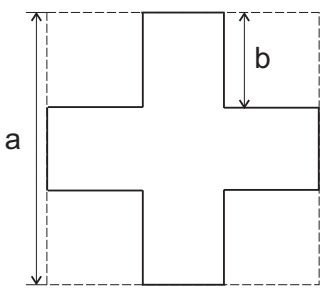

Figure 4.2: Geometry of a cross-shaped iris.

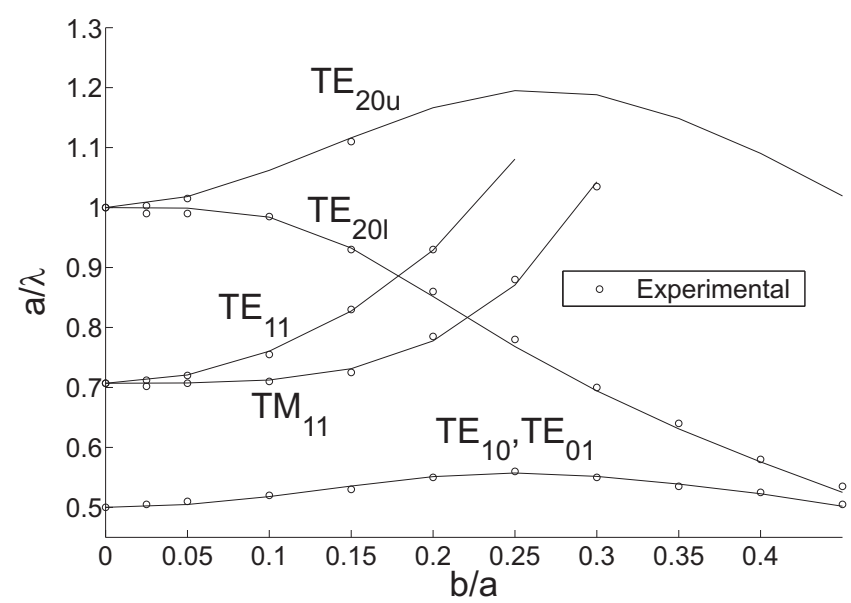

Figure 4.3: Normalized cutoff frequencies as function of $b / a$ for the cross-shaped iris shown in Fig. 4.2.

\subsubsection{Cross-Shaped Iris}

First, we have considered the cross-shaped iris whose geometry is shown in Fig. 4.2. These irises are typically used as inter-cavity coupling elements in circular waveguide dual-mode filters (see for instance [9]).

Making use of the Nyström-based BI-RME method, we have computed the normalized cutoff frequencies as a function of $b / a$. In Fig. 4.3, the results predicted by our method (with solid lines) are successfully compared with experimental data from [19] (with points). For labelling the modes, the same nomenclature used in [19] has been followed. 


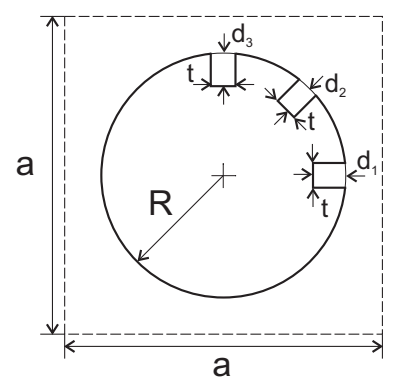

Figure 4.4: Circular iris with three rectangular metallic insertions $\left(d_{1}=\right.$ $1,64 \mathrm{~mm}, d_{2}=2,72 \mathrm{~mm}, d_{3}=1,74 \mathrm{~mm}, t=2 \mathrm{~mm}, R=12 \mathrm{~mm}$ and $a=25 \mathrm{~mm})$.

\subsubsection{Ridged Circular Iris}

The next example deals with the modal analysis of a circular waveguide with three metallic insertions (the "triseptum" waveguide) shown in Fig. 4.4, which is typically used in circular waveguide dual-mode filters. The dimensions of this example have been selected from a real device operating at $12 \mathrm{GHz}$ [15].

Using the Nyström-based BI-RME formulation, the first 75 modes have been computed using 500 modes of the auxiliary square waveguide shown in Fig. 4.4. Table 4.1 shows the ten lower cutoff frequencies, and their relative error when compared with the Galerkin implementation [6]. The analysis of the accuracy of the computed frequencies reveals that the mean value of the relative error is $0,2 \%$. The CPU time required for computing the modal spectrum has been of $5,5 \mathrm{sec}$. using the Nyström method, while the Galerkin technique takes 32,4 sec., which represents an overall reduction of $83 \%$.

The first coupling coefficients between the "triseptum" waveguide and a circular waveguide of diameter equal to $24 \mathrm{~mm}$ are collected in Table 4.2. The absolute error between such Nyström-based results and the Galerkin ones [6] have been included in the same table with italic letters. 
Table 4.1: Cutoff frequencies for the "triseptum" waveguide

\begin{tabular}{cccc}
\hline Order & $\begin{array}{c}\text { Mode Type } \\
(\mathrm{TE} / \mathrm{TM})\end{array}$ & $\begin{array}{c}\text { Nyström } \\
(\mathrm{GHz})\end{array}$ & $\begin{array}{c}\text { Relative } \\
\text { Error }(\%)\end{array}$ \\
\hline 1 & TE & 7,16415 & 0,09 \\
2 & TE & 7,42636 & 0,11 \\
3 & TM & 9,97961 & 0,13 \\
4 & TE & 11,7858 & 0,29 \\
5 & TE & 11,8576 & 0,21 \\
6 & TE & 15,0568 & 0,37 \\
7 & TE & 15,3597 & 0,04 \\
8 & TM & 15,5577 & 0,13 \\
9 & TM & 16,1950 & 0,12 \\
10 & TE & 16,6051 & 0,36 \\
\hline
\end{tabular}

\subsubsection{Inductively Coupled Rectangular Waveguide Fil- ter with Rounded Corners}

For evaluating the new CAD tool, we have first chosen an inductively coupled rectangular waveguide filter with rounded corners (see geometry and dimensions in Fig. 4.5), originally designed for operation at $11 \mathrm{GHz}$ with a bandwidth of $300 \mathrm{MHz}$ in [5]. This structure is composed of the cascaded connection of two kinds of transitions: one between rectangular waveguides and rounded coupling irises, and another one between rectangular waveguides with rounded corners. Therefore, the full-wave analysis of this structure will allow to validate the new theoretical aspects described in Section 4.2.3.

For verification purposes, a prototype of this filter has been manufactured (see Fig. 4.6). The simulated scattering parameters of such structure are shown in Fig. 4.7, where they are successfully compared with the experimental results of the manufactured prototype. Such results were obtained using 15 accessible modes, 70 basis functions and 
Table 4.2: Coupling coefficients between the "triseptum" waveguide and the circular one

\begin{tabular}{lllll}
\hline & \multicolumn{4}{c}{ "triseptum" waveguide modes } \\
& $T E_{1}$ & $T E_{2}$ & \multicolumn{1}{c}{$T M_{1}$} & \multicolumn{1}{c}{$T E_{3}$} \\
\hline$T E_{11 s}$ & 0,68196 & 0,69371 & -- & $-0,04683$ \\
& $9 \cdot 10^{-4}$ & $5,1 \cdot 10^{-3}$ & & $1,1 \cdot 10^{-3}$ \\
\hline$T E_{11 c}$ & $-0,67994$ & 0,69601 & -- & 0,05407 \\
& $4,5 \cdot 10^{-3}$ & $4 \cdot 10^{-4}$ & & $1 \cdot 10^{-3}$ \\
\hline$T M_{01}$ & 0,07117 & 0,00008 & $-0,93487$ & 0,06039 \\
& $1,5 \cdot 10^{-3}$ & $1 \cdot 10^{-6}$ & $1,8 \cdot 10^{-3}$ & $1,2 \cdot 10^{-3}$ \\
\hline$T E_{21 s}$ & 0,00298 & 0,00062 & -- & 0,89631 \\
& $7 \cdot 10^{-4}$ & $1 \cdot 10^{-5}$ & & $3,9 \cdot 10^{-3}$ \\
\hline$T E_{21 c}$ & 0,00062 & $-0,00759$ & -- & $-0,09502$ \\
& $4,8 \cdot 10^{-5}$ & $1,2 \cdot 10^{-3}$ & & $1,3 \cdot 10^{-2}$ \\
\hline
\end{tabular}

250 kernel terms in the integral equations related to the solution of each discontinuity. These simulating parameters involved a total CPU effort of $204 \mathrm{sec}$. (1000 frequency points) for the Galerkin method, and $144 \mathrm{sec}$. for the new Nyström-based approach. In this example, the total gain in computational cost is about $30 \%$, which clearly validates the Nyström method as a good alternative to the Galerkin approach for providing accurate results in quite lower CPU times.

\subsubsection{Circular Waveguide Dual-Mode Filter with Ellip- tical Irises and Tuning Elements}

After validating the new developed CAD tool based on the Nyström method, we have used such tool for the design of a four-pole dual-mode filter in circular waveguide technology. As it can be seen in Fig. 4.8, such structure is basically composed of two circular waveguide cavities coupled through a rotated elliptical iris, and fed to the 


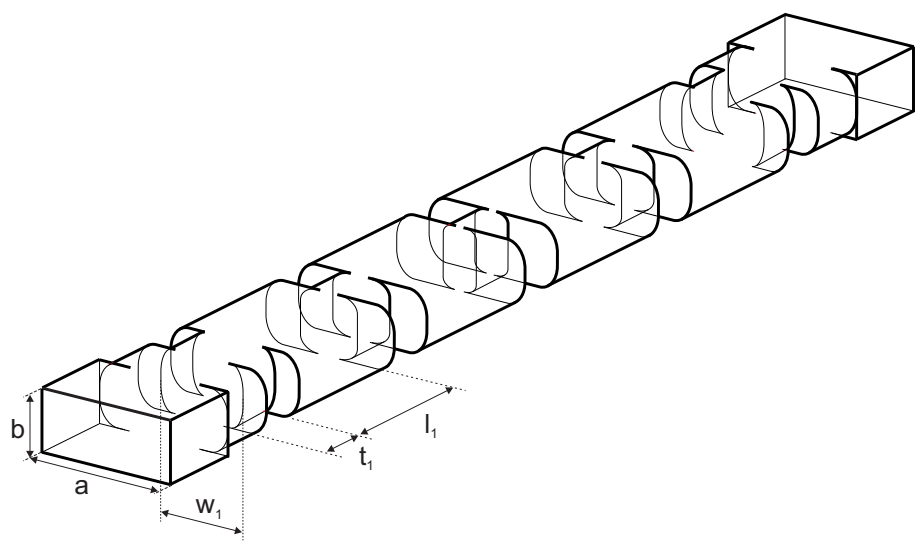

Figure 4.5: Inductive filter with rounded corners. The dimensions are: $a=22,86 \mathrm{~mm}, b=10,16 \mathrm{~mm}, l_{1}=4,00 \mathrm{~mm}, l_{2}=14,29 \mathrm{~mm}, l_{3}=15,84 \mathrm{~mm}$, $t_{1}=1,70 \mathrm{~mm}, t_{2}=1,77 \mathrm{~mm}, t_{3}=1,78 \mathrm{~mm}, w_{1}=10,50 \mathrm{~mm}, w_{2}=6,70 \mathrm{~mm}$, $w_{3}=6,15 \mathrm{~mm}$. The radius of the rounded corners is $R=2,00 \mathrm{~mm}$.

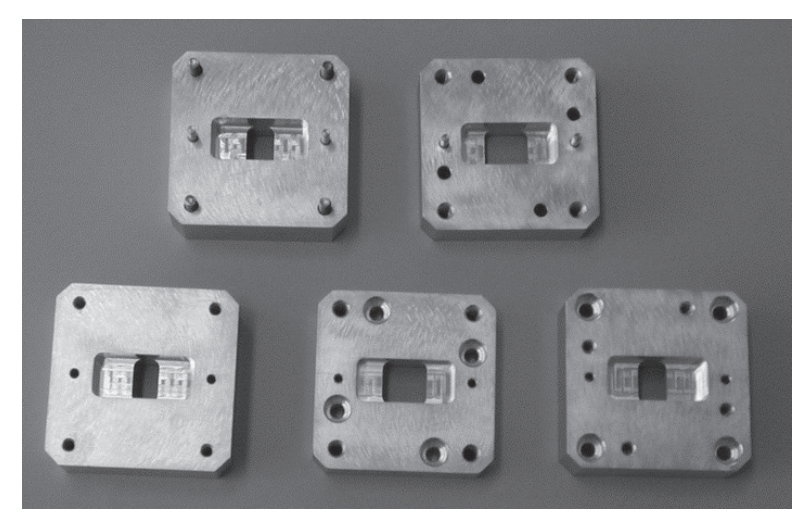

Figure 4.6: Internal pieces of the inductive filter with rounded corners composed each one of two half-cavities and a coupling iris.

input/output waveguides by means of two elliptical irises. In order to tune and couple each pair of degenerated modes, we have placed in the middle plane of each cavity a short circular waveguide with three metallic insertions (see Fig. 4.8). 


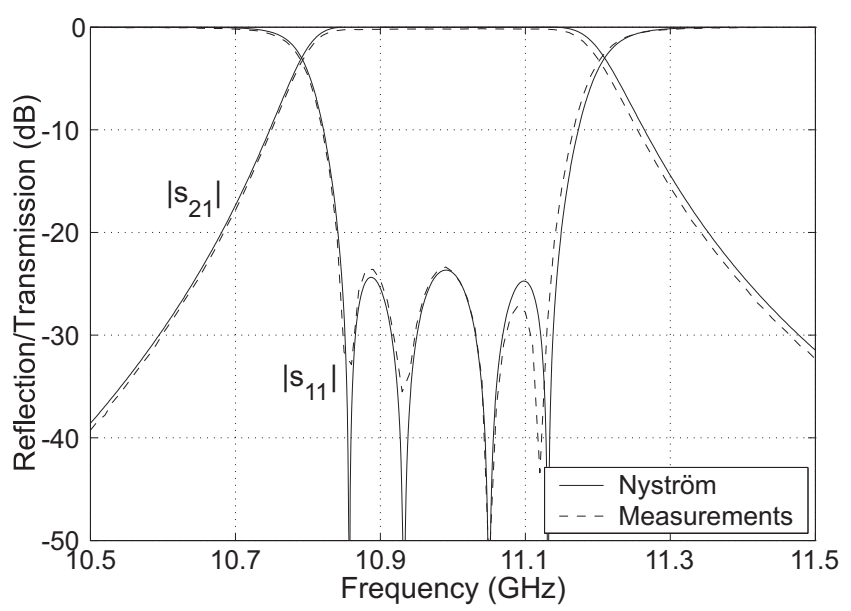

Figure 4.7: Magnitude of the reflection $\left(\mathrm{S}_{11}\right)$ and transmission $\left(\mathrm{S}_{21}\right)$ coefficients of the inductively coupled rectangular waveguide filter with rounded corners shown in Fig. 4.5. With solid line authors' results, and with dashed lines authors' measurements of the manufactured prototype (see Fig. 4.6).

In order to verify the geometrical dimensions provided by the novel CAD tool, we have manufactured a prototype of the circular waveguide dual-mode filter just described. This filter is composed of several pieces containing the input/output waveguides, the irises and the resonators of the structure (see the photograph shown in Fig. 4.9), which are connected in cascade to build the whole filter.

The simulated reflection and transmission coefficients of this filter are compared with the authors' measurements in Fig. 4.10. Some slight misalignments can be observed between both results in the bandpass frequencies, which can be attributed to manufacturing tolerances. Nevertheless, as it usually happens with these very sensitive structures, the desired electrical response could be recovered by replacing the fixed triangular tuning elements by real adjustable screws.

During the CAD stages of this dual-mode filter, it was required to use 100 accessible modes, 300 basis functions and 900 kernel terms in the corresponding integral equations for obtaining enough accurate and convergent results. The computational effort related to each simulation 
of the whole structure has been of 3,5 sec. per frequency point, which was rather adequate for design purposes.

\subsection{Conclusions}

A fast and rather accurate Nyström-based BI-RME method has been applied to the complete CAD of complex passive devices composed of cascaded arbitrarily shaped waveguides defined by linear, circular and elliptical arcs. This novel method offers some advantages compared to the standard Galerkin BI-RME approach: the first one is the simplicity of the implementation, and the second one is the reduction of the computational time. The new developed method has been successfully verified through several application examples of great practical interest, such as the modal chart computation of cross-shaped and ridged circular irises, the efficient full-wave analysis of inductively coupled rectangular waveguide filters with rounded corners, and the complete CAD of circular waveguide dual-mode filters with elliptical irises and tuning elements. CPU times have been included to validate the efficiency improvement provided by the inclusion of the Nyström approach within modern CAD tools.

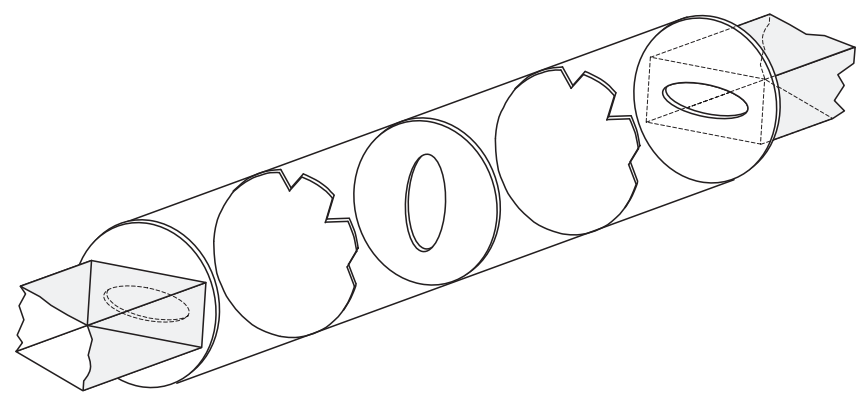

Figure 4.8: Geometry of the four-pole dual-mode filter in circular waveguide technology with elliptical irises and tuning elements. 


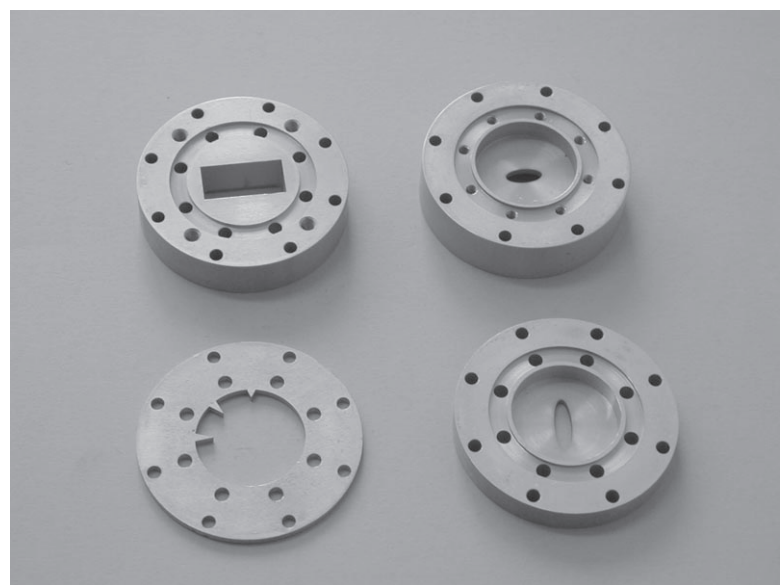

Figure 4.9: Internal pieces of the dual-mode circular waveguide filter with elliptical irises and tuning elements.

\subsection{Acknowledgements}

This work has been supported by Ministerio de Ciencia y Tecnología, Spanish Government, under the Special Action of Space National Plan with Ref. ESP2001-4547-PE.

The authors would like to thank Prof. Conciauro, from University of Pavia, Italy, for their valuable comments concerning the normalization issues discussed in Appendix 4.5, and Dr. Marco Guglgielmi, from European Space Research and Technology Centre (ESTEC, ESA), The Netherlands, for providing the prototypes used for verification purposes.

\section{Appendix A: Double Derivative of the scalar 2D Green function}

When solving the TE modes in the BI-RME method following the Nyström approach, the evaluation of $\frac{\partial^{2} g}{\partial l^{\prime} \partial l}$ is required (see eq. (4.20) in Section 4.2.2), where $g$ is the scalar Green function. For that purpose, 


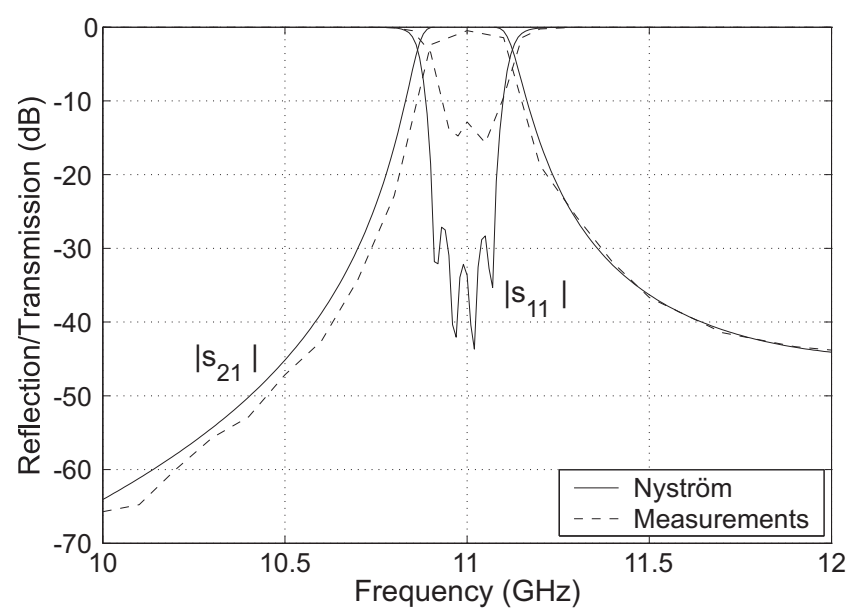

Figure 4.10: Magnitude of the reflection $\left(\mathrm{S}_{11}\right)$ and transmission $\left(\mathrm{S}_{21}\right)$ coefficients of the dual-mode circular waveguide filter with elliptical irises and tuning elements shown in Fig. 4.8. With solid line authors' results, and with dashed lines authors' measurements of the manufactured prototype (see Fig. 4.9).

a rapidly convergent expression for the dyadic $\nabla \nabla^{\prime} g$ has been derived from the bilinear form of the scalar 2D Green function [3]. The dyadic $\nabla \nabla^{\prime} g$ has been accelerated using the Poisson summation formula [16]. The directional derivatives have been then computed as follows

$$
\frac{\partial g}{\partial l}=\nabla g \cdot \hat{\mathbf{t}} \Rightarrow \frac{\partial^{2} g}{\partial l \partial l^{\prime}}=\hat{\mathbf{t}} \cdot \nabla \nabla^{\prime} g \cdot \hat{\mathbf{t}}^{\prime}
$$

where

$$
\nabla \nabla^{\prime} g=\frac{\partial^{2} g}{\partial x \partial x^{\prime}} \hat{\mathbf{x}} \hat{\mathbf{x}}+\frac{\partial^{2} g}{\partial x \partial y^{\prime}} \hat{\mathbf{x}} \hat{\mathbf{y}}+\frac{\partial^{2} g}{\partial y \partial x^{\prime}} \hat{\mathbf{y}} \hat{\mathbf{x}}+\frac{\partial^{2} g}{\partial y \partial y^{\prime}} \hat{\mathbf{y}} \hat{\mathbf{y}}
$$

being each term of a component of the dyadic [21].

For each component of the dyadic $\nabla \nabla^{\prime} g$, a corresponding rapidly convergent expression, which is going to be presented next, has been obtained. 


\section{Component $\hat{\mathbf{x}} \hat{\mathbf{x}}$}

$$
\frac{\partial^{2} g}{\partial x \partial x^{\prime}}=\frac{\pi}{4 a^{2}} \sum_{n=-\infty}^{\infty} T_{n}^{10}-T_{n}^{11}+T_{n}^{00}-T_{n}^{01}
$$

where

$$
\begin{gathered}
T_{n}^{p q}=\frac{\cosh \left[\frac{\pi}{a}\left(\rho_{n}^{q}\right)\right] \cos \left[\frac{\pi}{a}\left(\gamma_{p}\right)\right]-1}{\left\{\cosh \left[\frac{\pi}{a}\left(\rho_{n}^{q}\right)\right]-\cos \left[\frac{\pi}{a}\left(\gamma_{p}\right)\right]\right\}^{2}} \\
\gamma_{p}=x-(-1)^{p} x^{\prime} \\
\rho_{n}^{q}=y-(-1)^{q} y^{\prime}+2 n b
\end{gathered}
$$

\section{Component $\hat{\mathbf{x}} \hat{\mathbf{y}}$}

$$
\frac{\partial^{2} g}{\partial x \partial y^{\prime}}=\frac{\pi}{4 a^{2}} \sum_{n=-\infty}^{\infty} T_{n}^{11}+T_{n}^{10}-T_{n}^{01}-T_{n}^{00}
$$

with

$$
\begin{aligned}
T_{n}^{p q} & =S_{n}^{q} \frac{\sin \left[\frac{\pi}{a}\left(\gamma_{p}\right)\right] \sinh \left[\frac{\pi}{a}\left|\rho_{n}^{q}\right|\right]}{\left\{\cosh \left[\frac{\pi}{a}\left|\rho_{n}^{q}\right|\right]-\cos \left[\frac{\pi}{a}\left(\gamma_{p}\right)\right]\right\}^{2}} \\
S_{n}^{q} & =\operatorname{sgn}\left[\frac{\pi}{b}\left(y-(-1)^{q} y^{\prime}\right)+2 n \pi\right]
\end{aligned}
$$

\section{Components $\hat{\mathbf{y}} \hat{\mathbf{x}}, \hat{\mathbf{y}} \hat{\mathbf{y}}$}

The remaining components can be obtained from the previou ones, just using symmetry properties of the Green function

$$
\begin{aligned}
\frac{\partial^{2} g}{\partial y \partial x^{\prime}}\left(x, y ; x^{\prime}, y^{\prime} ; a, b\right) & =\frac{\partial^{2} g}{\partial x \partial y^{\prime}}\left(y, x ; y^{\prime}, x^{\prime} ; b, a\right) \\
\frac{\partial^{2} g}{\partial y \partial y^{\prime}}\left(x, y ; x^{\prime}, y^{\prime} ; a, b\right) & =\frac{\partial^{2} g}{\partial x \partial x^{\prime}}\left(y, x ; y^{\prime}, x^{\prime} ; b, a\right)
\end{aligned}
$$




\section{Appendix B: Normalization of the eigenvectors}

\section{TM Modes}

The scalar potential of the TM modes of the arbitrarily shaped waveguide must be normalized according to

$$
\int_{\Omega}\left(\psi^{T M \diamond}(\mathbf{r})\right)^{2} d \Omega=1
$$

This normalization condition can be developed using the expression for $\psi^{T M \diamond}(\mathbf{r})$ derived from (4.2), thus obtaining

$$
\begin{array}{r}
k^{\prime 2} \int_{\Omega} \int_{\sigma} \int_{\sigma} g\left(\mathbf{r}, \mathbf{s}^{\prime}\right) g\left(\mathbf{r}, \mathbf{s}^{\prime \prime}\right) J_{z}\left(l^{\prime}\right) J_{z}\left(l^{\prime \prime}\right) d l^{\prime} d l^{\prime \prime} d \Omega \\
+k^{\prime 2} \int_{\Omega} \sum_{m=1}^{M^{\prime}} \sum_{n=1}^{M^{\prime}} \frac{\psi_{m}^{T M \square}(\mathbf{r}) \psi_{n}^{T M \square}(\mathbf{r})}{h_{m}^{\prime 2} h_{n}^{\prime 2}} a_{m}^{\prime} a_{n}^{\prime} d \Omega \\
+2 k^{\prime 2} \int_{\Omega} g\left(\mathbf{r}, \mathbf{s}^{\prime}\right) J_{z}\left(l^{\prime}\right) \sum_{m=1}^{M^{\prime}} \frac{\psi_{m}^{T M \square}(\mathbf{r})}{h_{m}^{\prime 2}} a_{m}^{\prime} d l^{\prime} d \Omega=1
\end{array}
$$

If we consider the following eigenfunction expansion of the Green function

$$
g(\mathbf{r}, \mathbf{s})=\sum_{i} \frac{\psi_{i}^{T M \square}(\mathbf{r}) \psi_{i}^{T M \square}(\mathbf{s})}{h_{i}^{\prime 2}}
$$

and taking into account that the scalar potentials of the rectangular waveguide are also normalized according to

$$
\int_{\Omega} \psi_{m}^{T M \square}(\mathbf{r}) \psi_{n}^{T M \square}(\mathbf{r}) d \Omega=\delta_{m n}
$$

the equation (4.46) can be rewritten as follows

$$
\begin{aligned}
1= & k^{\prime 2} \sum_{m=1}^{M^{\prime}} \int_{\sigma} \frac{\psi_{m}^{T M \square}\left(\mathbf{s}^{\prime}\right)}{h_{m}^{\prime 2}} J_{z}\left(l^{\prime}\right) d l^{\prime} \int_{\sigma} \frac{\psi_{m}^{T M \square}\left(\mathbf{s}^{\prime \prime}\right)}{h_{m}^{\prime 2}} J_{z}\left(l^{\prime \prime}\right) d l^{\prime \prime} \\
& +k^{\prime 2} \sum_{m=1}^{M^{\prime}} \frac{a_{m}^{\prime 2}}{h_{m}^{\prime 4}}+2 k^{\prime 2} \sum_{m=1}^{M^{\prime}} \frac{a_{m}^{\prime}}{h_{m}^{\prime 2}} \int_{\sigma} \frac{\psi_{m}^{T M \square}\left(\mathbf{s}^{\prime}\right)}{h_{m}^{\prime 2}} J_{z}\left(l^{\prime}\right) d l^{\prime}
\end{aligned}
$$


Applying now the Nyström technique, and making use of the definitions of submatrices collected in (4.6)-(4.8), the previous equation can be written in matrix form as

$$
k^{\prime 2}\left[\mathbf{b}^{\prime T} \mathbf{R}^{\prime} \mathbf{R}^{\prime T} \mathbf{b}^{\prime}+\mathbf{a}^{\prime T} \mathbf{D}^{\prime T} \mathbf{D}^{\prime} \mathbf{a}^{\prime}+2 \mathbf{b}^{\prime T} \mathbf{R}^{\prime} \mathbf{D}^{\prime} \mathbf{a}^{\prime}\right]=1
$$

Finally, if we employ (4.5) in (4.50), the normalization condition is established as

$$
\mathbf{a}^{\prime T} \mathbf{a}^{\prime}=k^{\prime 2}
$$

\section{TE Modes}

In the case of the TE modes of the arbitrarily shaped waveguide, the electric modal vector must be normalized according to

$$
\int_{\Omega} \mathbf{e}^{T E \diamond}(\mathbf{r}) \cdot \mathbf{e}^{T E \diamond}(\mathbf{r}) d \Omega=1
$$

In this case, we must proceed in the same way proposed earlier for the TM normalization. First, we insert the definition of $\mathbf{e}^{T E \diamond}(\mathbf{r})$ given by (4.14) within equation (4.52). Next, the following eigenfunction expansion for the dyadic Green function $\overline{\mathbf{G}}_{s t}$ is considered,

$$
\overline{\mathbf{G}}_{s t}(\mathbf{r}, \mathbf{s})=\sum_{i} \frac{\mathbf{e}_{i}^{T E \square}(\mathbf{r}) \mathbf{e}_{i}^{T E \square}(\mathbf{s})}{h_{i}^{2}}
$$

and the following condition for the modal vectors of the rectangular waveguide is used

$$
\int_{\Omega} \mathbf{e}_{m}^{T M \square}(\mathbf{r}) \mathbf{e}_{n}^{T E \square}(\mathbf{r}) d \Omega=0
$$

Then, the following normalization condition for the eigenvector solutions of the problem defined by (4.18) is finally obtained

$$
\begin{array}{r}
\mathbf{x}^{T} \mathbf{B} \mathbf{x}=1 \\
\mathbf{x}^{T} \mathbf{A} \mathbf{x}=k^{2}
\end{array}
$$

where $\mathbf{x}, \mathbf{B}$ and $\mathbf{A}$ result of expressing the cited eigenvalue problem (4.18) in the compact form $\left[\mathbf{A}-k^{2} \mathbf{B}\right] \mathbf{x}=0$. 


\section{Bibliography}

[1] B. Alpert, Beylkin, R. Coifman, and V. Rohklin. Wavelet-like bases for the fast solution of second-kind integral equations. SIAM Journal of Scientific Computing, 14(1):159-184, January 1993.

[2] P. Arcioni. Fast evaluation of modal coupling coefficients of waveguide step discntinuities. IEEE Microwave Guided Wave Lett., 6(6):232-234, June 1996.

[3] C. A. Balanis. Advanced Engineering Electromagnetics. John Wiley and Sons, New York, 1989.

[4] M. Bozzi, G. Conciauro, and L. Perregrini. On the evaluation of modal coupling coefficients by contour integrals. IEEE Trans. Microwave Theory Tech., 50(7):1853-1855, July 2002.

[5] S. Cogollos, V. E. Boria, P. Soto, B. Gimeno, and M. Guglielmi. Efficient CAD tool for inductively coupled rectangular waveguide filters with rounded corners. In Proc. 31st Eur. Microwave Conf., pages 315-318, London, Sept. 2001.

[6] S. Cogollos, S. Marini, V.E. Boria, P. Soto, A. Vidal, H. Esteban, J. V. Morro, and B. Gimeno. Efficient modal analysis of arbitrarily shaped waveguides composed of linear, circular and elliptical arcs using the BI-RME method. IEEE Trans. Microwave Theory Tech., 51(12):2378-2390, Dec. 2003.

[7] G. Conciauro, M. Bressan, and C. Zuffada. Waveguide modes via an integral equation leading to a linear matrix eigenvalue problem. IEEE Trans. Microwave Theory Tech., 32(11):1495-1504, Nov. 1984.

[8] G. Conciauro, M. Guglielmi, and R. Sorrentino. Advanced Modal Analysis - CAD Techniques for Waveguide Components and Filters. John Wiley \& Sons, Ltd., Chichester, 2000.

[9] P. Couffignal, H. Baudrand, and B. Théron. A new rigorous method for the determination of iris dimensions in dual-mode cavity filters. IEEE Trans. Microwave Theory Tech., 42(7):1314-1320, July 1994. 
[10] P. J. Davis and P. Rabinowitz. Methods of numerical integration. Academic Press, San Diego, second edition, 1984.

[11] L.M. Delves and J.L. Mohamed. Computational methods for integral equations. Cambridge University Press, Cambridge, second edition, 1992.

[12] G. Gerini, M. Guglielmi, and G. Lastoria. Efficient integral equation formulations for impedance or admittance representation of planar waveguide junction. In IEEE MTT-S Int. Microw. Symp. Digest, pages 1747-1750, Baltimore, June 1998.

[13] R. F. Harrington. Field Computation by Moment Methods. IEEE Press, New York, 1992.

[14] T. Itoh. Numerical Techniques for Microwave and Millimeter-Wave Passive Structures. John Wiley \& Sons, Ltd., New York, 1989.

[15] J. R. Montejo-Garai and J. Zapata. Full-wave design and realization of multicoupled dual-mode circular waveguide filters. IEEE Trans. Microwave Theory Tech., 43(6):1290-1297, June 1995.

[16] P.M. Morse and H. Feshbach. Methods of Theoretical Physics. McGraw-Hill, New York, 1978.

[17] J.J. Ottusch and M. Wandzura. High-order Nyström method for computing waveguide modes. ACES Journal, 17(1):84-92, March 2002.

[18] P. P. Silvester and G. Pelosi. Finite Elements for Wave Electromagnetics. IEEE Press, New York, 1994.

[19] H.J. Stalzer, M.D. Greenman, and F.G. Willwerth. Modes of crossed rectangular waveguide. IEEE Transactions on Antenas and Propagation, 24(2):220-223, March 1976.

[20] A. Taflove. Computational Electromagnetics: The Finite-Difference Time-Domain Method. Artech House, Norwood, 1995.

[21] Chen-To Tai. Dyadic Green Functions in Electromagnetic Theory. Series on Electromagnetic Waves. IEEE Press, New York, second edition, 1994. 
[22] M. Taroncher, A. Vidal, V. E. Boria, S. Marini, S. Cogollos, J. Gil, and B. Gimeno. Efficient CAD tool of complex passive devices composed of arbitrarily shaped waveguides using Nyström and BI-RME methods. In Proc. 34th Eur. Microwave Conf., pages 12371240, Amsterdam, Oct. 2004.

[23] M. Taroncher, A. Vidal, V. E. Boria, S. Marini, P. Soto, S. Cogollos, and B. Gimeno. Efficient full wave modal analysis of arbitrarily shaped waveguides using BI-RME and Nystrom methods. In Proc. 33rd Eur. Microwave Conf., pages 455-458, Munich, Oct. 2003.

[24] J. Uher, J. Bornemann, and U. Rosenberg. Waveguide Components for Antenna Feed Systems: Theory and CAD. Artech House, Norwood, 1993.

[25] Johnson J. H. Wang. Generalized Moment Methods in Electromagnetics: Formulation and Computer Solution of Integral Equations. John Wiley \& Sons, New York, 1991. 



\title{
5
}

\section{Efficient and accurate waveguide mode computation using BI-RME and Lanczos methods}

\section{Authors}

V. M. García, A. Vidal, V.E. Boria, A.M. Vidal.

\begin{abstract}
In this paper, a special purpose algorithm for solving large eigenvalue problems based on the Lanczos method is successfully applied to an engineering problem: the electromagnetic analysis and design of passive waveguide devices. For dealing with such complex problems, the Boundary Integral - Resonant Mode Expansion (BI-RME) technique has been recently proposed. This technique solves Integral Equations (IEs) through the well-known Method of Moments (MoM), thus leading to structured eigenvalue problems. These problems frequently become very large when solving complex arbitrary geometries with high accuracy. In such cases, the eigenvalue problem can not be efficiently solved with standard methods by means of personal computers, essentially due to CPU time and memory allocation requirements. In this pa-
\end{abstract}


per, we propose an alternative technique, based on the Lanczos method, for the fast and accurate solution of large BI-RME generalized eigenvalue problems. The novel theoretical aspects of this approach, as well as the impact on the original BI-RME formulation, are described. Comparative benchmarks are also successfully presented for the full-wave analysis and design of real passive microwave devices.

\subsection{Introduction}

An increasing number of real passive waveguide components, such as filters and multiplexers, power dividers and combiners, orthomode transducers, and directional couplers, are composed of the cascaded connection of arbitrarily shaped waveguides [20]. The accurate analysis and design of such components has been traditionally based on numerical meshing techniques, i.e. the Finite-Elements (FE) method, the Transmission Line Matrix (TLM) method and the Finite-Difference Time-Domain (FDTD) method among others (see [12] and [18]), which typically have very strong requirements on CPU time and memory storage. More recently, and due to the appearance of the original BI-RME formulation for the accurate and efficient computation of arbitrarily shaped waveguide modes [6], modal analysis techniques are becoming more popular for dealing with these complex geometries $[7,5,19]$. However, in order to preserve accuracy in the final results, these modal techniques do usually demand the BI-RME computation of a big number of modes in the arbitrary waveguides.

As it will be detailed in next section, BI-RME is a hybrid method, which combines Boundary Integral (BI) and Resonant Mode Expansion (RME) techniques, for the accurate determination of the modal chart of arbitrarily shaped waveguides. The BI-RME method solves a set of IEs by means of the well-known MoM, thus leading to generalized eigenvalue problems involving structured matrices of very large dimensions. However, such matrices typically present a high degree of sparsity, and this feature has not yet been fully exploited in this kind of problems. The authors have verified that such feature can provide great savings in computational costs and memory requirements, which could be of great utility when designing real complex geometries for practical applications. 


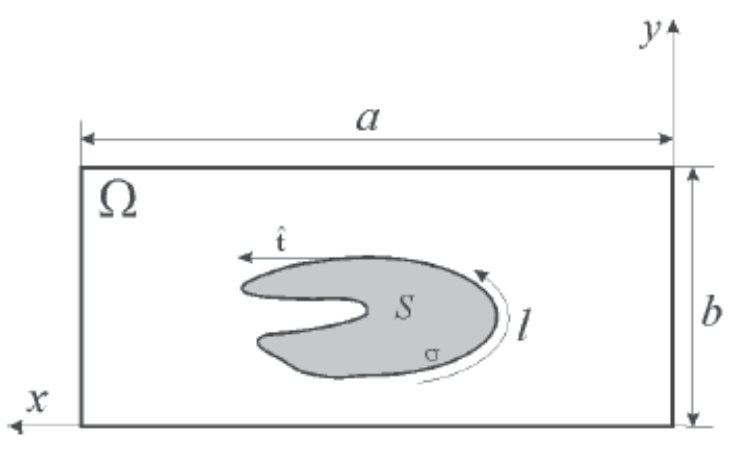

Figure 5.1: Arbitrarily shaped waveguide with cross section $S$.

Therefore, in this paper we propose a new strategy based on the Lanczos method for the efficient solution of large eigenvalue problems that arise with the BI-RME formulation. After a brief outline of the BIRME theory, the paper focuses on the eigenvalue equation solution. First, well-known standard techniques for solving large eigenvalue problems are mentioned, and then the new Lanczos-based method proposed by the authors is fully described. This method is intended to be integrated within a Computer Aided Design (CAD) tool of complex passive waveguide devices, where the repeated and intensive analysis of different geometries is typically needed. Making use of the Lanczos approach proposed, the complete modal charts of several arbitrarily shaped waveguides have been computed. The gain in efficiency due to the new approach has been successfully measured by comparing our results with those provided by a classical eigenvalue solver included in the LAPACK software [1]. Finally, the new CAD tool has been successfully applied to the full-wave design of a dual-mode filter in circular waveguide technology with elliptical irises, which is a typical passive component present in most satellite payloads $[11,8,15]$.

\subsection{Theory}

In this section, the theory related to the efficient and accurate modal computation of arbitrary waveguides is presented. First, we introduce 
the basics of BI-RME (see a more detailed formulation in [6, 7]), and then we fully describe the novel Lanczos based algorithm for the faster solution of large eigenvalue matrix problems.

\subsubsection{The Electromagnetic Problem}

The arbitrarily shaped waveguide to be considered has a cross-section $S$ shown in Fig. 5.1. The arbitrary contour $\sigma$ of such waveguide (defined by the tangent vector $\widehat{t}$ and a suitable abscisa $l$ also shown in Fig. 5.1) must be completely enclosed within a standard rectangular waveguide of cross-section $\Omega$. To derive the modal chart of the arbitrary waveguide under consideration, the original BI-RME approach (see [6]) will be followed.

\section{TE Modes}

The transversal component of the electric field at a generic observation point $\mathbf{r}$ inside $S$ (see Fig. 5.1) may be represented as follows (c.f. (6) in [6])

$$
\begin{array}{r}
\mathbf{E}_{t}(\mathbf{r})=j \frac{\eta}{k} \int_{\sigma} \nabla \frac{\partial g\left(\mathbf{r}, \mathbf{s}^{\prime}\right)}{\partial l^{\prime}} J_{t}\left(l^{\prime}\right) d l^{\prime}-j \eta k \int_{\sigma} \overline{\mathbf{G}}_{s t}\left(\mathbf{r}, \mathbf{s}^{\prime}\right) \cdot \widehat{\mathbf{t}}\left(l^{\prime}\right) J_{t}\left(l^{\prime}\right) d l^{\prime} \\
-j \eta k^{3} \sum_{m=1}^{M} \frac{\mathbf{e}_{m}^{T E^{\square}}(\mathbf{r})}{h_{m}^{2}\left(h_{m}^{2}-k^{2}\right)} \int_{\sigma} \mathbf{e}_{m}^{T E^{\square}}\left(\mathbf{s}^{\prime}\right) \cdot \widehat{\mathbf{t}}\left(l^{\prime}\right) J_{t}\left(l^{\prime}\right) d l^{\prime}
\end{array}
$$

where $j$ is the imaginary number $(j=\sqrt{-1}), \eta$ is the free-space wave impedance $(\eta=\sqrt{\mu / \varepsilon})$, and $k$ is the cutoff wavenumber of the arbitrary waveguide under consideration. On the other hand, $g$ means the scalar two-dimensional Green's function for the Poisson equation, $\overline{\mathbf{G}}_{s t}\left(\mathbf{r}, \mathbf{s}^{\prime}\right)$ the solenoidal dyadic Green function, and $J_{t}\left(l^{\prime}\right)$ represents the transversal component of the unknown current density $\mathbf{J}_{\sigma}$ (see details in [6]). Furthermore, $h_{m}$ and $\mathbf{e}_{m}^{T E^{\square}}$ are, respectively, the cutoff wavenumber and the normalized transversal electric field of the $m$-th TE mode of the surrounding standard rectangular waveguide (see [14]) related to the BI-RME method.

Next, an integral equation is obtained after forcing in (4.14) the boundary condition for TE modes [6,7]. Using a set of $N$ basis functions 
$\left(\omega_{n}\right)$ for solving such integral equation through the Galerkin version of MoM, we easily obtain

$$
\left\{\left[\begin{array}{cc}
\mathbf{I} & \mathbf{O}_{\mathbf{t}} \\
\mathbf{O} & \mathbf{C}
\end{array}\right]-k^{2}\left[\begin{array}{cc}
\mathbf{U} & \mathbf{R}_{\mathbf{t}} \\
\mathbf{R} & \mathbf{H}
\end{array}\right]\right\}\left[\begin{array}{l}
\mathbf{a} \\
\mathbf{b}
\end{array}\right]=0
$$

where $\mathbf{I}$ is the $M \times M$ identity matrix and $\mathbf{O}$ is the $N \times M$ null matrix. The expressions for the other matrices that compose the eigenvalue problem are

$$
\begin{gathered}
\mathbf{U}=\operatorname{diag}\left(h_{1}^{-2}, h_{2}^{-2}, \ldots, h_{M}^{-2}\right) \\
C_{i j}=\int_{\sigma} \int_{\sigma} g\left(\mathbf{s}, \mathbf{s}^{\prime}\right) \frac{\partial \omega_{i}(l)}{\partial l} \frac{\partial \omega_{j}\left(l^{\prime}\right)}{\partial l^{\prime}} d l d l^{\prime} \\
H_{i j}=\int_{\sigma} \int_{\sigma} \omega_{i}(l) \omega_{j}\left(l^{\prime}\right) \widehat{\mathbf{t}}(l) \cdot \overline{\mathbf{G}}_{s t}\left(\mathbf{s}, \mathbf{s}^{\prime}\right) \cdot \widehat{\mathbf{t}}\left(l^{\prime}\right) d l d l^{\prime} \\
R_{i m}=\frac{1}{h_{m}^{2}} \int_{\sigma} \omega_{i}(l) \widehat{\mathbf{t}}(l) \cdot \mathbf{e}_{m}^{T E \square}(\mathbf{s}) d l \\
i, j=1,2, \ldots, N \quad m=1,2, \ldots, M
\end{gathered}
$$

The solution of (5.2) provides as eigenvectors the modal expansion coefficients $\left(a_{m}\right)$ and the expansion coefficients of the transversal current density $\left(b_{j}\right)$, and the eigenvalues $\left(k^{2}\right)$ are related to the TE cutoff wavenumbers $(k)$ of the arbitrary waveguide under consideration.

The generalized eigenvalue problem in (5.2) involves structured matrices $\mathbf{A}$ and $\mathbf{B}$ of four subblocks each one

$$
\mathbf{A} \mathbf{x}=\lambda \mathbf{B} \mathbf{x}
$$

where

$$
\mathbf{A}=\left[\begin{array}{ll}
\mathbf{I} & \mathbf{O}_{\mathbf{t}} \\
\mathbf{O} & \mathbf{C}
\end{array}\right], \mathbf{B}=\left[\begin{array}{cc}
\mathbf{U} & \mathbf{R}_{\mathbf{t}} \\
\mathbf{R} & \mathbf{H}
\end{array}\right], \mathbf{x}=\left[\begin{array}{l}
\mathbf{a} \\
\mathbf{b}
\end{array}\right], \lambda=k^{2}
$$

The blocks $\mathbf{I}$ and $\mathbf{U}$ have dimension $M \times M$, where $M$ is the parameter that typically takes very large values when high accuracy is demanded. Since $\mathbf{I}$ and $\mathbf{U}$ are diagonal, the matrices $\mathbf{A}$ and $\mathbf{B}$ are naturally very sparse. In the previous related literature [6]-[5], the eigenvalue problem has always been solved via a standard dense symmetric and real generalized eigenvalue solver, like the routine DSYGV of LAPACK [1]. 
Following this procedure, only a limited number of waveguide modes may be obtained. The generalized eigenvalue problem presents a size of $(M+N) \times(M+N)$. Therefore, increasing $M$ provides very high computation costs, and it can not even be afforded when matrices $\mathbf{A}$ and $\mathbf{B}$ override the memory capacity of the computer. This is a strong limitation for the integration of this technique in a complete CAD tool, where a high number of waveguide modes are sometimes needed in order to characterize waveguide step discontinuities very accurately.

In this paper, we propose the use of a specially designed Lanczos method to take advantage of the particular structure of $\mathbf{A}$ and $\mathbf{B}$ matrices. Following this method, we achieve two main goals: first, the problem can be solved for a large number of modes $(M)$ since it uses far less memory, and secondly, the computation takes much less time for values of $M$ over a certain threshold. The proposed strategy is to obtain the eigenvalues $\lambda$ and eigenvectors $\mathbf{x}$ in small packets making a smart division of the eigenvalue range. As explained in [7], the region of interest for the desired eigenvalues $\lambda$ goes from zero to $1 /(4 \mathbf{U}(M, M))$. Therefore, that range will be properly segmented in order to compute the modal chart. Then, the corresponding eigenvectors must be normalized according to the following expression (see [2])

$$
\mathbf{x}_{\mathbf{t}} \mathbf{B x}=1
$$

The sparsity of matrices $\mathbf{A}$ and $\mathbf{B}$ is shown in Fig. 5.2 for an example considering a ridge waveguide with $M$ equal to 2813 and $N$ equal to 99 . The great sparsity of the matrices is due to the large number of rectangular waveguide modes, and consequently the large number of ridge waveguide modes that are demanded.

\section{TM Modes}

The longitudinal component of the electric field at a generic observation point $\mathbf{r}$ inside $S$ (see Fig. 5.1) may be represented as follows (cf. (7) in [6])

$$
\begin{gathered}
E_{z}(\mathbf{r})=-j \eta k^{\prime} \int_{\sigma} g\left(\mathbf{r}, \mathbf{s}^{\prime}\right) J_{z}\left(l^{\prime}\right) d l^{\prime} \\
-j \eta k^{\prime 3} \sum_{m=1}^{M^{\prime}} \frac{\psi_{m}^{T M \square}(\mathbf{r})}{h_{m}^{\prime 2}\left(h_{m}^{\prime 2}-k^{\prime 2}\right)} \int_{\sigma} \psi_{m}^{T M \square}\left(\mathbf{s}^{\prime}\right) J_{z}\left(l^{\prime}\right) d l^{\prime}
\end{gathered}
$$

where the meaning of $j, \eta, k^{\prime}$ and $g$ is the same one explained before in the TE case, whereas $J_{z}\left(l^{\prime}\right)$ represents now the longitudinal component 

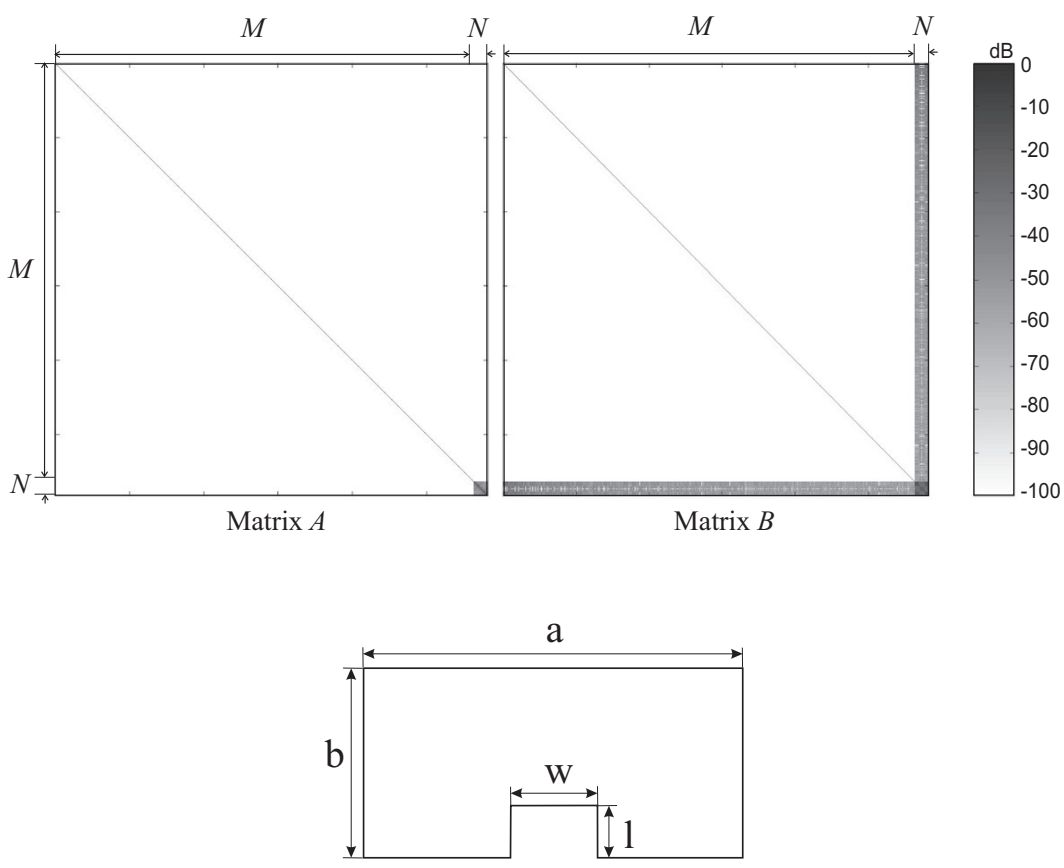

Ridge waveguide

Figure 5.2: Non-zero elements structure of matrices $\mathbf{A}$ and $\mathbf{B}$ for a ridge waveguide ( $a=19,05 \mathrm{~mm}, b=9,525 \mathrm{~mm}, w=3,00 \mathrm{~mm}$ and $l=3,00 \mathrm{~mm}$ ). 
of the current density $\mathbf{J}_{\sigma}$. Moreover, $h_{m}^{\prime}$ and $\psi_{m}^{T M \square}$ are, respectively, the cutoff wavenumber and the normalized scalar potential of the $m$ th TM mode of the surrounding standard rectangular waveguide $(\Omega$ in Fig. 5.1), whose expressions can be found in [14].

To compute now the TM modes, the boundary condition for the longitudinal component of the electric field must be imposed on $\sigma$. The resulting integral equation is solved again through the Galerkin version of the MoM using a set of $N$ basis functions $u_{n}$, thus leading to the following matrix eigenvalue problem

$$
\left\{\left[\begin{array}{ll}
\mathbf{I} & \mathbf{O}_{\mathbf{t}} \\
\mathbf{O} & \mathbf{O}^{\prime}
\end{array}\right]-k^{\prime 2}\left[\begin{array}{ll}
\mathbf{U}^{\prime} & \mathbf{R}_{\mathbf{t}}^{\prime} \\
\mathbf{R}^{\prime} & \mathbf{H}^{\prime}
\end{array}\right]\right\}\left[\begin{array}{l}
\mathbf{a}^{\prime} \\
\mathbf{b}^{\prime}
\end{array}\right]=0
$$

where $\mathbf{I}$ is the $M^{\prime} \times M^{\prime}$ identity matrix, $\mathrm{O}$ is the $N \times M^{\prime}$ null matrix and $\mathbf{O}^{\prime}$ is the $N \times N$ null matrix. The detailed expressions for the other matrices that define the eigenvalue problem are

$$
\begin{gathered}
\mathbf{U}^{\prime}=\operatorname{diag}\left(h_{1}^{\prime-2}, h_{2}^{\prime-2}, \ldots, h_{M^{\prime}}^{-2}\right) \\
H_{i j}^{\prime}=\int_{\sigma} \int_{\sigma} u_{i}(l) g\left(\mathbf{s}, \mathbf{s}^{\prime}\right) u_{j}\left(l^{\prime}\right) d l d l^{\prime} \\
R_{i m}^{\prime}=\frac{1}{h_{m}^{\prime 2}} \int_{\sigma} u_{i}(l) \psi_{m}^{T M \square}(\mathbf{s}) d l \\
i, j=1,2, \ldots, N \quad m=1,2, \ldots, M^{\prime}
\end{gathered}
$$

The solutions of this eigenvalue problem $\left(k^{\prime 2}\right)$ are related to the TM cutoff wavenumbers $\left(k^{\prime}\right)$ of the arbitrary waveguide under study. The previous TM generalized eigenvalue problem can be also cast into the following standard form

$$
\left(\mathbf{U}^{\prime}-\mathbf{R}_{\mathbf{t}}^{\prime} \mathbf{H}^{\prime-1} \mathbf{R}^{\prime}\right) \mathbf{a}^{\prime}=k^{\prime-2} \mathbf{a}^{\prime}
$$

In the TM problem, the eigenvalue matrix equation can be reduced to a smaller standard problem. However, the problems related to the computation time and the viability of the solution still remain when $M^{\prime}$ grows. If the reduced standard eigenvalue equation is formulated, the sparsity is completely lost and the new Lanczos approach cannot be applied. Alternatively, the problem can be treated as a generalized structured problem following the same strategy used in the TE case. The 
difference is that in this case only one subblock in matrix $\mathbf{A}^{\prime}$ is different from the null matrix. The equivalent generalized formulation can be written as follows

$$
\mathbf{A}^{\prime} \mathbf{x}^{\prime}=\lambda^{\prime} \mathbf{B}^{\prime} \mathbf{x}^{\prime}
$$

with

$$
\mathbf{A}^{\prime}=\left[\begin{array}{ll}
\mathbf{I} & \mathbf{O}_{\mathbf{t}} \\
\mathbf{O} & \mathbf{O}^{\prime}
\end{array}\right], \mathbf{B}^{\prime}=\left[\begin{array}{ll}
\mathbf{U}^{\prime} & \mathbf{R}_{\mathbf{t}}^{\prime} \\
\mathbf{R}^{\prime} & \mathbf{H}^{\prime}
\end{array}\right], \mathbf{x}^{\prime}=\left[\begin{array}{l}
\mathbf{a}^{\prime} \\
\mathbf{b}^{\prime}
\end{array}\right], \lambda^{\prime}=k^{\prime 2}
$$

According to [7], the region of interest for the desired eigenvalues $\lambda^{\prime}$ goes again from zero to $1 /\left(4 \mathbf{U}^{\prime}\left(M^{\prime}, M^{\prime}\right)\right)$. Therefore, that range will be properly segmented in order to compute the modal chart. Next, as proposed in [2], the corresponding eigenvectors must be normalized again according to the following expression

$$
\mathbf{x}_{\mathbf{t}}^{\prime} \mathbf{B}^{\prime} \mathbf{x}^{\prime}=1
$$

\subsubsection{Eigenvalue Equation Solution}

Both problems (computation of TE and TM modes) require the solution of a generalized eigenvalue problem $\mathbf{A} x=\lambda \mathbf{B} x$, where the matrices $\mathbf{A}$ and $\mathbf{B}$ are symmetric and, under some circumstances, $\mathbf{B}$ can be as well positive definite. The number of required eigenvalues and eigenvectors depends on the demanded accuracy, but such number is usually quite large, around $1 / 3$ of the size of the matrices. From Fig. 5.2 it can be seen as well that the matrices are very sparse and with a clear structure.

Next, we will briefly describe the standard techniques traditionally used for solving this problem. Then, we will describe our novel approach and some details about its practical implementation.

\section{Standard solution techniques}

The standard algorithm for generalized eigenvalue problems is the QZ algorithm $[1,10]$ which can be applied to square, general matrices. However, the application of this algorithm entails the reduction of the matrix A to upper Hessenberg form (or to tridiagonal form, in the symmetric case), and $\mathbf{B}$ to upper triangular form. Given the structure of the matrices shown in Fig. 5.2, this would mean to "fill" them during the 
process. Hence, full dimension matrices would have to be allocated and the structure of the matrix would not be exploited.

A similar algorithm is often used (implemented as well in LAPACK), when the matrix $\mathbf{B}$ is symmetric and positive definite $[1,10]$. In this case, the Cholesky decomposition of $\mathbf{B}$ is computed $\left(\mathbf{B}=\mathbf{Z Z}_{\mathbf{t}}\right)$ and the generalized eigenvalue problem is transformed into the following standard eigenvalue problem

$$
\mathbf{A} x=\lambda \mathbf{B} x \Longrightarrow \mathbf{Z}^{-1} \mathbf{A} \mathbf{Z}_{\mathbf{t}}^{-1} \mathbf{Z}_{\mathbf{t}} x=\lambda \mathbf{Z}_{\mathbf{t}} x
$$

So, the generalized eigenvalue problem is transformed into an standard eigenvalue problem with the matrix $\mathbf{Y}=\mathbf{Z}^{-1} \mathbf{A} \mathbf{Z}_{\mathbf{t}}^{-1}$. In our case, where the matrix $\mathbf{B}$ is not always positive definite, a similar technique was applied using instead the $\mathbf{L D L}_{\mathbf{t}}$ decomposition. However, although the matrix $\mathbf{Y}$ keeps the structure shown in Fig. 5.2, the tridiagonalization needed for the QR iterative method can only be done treating the matrix as "full", so that again a full matrix needs to be allocated.

These techniques (which are often referred to as "direct") have been usually chosen for solving our problem, but the great resources needed (time and memory) make them only suitable for large, possibly parallel computers. Therefore, it is not feasible to include them within a CAD tool for general use in personal computers.

Apart from the previous direct methods, there are also several iterative methods to solve the generalized eigenvalue problem, such as Jacobi-Davidson, Arnoldi, Lanczos, [10, 3]. However, these methods are more oriented towards the computation of a few extremal eigenvalues. Their use for obtaining (in a single call) a large number of eigenvalues would be, as well, quite costly in terms of memory and CPU time. However, as we will see next, these methods can be successfully adapted to solve our problem, thus avoiding the above mentioned difficulties.

\section{Iterative methods for generalized eigenvalue problems}

Iterative methods, such as Jacobi-Davidson, Arnoldi, Lanczos and variants, are mainly used to compute one or a few eigenvalue-eigenvector pairs [3]. In this work, we have chosen the Lanczos method, but any of the others could have also been selected. 
Since the early 50's, the Lanczos method is used for computing eigenvalues of a symmetric matrix A. Given an initial vector $r$, it builds an orthonormal basis $v_{1}, v_{2}, \ldots, v_{m}$ of the Krylov subspace $K^{m}(A, r)$. In the new orthonormal basis, the matrix $\mathrm{A}$ is represented as the following tridiagonal matrix

$$
T_{j}=\left[\begin{array}{cccc}
\alpha_{1} & \beta_{1} & & \\
\beta_{1} & \alpha_{2} & \ddots & \\
& \ddots & \ddots & \beta_{j-1} \\
& & \beta_{j-1} & \alpha_{j}
\end{array}\right]
$$

where the computation of the $\alpha_{j}, \beta_{j}$ is carried out as shown in the algorithm 1 (the formulation included below has been taken from [17]).

\section{Algorithm 1: Lanczos}

1. $\beta_{0}=\|r\|_{2}$

2. for $j=1,2, \ldots$ until convergence

3. $v_{j}=r / \beta_{j-1}$

4. $r=A v_{j}$

5. $r=r-v_{j-1} \cdot \beta_{j-1}$

6. $\alpha_{j}=v_{j}^{*} r$

7. $r=r-v_{j} \cdot \alpha_{j}$

8. re-orthogonalize if necessary

9. $\beta_{j}=\|r\|_{2}$

10. compute approximate eigenvalues of $\mathbf{T}_{j}$

11. test bounds for convergence

12. end for

13. compute approximate eigenvectors 
Some of the eigenvalues of the $\mathbf{T}$ matrix (called Ritz values) are good approximations to the eigenvalues of $\mathbf{A}$, and the eigenvectors can be easily obtained, as well, from the eigenvectors of the $\mathbf{T}$ matrix and the $v_{i}$ vectors.

As mentioned above, if this method is used in a single call to obtain all the eigenvalues, then the involved matrices (specially $\mathbf{V}=\left(v_{i}\right)$ ) would get really large, and it is unlikely that the convergence speed would be good for the last eigenvalues. Furthermore, the previous algorithm is only valid for eigenvalue problems, not for generalized eigenvalue problems. Fortunately, the method can be adapted in a very convenient way, as shown next.

Shift and invert technique The Lanczos method, as any of the iterative methods, converges first to the eigenvalues that are largest in magnitude. However, given a scalar $\sigma$, these methods can be used to obtain the eigenvalues closest to $\sigma$, through the "Shift-and-Invert" technique [16]. This technique can also be applied to generalized eigenvalue problems.

In this case, the technique consists of finding the eigenvalues of $\mathbf{W}=(\mathbf{A}-\sigma \mathbf{B})^{-1} \mathbf{B}$ through any iterative method. Any eigenvalue of this matrix gives us an eigenvalue of the pencil $(\mathbf{A}, \mathbf{B})$ : if $\lambda$ is such that $\mathbf{A} x=\lambda \mathbf{B} x$, then $\lambda^{*}=\frac{1}{(\lambda-\sigma)}$ is an eigenvalue of $(\mathbf{A}-\sigma \mathbf{B})^{-1} \mathbf{B}$. Clearly, since iterative methods converge first to eigenvalues of largest magnitude, these methods applied to the matrix $\mathbf{W}$ will deliver first the eigenvalues of $(\mathbf{A}, \mathbf{B})$ closest to $\sigma$. There are some subtleties in applying Lanczos method to a shifted-inverse problem; the algorithm below, along with the details, can be found in [16].

Algorithm 2: Lanczos with shift-invert for generalized symmetric problem

1. $r=$ starting vector; $q=B r, \beta_{0}=\left|q^{*} r\right|^{\frac{1}{2}}$

2. for $j=1,2, \ldots$ until convergence

3. $w_{j}=r / \beta_{j-1}, v_{j}=r / \beta_{j-1}$

4. $\quad r=(\mathbf{A}-\sigma \mathbf{B})^{-1} v_{j}$

5. $r=r-w_{j-1} \beta_{j-1}$ 
6. $\alpha_{j}=v_{j}^{*} r$

7. $r=r-w_{j} \cdot \alpha_{j}$

8. re-orthogonalize if necessary

9. $q=B r$

10. $\quad \beta_{j}=\left|q^{*} r\right|^{\frac{1}{2}}$

11. compute approximate eigenvalues of $\mathbf{T}_{j}$

12. test bounds for convergence

13. end for

14. compute approximate eigenvectors

In order to apply the Lanczos method to this problem, it is necessary to solve linear systems with coefficient matrix $\mathbf{A}-\sigma \mathbf{B}$. Using the structure of the matrices, these linear solves can be made very efficiently as indicated next.

Schur complement technique for solution of linear systems To apply the "Shift-and-Invert" technique, we need to solve efficiently the matrix system $(\mathbf{A}-\sigma \mathbf{B}) x=b$. Looking either at the matrices in (5.2) or in (5.17), we see that the structure of such matrix will be similar to the one shown in Fig. 5.2. Therefore, we can write

$$
\mathbf{A}-\sigma \mathbf{B}=\left(\begin{array}{cc}
\mathbf{U}_{\sigma} & \mathbf{R}_{\sigma \mathbf{t}} \\
\mathbf{R}_{\sigma} & \mathbf{H}_{\sigma}
\end{array}\right)
$$

where $\mathbf{U}_{\sigma}$ is a diagonal matrix $M \times M, \mathbf{R}_{\sigma}$ is an $M \times N$ matrix and $\mathbf{H}_{\sigma}$ is a square $N \times N$ matrix, and, as can be seen in Fig. 5.2, M is much larger than $\mathrm{N}$. The storage needed for this matrix would be of only $M+M \times N+N^{2}$ floating point numbers (vectors with lengths $M$ for the diagonal matrix, $M \times N$ for $\mathbf{R}$, and $N^{2}$ for $\mathbf{H}$ ).

Let us split the unknowns and the right hand side accordingly, so that the system can be written as follows

$$
\left(\begin{array}{cc}
\mathbf{U}_{\sigma} & \mathbf{R}_{\sigma \mathbf{t}} \\
\mathbf{R}_{\sigma} & \mathbf{H}_{\sigma}
\end{array}\right)\left(\begin{array}{l}
x \\
y
\end{array}\right)=\left(\begin{array}{l}
b_{1} \\
b_{2}
\end{array}\right)
$$


This system can be easily and efficiently solved using the Schur complement algorithm. It is extremely useful in this case since the larger matrix, $\mathbf{U}_{\sigma}$, is diagonal.

\section{Algorithm 3: Schur complement Algorithm}

1. Solve the system $\mathbf{U}_{\sigma} \cdot \mathbf{E}=\mathbf{R}_{\sigma \mathbf{t}}$ (trivial since $\mathbf{U}_{\sigma}$ is diagonal)

2. Compute $\mathbf{S}=\mathbf{H}_{\sigma}-\mathbf{R}_{\sigma} \cdot \mathbf{U}_{\sigma}^{-1} \cdot \mathbf{R}_{\sigma \mathbf{t}}=\mathbf{H}_{\sigma}-\mathbf{R}_{\sigma} \cdot \mathbf{E}$ ( $\mathbf{S}$ is the Schur complement matrix, of dimension $N \times N$, which is rather small when compared to the overall dimension of the system)

3. Compute an appropriate factorization of $\mathbf{S}$, such as $\mathbf{L D L}_{\mathbf{t}}$ or Cholesky

4. Solve $\mathbf{U}_{\sigma} \cdot f=b 1$ (again, trivial since $\mathbf{U}_{\sigma}$ is diagonal)

5. Compute $b_{2}^{\prime}=b_{2}-\mathbf{R}_{\sigma} \cdot f$

6. Using the factorization of step 3 , solve $\mathbf{S} \cdot y=b_{2}^{\prime}$

7. Compute $x=f-\mathbf{E} \cdot y$

Along any call to the Lanczos algorithm, there are many solves with the same matrix $\mathbf{A}-\sigma \mathbf{B}$ and different right hand sides. In the above algorithm, the first three steps only need to be carried out once, since the matrix $\mathbf{E}$ and the factorization of $\mathbf{S}$ are constant through the application of the complete algorithm. Therefore, the total CPU cost is further reduced, since these steps are the most expensive ones.

Finally, as mentioned above, the eigenvalues to be found are quite well localized, since all of them are positive, real and located in the interval $[0,1 /(4 \mathbf{U}(M, M))]$. Taking into account these facts, it is possible to obtain an algorithm to compute all the needed eigenvalues fairly efficiently and with minimal use of memory:

\section{Algorithm 4: Overall algorithm}

1. Divide the full interval $[0,1 /(4 \mathbf{U}(M, M))]$ in small subintervals

2. In each subinterval, compute a suitable "shift" $\sigma$, possibly the middle point of the subinterval 
3. Given the matrix $(\mathbf{A}-\sigma \mathbf{B})$, compute the $\mathbf{E}$ matrix and the factorization of the Schur Complement matrix $\mathbf{S}$

4. Apply Lanczos's method in each subinterval to the "shifted and inverted pencil" $\mathbf{C}=(\mathbf{A}-\sigma \mathbf{B})^{-1} \mathbf{B}$, to obtain all the eigenvalues and eigenvectors in the subinterval

5. Normalize the eigenvectors so that $\mathbf{x}_{\mathbf{t}} \mathbf{B x}=1$, and store them in disk

6. Repeat the steps $2,3,4,5$ in all subintervals

This algorithm computes only the eigenvalues in the desired range, in contrast with the LAPACK routine, which has to compute all the eigenvalues of the problem. Another positive aspect is that, for each subinterval, the extraction of eigenvalues is completely independent from the other subintervals, and therefore it can be carried out in parallel, either in shared or in distributed memory architectures. Implementations and experiments with parallel versions will be reported in a next authors' paper.

\section{Implementation details}

The new proposed algorithm has been implemented in Fortran 90, with the Intel Fortran Compiler for Linux and using BLAS and LAPACK [1] whenever it was possible.

The most important detail deals with the following strategy to obtain the subintervals. If the subintervals are too large (so that they contain too many eigenvalues), Algorithm 4 will need too much time and memory to extract them, and the subroutine might fail. On the other hand, if the subintervals contain too few (or none) eigenvalues, the search will be obviously computationally inefficient.

It is possible to use the Inertia Theorem [16] to know in advance how many eigenvalues contains a given interval $[\alpha, \beta]$. For such interval, the $\mathbf{L D L}_{\mathbf{t}}$ decompositions of $\mathbf{A}-\alpha \mathbf{B}$ (equal to $\mathbf{L}^{\alpha} \mathbf{D}^{\alpha} \mathbf{L}_{\mathbf{t}}{ }^{\alpha}$ ) and $\mathbf{A}-\beta \mathbf{B}$ (equal to $\mathbf{L}^{\beta} \mathbf{D}^{\beta} \mathbf{L}_{\mathbf{t}}{ }^{\beta}$ ) can be computed with a moderated cost (again, taking profit from the structures of the matrices). Then, the number of eigenvalues in the interval is simply the number $\nu\left(\mathbf{D}^{\beta}\right)-\nu\left(\mathbf{D}^{\alpha}\right)$, where $\nu(\mathbf{D})$ denotes the number of negative elements in the diagonal $\mathbf{D}$. 
However, in this problem it is known in advance that the eigenvalues are positive and are mostly clustered close to zero. This knowledge allows to use a simple adaptive algorithm which starts choosing a small subinterval width, and increases or decreases depending on the number of eigenvalues found in the last subinterval. For this problem, this strategy works quite well, so it is unnecessary to implement the more rigorous scheme described above.

When a subinterval is being processed, the eigenvalues in this subinterval should appear first, but it is also possible that some eigenvalues belonging to neighbor subintervals are detected as well. These outside eigenvalues could be saved, to avoid redundant computations, but it would increase the complexity of the code (it would also make less efficient the future parallel version of the code). Therefore, we preferred to keep the code simpler (although slightly less efficient) and to save only the eigenvalues strictly inside the interval being processed. (Of course, the discarded eigenvalues would have been detected in the previous subinterval, or shall be detected in the next subinterval).

\subsection{Validation Results}

Two scenarios have been selected for testing the new developed Lanczos-based BI-RME algorithm. The first one consists in the analysis of simple waveguide step discontinuities. For that purpose, the complete modal characterization of a single ridge waveguide and of an elliptic waveguide has been carried out for different problem sizes. The second benchmark consists in the analysis and design of a real passive microwave device composed of several discontinuities. All the CPU times included in this section have been obtained in a personal computer based on a Pentium IV platform at $2.4 \mathrm{GHz}$ with $1 \mathrm{~GB}$ of RAM.

For verification purposes, we have first considered a single ridge waveguide, which is widely used in many practical applications. For instance, it is typically employed to simulate the electrical behaviour of tuning elements present in many real passive waveguide devices, such as dual-mode resonator filters [13] and reentrant coaxial structures [4]. The selected ridge waveguide is built from a standard WR-75 waveguide $(a=19,05 \mathrm{~mm}$ and $b=9,525 \mathrm{~mm})$ with a single centered ridge of width $w=4 \mathrm{~mm}$ and depth $l=2,976 \mathrm{~mm}$ (see Fig. 5.2). In this example, 
Table 5.1: CPU time (sec.) and memory estimates (Mbytes) benchmark for the ridge waveguide

\begin{tabular}{rrrrr}
\hline$M+M^{\prime}$ & $\begin{array}{r}\text { TM Lanczos } \\
\text { time }\end{array}$ & $\begin{array}{r}\text { TM Lapack } \\
\text { time }\end{array}$ & $\begin{array}{r}\text { TM Lanczos } \\
\text { memory }\end{array}$ & $\begin{array}{r}\text { TM Lapack } \\
\text { memory }\end{array}$ \\
\hline 2000 & 11,62 & 9,41 & 3.50 & 9.28 \\
5000 & 51,51 & 145,85 & 8.02 & 53.13 \\
8000 & 186,53 & 585,37 & 12.55 & 132.98 \\
11000 & 417,43 & 1520,43 & 17.07 & 248.82 \\
14000 & 750,72 & 3117,51 & 21.59 & 400.67 \\
17000 & 1124,10 & 5968,20 & 26.12 & 588.52 \\
20000 & 1690,92 & - & 30.64 & 812.37 \\
\hline
\end{tabular}

\begin{tabular}{rrr}
\hline$M+M^{\prime}$ & $\begin{array}{r}\text { TE Lanczos } \\
\text { time }\end{array}$ & $\begin{array}{r}\text { TE Lapack } \\
\text { time }\end{array}$ \\
\hline 2000 & 6,61 & 18,85 \\
5000 & 49,05 & 256,93 \\
8000 & 178,46 & 1003,09 \\
11000 & 399,66 & 2555,95 \\
14000 & 733,08 & 5198,77 \\
17000 & 1260,11 & 9100,51 \\
20000 & 1849,012 & - \\
\hline
\end{tabular}

the perturbation over the basic rectangular contour is very small, and consequently the segmentation order $N$ in the BI-RME problem is also small.

In Table 5.1, we present the CPU times required in the solution of the eigenvalue equations that arise in the TM and the TE cases of the considered ridged waveguide. A comparison between the computational effort required by the standard (Lapack-based) BI-RME solution and by the new (Lanczos-based) BI-RME approach for different sizes of the problem (when the total number $M+M^{\prime}$ of TE and TM rectangular waveguide modes grows, with $\mathrm{N}$ constant equal to 177) has been performed. There is a gain in computation time for all cases in the TE solution and above $2000\left(M+M^{\prime}\right)$ for the TM case with very large differences when the problem grows. Such computational gain can be of 
Table 5.2: CPU time benchmark for the elliptic waveguide

\begin{tabular}{rrr}
\hline$M+M^{\prime}$ & Lanczos & Lapack \\
\hline 2000 & 57,07 & 45,50 \\
5000 & 615,79 & 537,54 \\
8000 & 1687,08 & 2032,31 \\
11000 & 3859,64 & 4946,42 \\
14000 & 7881,92 & 9703,92 \\
17000 & 15196,08 & 17138,52 \\
20000 & 25765,05 & - \\
\hline
\end{tabular}

paramount importance for design applications requiring a high degree of accuracy (i.e. when a big number of the ridge waveguide modes are needed). Furthermore, one of the most remarkable features comes from the fact that the new Lanczos approach can achieve appropriate results using less memory requirements than the Lapack scheme (see the comparative study for TM modes included in Table 5.1). From such table it can be concluded that, due to memory requirements, a standard computer is not able to cope with problems where $M+M^{\prime}=20000$.

The next structure we have considered is an elliptical waveguide, whose complete modal chart analysis has received considerable attention in the technical literature (see for instance [9]). For this example, we have considered an elliptical waveguide of major semi-axis equal to $6,39 \mathrm{~mm}$ and minor semi-axis of length $2,0 \mathrm{~mm}$. In order to apply the BI-RME method, we have considered that the ellipse is centered within a rectangular box of $15,05 \mathrm{~mm}$ width and $5,525 \mathrm{~mm}$ height. In such a case, the elliptical waveguide must be segmented with a bigger order $N$ than in the previous ridge case.

In Table 5.2, we compare again the CPU times consumed in the whole solution of the two eigenvalue equations (TE and TM modes) using the Lanczos algorithm and the Lapack software package. As it can be seen in the table, there is a computational gain using the new Lanczos algorithm when the number of required modes is large enough (from $M+M^{\prime}=8000$ ), and such gain is improved when the problem order grows. Such behaviour can be of great practical interest when designing complex waveguide devices involving elliptical waveguides, such 
as the dual-mode filter considered next. Again, the Lanczos-based solution allows to cope in personal computers with larger eigenvalue problems than the more classical Lapack subroutines.

For the full-wave analysis and design of passive waveguide devices composed of arbitrarily shaped waveguides, the accurate and efficient computation of the coupling coefficients of cascaded waveguides is also required (see [7]-[19]). The BI-RME algorithm is also capable of providing such data in a very efficient way after some post-processing of the eigenvector solutions for the TE and TM modes. Therefore, we should also verify that the new Lanczos-based BI-RME algorithm provides these coupling coefficients with the required accuracy. For such purposes, we have considered a simple discontinuity between the elliptical waveguide and the rectangular box just considered above. This is a typical discontinuity in novel dual-mode filters in circular waveguide technology, such as the one designed in this paper.

In Table 5.3 we compare the coupling integrals between the elliptical waveguide and the rectangular box modes provided by the Lanczos and Lapack algorithms. In this table, the rectangular waveguide modes

Table 5.3: Coupling integrals between the elliptical waveguide and the rectangular box modes

\begin{tabular}{llcc}
\hline Rectang. & Ellip. & Lanczos & Lapack \\
\hline$T M_{1,2}$ & $T E_{1}$ & $-4,4768255413 \cdot 10^{-1}$ & $-4,47682554148 \cdot 10^{-1}$ \\
$T M_{39,40}$ & $T E_{24}$ & $2,46388401980 \cdot 10^{-16}$ & $1,21988159886 \cdot 10^{-9}$ \\
$T M_{65,14}$ & $T E_{39}$ & $2,34873914445 \cdot 10^{-3}$ & $2,34873914350 \cdot 10^{-3}$ \\
$T M_{121,2}$ & $T E_{60}$ & $-2,06617084104 \cdot 10^{-15}$ & $-3,97897411044 \cdot 10^{-9}$ \\
$T M_{66,3}$ & $T E_{65}$ & $-1,43517296715 \cdot 10^{-15}$ & $-1,91484292810 \cdot 10^{-9}$ \\
$T M_{66,50}$ & $T E_{85}$ & $3,53622716467 \cdot 10^{-4}$ & $3,53622602232 \cdot 10^{-4}$ \\
$T E_{82,16}$ & $T E_{59}$ & $2,56154543169 \cdot 10^{-15}$ & $6,39947423141 \cdot 10^{-10}$ \\
$T E_{12,48}$ & $T E_{61}$ & $-1,05666961916 \cdot 10^{-15}$ & $-1,13587895332 \cdot 10^{-10}$ \\
$T M_{1,37}$ & $T M_{5}$ & $1,25309697451 \cdot 10^{-3}$ & $1,25309547142 \cdot 10^{-3}$ \\
$T M_{25,26}$ & $T M_{8}$ & $1,47959602841 \cdot 10^{-17}$ & $1,25471743981 \cdot 10^{-6}$ \\
$T M_{30,30}$ & $T M_{10}$ & $-1,28727184633 \cdot 10^{-17}$ & $-7,94627981935 \cdot 10^{-8}$ \\
$T M_{10,1}$ & $T M_{12}$ & $7,31693059625 \cdot 10^{-1}$ & $7,31693040595 \cdot 10^{-1}$ \\
$T M_{6,49}$ & $T M_{13}$ & $-1,61344247003 \cdot 10^{-18}$ & $-8,40292068626 \cdot 10^{-9}$ \\
$T M_{34,14}$ & $T M_{14}$ & $4,41682301868 \cdot 10^{-17}$ & $2,59467544482 \cdot 10^{-7}$ \\
\hline
\end{tabular}


are defined by their typical two indexes [14], whereas the elliptical waveguide modes have been ordered by a single number increasing with higher cutoff frequencies. As it can be observed, for the significant values (those higher than $10^{-5}$ ) of the required coupling coefficients, both solvers provide very similar results. However, for low values (below $10^{-6}$ ), the results provided by the Lanczos approach are smaller in some orders of magnitude. In fact, such low value coupling coefficients are really equal to 0 , as it is analytically proved in [7]. Therefore, we can conclude that the new Lanczos-based algorithm provides in such cases more accurate eigenvector solutions than the Lapack routine. The authors have verified that such feature can directly affect the accuracy in the full-wave analysis of some complex passive waveguide components.

Finally, we have integrated the novel Lanczos-based BI-RME method within a CAD tool of passive waveguide devices. Making use of such tool, we have completely designed a dual-mode filter in circular waveguide technology using only elliptical irises (see a complete structure scheme in Fig. 5.3). The input/output coupling elliptical irises are identical to the waveguide considered in the previous example. For the comparative full-wave analysis of this real filter, we have considered 100 accessible modes, 300 basis functions and 750 kernel terms (the meaning of these parameters is explained in $[5,19]$ ), which are rather high. However, it should be pointed out that such limit values have been fixed by the memory restrictions of the Lapack routine. If we wanted to obtain extremely accurate results, these numbers should be increased, and then only the new Lanczos-based algorithm could be employed. Then, for such example, the CPU times has been $4711,62 \mathrm{sec}$. for the new Lanczos method and $6295,85 \mathrm{sec}$. in the case of the Lapack conventional method. This important saving on CPU effort would be even improved for more accurate applications.

For verification purposes, a prototype of this dual-mode filter has been manufactured (see pieces at Fig. 5.4). The measured scattering parameters of this structure are compared in Fig. 5.5 with the theoretical results predicted by the Lanczos and Lapack algorithms. As can be seen in such figure, the two eigenvalue problem solvers provide very similar (almost identical) results, which are also rather close to the real measurements. Nevertheless, the small differences between measured and simulated results could be attributed to mechanical tolerances. 


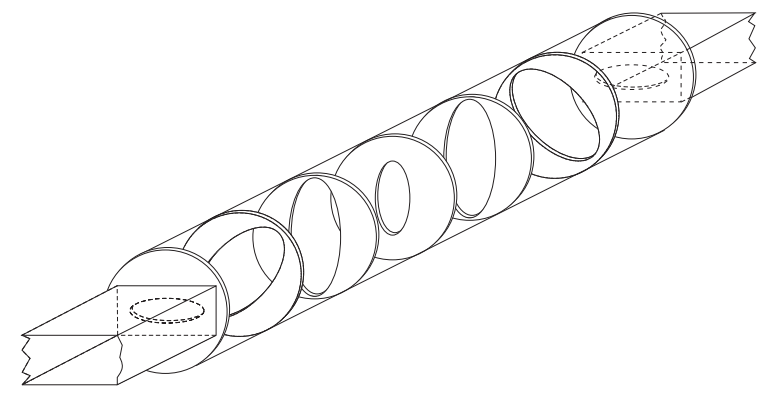

Figure 5.3: Dual-mode filter inner structure composed of circular waveguide sections and elliptical irises.

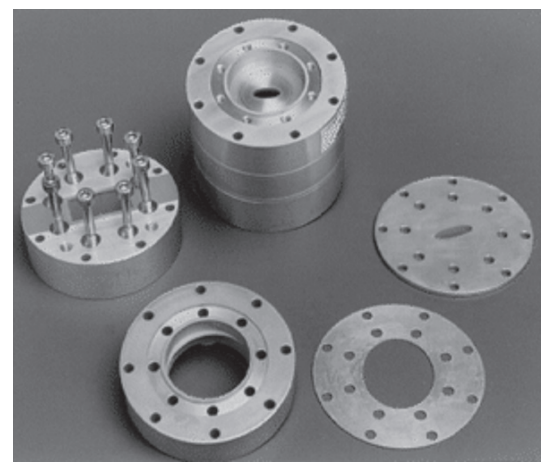

Figure 5.4: Photograph of the components of the manufactured dualmode filter prototype.

\subsection{Conclusions}

A novel Lanczos-based eigenvalue solver has been successfully developed for the fast solution of large eigenvalue problems arising with the BI-RME method. This new strategy provides stronger computational advantages than available standard eigenvalue routines, thus allowing the solution of larger matrix problems in lower CPU times. It has been proved that this gain is even greater when the size of the algebraic problem grows, which can be of great practical interest when designing complex passive waveguide devices. In order to validate the efficiency 


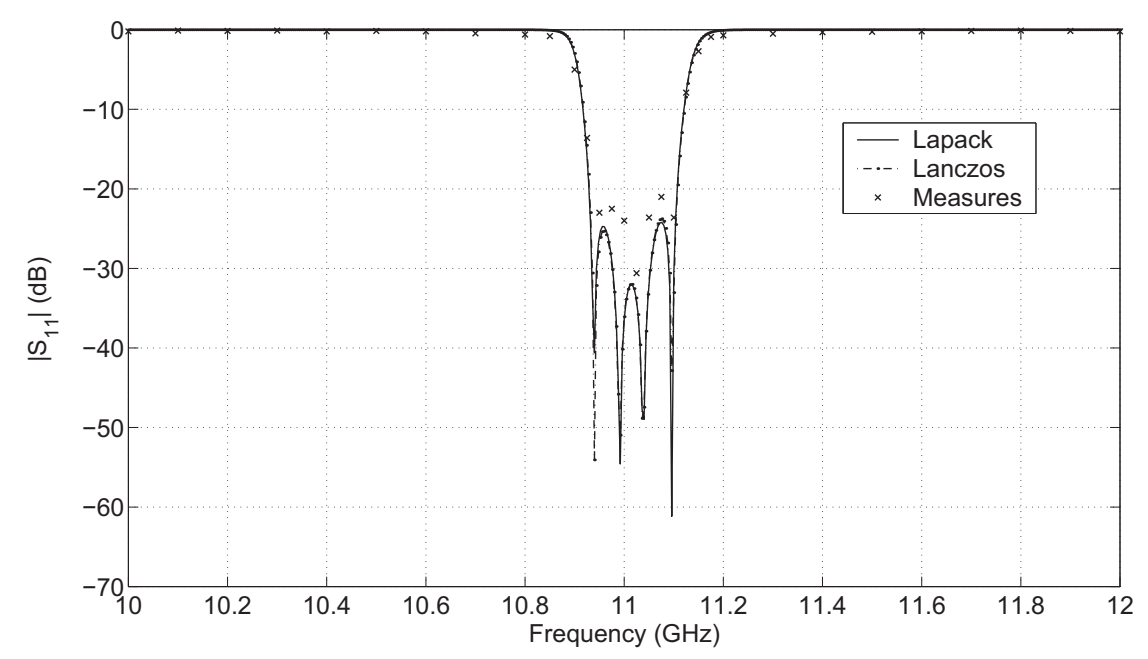

Figure 5.5: Comparison between the results provided by the conventional Lapack package and the new Lanczos-based implementation.

improvement provided by the inclusion of the new Lanczos approach within the BI-RME formulation, several comparative test benchmarks have been performed. For instance, the CPU times required for computing large modal charts of two widely used arbitrarily shaped waveguides, i.e. a ridge rectangular guide and an elliptical one, have been compared to the computational costs of standard eigenvalue solvers. Finally, making use of a CAD tool based on the novel Lanczos algorithm, we have designed a dual-mode circular waveguide filter with elliptical irises for space applications. A prototype of such filter has been manufactured and measured, thus fully validating the accuracy provided by the Lanczos method developed.

\section{Acknowledgements}

The authors would like to thank Dr. Marco Guglielmi, from European Space Research and Technology Centre (ESTEC, ESA), The Netherlands, for providing the dual-mode filter prototype used for verification purposes. 


\section{Bibliography}

[1] E. Anderson, Z. Bai, C. Bischof, S. Blackford, J. Demmel, J. Dongarra, J. Du Croz, A. Greenbaum, S. Hammarling, A. McKenney, and D. Sorensen. LAPACK Users' Guide. SIAM, Philadelphia, 1999.

[2] P. Arcioni, M. Bressan, and G. Conciauro. A new algorithm for the wide-band analysis of arbitrarily shaped planar circuits. IEEE Transactions on Microwave Theory and Techniques, 36(10):1426-1437, Oct. 1988.

[3] Z. Bai, J. Demmel, J. Dongarra, A. Ruhe, and H. Van der Vorst (editors). Templates for the Solution of Algebraic Eigenvalue Problems: A Practical Guide. SIAM, Philadelphia, first edition, 2000.

[4] V. E. Boria, G. Gerini, and M. Guglielmi. Computer aided design of reentrant coaxial filter including coaxial excitation. 1999 IEEE MTT-S Int. Microw. Symp. Digest, 3:1131-1134, June 1999.

[5] S. Cogollos, S. Marini, V.E. Boria, P. Soto, A. Vidal, H. Esteban, J. V. Morro, and B. Gimeno. Efficient modal analysis of arbitrarily shaped waveguides composed of linear, circular and elliptical arcs using the BI-RME method. IEEE Transactions on Microwave Theory and Techniques, 51(12):2378-2390, Dec. 2003.

[6] G. Conciauro, M. Bressan, and C. Zuffada. Waveguide modes via an integral equation leading to a linear matrix eigenvalue problem. IEEE Transactions on Microwave Theory and Techniques, 32(11):14951504, Nov. 1984.

[7] G. Conciauro, M. Guglielmi, and M. Sorrentino. Advanced Modal Analysis - CAD Techniques for Waveguide Components and Filters. John Wiley \& Sons, Ltd., Chichester, 2000.

[8] P. Couffignal, H. Baudrand, and B. Théron. A new rigorous method for the determination of iris dimensions in dual-mode cavity filters. IEEE Transactions on Microwave Theory and Techniques, 42(7):1314-1320, July 1994. 
[9] B. Gimeno and M. Guglielmi. Full wave network representation for rectangular, circular and elliptical to elliptical waveguide juntions. IEEE Transactions on Microwave Theory and Techniques, 45(3):376-384, March 1997.

[10] G.H. Golub and C.F. Van Loan. Matrix Computations. John Hopkins University Press, Baltimore, Maryland, third edition, 1996.

[11] M. Guglielmi, R. C. Molina, and A. Alvarez. Dual-mode circular waveguide filters without tuning screws. IEEE Microwave and Guided Wavel Letters, 2(11):457-458, November 1992.

[12] T. Itoh. Numerical Techniques for Microwave and Millimeter-Wave Passive Structures. John Wiley \& Sons, Ltd., New York, 1989.

[13] X.-P. Liang, K. A. Zaki, and A. E. Atia. Dual mode coupling by square corner cut in resonators and filters. IEEE Transactions on Microwave Theory and Techniques, 40(12):2294-2302, December 1992.

[14] N. Marcuvitz. Waveguide Handbook. Peter Peregrinus Ltd., IEE Electromagnetic Waves Series 21, London, UK, 1986.

[15] J. R. Montejo-Garai and J. Zapata. Full-wave design and realization of multicoupled dual-mode circular waveguide filters. IEEE Transactions on Microwave Theory and Techniques, 43(6):1290-1297, June 1995.

[16] A. Ruhe. Generalized Hermitian Eigenvalue Problem; Lanczos Method, In Templates for the Solution of Algebraic Eigenvalue Problems: a Practical Guide. SIAM, Philadelphia, first edition, 2000.

[17] A. Ruhe. Hermitian Eigenvalue Problem; Lanczos Method, In Templates for the Solution of Algebraic Eigenvalue Problems: a Practical Guide. SIAM, Philadelphia, first edition, 2000.

[18] A. Taflove. Computational Electromagnetics: The Finite-Difference Time-Domain Method. Artech House, Norwood, 1995.

[19] M. Taroncher, A. Vidal, V.E. Boria, S. Marini, S. Cogollos, G. Gil, and B. Gimeno. CAD of complex passive devices composed of 
arbitrarily shaped waveguides using Nyström and BI-RME methods. IEEE Transactions on Microwave Theory and Techniques, 53(7), To be published in July 2005.

[20] J. Uher, J. Bornemann, and U. Rosenberg. Waveguide Components for Antenna Feed Systems: Theory and CAD. Artech House, Norwood, 1993. 



\title{
6
}

\section{Parallel computation of arbitrarily shaped waveguide modes using BI-RME and Lanczos methods}

\section{Authors}

A. M. Vidal, A. Vidal, V. E. Boria, and García.

\begin{abstract}
This paper is devoted to the parallelization of a new method for solving large, structured eigenvalue problems which appear in the electromagnetic modal analysis of arbitrarily shaped waveguides, typically present in many modern passive devices. This new method, based on the Boundary Integral - Resonant Mode Expansion (BI-RME) technique and in the Lanczos method (for solution of the eigenvalue problem), was recently proposed by the authors, showing important advantages in terms of CPU time and memory over previously used solutions. As it will be fully described in this paper, the parallel version of such new method allows further important savings in the overall CPU computation time. Comparative benchmarks and scalability issues related to the implemented parallel algorithm are discussed.
\end{abstract}




\subsection{Introduction}

Single ridge and multi-ridge rectangular waveguides, elliptical and cross-shaped irises, as well as circular and elliptical shaped resonators including tuning elements, just to cite a few examples, are typically found in most common passive waveguide devices used in practical applications (see for instance [10]). For the accurate and efficient design of these components, Computer Aided Design (CAD) tools based on modal methods are becoming increasingly popular [4]. In many situations (i.e. such as the dual mode filter considered in [9] or the twist component analyzed in [2]), the practical usage of such analysis methods typically needs the knowledge of a huge number of modes of the aforementioned waveguides, which can be seen as particular cases of a waveguide with an arbitrary cross-section.

Among the many methods proposed in the technical literature for solving the modal problem under study, the BI-RME method originally described in [3] has become one of the most widely used, since it is based on the fast and rigorous Method of Moments (MoM) for the solution of integral equations. This method has been updated to deal with more complex geometries [2,9]; however, the computing times needed for these cases were too high. A solution for this problem was recently published by the authors: an updated version of the BI-RME method based on the Lanczos algorithm, which was used for the faster solution of the related generalized eigenvalue problems [5]. Despite that, the accurate analysis of some real devices involving many arbitrarily shaped waveguide geometries still suffer from very high CPU costs, which is not suitable for automated design procedures.

Therefore, any further effort related to improve the computational efficiency of the BI-RME method would be really welcomed. With such aim, this paper deals with the parallel implementation of the Lanczosbased BI-RME method. For this purpose, first we briefly review the basics of the electromagnetic theory related to the formulation of the well-known BI-RME method in terms of generalized eigenvalue problems. Next, we describe the sequential implementation of the Lanczos algorithm originally proposed in [5], but making special emphasis in all aspects of such method that could be parallelized. Then, the novel parallel version proposed for efficiently implementing the Lanczos-based BI-RME method is thoroughly described. Finally, several numerical re- 


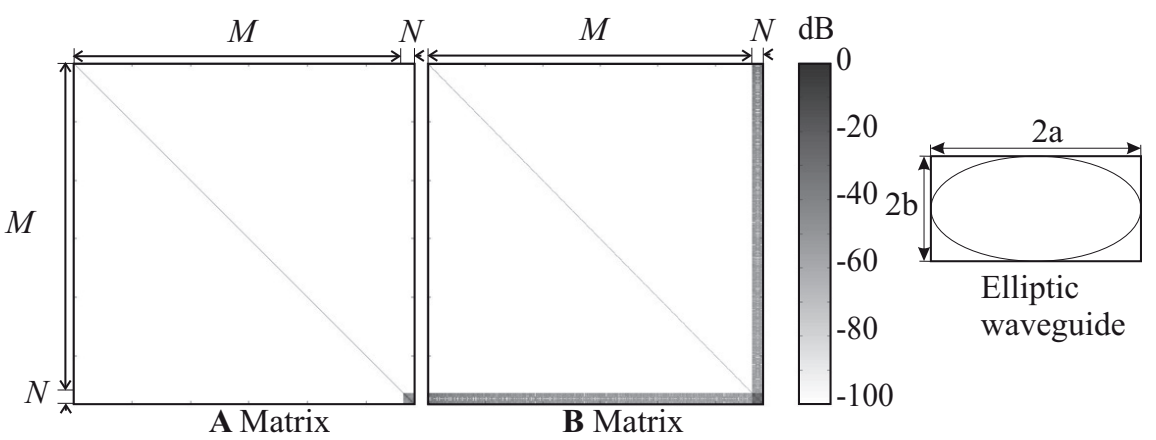

Figure 6.1: Non-zero elements structure of matrices $\mathbf{A}$ and $\mathbf{B}$ for the TE modal analysis of an elliptical waveguide $(2 a=12,78 \mathrm{~mm}$, and $2 b=$ $4,00 \mathrm{~mm})$.

sults confirming the efficiency gain related to the parallel implementation of the Lanczos-based BI-RME method are shown. These results correspond to the accurate modal analysis of two widely used waveguides, such as ridge and elliptical waveguides typically present in different filter configurations $[1,8]$. The scalability of the novel parallel algorithm is also discussed.

\subsection{BI-RME Theory}

The BI-RME method provides the modal chart of arbitrarily shaped waveguides by solving a set of Integral Equations (IEs) by the Galerkin version of the MoM. The main advantage of this method is that leads to generalized eigenvalue problems involving structured matrices (see the detailed original formulation in [3]).

Following the BI-RME method as described in [5], we obtain two different generalized eigenvalue problems for solving the TE and TM family modes. In both cases, the matrix problem can be cast into the following way

$$
\mathbf{A x}=\lambda \mathbf{B} \mathbf{x}
$$

where $A$ and $B$ are structured matrices of four subblocks each one, 
which are defined as follows for the TE case

$$
\mathbf{A}=\left[\begin{array}{cc}
\mathbf{I} & \mathrm{O}_{\mathrm{t}} \\
\mathbf{O} & \mathrm{C}
\end{array}\right] \quad \mathbf{B}=\left[\begin{array}{cc}
\mathbf{U} & \mathbf{R}_{\mathrm{t}} \\
\mathbf{R} & \mathbf{H}
\end{array}\right]
$$

and for the TM case

$$
\mathbf{A}=\left[\begin{array}{ll}
\mathbf{I} & \mathbf{O}_{\mathbf{t}} \\
\mathbf{O} & \mathbf{O}^{\prime}
\end{array}\right] \quad \mathbf{B}=\left[\begin{array}{ll}
\mathbf{U}^{\prime} & \mathbf{R}_{\mathbf{t}}^{\prime} \\
\mathbf{R}^{\prime} & \mathbf{H}^{\prime}
\end{array}\right]
$$

The meanings of all previous block matrices, their dimensions and also the mathematical definition of their corresponding elements, are fully detailed in [5]. However, it must be recalled that $\mathbf{O}$ and $\mathbf{O}^{\prime}$ are null matrices, the subscript ${ }_{t}$ denotes transpose, $\mathbf{I}$ is the identity matrix, whereas $\mathbf{U}$ and $\mathbf{U}^{\prime}$ are diagonal matrices. Therefore, the matrices $\mathbf{A}$ and $\mathbf{B}$ are very sparse, as it can be seen in Fig. 6.1 for the TE modal analysis of an elliptical waveguide (similar matrices would be obtained for the TM case, but in such case the A matrix would only have non-zero entries in the main diagonal of subblock I).

The eigenvalue and eigenvector solutions of Eq.(6.1) are related, respectively, to the cutoff wavenumbers of the arbitrarily shaped waveguide modes, and to their corresponding normalized electromagnetic modal solutions. As shown in Fig. 6.1, the generalized eigenvalue problem for the TE case presents a size of $(M+N) \times(M+N)$, where $M$ is the number of standard rectangular waveguide TE modes used for expanding each arbitrary waveguide mode, and $N$ is the number of basis functions used to expand the unknown surface current density (in most cases $M$ is much larger than $N$ ). For the TM problem, the same corresponding numbers are usually labelled as $M^{\prime}$ and $N^{\prime}$ (see [5]).

\subsection{Sequential Generalized Eigenvalue Equa- tion Solution}

In the previous paper [5], the authors proposed an algorithm based on the Lanczos technique, which uses the structure of the matrices to minimize the cost, in time and specially in memory, of the algorithm. It was based on the Shift-and-Invert version of the Lanczos algorithm for generalized symmetric eigenvalue problems, which given a real number $\sigma$ (the "shift"), delivers the eigenvalues closer to $\sigma$. The Shift-and 
Invert version of the Lanczos algorithm for generalized eigenproblems is as follows (The formulation has been taken from [7]; all the details can be checked there as well).

Algorithm 1: Lanczos with shift-invert for generalized symmetric eigenvalue problem.

1. $r=$ starting vector; $q=B r, \beta_{0}=\left|q^{*} r\right|^{\frac{1}{2}}$

2. for $j=1,2, \ldots$ until convergence

3. $w_{j}=r / \beta_{j-1}, v_{j}=r / \beta_{j-1}$

4. $r=(\mathbf{A}-\sigma \mathbf{B})^{-1} v_{j}$

5. $\quad r=r-w_{j-1} \beta_{j-1}$

6. $\alpha_{j}=v_{j}^{*} r$

7. $r=r-w_{j} \cdot \alpha_{j}$

8. re-orthogonalize if necessary

9. $q=B r$

10. $\beta_{j}=\left|q^{*} r\right|^{\frac{1}{2}}$

11. if $j>1$ compute approximate eigenvalues of $\mathbf{T}_{j}$ :

$$
T_{j}=\left[\begin{array}{cccc}
\alpha_{1} & \beta_{1} & & \\
\beta_{1} & \alpha_{2} & \ddots & \\
& \ddots & \ddots & \beta_{j-1} \\
& & \beta_{j-1} & \alpha_{j}
\end{array}\right]
$$

12. test bounds for convergence

13. end for

14. compute approximate eigenvectors

In order to apply the Lanczos method to this problem, it is necessary to solve linear systems with coefficient matrix $\mathbf{A}-\sigma \mathbf{B}$. Using the structure of the matrices, these linear solves can be made very efficiently as indicated next. 
Schur complement technique for solution of linear systems To apply the "Shift-and-Invert" technique, we need to solve efficiently the linear system $(\mathbf{A}-\sigma \mathbf{B}) x=b$. Looking either at the matrices in Eq.(6.2) or (6.3), we see that the structure of such matrix $\mathbf{A}-\sigma \mathbf{B}$ will be similar to the one shown in Fig. 6.1. Therefore, we can write

$$
\mathbf{A}-\sigma \mathbf{B}=\left(\begin{array}{cc}
\mathbf{U}_{\sigma} & \mathbf{R}_{\sigma \mathbf{t}} \\
\mathbf{R}_{\sigma} & \mathbf{H}_{\sigma}
\end{array}\right)
$$

where $\mathbf{U}_{\sigma}$ is an $M \times M$ diagonal matrix, $\mathbf{R}_{\sigma}$ is an $M \times N$ matrix and $\mathbf{H}_{\sigma}$ is a square $N \times N$ matrix, and, as can be seen in Fig. 6.1, $\mathrm{M}$ is much larger than $\mathrm{N}$. The storage needed for this matrix would be of only $M+$ $M \times N+N^{2}$ floating point numbers (vectors with lengths $M$ for the diagonal matrix, $M \times N$ for $\mathbf{R}$, and $N^{2}$ for $\mathbf{H}$ ).

Let us split the unknowns and the right hand side accordingly, so that the system can be written as follows

$$
\left(\begin{array}{cc}
\mathbf{U}_{\sigma} & \mathbf{R}_{\sigma \mathbf{t}} \\
\mathbf{R}_{\sigma} & \mathbf{H}_{\sigma}
\end{array}\right)\left(\begin{array}{l}
x \\
y
\end{array}\right)=\left(\begin{array}{c}
b_{1} \\
b_{2}
\end{array}\right)
$$

This system can be easily and efficiently solved using the Schur complement algorithm. It is extremely useful in this case since the larger matrix, $\mathbf{U}_{\sigma}$, is diagonal.

Algorithm 2: Schur complement Algorithm

1. Solve the system $\mathbf{U}_{\sigma} \cdot \mathbf{E}=\mathbf{R}_{\sigma \mathbf{t}}$ (trivial since $\mathbf{U}_{\sigma}$ is diagonal)

2. Compute $\mathbf{S}=\mathbf{H}_{\sigma}-\mathbf{R}_{\sigma} \cdot \mathbf{U}_{\sigma}^{-1} \cdot \mathbf{R}_{\sigma \mathbf{t}}=\mathbf{H}_{\sigma}-\mathbf{R}_{\sigma} \cdot \mathbf{E}$ (S is the Schur complement matrix, of dimension $N \times N$, which is rather small when compared to the overall dimension of the system)

3. Compute an appropriate factorization of $\mathbf{S}$, such as $\mathbf{L D L}_{\mathbf{t}}$ or Cholesky

4. Solve $\mathbf{U}_{\sigma} \cdot f=b_{1}$ (again, trivial since $\mathbf{U}_{\sigma}$ is diagonal)

5. Compute $b_{2}^{\prime}=b_{2}-\mathbf{R}_{\sigma} \cdot f$

6. Using the factorization of step 3 , solve $\mathbf{S} \cdot y=b_{2}^{\prime}$

7. Compute $x=f-\mathbf{E} \cdot y$ 
Along any call to the Lanczos algorithm, there are many solves with the same matrix $\mathbf{A}-\sigma \mathbf{B}$ and different right hand sides. In the above algorithm, the first three steps only need to be carried out once, since the matrix $\mathbf{E}$ and the factorization of $\mathbf{S}$ are constant through the application of the complete algorithm. Therefore, the total CPU cost is further reduced, since these steps are the most expensive ones.

Finally, as mentioned above, the eigenvalues to be found are quite well localized, since all of them are real, positive, and located in the interval $[0,1 /(4 \mathbf{U}(M, M))]$. Taking into account these facts, it is possible to obtain an algorithm to compute all the needed eigenvalues fairly efficiently and with minimal use of memory:

\section{Algorithm 3: Overall algorithm}

1. Divide the full interval $[0,1 /(4 \mathbf{U}(M, M))]$ in small subintervals

2. In each subinterval, compute a suitable "shift" $\sigma$, possibly the middle point of the subinterval

3. Given the matrix $(\mathbf{A}-\sigma \mathbf{B})$, compute the $\mathbf{E}$ matrix and the factorization of the Schur Complement matrix $\mathbf{S}$

4. Apply Lanczos's method in each subinterval to the "shifted and inverted pencil" $\mathbf{C}=(\mathbf{A}-\sigma \mathbf{B})^{-1} \mathbf{B}$, to obtain all the eigenvalues and eigenvectors in the subinterval

5. Normalize the eigenvectors so that $\mathbf{x}_{\mathbf{t}} \mathbf{B} \mathbf{x}=1$, and store them in disk

6. Repeat the steps $2,3,4,5$ in all subintervals

This algorithm has been implemented embedding all the calculations for a subinterval in a driver routine. This routine takes as input the matrices and the limits of the interval, and returns the generalized eigenvalues contained in the subinterval, along with their associated eigenvectors. There is a maximum number of eigenvalues that can be computed in each subinterval; this number can be set by the user, but our experience shows that 100 is a reasonable number. If the number of eigenvalues in the interval exceeds the limit, the routine returns a warning, so that the interval limits can be readjusted. In this case, there 
will be as well a loss of efficiency, since many calculations should be repeated.

If there are no eigenvalues in the subinterval, the routine will detect it and issues a message to the calling program, so that this interval is skipped. Again, this causes a waste of CPU time. Experimentation shows that the best efficiency is obtained if the number of eigenvalues in the interval is around 20 or 30.

It is quite clear that the choice of the subintervals will have a strong influence on the global efficiency of the method. In the previous paper [5], when the sequential version of the algorithm was presented, a simple adaptive strategy was chosen, since the gains to be obtained using more sophisticated strategies were not too important. However, as we will see in the next section, this matter is much more relevant considering the parallel processing of the intervals.

\subsection{Parallel Generalized Eigenvalue Equation Solution}

The algorithm proposed in [5] and described above has many advantages over the standard Lapack-based software for this problem, even in sequential computing. In a parallel computing environment, the advantages are still larger: even without performing any test at all, it is fairly clear that computing the eigenvalues of each subinterval can be performed independently to the process of any other subinterval; therefore, it is an excellent algorithm to be parallelized.

However, a straightforward parallelization, just dividing the main interval (where all the eigenvalues of interest are located) in subintervals of the same length among the available processors, obtains some gains over the sequential version, but far from the gains expected. The reasons for this are twofold: First, the distribution of the eigenvalues over the interval can be quite irregular, so that these can be clustered in a few of the subintervals. This, of course, can lead to a load imbalance among the processors, with some processors doing most of the work while others are idle. Second, even if the number of eigenvalues on each subinterval is well balanced, in some intervals the work needed to obtain all the eigenvalues might be different. This can happen 
because some eigenvalues may need more Lanczos iterations than others. Again, this might create a load imbalance.

Next, we will describe the strategy followed to select the subintervals, so that the load imbalance is minimized.

\subsubsection{Selection of subintervals}

As mentioned in [5] it is possible to use the Inertia Theorem [7] to know in advance how many eigenvalues contains a given interval $[\alpha, \beta]$. For such interval, the $\mathbf{L D L}_{\mathbf{t}}$ decompositions of $\mathbf{A}-\alpha \mathbf{B}$ (equal to $\mathbf{L}^{\alpha} \mathbf{D}^{\alpha} \mathbf{L}_{\mathbf{t}}{ }^{\alpha}$ ) and $\mathbf{A}-\beta \mathbf{B}$ (equal to $\mathbf{L}^{\beta} \mathbf{D}^{\beta} \mathbf{L}_{\mathbf{t}}{ }^{\beta}$ ) can be computed with a moderated cost (as we will see below). Then, the number of eigenvalues in the interval is simply the number $\nu\left(\mathbf{D}^{\beta}\right)-\nu\left(\mathbf{D}^{\alpha}\right)$, where $\nu(\mathbf{D})$ denotes the number of negative elements in the diagonal $\mathbf{D}$.

Let us now find out how is the $\mathbf{L D L}_{\mathbf{t}}$ decomposition of the matrices in our case. For a matrix $(\mathbf{A}-\sigma \mathbf{B})$ with $\mathbf{A}$ and $\mathbf{B}$ as above, we can write

$$
\begin{aligned}
\mathbf{A}-\sigma \mathbf{B} & =\left(\begin{array}{cc}
\mathbf{U}_{\sigma} & \mathbf{R}_{\sigma t} \\
\mathbf{R}_{\sigma} & \mathbf{H}_{\sigma}
\end{array}\right) \\
& =\left(\begin{array}{cc}
\mathbf{D} & \mathbf{0} \\
\mathbf{F} & \mathbf{T}
\end{array}\right) \cdot\left(\begin{array}{cc}
\mathbf{D}_{l} & \mathbf{0} \\
\mathbf{0} & \mathbf{D}_{s}
\end{array}\right) \cdot\left(\begin{array}{cc}
\mathbf{D}_{\mathbf{t}} & \mathbf{F}_{\mathbf{t}} \\
\mathbf{0} & \mathbf{T}_{\mathbf{t}}
\end{array}\right) \\
& =\left(\begin{array}{cc}
\mathbf{D} \cdot \mathbf{D}_{l} \cdot \mathbf{D}_{\mathbf{t}} & \mathbf{D} \cdot \mathbf{D}_{l} \cdot \mathbf{F}_{\mathbf{t}} \\
\mathbf{F} \cdot \mathbf{D}_{l} \cdot \mathbf{D}_{t} & \mathbf{F} \cdot \mathbf{D}_{l} \cdot \mathbf{F}_{\mathbf{t}}+\mathbf{T} \cdot \mathbf{D}_{s} \cdot \mathbf{T}_{\mathbf{t}}
\end{array}\right)
\end{aligned}
$$

It is easy to check that we can take $\mathbf{D}$ as the identity matrix, so that equating parts of this equation we arrive to the following procedure to compute the $\mathbf{L D L}_{\mathbf{t}}$ decomposition:

1. Take $\mathbf{D}_{l}$ equal to $\mathbf{U}_{\sigma}$.

2. $\mathbf{F}=\mathbf{R}_{\sigma} \cdot \mathbf{D}_{l}^{-1}$ (trivial, since $\mathbf{D}_{l}$ is diagonal).

3. $\mathbf{T}$ and $\mathbf{D}_{s}$ are obtained computing the $\mathbf{L D L} \mathbf{L}_{\mathbf{t}}$ decomposition of $\mathbf{H}_{\sigma}-\mathbf{F} \cdot \mathbf{D}_{l} \cdot \mathbf{F}_{\mathbf{t}}$.

Therefore, it is possible to implement a search procedure such that it selects an initial division of the main interval and computes the number of eigenvalues on each subinterval (computing an $\mathbf{L D L}_{\mathbf{t}}$ decomposition 
for each limit). Then, it would reduce the width of the intervals with too many eigenvalues and increases the width of those intervals with too few eigenvalues, discarding the subintervals without any eigenvalues. The main cost of this algorithm would be the $\mathbf{L D L}_{\mathbf{t}}$ decompositions on step 3; this is not a very high cost, since the dimension of the matrices involved is $N$. In this way, we might obtain a perfectly balanced load distribution.

However, the special form of the $\mathbf{L D L}_{\mathbf{t}}$ decompositions in this case suggests a different algorithm, somewhat less accurate but with very low cost.

With the formulation above, the diagonal block of the $\mathbf{L D L}_{\mathbf{t}}$ decomposition, $\mathbf{D}_{l}$, coincides with the diagonal matrix $\mathbf{U}$. Since the dimension $M$ of this block is much larger than the dimension $N$ of the $\mathbf{H}_{\sigma}$ block, the number of positive and negative values in $\mathbf{D}_{l}$ should be very close to the total number of positive and negative values in the full diagonal of the $\mathbf{L D L}_{\mathbf{t}}$ (which would be made of $\mathbf{D}_{l}$ and $\mathbf{D}_{s}$ ).

Therefore, for two limits $\sigma_{1}$ and $\sigma_{2}$ of a subinterval, we only need to count the negative values in the diagonal of the $M \times M$ main block of the matrices $\mathbf{A}-\sigma_{1} \mathbf{B}$ and of $\mathbf{A}-\sigma_{2} \mathbf{B}$. The difference of these two numbers should give a close guess of the number of eigenvalues in the subinterval.

For the test cases considered, we have determined experimentally that this gives a nearly perfect division of the eigenvalues among the processors.

\subsubsection{Implementation Details}

The parallel code was written in Fortran 90, using the Intel Fortran Compiler and MPI for the parallelization.

Using the technique described in the previous section, a set of intervals is generated, with approximately 20 eigenvalues on each subinterval. The subintervals are assigned to the available processors, as evenly as possible, and only then the processors start the actual work.

From then until the end, there is no synchronization among the processors, since each one has the data of all the subintervals that must process.

In some cases there exists a slight load imbalance due to the different work needed for obtaining some eigenvalues. To avoid (as much 
as possible) this problem, a different version of the code was written, in which the intervals were assigned to the processors in a dynamic way, using a Master-Slave structure. However, the results of the Master-Slave code were generally worse than the original version, because the load imbalance is very slight, and does not compensate the extra work needed for the dynamic version. Therefore, the results reported below are based on the original "static"version.

\subsection{Numerical Results and Discussion}

The code has been tested with two of the test cases used in the previous paper (see [5]). They deal with the modal analysis of two arbitrarily shaped waveguides considering different matrix sizes. The first one is a single ridge (of width $4 \mathrm{~mm}$ and height 2,976 mm) WR-75 waveguide $(a=19,05 \mathrm{~mm}$ and $b=9,525 \mathrm{~mm}$ ), and the second one is an elliptic waveguide (of major semi-axis equal to $6,39 \mathrm{~mm}$ and minor semi-axis of length $2,0 \mathrm{~mm}$ ). The problems have been solved with different number of processors, up to 32, in an SGI Altix 3700 cluster of Itanium II Processors, obtaining exactly the same numerical results than with the sequential version. The CPU times needed for each run are summarized in tables 6.1 and 6.2. The authors have verified that the large number of modes considered in tables 6.1 and 6.2 are required for the accurate analysis of complex geometries, such as those mentioned in the introduction.

For the sake of comparison, we recall as well the CPU times shown in [5] for the elliptic waveguide, using LAPACK (subroutine DSYGV) and the sequential Lanczos approach (see Table 6.3). These results were obtained in a personal computer based on a Pentium IV platform at 2.4 GHz with $1 \mathrm{~GB}$ of RAM.

One of the advantages of the Lanczos-based approach is that it requires much less memory than the Lapack-based version, since it needs to store the matrices as full, dense matrices. In fact, the case with size $M+M^{\prime}=20000$ executed in a PC (table 6.3) with the Lapack software failed, due to insufficient memory. Lanczos approach might cope with sizes far larger than those used for the tests in this paper.

The results of table 6.3 are worse than those of table 6.2 with a single processor, partly because the Itanium II CPU is faster than the Pentium 
Table 6.1: CPU time (sec.) for the modal analysis of a ridge waveguide, with different problem sizes and varying the number of processors.

\begin{tabular}{crrrrrrr}
\hline $\begin{array}{c}M+M^{\prime} \\
\text { Processors }\end{array}$ & 2000 & 5000 & 8000 & 11000 & 14000 & 17000 & 20000 \\
\hline 1 & 2,58 & 26,19 & 76,78 & 156,05 & 277,58 & 440,18 & 647,99 \\
2 & 1,40 & 15,75 & 42,56 & 94,76 & 161,58 & 247,73 & 370,88 \\
3 & 1,01 & 10,11 & 30,36 & 66,88 & 111,37 & 165,46 & 287,69 \\
4 & 1,13 & 8,04 & 21,12 & 47,65 & 78,32 & 122,74 & 195,13 \\
5 & 0,54 & 5,25 & 16,24 & 32,39 & 52,15 & 96,65 & 147,05 \\
6 & 0,53 & 5,22 & 15,29 & 32,53 & 51,52 & 83,27 & 123,38 \\
8 & 0,59 & 3,76 & 10,47 & 25,36 & 37,45 & 62,70 & 95,61 \\
10 & 0,53 & 2,98 & 9,41 & 20,34 & 31,93 & 47,65 & 72,28 \\
16 & 0,13 & 2,61 & 5,94 & 12,60 & 18,27 & 30,94 & 43,98 \\
22 & 0,12 & 1,40 & 4,35 & 9,59 & 15,74 & 22,92 & 36,28 \\
32 & 0,12 & 1,28 & 2,82 & 7,76 & 10,65 & 18,80 & 28,18 \\
\hline
\end{tabular}

Table 6.2: CPU time (sec.) for the modal analysis of an elliptic waveguide, with different problem sizes and varying the number of processors.

\begin{tabular}{crrrrrrr}
\hline $\begin{array}{c}M+M^{\prime} \\
\text { Processors }\end{array}$ & 2000 & 5000 & 8000 & 11000 & 14000 & 17000 & 20000 \\
\hline 1 & 16,61 & 383,65 & 462,93 & 1133,62 & 1928,91 & 3144,71 & 4727,59 \\
2 & 10,66 & 323,61 & 288,90 & 657,02 & 1138,26 & 1801,31 & 3827,02 \\
3 & 8,02 & 221,31 & 183,34 & 446,90 & 722,36 & 1231,97 & 1599,26 \\
4 & 6,60 & 163,37 & 133,30 & 321,69 & 565,43 & 931,64 & 1446,46 \\
5 & 4,58 & 111,20 & 91,39 & 235,27 & 375,16 & 636,83 & 1153,51 \\
6 & 5,05 & 110,52 & 88,68 & 210,72 & 369,51 & 648,29 & 977,75 \\
8 & 2,41 & 80,29 & 68,10 & 167,94 & 308,03 & 469,01 & 741,32 \\
10 & 2,02 & 74,77 & 56,42 & 135,42 & 237,52 & 349,83 & 561,66 \\
16 & 1,13 & 44,81 & 38,21 & 86,11 & 148,53 & 221,96 & 326,87 \\
22 & 1,14 & 30,79 & 30,36 & 68,04 & 117,32 & 159,85 & 255,94 \\
32 & 1,13 & 23,19 & 17,43 & 45,82 & 78,23 & 138,34 & 213,00 \\
\hline
\end{tabular}

IV used in table 6.3, but also due to the improved interval distribution of the parallel version, described above.

In any case, it is evident that the parallel version obtains a very important reduction in execution time. For the largest case, the elliptic waveguide with $M+M^{\prime}=20000$, the execution time goes from over 1 
Table 6.3: CPU time benchmark for the elliptic waveguide reported in [5].

\begin{tabular}{rrr}
\hline$M+M^{\prime}$ & Lanczos & Lapack \\
\hline 2000 & 57,07 & 45,50 \\
5000 & 615,79 & 537,54 \\
8000 & 1687,08 & 2032,31 \\
11000 & 3859,64 & 4946,42 \\
14000 & 7881,92 & 9703,92 \\
17000 & 15196,08 & 17138,52 \\
20000 & 25765,05 & - \\
\hline
\end{tabular}

hour and 18 minutes down to less than 4 minutes; this case would take 7 hours with the former Lanczos version in a PC, and could not be executed with the Lapack-based code.

The speedups obtained for both test cases are displayed in tables 6.4 and 6.5. For an average number of processors (5-10), the speedup is close to the optimum, and can be regarded as excellent. Theoretically, we could increase the number of processors up to the point where each processor searches eigenvalues in a single interval. However, close to this point we would have a logical loss of efficiency. This is the reason why when the number of processor grows, the speedup drifts slightly away from the optimum. This might be artificially overcome, up to a certain point, selecting subintervals with less eigenvalues. However, this would improve the speedups by worsening the overall computing time, which certainly is not desirable.

We study now the scalability of the parallel algorithm. The scalability of a parallel system is a measure of its capacity to increase speedup in proportion to the number of processing elements. It reflects a parallel system's ability to utilize increasing processing resources effectively [6].

In our case we use the scaled speedup as defined in [6] due to its ease of use when experimental data are available. The scaled speedup is defined as the speedup obtained when the problem size is increased linearly with the number of processing elements. A system is considered scalable if the scaled-speedup is close to linear with respect to the number of processing elements. To analyze the scalability, the problem 
size must be scaled with the number of processors, where the problem size is defined as the number of computations carried out in the best sequential algorithm.

In this case we consider that the theoretical computational cost of the sequential algorithm is $W=O\left(n^{3}\right)$. (Using the results of the tables 6.1 and 6.2 it is easy to check that this is a reasonable assumption). Thus, scaling the number of processors $p$ and the problem size in the same ratio implies that if we scale $p$ as $p=k p_{0}$ then $W$ must be scaled as

$$
W=k \cdot W_{0}=k \cdot O\left(n_{0}^{3}\right)=O\left(k^{1 / 3} * n_{0}\right)^{3}
$$

that means that $n$ must be scaled by $k^{1 / 3}$. In the practical experiments we have considered several cases, by varying the type of case study, Ridge guide or Elliptic guide, and taking as initial points $p_{0}=1, n_{0}=$ 5000 , and $p_{0}=1, n_{0}=8000$. If we consider, for instance, the case $p_{0}=1$, $n_{0}=5000$, and we increase $n$ by 3000 each time, we have $n=8000=$ $k^{1 / 3} * 5000$, that is, $k \approx 4$, and thus the next point to plot is the value of Speedup for $p=4, n=8000$. By repeating the operation we have to plot the speedup for the cases $p=(1,4,10,22)$ and matrix dimension corresponding to $n=(5000,8000,11000,14000)$. This is plotted in figure 6.2. In the same way we obtain the values $p=(1,2,6,6,10,16)$ if we use $n_{0}=8000$ as initial value of $n$, and successive values 11000, 14000, 17000,20000 . The speedup for this case is plotted in figure 6.3. (To offer an idea of the speedup corresponding to $p=2.6$ and $n=11000$, we have plotted the speedup for 2 and 3 processors and $n=11000$ ).

As we can observe in both figures the scaled-speedup is close to linear behaviour (especially in figure 6.3, that is for a larger initial problem) thus indicating a reasonable scalability of the developed algorithm.

\subsection{Conclusions}

The parallel algorithm described in this paper complements the sequential algorithm proposed in [5]. The sequential algorithm introduced there allowed the computation of arbitrarily shaped waveguides in cases where it was not possible with Lapack subroutines, due to memory problems, and improved the execution times; however, these we- 


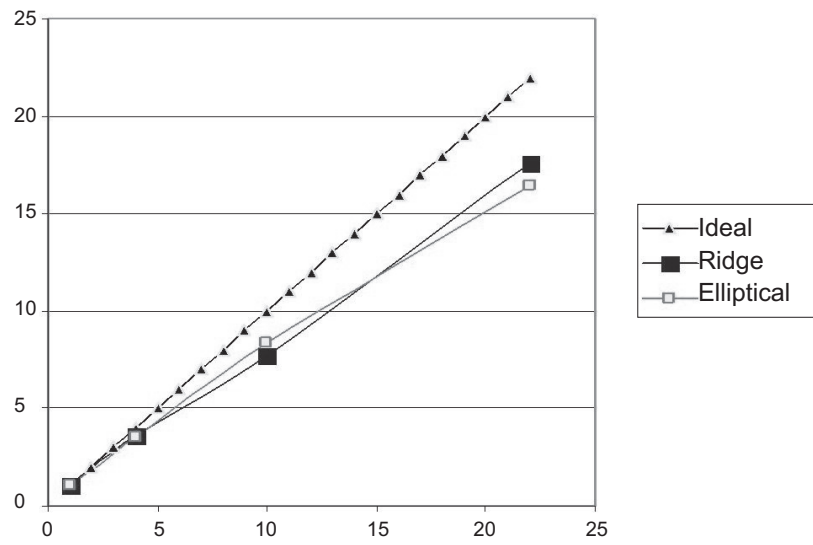

Figure 6.2: Scaled speedup 1.

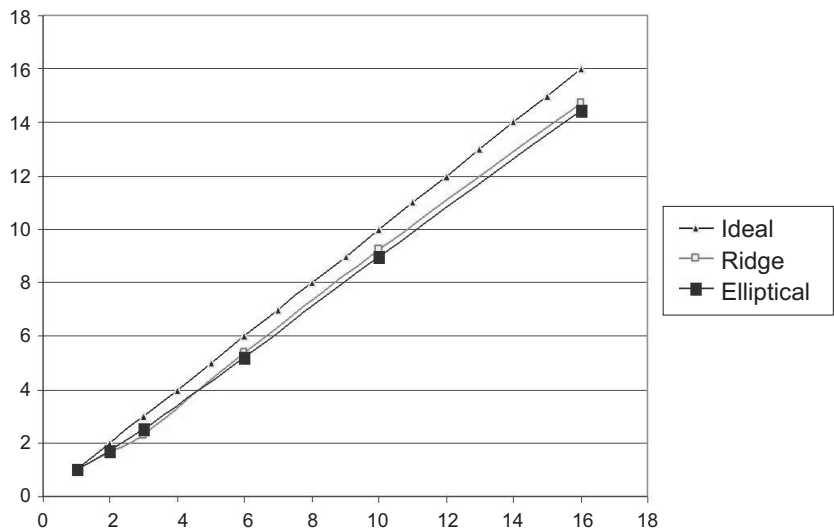

Figure 6.3: Scaled speedup 2. 
Table 6.4: Speedups for the modal analysis of a ridge waveguide, with different problem sizes.

\begin{tabular}{crrrrrrr}
\hline $\begin{array}{c}M+M^{\prime} \\
\text { Processors }\end{array}$ & 2000 & 5000 & 8000 & 11000 & 14000 & 17000 & 20000 \\
\hline 2 & 1,84 & 1,66 & 1,80 & 1,65 & 1,72 & 1,78 & 1,75 \\
3 & 2,55 & 2,59 & 2,53 & 2,33 & 2,49 & 2,66 & 2,25 \\
4 & 2,29 & 3,26 & 3,64 & 3,28 & 3,54 & 3,59 & 3,32 \\
5 & 4,76 & 4,99 & 4,73 & 4,82 & 5,32 & 4,55 & 4,41 \\
6 & 4,84 & 5,02 & 5,02 & 4,80 & 5,39 & 5,29 & 5,25 \\
8 & 4,37 & 6,97 & 7,33 & 6,15 & 7,41 & 7,02 & 6,78 \\
10 & 4,84 & 8,80 & 8,16 & 7,67 & 8,69 & 9,24 & 8,97 \\
16 & 19,85 & 10,03 & 12,92 & 12,38 & 15,20 & 14,23 & 14,73 \\
22 & 21,46 & 18,75 & 17,64 & 16,27 & 17,63 & 19,21 & 17,86 \\
32 & 21,62 & 20,41 & 27,19 & 20,11 & 26,05 & 23,41 & 22,99 \\
\hline
\end{tabular}

Table 6.5: Speedups for the modal analysis of an elliptic waveguide, with different problem sizes.

\begin{tabular}{crrrrrrr}
\hline $\begin{array}{c}M+M^{\prime} \\
\text { Processors }\end{array}$ & 2000 & 5000 & 8000 & 11000 & 14000 & 17000 & 20000 \\
\hline 2 & 1,56 & 1,19 & 1,60 & 1,73 & 1,69 & 1,75 & 1,24 \\
3 & 1,33 & 1,73 & 2,53 & 2,54 & 2,67 & 2,55 & 2,96 \\
4 & 2,52 & 2,35 & 3,47 & 3,52 & 3,41 & 3,38 & 3,27 \\
5 & 3,63 & 3,45 & 5,07 & 4,82 & 5,14 & 4,94 & 4,10 \\
6 & 3,29 & 3,47 & 5,22 & 5,38 & 5,22 & 4,85 & 4,84 \\
8 & 6,89 & 4,78 & 6,80 & 6,75 & 6,26 & 6,70 & 6,38 \\
10 & 8,24 & 5,13 & 8,21 & 8,37 & 8,12 & 8,99 & 8,42 \\
16 & 14,68 & 8,56 & 12,11 & 13,16 & 12,99 & 14,17 & 14,46 \\
22 & 14,59 & 12,46 & 15,25 & 16,66 & 16,44 & 19,67 & 18,47 \\
32 & 14,76 & 16,55 & 26,56 & 24,74 & 24,66 & 22,73 & 22,20 \\
\hline
\end{tabular}

re still too high. As it has been shown in this work, this problem can be tackled succesfully through parallel computing.

The technique used to distribute the eigenvalues among the processors, described in section 6.4.1, obtains a very good load balance, and, 
moreover, it has improved the sequential version, since it avoids intervals with too much or too few eigenvalues.

The speedups obtained are quite good, which was confirmed by the scalability study. The efficiencies obtained are always over $75 \%$.

Finally, it is interesting to note that the approach followed can be used for other similar eigenvalue problems. If the structure of the matrices causes that standard techniques (tridiagonalization + iterative $\mathrm{QR}$, QZ) are too costly and, on the other hand, the structure of the matrices allows efficient solution of linear systems and matrix-vector products, then the technique described in [5] and here can be applied with high likelihood of success.

\section{Bibliography}

[1] L. Accatino, G. Bertin, and M. Mongiardo. Elliptical cavity rseonators for dual-mode narrow-band filters. IEEE Transactions on Microwave Theory and Techniques, 45(12):2393-2401, December 1997.

[2] S. Cogollos, S. Marini, V.E. Boria, P. Soto, A. Vidal, H. Esteban, J. V. Morro, and B. Gimeno. Efficient modal analysis of arbitrarily shaped waveguides composed of linear, circular and elliptical arcs using the BI-RME method. IEEE Transactions on Microwave Theory and Techniques, 51(12):2378-2390, Dec. 2003.

[3] G. Conciauro, M. Bressan, and C. Zuffada. Waveguide modes via an integral equation leading to a linear matrix eigenvalue problem. IEEE Transactions on Microwave Theory and Techniques, 32(11):14951504, Nov. 1984.

[4] G. Conciauro, M. Guglielmi, and M. Sorrentino. Advanced Modal Analysis - CAD Techniques for Waveguide Components and Filters. John Wiley \& Sons, Ltd., Chichester, 2000.

[5] V.M. Garcia, A. Vidal, V. E. Boria, and A. M. Vidal. Efficient and accurate waveguide mode computation using BI-RME and Lanczos methods. International Journal for Numerical Methods in Engineering (published online DOI: 10.1002/nme.1520), October 2005. 
[6] A. Grama, A. Gupta, G. Karypis, and V. Kumar. Introduction to Parallel Computing, 2nd edition. Pearson Education Limited, 2003.

[7] A. Ruhe. Generalized Hermitian Eigenvalue Problem; Lanczos Method, In Templates for the Solution of Algebraic Eigenvalue Problems: a Practical Guide. SIAM, Philadelphia, first edition, 2000.

[8] P. Soto, V. E. Boria, J. M. Catalá, N. Chouaib, M. Guglielmi, and B. Gimeno. Analysis, design and experimental verification of microwave filters for safety issues in open-ended waveguide systems. IEEE Transactions on Microwave Theory and Techniques, 48(11):2133-2140, November 2000.

[9] M. Taroncher, A. Vidal, V.E. Boria, S. Marini, S. Cogollos, G. Gil, and B. Gimeno. CAD of complex passive devices composed of arbitrarily shaped waveguides using Nyström and BI-RME methods. IEEE Transactions on Microwave Theory and Techniques, 53(6):2153-2163, June 2005.

[10] J. Uher, J. Bornemann, and U. Rosenberg. Waveguide Components for Antenna Feed Systems: Theory and CAD. Artech House, Norwood, 1993. 


\title{
Robust Parallel Implementation of a Lanczos-based Algorithm for an Structured Electromagnetic Eigenvalue Problem
}

\section{Authors}

Miguel O. Bernabeu, Máriam Taroncher, Víctor M. García and A. Vidal.

\begin{abstract}
This paper describes a parallel implementation of a Lanczos-based method to solve generalised eigenvalue problems related to the modal computation of arbitrarily shaped waveguides. This efficient implementation is intended for execution mainly in moderate-low cost workstations ( 2 to 4 processors). The problem under study has several features: the involved matrices are sparse with a certain structure, and all the eigenvalues needed are contained in a given interval. The novel parallel algorithms proposed show excellent speed-up for small number of processors.
\end{abstract}




\subsection{Introduction and examples}

This paper is focused on the parallelisation of a Lanczos-based method for the solution of the following generalised eigenvalue problem: Given a symmetric pencil $\mathbf{A} x=\lambda \mathbf{B} x$, find all the generalised eigenvalues (and the corresponding eigenvectors) comprised in a given interval. This interval contains a large number of eigenvalues.

An efficient sequential method was already proposed in [4]. However, when the number of desired eigenvalues is very large, the execution time is still too long. A first parallel algorithm was recently introduced in [7], using MPI and a distributed-memory approach. The results presented in that paper show that the method parallelises extremely well.

A code based in the proposed technique will be included in a CAD tool for design of passive waveguide components. However, this CAD tool will usually run in low cost workstations or, at most, small PC clusters. For these small systems, a different approach should be chosen.

Therefore, the main goal of this paper is to explore different parallel programming approaches for the implementation of the sequential technique described in [4], in low cost workstations and small clusters.

Three different approaches have been examined: First, we have designed an OpenMP version of the Lanczos algorithm to take advantage of two-processor machines. Next, we implemented a version for distributed memory machines using MPI (Message Passing Interface), to execute it on clusters of PCs. Finally, a mixed approach was proposed in order to achieve optimum performance on clusters of two-processors.

A number of modifications have been carried out lately in the algorithm, to improve the reliability of the code, these shall be described as well. The main corrections have been i) the inclusion of ARPACK [5] routines for the extraction of all the generalised eigenvalues in a small subinterval, ii) the correction of the algorithm for balancing workload, and iii) the improvement of the linear solver, formerly based in the LUSchur complement and now based on the $L D L_{t}$ decomposition.

The paper is organised as follows: first, we will briefly outline the sequential problem (described in [4]), including the algorithmic modifications. Then, the new parallelisation schemes will be completely described, taking into account the different proposed options: i.e. MPI, OpenMP, MPI+OpenMP and so on. Finally, some numerical results are shown, and then the conclusions of this work are given. 


\subsection{Problem Description and Sequential Algo- rithm}

\subsubsection{The electromagnetic problem}

In this study, the efficient and accurate modal computation of arbitrary waveguides is based on the Boundary Integral - Resonant Mode Expansion (BI-RME) method (see the detailed formulation in $[4,3]$ ). This technique provides the modal cut-off frequencies of an arbitrary waveguide from the solution of two eigenvalue problems. The first one is a generalised eigenvalue problem that models the transversal electric (TE) family of modes of the arbitrary waveguide. The structure of the corresponding matrices $\mathbf{A}$ and $\mathbf{B}$, shown in Fig. 7.1, presents a very sparse nature that is conveniently exploited in this work. Both matrices have a non-zero main diagonal, and a small $N \times N$ block in the right, bottom corner. Furthermore, the $B$ matrix has two thin nonzero stripes $\mathbf{R}$ (with dimensions $N \times M)$ and $\mathbf{R}_{\mathbf{t}}(M \times N)$ ), in the last $N$ rows and the last $N$ columns. The size of the matrices is $(M+N) \times(M+N)$, but since $M$ is far larger than $N$ the matrices are very sparse (see [4]). This situation is given when a large number of cut-off frequencies is demanded. The transversal magnetic (TM) family of modes can be also formulated as a generalised eigenvalue problem (see [4]) with matrices $\mathbf{A}$ and $\mathbf{B}$ very similar to those explained before for the TE modes.

Here we will consider only the TE case.

\subsubsection{The sequential algorithm}

\section{Shift-and-Invert Lanczos' algorithm}

The standard techniques for generalised eigenvalue problems is the QZ algorithm. However, as was described in [4], in this case is not efficient since it does not use the structure of the matrices.

The technique proposed in [4] by the authors is based on Lanczos algorithm [6]. This algorithm, in its most basic form, allows the computation of a reduced number of extremal eigenvalues (the largest or sma- 


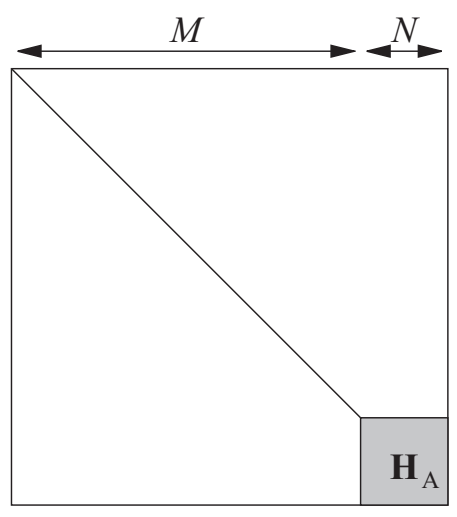

Matrix A

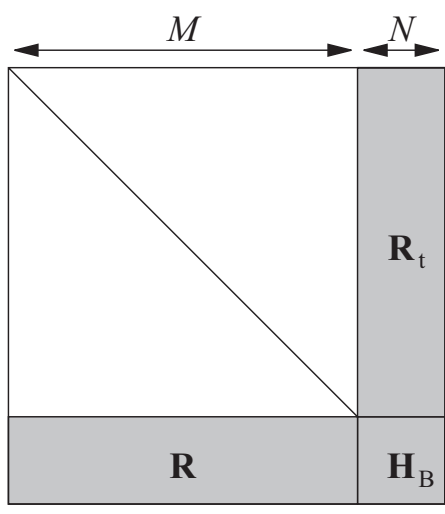

Matrix B

Figure 7.1: Structured matrices $\mathbf{A}$ and $\mathbf{B}$ for the TE problem in a ridge waveguide.

llest in magnitude). However, given a real number (usually called shift) $\sigma$, Lanczos' algorithm can be applied to the matrix $\mathbf{W}=(\mathbf{A}-\sigma \mathbf{B})^{-1} \mathbf{B}$. Lanczos' algorithm applied to this matrix will deliver as result the eigenvalues of the original problem closer to the shift $\sigma$. (This is called the "Shift-and-Invert"version of the Lanczos' algorithm.) The application of the Lanczos' method to this problem requires the solution of several linear systems, with $\mathbf{A}-\sigma \mathbf{B}$ as coefficient matrix. However, the structure of the matrices $\mathbf{A}$ and $\mathbf{B}$ allows a very efficient solution of these systems, using the Schur complement method. This method, described in [4] for this problem, was based in the LU decomposition; one of the algorithmic improvements mentioned above has been to change the LU-based technique to a $L D L_{t}$ based algorithm, described next. 


\section{$L D L_{t}$ decomposition}

Let us now find out how is the $\mathbf{L D L}_{\mathbf{t}}$ decomposition of the matrices in our case. For a matrix $(\mathbf{A}-\sigma \mathbf{B})$ with $\mathbf{A}$ and $\mathbf{B}$ as above, we can write

$$
\begin{aligned}
\mathbf{A}-\sigma \mathbf{B} & =\left(\begin{array}{ll}
\mathbf{U}_{\sigma} & \mathbf{R}_{\sigma t} \\
\mathbf{R}_{\sigma} & \mathbf{H}_{\sigma}
\end{array}\right) \\
& =\left(\begin{array}{cc}
\mathbf{D} & \mathbf{0} \\
\mathbf{F} & \mathbf{T}
\end{array}\right) \cdot\left(\begin{array}{cc}
\mathbf{D}_{l} & \mathbf{0} \\
\mathbf{0} & \mathbf{D}_{s}
\end{array}\right) \cdot\left(\begin{array}{cc}
\mathbf{D}_{\mathbf{t}} & \mathbf{F}_{\mathbf{t}} \\
\mathbf{0} & \mathbf{T}_{\mathbf{t}}
\end{array}\right) \\
& =\left(\begin{array}{cc}
\mathbf{D} \cdot \mathbf{D}_{l} \cdot \mathbf{D}_{\mathbf{t}} & \mathbf{D} \cdot \mathbf{D}_{l} \cdot \mathbf{F}_{\mathbf{t}} \\
\mathbf{F} \cdot \mathbf{D}_{l} \cdot \mathbf{D}_{t} & \mathbf{F} \cdot \mathbf{D}_{l} \cdot \mathbf{F}_{\mathbf{t}}+\mathbf{T} \cdot \mathbf{D}_{s} \cdot \mathbf{T}_{\mathbf{t}}
\end{array}\right)
\end{aligned}
$$

where the structure of matrix $\mathbf{A}-\sigma \mathbf{B}$ is identical to that of matrix $\mathbf{B}$ (Figure 7.1).

It is easy to check that we can take $\mathbf{D}$ as the identity matrix (since $\mathbf{U}_{\sigma}$ is diagonal), so that equating parts of this equation we arrive to the following procedure to compute the $\mathbf{L D L}_{\mathbf{t}}$ decomposition:

1. Take $\mathbf{D}_{l}$ equal to $\mathbf{U}_{\sigma}$.

2. $\mathbf{F}=\mathbf{R}_{\sigma} \cdot \mathbf{D}_{l}^{-1}$ (trivial, since $\mathbf{D}_{l}$ is diagonal).

3. $\mathbf{T}$ and $\mathbf{D}_{s}$ are obtained computing the $\mathbf{L D L}_{\mathbf{t}}$ decomposition of $\mathbf{H}_{\sigma}-\mathbf{F} \cdot \mathbf{D}_{l} \cdot \mathbf{F}_{\mathbf{t}}$, through the LAPACK routine dsytrf .

\section{Main interval decomposition}

As we have mentioned before, the shift-and-invert version of the Lanczos' algorithm computes a subset of the spectrum centred in the shift point. The number of eigenvalues required will determine the number of iterations of the Lanczos' algorithm and its spatial cost [5]. Obviously, we cannot apply the Lanczos' algorithm to the main interval $[\alpha, \beta]$ where all the desired eigenvalues lie. The original problem should be split into many smaller ones to ensure the optimal performance of the Lanczos' algorithm.

As shown in [4], it is possible to use the Inertia Theorem to know in advance how many eigenvalues contain a given interval $[\alpha, \beta]$. For such interval, the $\mathbf{L D L}_{\mathbf{t}}$ decompositions of $\mathbf{A}-\alpha \mathbf{B}$ (equal to $\mathbf{L}^{\alpha} \mathbf{D}^{\alpha} \mathbf{L}_{\mathbf{t}}{ }^{\alpha}$ ) and $\mathbf{A}-\beta \mathbf{B}$ (equal to $\mathbf{L}^{\beta} \mathbf{D}^{\beta} \mathbf{L}_{\mathbf{t}}{ }^{\beta}$ ) can be computed with a moderated cost (as described above). Then, the number of eigenvalues in the interval 
is simply the number $\nu\left(\mathbf{D}^{\beta}\right)-\nu\left(\mathbf{D}^{\alpha}\right)$, where $\nu(\mathbf{D})$ denotes the number of negative elements in the diagonal $\mathbf{D}$. It must be taken into account that the diagonal returned by dsytrf may not be completely "diagonal"; instead, it can be diagonal with $1 * 1$ and $2 * 2$ blocks, as a consequence of the special pivoting strategy. In this case, the eigenvalues of this special diagonal matrix can be easily found (solving the characteristic equation for the $2 * 2$ blocks), which allows to compute the inertia quite efficiently anyway.

Thus, we can divide the original $[\alpha, \beta]$ interval into $m$ subintervals $\left[\alpha_{i}, \beta_{i}\right]$ of different length, but containing nearly the same number of eigenvalues, and where the number of eigenvalues in each subinterval is known exactly. Therefore, the CPU time needed to compute the eigenvalues of every subinterval is expected to be nearly constant.

\section{Sequential algorithm}

The full sequential algorithm is as follows: The interval where lie the desired eigenvalues, $[\alpha, \beta]$, is divided in many small subintervals. Then, in each subinterval, a shift (possibly the middle point) is selected, and then the "Shift-and Invert"Lanczos algorithm is applied independently to each subinterval. This will compute all the eigenvalues in each subinterval, independently of the other subintervals. The number of subintervals and its width are chosen so that the number of eigenvalues on each subinterval is not too large.

This allows to obtain all the eigenvalues in the full interval in a reasonable time and without memory problems (see [4] for all the details).

\section{Algorithm 1 Sequential overall algorithm.}

INPUT: matrices $\mathbf{A}$ and $\mathbf{B}$, the main subinterval $[\alpha, \beta]$ and the maximum number of eigenvalues per subinterval

OUTPUT: eigenvalues of the pair $(\mathbf{A}, \mathbf{B})$ contained in $[\alpha, \beta]$ and its corresponding eigenvectors

1. Apply the Inertia Theorem to the full interval $[\alpha, \beta]$ to divide it into $m$ smaller subintervals $\left[\alpha_{i}, \beta_{i}\right]$ 


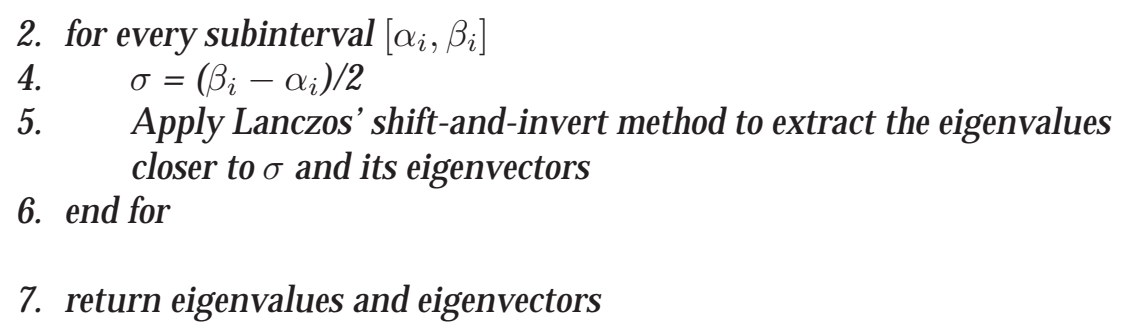

In the latest versions of the code, the robustness has been improved by using the ARPACK [5] routines for the symmetric generalised eigenvalue problem dsaupd. This routine is faster and safer than our previous versions of the Lanczos algorithm.

\subsection{Parallel implementations}

\subsubsection{Algorithmic approach}

Clearly, the basic idea for the parallel implementation is to distribute the subintervals among the available processors; in each subinterval, the extraction of the eigenvalues will still be carried out in a sequential way.

Once we have computed the bounds of every $\left[\alpha_{i}, \beta_{i}\right]$ subinterval, $m / p$ subintervals are assigned to each processor. This assignation is performed at the beginning of the algorithm, and there is no more communication among the processors until all of them have ended its work and results have been gathered.

As we have mentioned in Section 7.2.2, the CPU time needed to extract the eigenvalues of every subinterval is expected to be nearly constant. Thus, just distributing them among the available processors the work load balance is expected to be close to the optimal.

\section{Algorithm 2 Parallel overall algorithm.}

INPUT: matrices $\mathbf{A}$ and $\mathbf{B}$, the main interval $[\alpha, \beta]$ and the maximum 
number of eigenvalues per subinterval

OUTPUT: eigenvalues of the pair $(\mathbf{A}, \mathbf{B})$ contained in $[\alpha, \beta]$ and its corresponding eigenvectors

Let us suppose that $m$ is multiple of $p$

1. At the master processor

2. Apply the Inertia Theorem to the full interval $[\alpha, \beta]$ to divide it into $m$ smaller subintervals $\left[\alpha_{i}, \beta_{i}\right]$

3. Assign $m / p$ subintervals to each processor

4. End at the master processor

5. For each processor

6. for every assigned subinterval $\left[\alpha_{i}, \beta_{i}\right]$

7. $\quad \sigma=\left(\beta_{i}-\alpha_{i}\right) / 2$

8. Apply Lanczos' shift-and-invert method to extract the eig

9. end for eigenvalues closer to $\sigma$ and its eigenvectors

10. Send eigenvalues and eigenvectors to the master processor

11. End for each processor

12. At the master processor

13. Gather the results from all the processors

14. End at the master processor

\subsubsection{Implementation details}

The new proposed algorithms have been implemented in Fortran 90, making use of the Intel Fortran Compiler for Linux. OpenMP and MPI standards have been used for the shared-memory version and distributed-memory version, respectively. In addition, BLAS and LAPACK [2] have been used whenever it was possible.

We have implemented three versions of Algorithm 2:

1. MPI version of algorithm 2

2. OpenMP version of algorithm 2 
3. MPI+OpenMP version of algorithm 2

In the MPI version, all the processes read the input data from disk (matrices and main interval). Then, the main interval is divided with the technique described in the previous section. Next, a distributed algorithm is executed to assign the subintervals that should be solved by each process. Once it is done, every process solves its corresponding subintervals sequentially. Then, the results are gathered by the master process. This version is oriented to distributed memory machines, although it should work as well in shared memory machine.

In the OpenMP version, only the main thread reads the input data from disk. Then, the $[\alpha, \beta]$ interval is divided by the main thread, again. Next, the subintervals are assigned and distributed among the threads. This version is designed to run on shared memory machines.

Finally, the MPI+OpenMP version combines both techniques. In the first level of parallelism, a set of $p$ MPI processes are spawned and they execute the MPI algorithm described before. Then, in the step where each MPI process solves its $m / p$ subintervals, a second level of parallelism is introduced. Instead of sequentially solving those intervals, a group of $p^{\prime}$ OpenMP threads are created and the $m / p$ intervals are divided among them in the same way described in the OpenMP version. There are $p * p^{\prime}$ processors working on the solution of the problem. Note that this version is a combination of the two previous ones, and has been designed to run on a cluster of SMP machines.

\subsection{Experimental results}

\subsubsection{Description of the test environment}

In order to test the performance of the three implemented versions of algorithm 2, we have chosen two different environments: an SMP Cluster and an SGI Computation Server.

The SMP Cluster consists of two Intel Xeon bi-processors running at 2.2 GHz with 4GB of RAM each one, interconnected through a GigabitEthernet network.

The SGI Computation Server is an SGI Altix 3700. This machine is a cluster of 44 Itanium II tetraprocessors, although it has been designed 
as a ccNUMA machine [1] and therefore can be programmed as a SMP machine.

As mentioned previously, the algorithms have been designed to be included into a CAD tool of complex passive waveguide components. This kind of tools are expected to run in moderate-low cost workstations, so the SMP Cluster is the perfect testing environment. Despite of this, we have also chosen a more complex and powerful machine, the SGI Server, in order to test the algorithm performance using more expensive machines. Obviously, we will only use 4 of the 44 processors available for fair comparison purposes with the cheaper machine.

\subsubsection{Experimental results}

The following tables show the execution times of the implementations listed in section 7.3 for both test environments.

For the testbed, we have considered a single ridge waveguide described in [4].

Table 7.1: Execution time (s) for MPI implementation at the SMP Cluster.

\begin{tabular}{crrr}
\hline$M+N$ & $p=1$ & $p=2$ & $p=4$ \\
\hline 5000 & 71.68 & 40.92 & 20.45 \\
8000 & 199.26 & 121.22 & 67.98 \\
11000 & 426.32 & 257.13 & 140.06 \\
14000 & 772.10 & 413.06 & 221.21 \\
17000 & 1247.71 & 655.40 & 367.26 \\
20000 & 1685.27 & 1003.56 & 540.88 \\
\hline
\end{tabular}

\subsubsection{Analysis of the experimental results}

The previous results show that the method described in section 7.2 parallelises extremely well in affordable machines. The key points for this good behaviour are the application of Inertia Theorem to ensure a good work-load balance, as well as the absence of communications during the execution of the algorithm. 
Table 7.2: Execution time (s) for OpenMP implementation at the SMP Cluster.

\begin{tabular}{crr}
\hline$M+N$ & $p=1$ & $p=2$ \\
\hline 5000 & 71.68 & 38.11 \\
8000 & 199.26 & 109.78 \\
11000 & 426.32 & 246.32 \\
14000 & 772.10 & 419.12 \\
17000 & 1247.71 & 646.51 \\
20000 & 1685.27 & 963.91 \\
\hline
\end{tabular}

Table 7.3: Execution time (s) for MPI+OpenMP implementation at the SMP Cluster.

\begin{tabular}{crr}
\hline$M+N$ & $p=1$ & $p=4$ \\
\hline 5000 & 71.68 & 20.53 \\
8000 & 199.26 & 61.59 \\
11000 & 426.32 & 134.88 \\
14000 & 772.10 & 216.84 \\
17000 & 1247.71 & 333.86 \\
20000 & 1685.27 & 534.69 \\
\hline
\end{tabular}

Table 7.4: Execution time (s) for OpenMP implementation at the SGI Server.

\begin{tabular}{crrrr}
\hline$M+N$ & $p=1$ & $p=2$ & $p=3$ & $p=4$ \\
\hline 5000 & 44.14 & 25.44 & 18.66 & 14.95 \\
8000 & 161.99 & 86.46 & 69.25 & 55.67 \\
11000 & 321.68 & 185.16 & 148.37 & 133.35 \\
14000 & 598.13 & 337.35 & 249.26 & 247.38 \\
17000 & 893.64 & 494.42 & 405.15 & 351.61 \\
20000 & 1259.16 & 665.58 & 556.76 & 532.72 \\
\hline
\end{tabular}


Table 7.5: Execution time (s) for MPI implementation at the SGI Server.

\begin{tabular}{crrrr}
\hline$M+N$ & $p=1$ & $p=2$ & $p=3$ & $p=4$ \\
\hline 5000 & 44.14 & 23.69 & 16.17 & 13.09 \\
8000 & 161.99 & 86.34 & 60.85 & 49.24 \\
11000 & 321.68 & 172.88 & 117.61 & 91.53 \\
14000 & 598.13 & 310.42 & 217.38 & 170.07 \\
17000 & 893.64 & 498.16 & 304.24 & 241.64 \\
20000 & 1259.16 & 658.08 & 446.46 & 349.44 \\
\hline
\end{tabular}

The different versions of the developed algorithms differ in the parallel programming standard used: MPI, OpenMP, or both of them. Both standards offer good performance and the final choice depends more on the machine architecture rather than on the sequential algorithm characteristics.

Table 7.6: Speed-up @ the SMP Cluster. Comparative study between OpenMP and MPI versions $(p=2)$.

\begin{tabular}{ccc}
\hline$M+N$ & OpenMP & MPI \\
\hline 5000 & 1.88 & 1.75 \\
8000 & 1.82 & 1.64 \\
11000 & 1.73 & 1.66 \\
14000 & 1.84 & 1.87 \\
17000 & 1.93 & 1.90 \\
20000 & 1.75 & 1.68 \\
\hline
\end{tabular}

Table 7.6 shows the speed-up of MPI and OpenMP versions in a two-processor board (one of the nodes of the SMP Cluster). OpenMP results are slightly better than MPI ones. This result was expected because OpenMP can take more advantage of the shared memory architecture of the machine.

Table 7.7 shows the speed-up of MPI and MPI+OpenMP versions in a cluster of 2 two-processor boards. In this kind of environments with 
Table 7.7: Speed-up @ the SMP Cluster. Comparative study between MPI+OpenMP and MPI versions $(p=4)$.

\begin{tabular}{ccc}
\hline$M+N$ & MPI+OpenMP & MPI \\
\hline 5000 & 3.49 & 3.51 \\
8000 & 3.24 & 2.93 \\
11000 & 3.16 & 3.04 \\
14000 & 3.56 & 3.49 \\
17000 & 3.74 & 3.40 \\
20000 & 3.15 & 3.12 \\
\hline
\end{tabular}

two levels of parallelism (shared memory at each node and distributed memory for the global view of the machine) the combination of MPI and OpenMP standards show better results than the use of MPI only. Again, OpenMP is taking advantage of shared memory features of the machine while MPI is not doing so.

Table 7.8: Comparative analysis between OpenMP and MPI versions @ SGI Server $(M+N=20000)$.

\begin{tabular}{crrr}
\hline version & $p=2$ & $p=3$ & $p=4$ \\
\hline MPI version & 1,91 & 2,82 & 3,60 \\
OpenMP version & 1,89 & 2,26 & 2,36 \\
\hline
\end{tabular}

Table 7.8 shows the speed-up of MPI and OpenMP versions at the SGI Server. In this machine, the MPI version scales better than OpenMP version. This rather surprising result is due to the scheduling policy. When the batch system runs the parallel algorithm, it can schedule the $p$ threads/processes to different boards. With the MPI algorithm this does not create problems, since each process owns all the necessary data to perform its part of the algorithm. However, for the OpenMP implementation it is different, because all the threads need to access master thread's memory. This would create accesses to memory placed in a different board, which shall slow down the algorithm. Obviously, the 
problem worsens as the number of threads increases.

\subsection{Conclusions}

Three parallel implementations of a Lanczos-based method for solving a generalised eigenvalue problem have been successfully developed. The problem has got several distinct characteristics: matrices are sparse and structured, and the search of eigenvalues is reduced to a fixed interval.

The proposed technique parallelises very well and any of the implementations present very good speed-up even for a small number of processors.

OpenMP is the best choice for parallel programming of two-processors boards (and any SMP environment). For NUMA systems, it is concluded that OpenMP may present some problems and its use should be studied carefully.

Multi level programming (MPI + OpenMP) is the best choice for hybrid machines (those with two levels of parallelism), since this paradigm can take advantage of both shared and distributed memory features of the machine.

Finally, we can conclude that execution times in both machines are not too different, while speed-up is clearly better at the SMP Cluster. So, in this case, the performance-cost ratio is clearly better for the SMP Cluster.

\section{Acknowledgement}

Contract/grant sponsor: partially supported by Ministerio de Educación y Ciencia, Spanish Government, and FEDER funds, European Commission; contract/grant number: TIC2003-08238- C02-02, and by Programa de Incentivo a la Investigación UPV-Valencia 2005 Project 005522 


\section{Bibliography}

[1] Grbic A. Assessment of Cache Coherence Protocols in Shared-memory Multiprocessors. PhD thesis, University of Toronto, 2003.

[2] E. Anderson, Z. Bai, C. Bischof, S. Blackford, J. Demmel, J. Dongarra, J. Du Croz, A. Greenbaum, S. Hammarling, A. McKenney, and D. Sorensen. LAPACK Users' Guide. SIAM, Philadelphia, 1999.

[3] G. Conciauro, M. Bressan, and C. Zuffada. Waveguide modes via an integral equation leading to a linear matrix eigenvalue problem. IEEE Transactions on Microwave Theory and Techniques, 32(11):14951504, Nov. 1984.

[4] V. M. García, A. Vidal, V. E. Boria, and A. M. Vidal. Efficient and accurate waveguide mode computation using BI-RME and Lanczos methods. International Journal for Numerical Methods in Engineering, 65:1773-1788, October 2006.

[5] R. B. Lehoucq, D. C. Sorensen, and C. Yang. ARPACK Users' Guide: Solution of Large-Scale Eigenvalue Problems with Implicitly Restarted Arnoldi Methods. SIAM, Philadelphia, 1998.

[6] A. Ruhe. Generalized Hermitian Eigenvalue Problem; Lanczos Method, In Templates for the Solution of Algebraic Eigenvalue Problems: a Practical Guide. SIAM, Philadelphia, first edition, 2000.

[7] A. M. Vidal, A. Vidal, V. E. Boria, and V. M. García. Parallel computation of arbitrarily shaped waveguide modes using BI-RME and Lanczos method. Communications in Numerical Methods in Engineering, 23(4):273-284, April 2007. 



\section{Parte III}

\section{Discusión general y conclusiones}





\section{Capítulo 8}

\section{Métodos modales en entornos cerrados tridimensionales: BI-RME 3D}

En este capítulo se describe el trabajo relacionado con la mejora de eficiencia computacional para un nuevo problema de electromagnetismo, que consiste en el análisis modal de cavidades canónicas tridimensionales perturbadas por elementos metálicos arbitrarios mediante la técnica Three Dimensional Boundary Element Resonant Mode Expansion (BIRME 3D). Este trabajo no se ha incluido en la recopilación anterior de la Parte II de la tesis porque de momento se ha presentado a la comunidad mediante ponencia en dos congresos internacionales y se está preparando la publicación en prensa científica correspondiente. Finalmente, se presentan resultados comparativos del análisis, realizado con las técnicas presentadas en este capítulo, de dispositivos reales incluyendo medidas experimentales en uno de los casos.

\subsection{Base teórica de BI-RME 3D}

El método BI-RME se formuló inicialmente para el cálculo de los modos que propagan en guías uniformes de sección arbitraria, por lo tanto las perturbaciones sobre la guía canónica circular o rectangular se expresaban en el plano. En esta técnica se calculaban las corrientes, 
los coeficientes modales y las frecuencias de corte de los modos de la guía perturbada resolviendo un problema generalizado de autovalores y autovectores (ver [8] y [7]). Posteriormente se aplicó también a la caracterización en banda ancha de filtros construidos en plano $\mathrm{E}$ y plano $\mathrm{H}(\operatorname{ver}[4,6])$.

El método BI-RME se extendió posteriormente a la solución de los parámetros circuitales de cavidades resonantes tridimensionales (ver [10, 5]). Sin embargo, en esta extensión no se contemplaba la inclusión del conductor interno del puerto coaxial en la cavidad. Esta forma de excitación se emplea frecuentemente en dispositivos reales y por tanto sería importante disponer de un algoritmo de software capaz de analizar eficientemente este tipo de estructura. En este capítulo se parte de una cavidad resonante que consiste en una cavidad de sección rectangular con una perturbación arbitraria incluyendo la penetración del conductor interno de los puertos coaxiales. Se realiza un mallado de la superficie conductora $S$ de la perturbación sobre la cavidad canónica mediante triángulos. Posteriormente, sobre las aristas de estos triángulos se definen las funciones base de Rao Wilton y Glisson (RWG) descritas en [12] y que son un estándar de hecho en el análisis electromagnético.

La contribución de la tesis en este trabajo consiste en la adaptación del método BI-RME 3D formulado inicialmente para funciones base espaciales solenoidales y no solenoidales a un problema mallado espacialmente con funciones RWG y sin restricciones en cuanto a la introducción de los conductores internos de los puertos coaxiales en la cavidad resonante. Esta adaptación se ha realizado mediante un método numérico basado en la Descomposición en Valores Singulares (SVD). Esta aportación, presentada por primera vez en [11], ha hecho posible la obtención de resultados de análisis de cavidades que no se habían podido estudiar hasta ahora y se han integrado en un software de análisis electromagnético llamado FEST 3D desarrollado originalmente por la ESA y mantenido y ampliado por la empresa Aurora Software and Testing (AuroraSAT) (ver [1]).

En el método BI-RME 3D (ver [8]) se llega a un problema matricial con la siguiente forma:

$$
\left(\mathbf{A}-k^{2} \mathbf{B}\right) \mathbf{x}=\mathbf{C v},
$$

el vector incógnita $\mathrm{x}$ recoge los coeficientes modales y los coeficientes de las bases que expresan la corriente en la superficie de perturbación 
$S$ asociada a las bases no solenoidales. v es el vector de excitación y $k$ es el número de onda correspondiente a la frecuencia de trabajo.

Cuando $\left(\mathbf{A}-k^{2} \mathbf{B}\right)$ se hace singular, entonces $k$ se convierte en un número de onda de corte de un modo resonante de la cavidad perturbada y el problema consistirá en la solución de un problema generalizado de autovalores y autovectores:

$$
\left(\mathbf{A}-k^{2} \mathbf{B}\right) \mathbf{x}=0 .
$$

El resto de las anteriores matrices y vectores se definen en subbloques tal y como sigue:

$$
\begin{aligned}
& \mathbf{A}=\left[\begin{array}{cc}
\mathbf{K}^{4} & \mathbf{0} \\
\mathbf{0} & \mathbf{S}
\end{array}\right] \\
& \mathbf{B}=\left[\begin{array}{cc}
\mathbf{K}^{2}-\mathbf{R}^{\prime \prime} \mathbf{W}^{-1} \mathbf{R}_{\mathbf{t}}^{\prime \prime} & \mathbf{R}^{\prime}-\mathbf{R}^{\prime \prime} \mathbf{W}^{-1} \mathbf{Q}_{\mathbf{t}} \\
\mathbf{R}_{\mathbf{t}}{ }^{-} \mathbf{Q} \mathbf{W}^{-1} \mathbf{R}_{\mathbf{t}}^{\prime \prime} & \mathbf{V}-\mathbf{Q} \mathbf{W}^{-1} \mathbf{Q}_{t}
\end{array}\right] \\
& \mathbf{C}=\left[\begin{array}{c}
-\mathbf{K} \mathbf{F}+\mathbf{R}^{\prime \prime} \mathbf{W}^{-1} \mathbf{L}^{\prime \prime} \\
-\mathbf{L}^{\prime}+\mathbf{Q} \mathbf{W}^{-1} \mathbf{L}^{\prime \prime}
\end{array}\right] .
\end{aligned}
$$

Cada una de las matrices elementales anteriores se define a continuación:

$$
\begin{aligned}
\mathbf{S}_{r p} & =\int_{S} \int_{S^{\prime}} \nabla_{S} \cdot \mathbf{V}_{r}(\mathbf{r}) g^{e}\left(\mathbf{r}, \mathbf{r}^{\prime}\right) \nabla_{S} \cdot \mathbf{V}_{p}\left(\mathbf{r}^{\prime}\right) d S^{\prime} d S \\
\mathbf{V}_{r p} & =\int_{S} \int_{S^{\prime}} \mathbf{V}_{r}(\mathbf{r}) \cdot \overline{\mathbf{G}}_{\mathbf{0}}^{\mathbf{A}}\left(\mathbf{r}, \mathbf{r}^{\prime}\right) \cdot \mathbf{V}_{p}\left(\mathbf{r}^{\prime}\right) d S^{\prime} d S \\
\mathbf{W}_{s q} & =\int_{S} \int_{S^{\prime}} \mathbf{W}_{s}(\mathbf{r}) \cdot \overline{\mathbf{G}}_{\mathbf{0}}^{\mathbf{A}}\left(\mathbf{r}, \mathbf{r}^{\prime}\right) \cdot \mathbf{W}_{q}\left(\mathbf{r}^{\prime}\right) d S^{\prime} d S \\
\mathbf{Q}_{r q} & =\int_{S} \int_{S^{\prime}} \mathbf{V}_{r}(\mathbf{r}) \cdot \overline{\mathbf{G}}_{\mathbf{0}}^{\mathbf{A}}\left(\mathbf{r}, \mathbf{r}^{\prime}\right) \cdot \mathbf{W}_{q}\left(\mathbf{r}^{\prime}\right) d S^{\prime} d S \\
\mathbf{G}_{l n} & =\int_{S} \int_{S^{\prime}} \nabla_{S} \cdot \mathbf{h}_{l}(\mathbf{r}) g^{m}\left(\mathbf{r}, \mathbf{r}^{\prime}\right) \nabla_{S} \cdot \mathbf{h}_{n}\left(\mathbf{r}^{\prime}\right) d S^{\prime} d S \\
\mathbf{T}_{l n} & =\int_{S} \int_{S^{\prime}} \mathbf{h}_{l}(\mathbf{r}) \cdot \overline{\mathbf{G}}_{\mathbf{0}}^{\mathbf{F}}\left(\mathbf{r}, \mathbf{r}^{\prime}\right) \cdot \mathbf{h}_{n}\left(\mathbf{r}^{\prime}\right) d S^{\prime} d S
\end{aligned}
$$




$$
\begin{aligned}
& \mathbf{R}_{m p}^{\prime}=\int_{S} \mathbf{E}_{\mathbf{m}}(\mathbf{r}) \cdot \mathbf{V}_{p}(\mathbf{r}) d S \\
& \mathbf{R}_{m q}^{\prime \prime}=\int_{S} \mathbf{E}_{\mathbf{m}}(\mathbf{r}) \cdot \mathbf{W}_{q}(\mathbf{r}) d S \\
& \mathbf{F}_{m n}=\int_{S} \mathbf{H}_{\mathbf{m}}(\mathbf{r}) \cdot \mathbf{h}_{n}(\mathbf{r}) d S \\
& \mathbf{L}_{r n}^{\prime}=\int_{S} \int_{S^{\prime}} \mathbf{V}_{r}(\mathbf{r}) \cdot \nabla_{S} \times \overline{\mathbf{G}}_{\mathbf{0}}^{\mathbf{F}}\left(\mathbf{r}, \mathbf{r}^{\prime}\right) \nabla_{S} \cdot \mathbf{h}_{n}\left(\mathbf{r}^{\prime}\right) d S^{\prime} d S \\
&-\frac{1}{2} \int_{S} \cdot \mathbf{V}_{r}(\mathbf{r}) \cdot \mathbf{e}_{n}(\mathbf{r}) d S \\
& \mathbf{L}^{\prime \prime}{ }_{s n}=\int_{S} \int_{S^{\prime}} \mathbf{W}_{s}(\mathbf{r}) \cdot \nabla_{S} \times \overline{\mathbf{G}}_{\mathbf{0}}^{\mathbf{F}}\left(\mathbf{r}, \mathbf{r}^{\prime}\right) \nabla_{S} \cdot \mathbf{h}_{n}\left(\mathbf{r}^{\prime}\right) d S^{\prime} d S \\
&-\frac{1}{2} \int_{S} \cdot \mathbf{W}_{s}(\mathbf{r}) \cdot \mathbf{e}_{n}(\mathbf{r}) d S \\
& \mathbf{K}=\operatorname{diag}\left\{\kappa_{1}, \kappa_{2}, \cdots \kappa_{n}\right\}
\end{aligned}
$$

En las expresiones anteriores, $\mathrm{V}$ son funciones de base no solenoidales y $\mathbf{W}$ son funciones de base de tipo solenoidal. Las funciones $g^{e}$ y $g^{m}$ son las funciones de Green para el potencial escalar eléctrico y magnético respectivamente. A su vez, $\overline{\mathbf{G}}_{0}^{\mathbf{A}}$ y $\overline{\mathbf{G}}_{0}^{\mathbf{F}}$ son las funciones diádicas de Green independientes de la frecuencia para el potencial vector eléctrico y magnético respectivamente. $\mathbf{e}_{n}$ y $\mathbf{h}_{n}=\mathbf{n} \times \mathbf{e}_{n}$ son los vectores modales eléctricos y magnéticos normalizados, respectivamente del modo resonante $n$ de la cavidad canónica, cuyo número de onda asociado es $\kappa_{n}$, siendo $\mathbf{n}$ es el vector normal unitario entrante en $S$. Los vectores conocidos $\mathbf{E}_{\mathrm{m}}$ y $\mathbf{H}_{\mathbf{m}}$ son los vectores modales resonantes eléctricos y magnéticos respectivamente de la cavidad canónica asociados a su modo $m$.

El vector $\mathbf{v}$ representa la excitación (coeficientes modales en los puertos de entrada/salida), mientras que el vector $\mathrm{x}$ se corresponde con las incógnitas del problema:

$$
\mathbf{x}=\left[\begin{array}{l}
\mathbf{a} \\
\mathbf{b}
\end{array}\right]
$$

donde $\mathbf{b}$ es el vector de coeficientes de corriente correspondiente a las funciones de base no solenoidales, mientras que a son los coeficientes 
de las amplitudes modales definidas como:

$$
a_{m}=\frac{1}{k_{m}^{2}\left(k_{m}^{2}-k^{2}\right)}\left(j k \eta \int_{S} \mathbf{E}_{m} \cdot \mathbf{J} d S-k_{m} \sum_{n=1}^{N} v_{n} \int_{S} \mathbf{H}_{m} \cdot \mathbf{h}_{n} d S\right)
$$

\subsection{Desarrollo de una nueva técnica numérica para la conversión de bases}

Una vez se ha planteado el problema de forma original en funciones base solenoidales y no solenoidales, se va a formular el mismo problema mediante bases convencionales RWG. En primer lugar se plantea el problema de forma análoga y de tamaño mayor, puesto que el número de bases espaciales RWG es igual a la suma de las funciones solenoidales y no solenoidales:

$$
\left(\mathbf{A}^{\mathbf{R W G}}-k^{2} \mathbf{B}^{\mathbf{R W G}}\right) \mathbf{x}^{\mathbf{R W G}}=\mathbf{C}^{\mathbf{R W G}} \mathbf{v}^{\mathbf{R W G}},
$$

con

$$
\begin{aligned}
\mathbf{A}^{\mathbf{R W G}} & =\left[\begin{array}{cc}
\mathbf{K}^{4} & \mathbf{0} \\
\mathbf{0} & \mathbf{S}^{\mathrm{RWG}}
\end{array}\right] \\
\mathbf{B}^{\mathbf{R W G}} & =\left[\begin{array}{cc}
\mathbf{K}^{2} & \mathbf{R}^{\mathrm{RWG}} \\
\mathbf{R}_{\mathbf{t}}^{\mathrm{RWG}} & \mathbf{V}^{\mathrm{RWG}}
\end{array}\right] \\
\mathbf{C}^{\mathrm{RWG}} & =\left[\begin{array}{c}
-\mathbf{K F} \\
-\mathbf{L}^{\mathbf{R W G}}
\end{array}\right] .
\end{aligned}
$$

En este caso las submatrices del problema se definen como: 


$$
\begin{aligned}
& \mathbf{S}_{r p}^{\mathbf{R W G}}=\int_{S} \int_{S^{\prime}} \nabla_{S} \cdot \mathbf{f}_{r}(\mathbf{r}) g^{e}\left(\mathbf{r}, \mathbf{r}^{\prime}\right) \nabla_{S} \cdot \mathbf{f}_{p}\left(\mathbf{r}^{\prime}\right) d S^{\prime} d S \\
& \mathbf{V}_{r p}^{\mathbf{R W G}}=\int_{S} \int_{S^{\prime}} \mathbf{f}_{r}(\mathbf{r}) \cdot \overline{\mathbf{G}}_{\mathbf{0}}^{\mathbf{A}}\left(\mathbf{r}, \mathbf{r}^{\prime}\right) \cdot \mathbf{f}_{p}\left(\mathbf{r}^{\prime}\right) d S^{\prime} d S \\
& \mathbf{R}^{\mathbf{R W G}}=\int_{S} \mathbf{E}_{\mathbf{m}}(\mathbf{r}) \cdot \mathbf{f}_{p}(\mathbf{r}) d S \\
& \mathbf{L}^{\mathbf{R W G}}{ }_{r n}=\int_{S} \int_{S^{\prime}} \mathbf{f}_{r}(\mathbf{r}) \cdot \nabla_{S} \times \overline{\mathbf{G}}_{\mathbf{0}}^{\mathbf{F}}\left(\mathbf{r}, \mathbf{r}^{\prime}\right) \nabla_{S} \cdot \mathbf{h}_{n}\left(\mathbf{r}^{\prime}\right) d S^{\prime} d S \\
& -\frac{1}{2} \int_{S} \cdot \mathbf{f}_{r}\left(\mathbf{r}^{\prime}\right) \cdot \mathbf{e}_{n}(\mathbf{r}) d S
\end{aligned}
$$

donde $\mathbf{f}$ denota una función base de tipo RWG.

Una vez calculadas las diferentes expresiones (8.10), es posible obtener las matrices necesarias para el método mostradas en (8.4), empleando matrices de transformación tal y como se señala en [8]. La determinación de dichas matrices de transformación a funciones de base no solenoidales $\mathbf{t}_{V}$ y funciones de base solenoidales $\mathbf{t}_{W}$ se puede realizar mediante procedimientos algebraicos o teniendo en cuenta la física del problema, definiendo funciones de tipo estelar y en anillo.

En el método propuesto en la presente tesis se ha recurrido al procedimiento algebraico para la solución del problema. Este procedimiento consiste en llevar a cabo una descomposición en valores singulares (ver [9]) de la matriz $\mathbf{S}^{\mathbf{R W G}}$ obtenida según (8.10a). Con esta descomposición se llega a:

$$
\mathbf{S}^{\mathrm{RWG}}=\mathbf{U} \boldsymbol{\Lambda} \mathbf{V} .
$$

La matriz $\Lambda$ es de tipo diagonal, y en ella se encuentran los valores singulares de la descomposición SVD. Los valores singulares no nulos $N_{n s o l}$ se corresponden con el espacio de las funciones no solenoidales, mientras que los valores singulares nulos $N_{\text {sol }}$ lo hacen con el espacio de las funciones solenoidales. En la diagonal de la matriz $\boldsymbol{\Lambda}$, los valores singulares se encuentran ordenados de mayor a menor, por lo que entre $1: N_{n s o l}$ tenemos los correspondientes a las funciones de base no solenoidales, mientras que entre $N_{n s o l}+1: N_{n s o l}+N_{\text {sol }}$ se encuentra los correspondientes a las funciones de base solenoidales. El número total de funciones de base RWG será $N_{t o t}=N_{n s o l}+N_{\text {sol }}$. 
Las matrices de transformación $\mathbf{t}_{V}$ y $\mathbf{t}_{W}$ se obtienen a partir de $\mathbf{U}_{N_{t o t} \times N_{t o t}}$ como:

$$
\begin{aligned}
\mathbf{t}_{V} & =\mathbf{U}\left(:, 1: N_{\text {nsol }}\right)^{T} \\
\mathbf{t}_{W} & =\mathbf{U}\left(:, N_{\text {nsol }}+1: N_{\text {tot }}\right)^{T} .
\end{aligned}
$$

La matriz $\mathbf{t}_{V}$ es de tamaño $N_{n s o l} \times N_{t o t}$, mientras que la matriz $\mathbf{t}_{W}$ lo es de tamaño $N_{\text {sol }} \times N_{\text {tot }}$.

La transformación entre las funciones de base RWG originales y las solenoidales y no solenoidales se realiza como se propone en [8]:

$$
\begin{aligned}
& \left(\begin{array}{c}
W_{1} \\
W_{2} \\
\vdots \\
W_{N_{s o l}}
\end{array}\right)=\mathbf{t}_{W}\left(\begin{array}{c}
f_{1} \\
f_{2} \\
\vdots \\
f_{N_{t o t}}
\end{array}\right) \\
& \left(\begin{array}{c}
V_{1} \\
V_{2} \\
\vdots \\
V_{N_{n s o l}}
\end{array}\right)=\mathbf{t}_{V}\left(\begin{array}{c}
f_{1} \\
f_{2} \\
\vdots \\
f_{N_{\text {tot }}}
\end{array}\right) .
\end{aligned}
$$

Dado que los valores singulares de una matriz simétrica coinciden con los valores absolutos de los valores propios de dicha matriz, nos limitaremos a calcular la descomposición en valores propios de la matriz $\mathbf{S}^{\mathbf{R W G}}$. Con todo ello, el coste computacional necesario para obtener la matriz de transformación $\mathbf{U}$ se reduce aproximadamente en un factor dos utilizando esta segunda estrategia, lo cual resulta de mucha utilidad cuando el número de funciones de base crece en tamaño con el mallado de las estructuras a resolver.

Una vez calculada la matriz $\mathbf{U}$ y separada convenientemente en las matrices $\mathbf{t}_{V} \mathrm{y} \mathbf{t}_{W}$, se pueden recuperar las diferentes matrices (8.4) a partir de (8.10): 


$$
\begin{aligned}
\mathbf{S} & =\mathbf{t}_{V} \cdot \mathbf{S}^{\mathbf{R W G}} \cdot \mathbf{t}_{V}^{T} \\
\mathbf{V} & =\mathbf{t}_{V} \cdot \mathbf{V}^{\mathbf{R W G}} \cdot \mathbf{t}_{V}^{T} \\
\mathbf{W} & =\mathbf{t}_{W} \cdot \mathbf{V}^{\mathbf{R W G}} \cdot \mathbf{t}_{W}^{T} \\
\mathbf{Q} & =\mathbf{t}_{V} \cdot \mathbf{V}^{\mathbf{R W G}} \cdot \mathbf{t}_{W}^{T} \\
\mathbf{R}^{\prime} & =\mathbf{R}^{\mathbf{R W G}} \cdot \mathbf{t}_{V}^{T} \\
\mathbf{R}^{\prime \prime} & =\mathbf{R}^{\mathbf{R W G}} \cdot \mathbf{t}_{W}^{T} \\
\mathbf{L}^{\prime} & =\mathbf{t}_{V} \cdot \mathbf{L}^{\mathbf{R W G}} \\
\mathbf{L}^{\prime \prime} & =\mathbf{t}_{W} \cdot \mathbf{L}^{\mathbf{R W G}}
\end{aligned}
$$

Las diferentes operaciones efectuadas en (8.14), especialmente los casos de (8.14b), (8.14c) y (8.14d), suponen un importante coste desde el punto de vista computacional, puesto que se deben realizar productos matriciales y posteriormente inversas de matrices, todos ellos con matrices llenas. Es posible economizar el tiempo de cálculo precalculando factores comunes y buscando alternativas a la realización de inversas mediante descomposiciones QR.

Sin embargo y gracias a las descomposición SVD de la matriz $\mathbf{S}^{\mathbf{R W G}}$ no es necesario aplicar las transformaciones de (8.14a) en la matriz S. De este modo, los autovalores no nulos ordenados de $\boldsymbol{\Lambda}$ se corresponderán directamente con la nueva matriz diagonal S. Gracias a ello, el problema generalizado de autovalores (8.2) se convierte en un problema estándar, ya que la matriz $\mathbf{A}$ antes llena se convierte en matriz diagonal.

Para realizar la descomposición de autovalores tanto de la matriz $\mathbf{S}$ como la del problema generalizado derivado de (8.1), se emplea actualmente la rutina de LAPACK dsyevx. Esta rutina permite tanto obtener todo el conjunto de autovalores del problema, como los especificados en un rango. Para la descomposición de la matriz $\mathbf{S}$ se calculan todos los autovalores (tamaño $N_{\text {nsol }} \times N_{\text {nsol }}$ ), mientras que para el problema final (tamaño $N_{c a v}+N_{\text {nsol }} \times N_{\text {cav }}+N_{\text {nsol }}$ ) se trabaja con esta segunda opción, utilizándose unas cotas mínima y máxima $k_{\min }$ y $k_{\max }$, asociadas a las inversas del cuadrado de las frecuencias de corte del problema. De este modo, $k_{\min }$ delimita el máximo autovalor que desea calcularse, y vendrá impuesto por la frecuencia máxima que el usuario indique que desea calcular en el problema. Por otra parte, $k_{\max }$ se toma con va- 


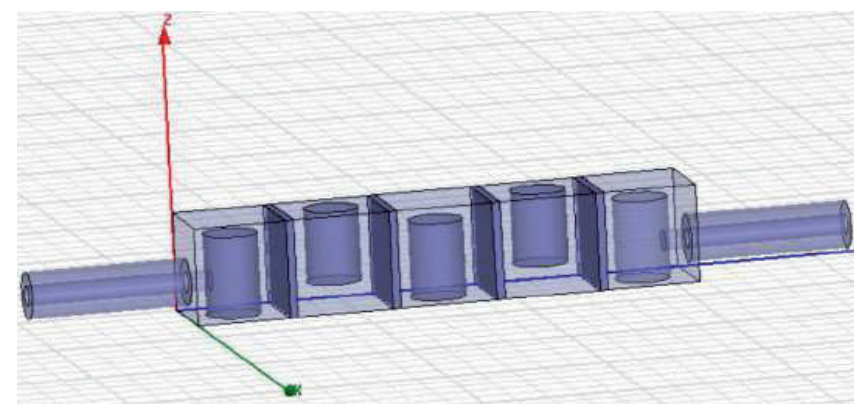

Figura 8.1: Geometría del filtro interdigital.

lor 1000, lo cual corresponde a una frecuencia de corte del orden de 1 $\mathrm{MHz}$, que es suficientemente baja al trabajar normalmente en bandas de frecuencia del orden de GHz.

\subsection{Dispositivos analizados}

El primer dispositivo analizado con el nuevo método es un filtro paso-banda interdigital de quinto orden mostrado en la Figura 8.1. Se analizó originalmente con 2716 funciones RWG. Tras la transformada SVD se convierten en 918 bases solenoidales y 1768 bases no solenoidales. Se ha comparado el resultado del parámetro de dispersión (amplitud de $S_{11}$ ) obtenido con el método propuesto (BI-RME 3D) y con los paquetes de software comerciales Ansys ${ }^{\circledR} \operatorname{HFSS}^{\mathrm{TM}}$ [2] y MICIAN ${ }^{\circledR}[3]$. En la Figura 8.2 se muestran los resultados que concuerdan en los tres casos. Sin embargo, el resultado mediante BI-RME 3D tardó 3 minutos mientras que los otros paquetes software emplearon 3 horas en el mismo ordenador.

El siguiente ejemplo es otro filtro paso-banda combline de quinto orden con excitación mediante contacto del conductor interno del coaxial al primer poste mostrado en la Figura 8.3. Además, esa conexión se realiza mediante un codo en forma de $\mathrm{S}$. Cada una de las cavidades en las que se realiza el contacto se malla con 5400 funciones base RWG, que tras la transformación SVD proporcionan 3400 funciones no solenoidales. El tiempo total de análisis es de unos 465 segundos con el software 


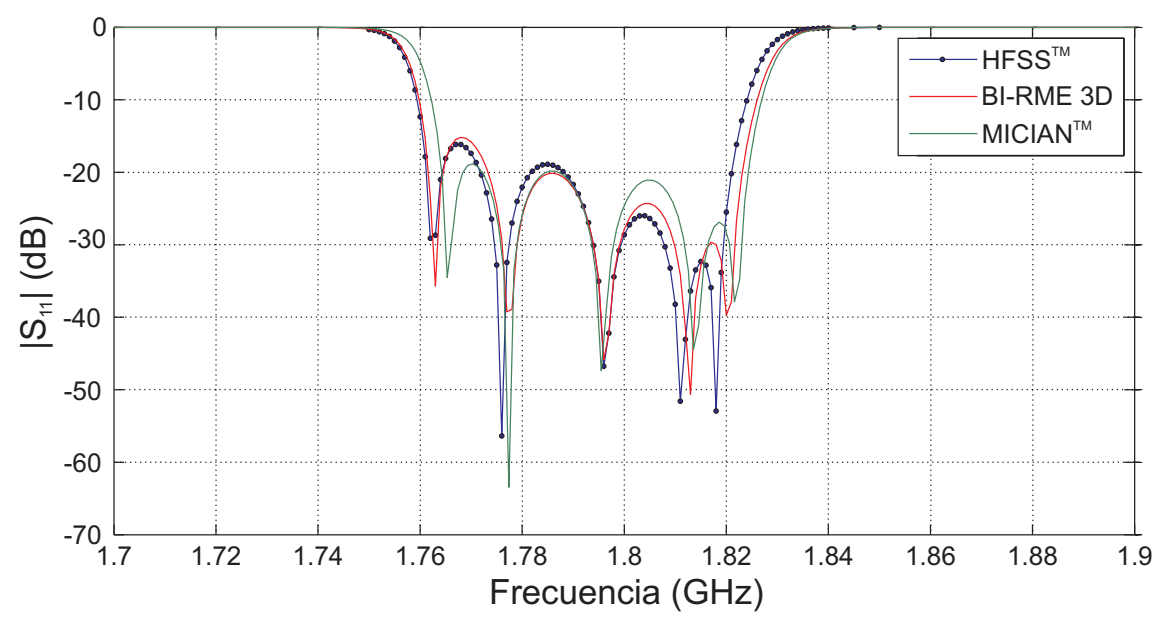

Figura 8.2: Resultados del filtro interdigital.

BI-RME 3D programado en la herramienta FEST-3D [1] ejecutado en un ordenador convencional de cuatro núcleos, que representa un tiempo mucho menor que el empleado por el software Ansys ${ }^{\circledR}$ HFSS $^{\mathrm{TM}}$ [2] (varias horas de ejecución) en el mismo escenario. Sin embargo, los resultados obtenidos (ver Figura 8.4) para la amplitud de los parámetros de dispersión son muy cercanos a los proporcionados por el software Ansys ${ }^{\circledR}$ HFSS $^{\text {TM }}$.

El siguiente ejemplo es importante porque se dispone de medidas que pueden validar la técnica en un entorno real. Se trata de uno de los brazos de un diplexor de banda ancha mostrado en la Figura 8.5. Este filtro presenta 10 cavidades, aunque por simetría sólo se analizan 5 de ellas, mallando cada cavidad con 300 funciones RWG, que tras la técnica de transformación se convierten en 200 no solenoidales y 100 funciones solenoidales. El tiempo de análisis de este filtro es de unos 11 segundos usando FEST-3D [1] en un ordenador convencional de 4 núcleos, mucho menor de nuevo que el empleado por Ansys ${ }^{\circledR}$ HFSS $^{\mathrm{TM}}$ [2] del orden de horas. En la Figura 8.6 se muestran los resultados obtenidos por la técnica propuesta, por el software comercial Ansys ${ }^{\circledR}$ HFSS $^{\mathrm{TM}}$ y las medidas realizadas en el laboratorio del codo analizado. La concordancia de resultados es muy alta y por lo tanto valida el método propuesto en el marco de la tesis. 


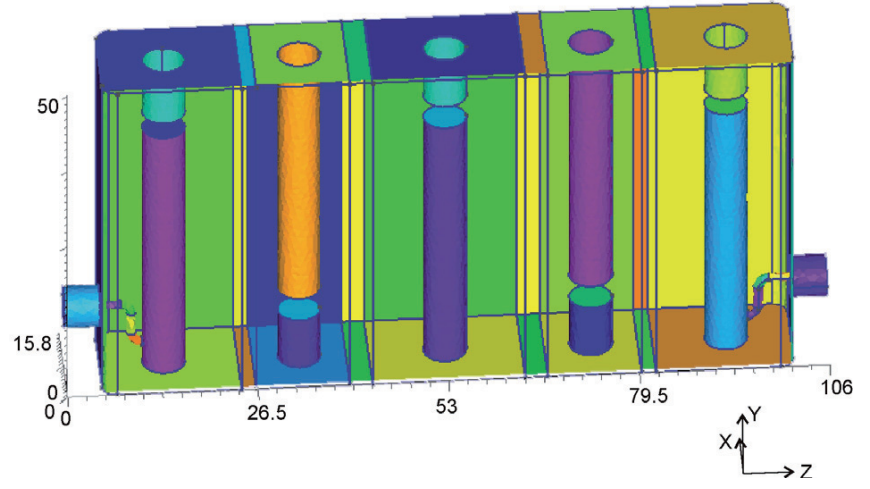

Figura 8.3: Geometría del filtro combline con excitación mediante codo en S. Las unidades vienen dadas en $\mathrm{cm}$.

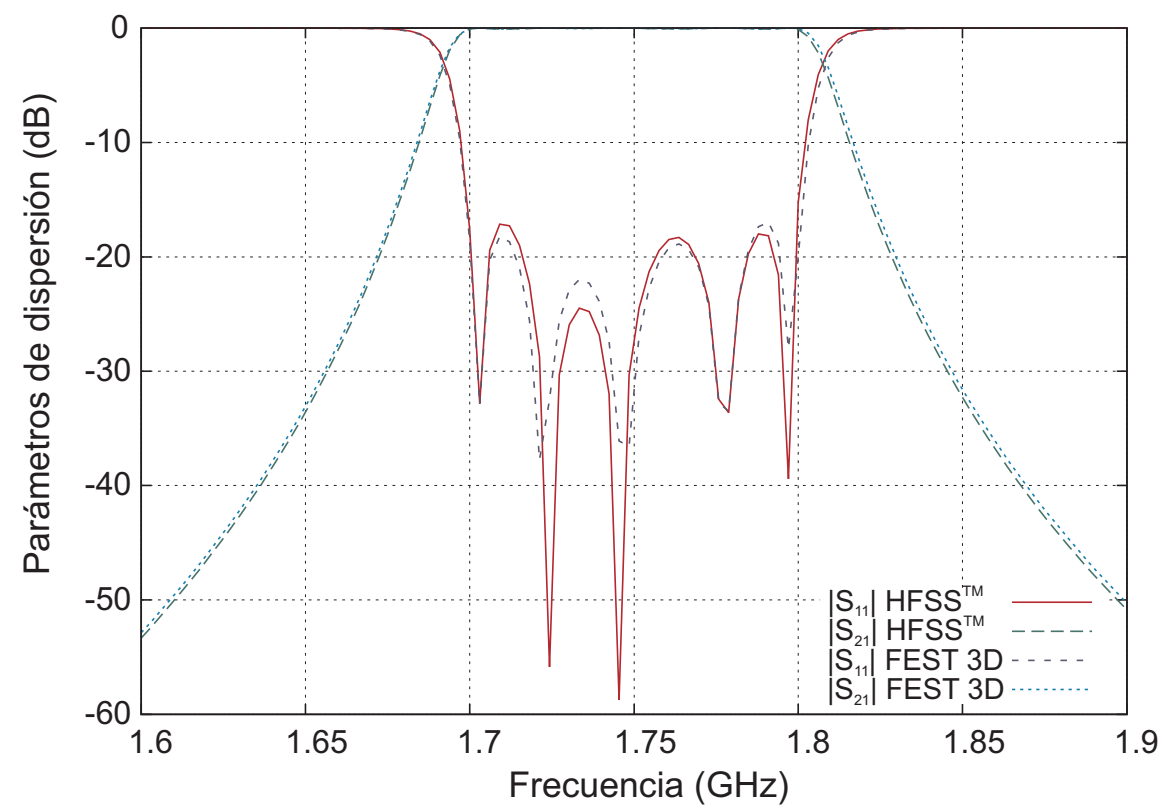

Figura 8.4: Resultados del filtro combline con excitación mediante codo en $\mathrm{S}$. 


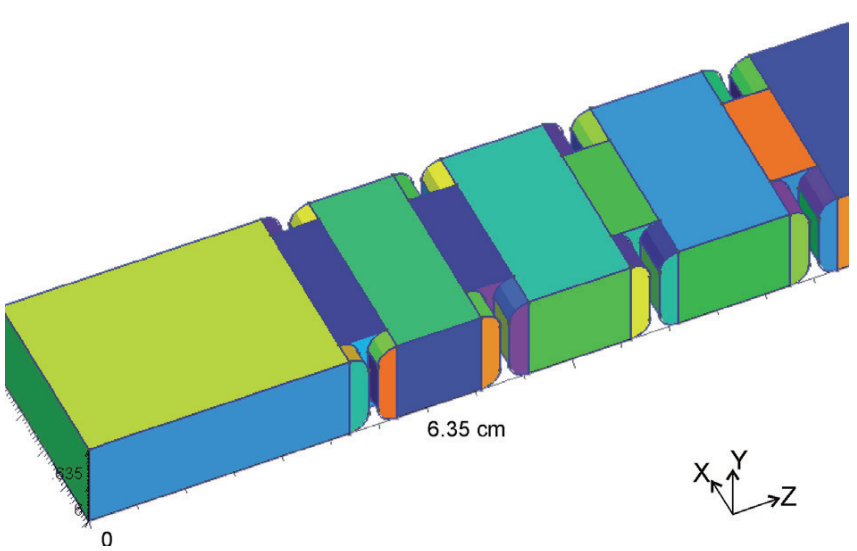

Figura 8.5: Geometría del filtro de uno de los brazos de un diplexor.

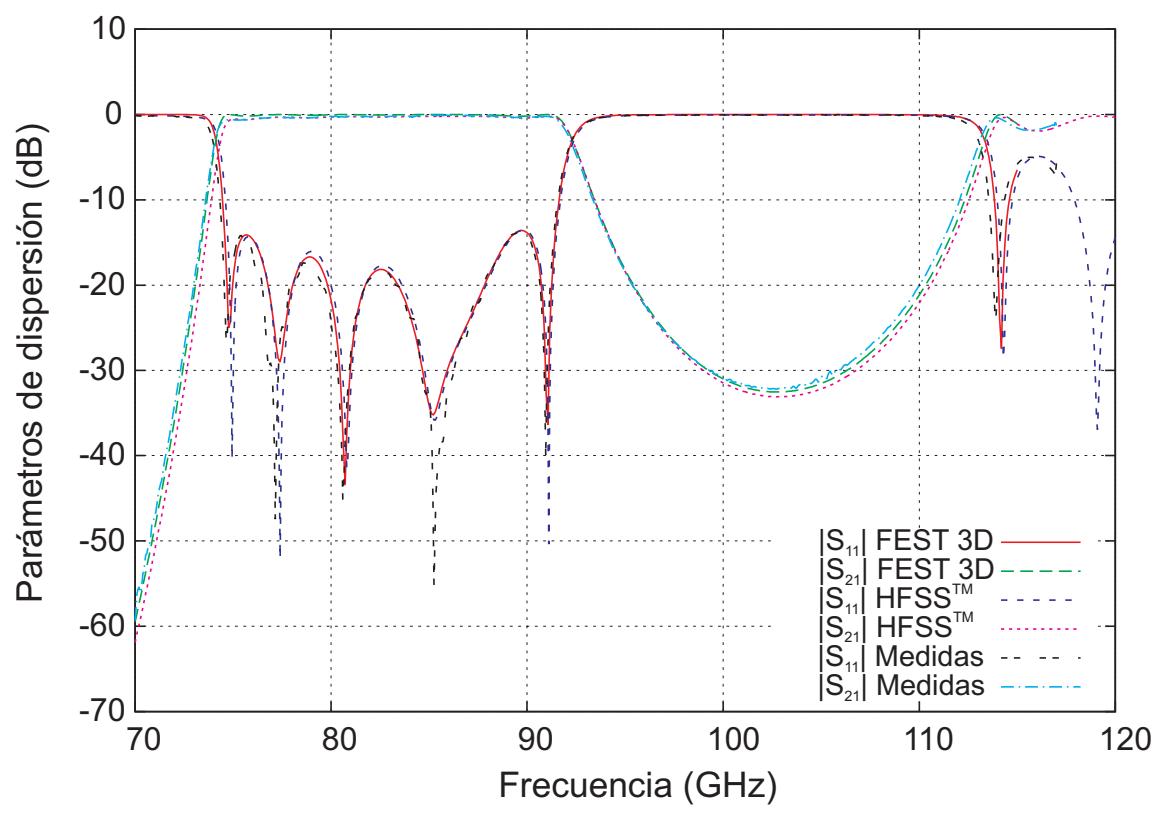

Figura 8.6: Resultados del filtro de uno de los brazos de un diplexor. 
Los resultados presentados anteriormente validan el método algebraico propuesto y posibilitan el análisis de dispositivos que no habían sido analizados hasta ahora por el método BI-RME 3D. La gran ventaja que presenta este nuevo método es que el mallado de la superficie en el espacio tridimensional se puede realizar con un tipo de bases generales (RWG) muy extendidas en la comunidad electromagnética. Así se pueden emplear rutinas de mallado ya existentes y no es necesario emplear funciones base construidas especialmente para cada geometría con la complejidad que ello supone.

\section{Bibliografía}

[1] http://www. fest3d.com.

[2] http://www.ansys.com.

[3] http://www.mician.com.

[4] P. Arcioni, M. Bressan, G. Conciauro y M. Perregrini. Wideband modelling of arbitrarily shaped E-plane components by the boundary integral-resonant mode expansion method. IEEE Trans. Microwave Theory Tech., 44(11):2083-2092, Noviembre 1996.

[5] P. Arcioni, M. Bressan y M. Perregrini. A new boundary integral approach to the determination of the resonant modes of arbitrarily shaped cavities. IEEE Trans. Microwave Theory Tech., 43(8):18481855, Agosto 1995.

[6] G. Conciauro, P. Arcioni, M. Bressan y M. Perregrini. Wideband modelling of arbitrarily shaped H-plane components by the boundary integral-resonant mode expansion method. IEEE Trans. Microwave Theory Tech., 44(7):1057-1066, Julio 1996.

[7] G. Conciauro, M. Bressan y C. Zuffada. Waveguide modes via an integral equation leading to a linear matrix eigenvalue problem. IEEE Trans. Microwave Theory Tech., 32(11):1495-1504, Noviembre 1984.

[8] G. Conciauro, M. Guglielmi y R. Sorrentino. Advanced Modal Analysis - CAD Techniques for Waveguide Components and Filters. John Wiley \& Sons, Ltd., Chichester, 2000. 
[9] G.H. Golub y C.F. Van Loan. Matrix Computations. John Hopkins University Press, Baltimore, Maryland, third edition, 1996.

[10] F. Mira, M. Bressan, G. Conciauro, B. Gimeno y V. E. Boria. Fast S-domain modeling of rectangular waveguides with radially symmetric metal insets. IEEE Trans. Microwave Theory Tech., 53(4):12941303, Abril 2005.

[11] F. Quesada, A. Vidal, F. J. Pérez, A. Berenguer, A. San Blas, F. Mira, V. E. Boria, B. Gimeno y A. Álvarez. Broad band analysis of arbitrarily shaped microwave filters using a novel Singular Value Decomposition technique. En Proceedings of the Fourth European Conference on Antennas and Propagation (EuCAP), páginas 1-3, Barcelona, Abril 2010.

[12] S. M. Rao, D. R. Wilton y A. W. Glisson. Electromagnetic scattering by surfaces of arbitrarily shape. IEEE Trans. Antennas Propagat., 30(5):409-418, Mayo 1982. 


\section{Capítulo 9}

\section{Discusión general de resultados}

En este capítulo se realiza una discusión de los resultados obtenidos en esta tesis y su relación con los objetivos planteados en su inicio. A continuación se presenta la colaboración realizada con una empresa para la integración de las mejoras propuestas en un software electromagnético bajo el concepto Computer Aided Design (CAD).

\subsection{Resumen de las mejoras y aportaciones in- troducidas por la tesis}

En esta tesis se han presentado distintas herramientas desarrolladas para mejorar la eficiencia de tiempo de cálculo en el análisis de dispositivos electromagnéticos sin degradar en gran medida la precisión de dichos algoritmos. Para ello, el punto de partida ha sido recoger problemas que se resolvían mediante técnicas convencionales y probadas. Así después se ha realizado una búsqueda de recursos para intentar mejorar la eficiencia de los algoritmos convencionales sin perder precisión en el resultado. Otra de las cualidades buscadas en este trabajo ha sido lograr la máxima generalización en la aplicación de las técnicas seleccionadas. Esto implica que las mejoras sean extensibles al máximo número de ejemplos o geometrías para un problema electromagnético concreto sin demasiadas modificaciones.

En el ámbito de la transformada Wavelet (objetivo 2 de la tesis), se 
ha comprobado que ésta es una muy buena herramienta para convertir problemas matriciales densos, causados por la discretización del operador integral en problemas de matrices dispersas. Las matrices dispersas emplean métodos de almacenamiento optimizado y pueden hacer uso de algoritmos de resolución recursivos y altamente eficientes. Sin embargo, no todas los métodos basados en la transformada Wavelet proporcionan una mejora en el tiempo de cálculo. De hecho, si no se diseña de forma adecuada, la transformada Wavelet puede incluso incrementar el balance total de tiempos de los algoritmos. Se ha comprobado además que no todas las familias de funciones Wavelet proporcionan la misma ganancia en eficiencia. En los dos problemas que se han analizado, las funciones Wavelet-like proporcionan los mejores resultados gracias a su carácter compacto y al orden de sus momentos.

En general, la mejora de la eficiencia mediante esta técnica depende del carácter que presente la matriz que representa el operador integral (kernel o matriz de impedancias). Cuanto más suave sea dicha matriz, mejor compresión se va a poder realizar mediante la transformada Wavelet y más dispersa será la matriz transformada. Por lo tanto, este es un método que no asegura una mejora computacional en todos los casos y que se extiende con dificultad a problemas en geometrías tridimensionales. Esto se debe a que la ordenación de elementos de superficie en el espacio tridimensional es más compleja que el problema de la parametrización de un contorno en el espacio bidimensional. Como consecuencia, los elementos vecinos de las matrices no representan siempre entradas de funciones base vecinas y así las matrices de geometrías 3D son más complejas y difícilmente configuran una superficie suave.

De cualquier modo, en el análisis de geometrías bidimensionales se puede afirmar que en determinadas ocasiones la transformada Wavelet proporciona una gran ventaja de tiempo de cálculo y también de volumen de almacenamiento de forma sencilla. Otra buena propiedad de las técnicas de transformada Wavelet presentadas es que son generalizables para el análisis electromagnético de objetos dispersores en el espacio bidimensional si la necesidad de establecer una nueva formulación para los elementos de las matrices.

Otra aportación novedosa en el ámbito de la solución de problemas electromagnéticos es la técnica de discretización espacial llamada método de Nyström (objetivo 1 de la tesis). En electromagnetismo siempre ha sido mucho más habitual el uso del Método de los Momentos pa- 
ra su solución numérica. En esta tesis se ha presentado un método de Nyström simplificado en la implementación del método BI-RME. Esta nueva técnica proporciona ventajas en cuanto al cálculo de la matriz que representa el operador integral, aunque requiere el desarrollo de una nueva formulación, que se presenta en el marco de la técnica BIRME. Eso sí, una vez se ha establecido la nueva formulación, ésta se puede aplicar a todo tipo de geometrías (compuestas de tramos lineales, circulares y elípticos) sin una merma significativa de la precisión con respecto al mismo problema formulado con el Método de los Momentos.

También se han experimentado técnicas de optimización de algoritmos basados en la estructura de las matrices que aparecen en el método BI-RME (objetivo 4 de la tesis). Dicha optimización ha sido clave a la hora de la implementación del algoritmo y ha hecho posible la resolución de problemas inabordables en ordenadores convencionales. Esto se debe a la ganancia en el sistema de almacenamiento de las matrices dispersas y a los métodos que se han diseñado específicamente para el tipo de matrices que aparecen en el problema BI-RME. La opción previa pasaba por el uso de algoritmos generales de solución a problemas de autovalores y autovectores mediante una librería como Lapack. Se ha demostrado que el desarrollo de rutinas numéricas optimizadas a la estructura matricial proporciona no sólo ahorro en el tiempo de cálculo, sino también en almacenamiento de memoria. Se ha comprobado que ciertos mecanismos de solución de problemas de autovalores y autovectores basados en técnicas iterativas como Lanczos están especialmente indicados cuando existen matrices dispersas o altamente estructuradas, tal y como ocurre en el método BI-RME bidimensional. Esta mejora es extensible a cualquier implementación del método BI-RME y se ha integrado de forma sistemática en la solución de estos problemas (objetivo 3 de la tesis).

La siguiente mejora introducida por esta tesis ha consistido en avances relacionados con el procesado en paralelo (objetivo 5 de la tesis). Esta técnica es altamente recomendable en la resolución de problemas electromagnéticos como los propuestos, que normalmente acaban con un sistema lineal de ecuaciones o bien con la solución a un problema de autovalores y autovectores. Sin embargo, la adaptación de los sistemas matriciales obtenidos a la resolución en paralelo requiere de un diseño específico que incluye tener en cuenta el tipo de estructura que 
presenta la matriz, su densidad y su número de condición. Las técnicas de procesado en paralelo se han utilizado para el problema BI-RME proporcionando resultados excelentes, sobre todo cuando el tamaño del problema crece.

Finalmente, se ha introducido una importante mejora en la solución numérica de un problema relacionado con la técnica BI-RME 3D. Esta mejora ha hecho posible el análisis de dispositivos que no habían podido ser analizados hasta ahora por su geometría y por las condiciones que se exigían a las funciones base originales que discretizaban el dominio espacial cuando se formuló el método en su versión original. Con esta aportación y partiendo de una discretización clásica mediante funciones base RWG se puede llegar al análisis completo de cavidades electromagnéticas con geometrías arbitrarias.

\subsection{Integración de las mejoras propuestas en software CAD}

Varias de las propuestas de mejora introducidas por esta tesis se han integrado en una herramienta software de distribución comercial mantenida por la empresa Aurora Software and Testing (AuroraSAT) (spin-off de la UPV y la UV). El software de análisis electromagnético CAD llamado FEST 3D fue desarrollado originalmente por la Agencia Europea del Espacio y AuroraSAT se encarga actualmente de su mantenimiento y actualización. En este software se han integrado las optimizaciones relacionadas con los artículos presentados en los Capítulos 5, 6, 7 y 8. FEST 3D lleva integrados en sus rutinas los algoritmos BI-RME y BI-RME 3D para la solución eficiente de dispositivos formados por tramos de guía y por cavidades. Así, en primer lugar se ha aprovechado la estructura de las matrices que participan en el problema BI-RME bidimensional para resolver el problema de autovalores y autovectores más eficientemente. De esta forma se han implementado las técnicas de solución de problemas de autovalores y autovectores basadas en la técnica de Lanczos (ver Capítulo 5).

Además se han introducido las técnicas paralelas propuestas en esta tesis (ver Capítulos 6 y 7). Se ha utilizado el trabajo aquí presentado para diseñar la estrategia de paralelizado más adecuada. Así, se han seleccionado las fases más interesantes para su procesado en paralelo y 
se ha estudiado el tipo de paralelismo más adecuado en cada momento. Si se combinan las técnicas recursivas de tipo Lanczos y el procesado en paralelo, el resultado es óptimo y es el que se ha empleado en el software comercial (ver Capítulo 6).

Todo esto ha contribuido en la mejora del tiempo de cálculo de las técnicas implementadas en el software de forma considerable. Esta mejora se hace más patente en el caso de los problemas grandes, bien porque el mallado espacial bidimensional necesario se hace muy grande o bien porque la precisión requerida hace necesario el uso de un número muy elevado de modos en la guía.

Además, la última aportación de la tesis, que no ha sido publicada, en el marco del problema BI-RME 3D (Capítulo 8) directamente hace solubles mediante dicha técnica problemas que antes no se podían abordar debido a la geometría de mallado necesaria. Esta mejora también se ha integrado en el software FEST 3D, con el que se han obtenido los resultados presentados en el Capítulo 8, que se validan completamente al comparar resultados de análisis con medidas reales en laboratorio.

Gracias al marco de colaboración existente entre AuroraSAT y la Universidad se han podido transferir los avances aportados en esta tesis al software comercial mencionado, dando un sentido práctico al trabajo de investigación desarrollado. Así, las distintas empresas que hacen uso de este software para el análisis y el diseño de sus dispositivos podrán hacer uso de los nuevos algoritmos diseñados. 



\section{Capítulo 10}

\section{Conclusiones y líneas futuras}

En este capítulo se exponen las conclusiones de la tesis y posteriormente se proponen las líneas de investigación futuras en el marco de los problemas presentados. Finalmente se añaden las aportaciones de la tesis en forma de otros artículos en prensa científica y congresos internacionales relacionados con la temática de la tesis y en otros ámbitos de investigación.

\subsection{Conclusiones de los resultados obtenidos}

En el Capítulo 9 se ha realizado una exposición de las mejoras aportadas por esta tesis y por lo tanto se han presentado los resultados agrupados de las contribuciones en prensa científica que forman los Capítulos 2-7 y el Capítulo 8 acerca de la técnica BI-RME 3D de esta tesis. De todos estos resultados que se han obtenido mediante técnicas de la mejora de la eficiencia se pueden extraer conclusiones de forma conjunta de todo el trabajo realizado.

Le primera conclusión que se extrae es que la transformada Wavelet presenta buenos resultados en el análisis de geometrías espaciales bidimensionales, donde se debe discretizar un contorno en el espacio 2D (en relación al objetivo 2 de la tesis). Aún así, se debe tener especial cuidado e la construcción de la matriz de impedancias para que la técnica produzca el máximo beneficio. Sin embargo, se ha observado que su implementación debe ser cuidadosa y que es difícilmente extensible 
a geometrías tridimensionales, donde el reto en cuanto a tamaño matricial y tiempo de cómputo lo haría mucho más atractivo. Por lo tanto concluimos que es una buena técnica de mejora de la eficiencia computacional en casos concretos, tales como los presentados en esta tesis. Sin embargo es difícil extender estos resultados a otras geometrías o tamaños de problema.

Con respecto al problema de la discretización, se ha presentado una implementación numérica en la resolución de una ecuación integral (del problema BI-RME) haciendo uso de una técnica alternativa al clásico método de los momentos llamada método de Nyström (objetivo 1 de la tesis). Este método ya se utilizaba en otros ámbitos, pero no se hallaba con frecuencia en análisis electromagnético. No obstante, recientemente se ha ido aplicando cada vez con más frecuencia en la literatura debido a la simplicidad de su implementación. La técnica de Nyström se puede implementar de una manera muy simple evitando un grado de integración en los elementos de las matrices que modelan el sistema. En su versión más simple se pueden obtener las matrices en menos tiempo y sólo es necesario cuidar especialmente la obtención de los elementos de la diagonal por su elevado grado de singularidad (aparecen elementos hiper-singulares). El método de Nyström ofrece una buena precisión numérica en el resultado final y ofrece ganancias sustanciales en el ahorro de tiempo en la implementación del método BI-RME. La conclusión acerca de esta implementación es que conviene tenerla en cuenta a la hora de plantear el problema electromagnético frente al clásico MoM. Aunque no presenta una mejora en eficiencia tan grande como las nuevas rutinas de solución del problema de autovalores presentadas a continuación, sí que simplifica la formulación y la obtención de las matrices que intervienen en el problema BI-RME.

Las conclusiones acerca de los objetivos 4 y 3 , referentes a la explotación de la estructura matricial y el desarrollo de rutinas adaptadas a dicha estructura, es que se han desarrollado de forma altamente satisfactoria. Prueba de ello es que se han integrado en un software comercial de amplia distribución. El método BI-RME presenta una estructura determinada por la doble expansión que lleva a cabo en el dominio espectral y espacial. Debido a ello, la estructura de matrices por sub-bloques es permanente y está presente para todos los ejemplos posibles. Combinando la explotación matricial en sub-bloques y el desarrollo de una rutina iterativa que obtiene autovalores y autovectores en 
intervalos, se obtiene una gran mejora que afecta a tiempo de cálculo y al almacenamiento de memoria. Así, se concluye que esta mejora es altamente recomendable y además convierte a la solución del sistema de autovalores en un candidato idóneo para ser procesado en paralelo. Esto es debido que al romper la solución del sistema de autovalores y autovectores en intervalos independientes, éstos pueden ser asumidos de forma directa por procesadores diferentes.

En esta tesis también se ha presentado un trabajo acerca del procesado en paralelo para la rutina BI-RME optimizada explotando la estructura en sub-bloques (objetivo 5). La conclusión es que ha dado resultados altamente satisfactorios, permitiendo abordar en ordenadores convencionales la solución a problemas grandes en tamaño, que habrían tardado varias horas en solucionarse mediante técnicas secuenciales. Se ha demostrado que este problema proporciona muy buena ganancia en velocidad (speedup) incluso con poca cantidad de procesadores. También se concluye que la programación en paralelo multi-nivel (MPI + OpenMP) es la que ofrece un mejor resultado en el entorno esperado de cálculo, que consiste en ordenadores convencionales. De esta forma se puede hacer uso de memoria distribuida y compartida en distintos niveles del algoritmo.

Finalmente, se ha añadido el trabajo realizado con la solución numérica relacionada con el cambio de bases espaciales para la solución del problema BI-RME 3D. Gracias a él se han podido analizar estructuras que quedaban fuera del planteamiento originales en bases solenoidales y no solenoidales. La conclusión de esta última aportación es que ha proporcionado una forma rápida y fiable de resolver geometrías tridimensionales caracterizadas con funciones base RWG. Estas bases están ampliamente extendidas en el análisis electromagnético y por lo tanto llevan a una fácil y rápida solución a cualquier geometría que ya no necesita el desarrollo de funciones base realizadas a medida con características solenoidales y no solenoidales.

\subsection{Trabajo futuro}

Como trabajo futuro se propone aplicar las técnicas ya desarrolladas en el marco de los problemas estudiados a otros problemas electromagnéticos que representen un reto en la actualidad, bien porque 
el tiempo de cálculo es excesivo empleando las técnicas clásicas o bien porque sean problemas inabordables en ordenadores convencionales. La colección de nuevas herramientas presentadas en esta tesis, desde las técnicas de discretización y la utilización eficiente de la transformada Wavelet hasta las técnicas de cálculo en paralelo, pueden hacer que algunos algoritmos hasta ahora pesados en tiempo de cálculo se puedan ejecutar de forma más ágil en ordenadores convencionales. Por lo tanto, el objetivo futuro del trabajo desarrollado es aprovechar la experiencia acumulada de distintas técnicas de análisis de problemas electromagnéticos a nuevos escenarios. El fin último es que se puedan integrar las nuevas técnicas numéricas en simuladores software tales como FEST-3D y que se puedan obtener resultados en máquinas normales (no super-computadores) en tiempos de cálculo razonables.

\subsection{Aportaciones adicionales de la tesis}

Además de las publicaciones presentadas en esta tesis, el trabajo realizado ha dado lugar a otras publicaciones presentadas en prensa científica y en congresos internacionales, que se pasan a detallar a continuación. En primer lugar se detallan contribuciones en prensa científica listadas en JCR en las que ha colaborado la autora. El índice de impacto de dichas revistas va desde 0.29 (International Journal of RF and Microwave Computer-Aided Engineering) hasta 1.9 (IEEE Transactions on Microwave Theory and Techniques).

[1] F. Quesada, V. E. Boria, J. Pascual, A. Vidal, A. Alvarez, J.L. Gómez y B. Gimeno. Efficient analysis of arbitrarily shaped inductive obstacles in rectangular waveguides using a surface integral equation formulation. IEEE Transactions on Microwave Theory and Techniques, 55:715-721, 2007.

[2] V. E. Boria, B. Gimeno, S. Marini, M. Taroncher, S. Cogollos, P. Soto, A. Vidal y J. Gil;. Recent advances in modeling, design and fabrication of microwave filters for space applications. International Journal of RF and Microwave Computer-Aided Engineering, 17:70-76, 2007.

[3] M. Taroncher, J. Hueso, S. Cogollos, B. Gimeno, V. E. Boria, A. Vidal, H. Esteban y M. Gugliemi. Accurate consideration of metal losses 
at waveguide junctions using admittance and impedance integral equation formulations. RADIO SCIENCE, 40:1-12, 2005.

[4] S. Cogollos, S. Marini, V. E. Boria, P. Soto, A. Vidal, H. Esteban, J.V. Morro y B. Gimeno. Efficient modal analysis of arbitrarily shaped waveguides composed of linear, circular and elliptical arcs using the BI-RME method. IEEE Transactions on Microwave Theory and Techniques, 51:2378-2390, 2003.

[5] A. Coves, B. Gimeno, A. A. San Blas, A. Vidal, V. E. Boria y M. V. Andrés. Three-dimensional scattering of dielectric gratings under plane-wave excitation. IEEE Antennas and Wireless Propagation Letters, 2:215-218, 2003.

Tanto el trabajo en la tesis como otros trabajos en electromagnetismo han dado lugar a diferentes contribuciones en congresos científicos internacionales con libros de actas con referencia ISBN, que se detallan a continuación.

[1] F. D. Quesada, A. Vidal, F. J. Pérez, A. Berenguer, A. A. San Blas, F. Mira, V. E. Boria, B. Gimeno y A. Álvarez. Broad band analysis of arbitrarily shaped microwave filters using a novel Singular Value Decomposition technique. En 4th European Conference on Antennas and Propagation (EuCAP 2010), Abril 2010.

[2] F. D. Quesada, A. Vidal, F. J. Pérez, A. Berenguer, A. A. San Blas, F. Mira, V. E. Boria, B. Gimeno y A. Álvarez. Broad band analysis of arbitrarily shaped microwave filters using a novel Singular Value Decomposition technique. En IV European Conference on Computational Mechanics (ECCM 2010), Mayo 2010.

[3] M. Taroncher, J. Hueso, S. Cogollos, A. Vidal, V. E. Boria y B. Gimeno. Efficient and accurate consideration of ohmic losses in waveguide diplexers and multiplexers. En IEEE International Microwave Theory and Techniques Symposium (MTT-S), 2006.

[4] M. O. Bernabeu, M. Taroncher, V. M. Garcia y A. Vidal. Parallel implementation in pc clusters of a lanczos-based algorithm for an electromagnetic eigenvalue problem. En 5th IEEE International Symposium on Parallel and Distributed Computing, 2006. 
[5] M. Taroncher, J. Hueso, S. Cogollos, B. Gimeno, A. Vidal, V. E. Boria y M. Guglielmi. Accurate consideration of ohmic losses in passive waveguide circuits for microwave and millimetre-wave applications. En 13th IEEE Mediterranean Electrotechnical Conference (MELECON 2006), 2006.

[6] F. Quesada, A. Vidal, V. E. Boria, A. Álvarez y D. Cañete. Radar cross section computation of multi-layered dielectric and magnetic obstacles using an efficient wavelet-like method. En IEEE International Symposium on Antennas and Propagation, 2005.

[7] F. Quesada, A. Vidal, V. E. Boria, A. Álvarez, J. Pascual y A. Pérez. Wavelet-like based efficient analysis of dielectric and magnetic scatterers using the equivalence principle. En IEEE International Symposium on Antennas and Propagation, 2005.

[8] M. Taroncher, S. Cogollos, V. E. Boria, B. Gimeno, A. Vidal, J. Hueso y I. Hidalgo. On the rigorous calculation of all ohmic losses in rectangular waveguide multi-port junctions. En IEEE International Microwave Theory and Techniques Symposium, 2005.

[9] J. Hueso, S. Cogollos, B. Gimeno, V. E. Boria, A. Vidal, M. Taroncher, H. Esteban y M. Guglielmi. Accurate consideration of metal losses in planar waveguide junctions using an efficient integral equation technique. En IEEE International Microwave Theory and Techniques Symposium, 2004.

[10] M. Taroncher, A. Vidal, V. E. Boria, S. Marini, P. Soto, S. Cogollos y B. Gimeno. Efficient full-wave modal analysis of arbitrarily shaped waveguides using BI-RME and Nyström methods. En 33rd European Microwave Conference, 2003.

[11] A. Coves, B. Gimeno, A. A. San Blas, A. Vidal, V. E. Boria y M. V. Andrés. Three-dimensional scattering of dielectric gratings under plane-wave excitation. IEEE Antennas and Wireless Propagation Letters, 2:215-218, 2003.

[12] M. Taroncher, A. Vidal, V. E. Boria, S. Marini, P. Soto y S. Cogollos. Efficient coupling integrals computation of waveguide step discontinuities using BI-RME and Nyström methods. En 9th International Symposium on Microwave Technology (ISMOT), 2003. 
[13] B. Tebar, A. Vidal, S. Cogollos, C. Bachiller y V. E. Boria. Wavelet efficient technique for the full-wave modal analysis of arbitrary geometry waveguides. En Progress In Electromagnetics Research Symposium (PIERS 2002), 2002.

[14] A. Belenguer, A. Vidal, H. Esteban, C. Bachiller y V. E. Boria. Highly efficient mom analysis of conducting 2-d scatterers using wavelet basis functions. En 2002 IEEE International Symposium on Antennas and Propagation, 2002.

[15] H. Esteban, S. Cogollos, A. Vidal, V. E. Boria y M. Ferrando. A new hybrid mode-matching method for the analysis of inductive obstacles and discontinuities. En IEEE International Symposium on Antennas and Propagation, 1999.

[16] S. Cogollos, Ana Vidal, Héctor Esteban y V. E. Boria. Efficient waveguide mode computation using wavelet-like basis functions. En IEEE International Symposium on Antennas and Propagation, 1999.

[17] S. Cogollos, A. Vidal, H. Esteban y V. E. Boria. An efficient approach for the computation of the modal spectrum of a ridged rectangular waveguide. En Progress In Electromagnetics Research Symposium (PIERS), 1998.

\subsection{Contribuciones en otros ámbitos de inves- tigación}

Aparte del trabajo realizado en el área de electromagnetismo, se han realizado contribuciones en otras líneas de investigación, principalmente en el ámbito de la Observación de la Tierra. En primer lugar se presentan algunos trabajos relacionados con el procesado de datos de Radar de Apertura Sintética (SAR). En algunos de estos trabajos se han empleado técnicas de la transformada Wavelet y también técnicas de clasificación de imágenes de teledetección. Posteriormente se aportan trabajos relacionados con la clasificación y la detección en imagen de satélite SAR y en el espectro óptico combinando distintas fuentes de información. A continuación se enumeran los trabajos más destacados 
publicados en prensa científica. El índice de impacto JCR de dichas revistas es de 1.1 (International Journal Of Remote Sensing), la revista Waves no está listada en el JCR.

[1] A. Vidal y D. Martí. Comparison of different speckle reduction techniques in SAR images using wavelet transform. International Journal of Remote Sensing, 25:4915-4932, 2004.

[2] A. Vidal y M. Ferrando. On-board medium resolution SAR processing for fast image generation. International Journal of Remote Sensing, 25:161-176, 2004.

[3] A. Vidal, B. Hoyos, M. Llopis, M. Montoliu, M. R. Moreno, M. Taroncher y V. E. Boria. Satellite remote sensing activities for earth obervation. Waves, 1:35-44, 2009.

[4] A. Vidal y M. R. Moreno. Change detection of isolated housing using a new hybrid approach based on object classification with optical and TerraSAR-X data. International Journal Of Remote Sensing, 32:9621-9635, 2011.

También se han producido las siguientes aportaciones a congresos internacionales con libros de actas con ISBN en el ámbito de la teledetección.

[1] M. Llopis, A. Vidal y B. Hoyos. Multi-temporal classification for irrigation detection in the vinalopo region in spain using ASTER images. En IEEE International Geoscience and Remote Sensing Symposium (IGARSS), 2007.

[2] B. Hoyos, A. Vidal y M. Hidalgo. Evaluation of multi-temporal methods for crop classification. En 2nd International Symposium on Recent Advances In Quantitative Remote Sensing (RAQRS 2006), 2006.

[3] A. Vidal y M. Ferrando. Quality evaluation for efficient scansar data processing algorithms. En IEEE International Symposium on Geoscience and Remote Sensing (IGARSS), 2003.

[4] A. Vidal y D. Martí. Comparison of different speckle reduction techniques in sar images using wavelet transform. En International Symposium on Recent Advances In Quantitative Remote Sensing (RAQRS 2002), 2002. 
[5] A. Vidal y M. Ferrando. On-board medium resolution sar processing for fast image generation. En International Symposium on Recent Advances In Quantitative Remote Sensing (RAQRS 2002), 2002.

[6] A. Vidal, C. Bachiller, A. San-Blas y M. Ferrando. Evaluation of a new spectral analysis multilook strategy for synthetic aperture radar processing. En Progress In Electromagnetics Research Symposium (PIERS 2002), 2002.

[7] A. Vidal, C. Bachiller, A. San-Blas y M. Ferrando. Synthetic aperture radar spectral analysis processing for efficient scansar image generation. En Progress In Electromagnetics Research Symposium (PIERS 2002), 2002.

[8] A. Vidal y M. Ferrando. SPECAN techniques for range and azimuth ScanSAR processing. En SAR Image Analysis, Modeling, and Techniques III (EUROPTO 2000), 2000.

[9] A. Vidal y M. Ferrando. A comparison of SAR processing SPECAN techniques for efficient ScanSAR image generation. En SAR Image Analysis, Modeling, and Techniques (EUROPTO 98), 1999.

[10] A. Vidal, R. Oviol y M. Ferrando. A comparison of phase unwrapping techniques in synthetic aperture radar interferometry. En IEEE International Symposium on Geoscience and Remote Sensing, 1999.

[11] A. Vidal, D. Martí y M. Ferrando. An adaptive multiresolution method for speckle noise reduction in synthetic aperture radar images. En IEEE International Symposium on Geoscience and Remote Sensing (IGARSS), 1999.

[12] A. Vidal, R. Oviol y M. Ferrando. 2-d Phase unwrapping in Synthetic Aperture Radar Interferometry. En EARSeL Symposium on Remote Sensing in the 21st Century, 1999.

[13] A. Vidal, D. Martí y M. Ferrando. An adaptive soft thresholding method for speckle noise reduction in synthetic aperture radar. En EARSeL Symposium on Remote Sensing in the 21st Century, 1999. 
[14] A. Vidal y M. Ferrando. A new spectral analysis algorithm for SAR data processing of ScanSAR data and medium resolution data without interpolation. En IEEE International Symposium on Geoscience and Remote Sensing, 1998.

[15] A. Vidal. Comparison of medium resolution algorithms for spacecraft on-board sar image generation. En IEEE International Symposium on Geoscience and Remote Sensing (IGARSS), 1996. 